\title{
Método para a Avaliação do Ganho Empregado pelo Piloto em Ensaios de PIO
}

\author{
André Luis Celere
}

Tese apresentada à Escola de Engenharia de São Carlos da Universidade de São Paulo para a obtenção do título de Doutor em Engenharia Mecânica

Área de Concentração: Dinâmica de Máquinas e Sistemas

ORIENTADOR: Prof. Titular Paulo Sérgio Varoto 

Para minha grande incentivadora, querida mãe, Neuza.

Sem sua iniciativa eu não teria terminativa...

Ao meu pai, Samuel, que há tempos se foi, mas há tempos permanece.

À Luciana, Vítor e Fernando; pelo amor que nos une. 

É difícil expressar em palavras minha gratidão. Muitos contribuiram para que este trabalho fosse realizado.

Ao meu orientador, Prof. Paulo Sérgio Varoto, que me conduziu por este complexo processo de aprendizagem e crescimento;

Ao Prof. Carlos Dias Maciel, que propôs uma direção de sucesso na fase de maior desânimo;

Ao amigo Roberto Becker, gerente da Engenharia de Ensaios em Vôo da EMBRAER, que incentivou e contribuiu com meu crescimento;

À EMBRAER, que possibilitou esta custosa pesquisa.

A todos os que não estão diretamente mencionados, mas que estão aqui dentro do texto, cada um na sua forma e contribuição, OBRIGADO! 



\section{Sumário}

\section{Resumo}

\section{Abstract}

1 Introdução

1.1 Objetivo e Motivação . . . . . . . . . . . . . . . . . . . . . . 19

1.2 Justificativa e Relevância . . . . . . . . . . . . . . . . . . . . . 20

1.3 Contribuições da Tese . . . . . . . . . . . . . . . . . . . . 21

1.4 Histórico e Avanços da Pesquisa no Setor . . . . . . . . . . . . . . . . 21

$\begin{array}{lll}2 & \text { Requisitos de Aeronavegabilidade } & 31\end{array}$

3 Ensaios em Vôo - Prática Atual e Colocação da Tese 37

3.1 Histórico dos Ensaios . . . . . . . . . . . . . . . . . . 37

3.2 Descrição das Manobras e a Prática Atual . . . . . . . . . . . . . . . 38

3.3 Método de Validação Proposto - Tese . . . . . . . . . . . . . . . . . . . 47

3.4 Técnica de Manobras Sintéticas _. . . . . . . . . . . . . . . . 48

3.4 .1 Descrição e História . . . . . . . . . . . . . . . . . . . . 48

$3.4 .2 \quad$ Aparato Experimental . . . . . . . . . . . . . . . . . . . 49

3.4.3 Definição das Tarefas . . . . . . . . . . . . . . . . . . . . . 54

3.5 Escala PIOR . . . . . . . . . . . . . . . . . . 57

4 Modelagem Analítica $\quad 63$

4.1 O Modelo de Piloto Humano . . . . . . . . . . . . . . . . 63

4.1.1 Modelo Crossover . . . . . . . . . . . . . . . . . . . . 65

$4.1 .2 \quad$ O Modelo Estrutural . . . . . . . . . . . . . . . . 68

4.1.3 Análise e Escolha do Modelo . . . . . . . . . . . . . . . . . . . . 72 
4.2 Modelo da Planta . . . . . . . . . . . . . . . . . . . . . 73

4.2 .1 Interlúdio . . . . . . . . . . . . . . . . 73

4.2 .2 Modelo Laterodirecional . . . . . . . . . . . . . . . 73

4.2.3 Identificação de Parâmetros da Planta . . . . . . . . . . . . . . . 75

4.2.3.1 Descrição do Modelo . . . . . . . . . . . . . . . . 75

4.2.3.2 Método de Identificação do Modelo . . . . . . . . . . 76

4.2.3.3 Identificação do Modelo . . . . . . . . . . . . . . . 77

5 Simulações em Malha Fechada - Teoria $\quad 81$

6 Comparação de Sinais - Introduzindo o Conceito de Entropia Esta$\begin{array}{ll}\text { tística } & 87\end{array}$

6.1 Análise de Sinais . . . . . . . . . . . . . . . . . . . . . . . . . 88

6.2 Entropia Estatística . . . . . . . . . . . . . . . . . . . . 88

6.3 Algoritmo Utilizado para Cálculo da Entropia . . . . . . . . . . . . . . 91

7 Resultados de Ensaios, Simulações e Análise $\quad 97$

7.1 Ensaios . . . . . . . . . . . . . . . . . . . . . . . . 97

7.1 .1 Condução do Ensaio . . . . . . . . . . . . . . . . . . . . . . 99

7.1.2 Configurações Ensaiadas e Modelos Ajustados . . . . . . . . . . 101

7.2 Resultados do Cálculo de Entropia . . . . . . . . . . . . . . . . . . 107

7.2.1 Formação do Critério - Análise Direta . . . . . . . . . . . . . . 108

7.2.2 Formação do Critério - Análise Estatística . . . . . . . . . . . . 112

7.2.3 Avaliação do Critério - Utilizando a Análise Estatística ... . 119

8 Conclusões e Recomendações para Pesquisas Futuras 127

8.1 Conclusões . . . . . . . . . . . . . . . . . . . . . . 127

8.2 Recomendações para Implementação . . . . . . . . . . . . . . . . . . . . 128

8.3 Recomendações para Pesquisas Futuras . . . . . . . . . . . . . . . . 129

Referências

\section{Apêndices}

A.1 FAR $25 \ldots \ldots \ldots \ldots \ldots \ldots \ldots \ldots \ldots$ 


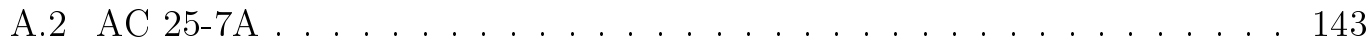

$\begin{array}{ll}\text { B Gráficos dos Resultados } & 147\end{array}$

$\begin{array}{ll}\text { C Listagem de Programas } & 185\end{array}$

C.1 Cálculo da Entropia . . . . . . . . . . . . . . . . . . . . . 185

C.2 Scripts de Entrada de Dados . . . . . . . . . . . . . . . 193

$\begin{array}{ll}\text { D Flight Test Instrumentation List } & 199\end{array}$

$\begin{array}{ll}\text { E Modelo Laterodirecional } & 203\end{array}$

$\begin{array}{lll}\text { F Escalas Originais } & 211\end{array}$ 



\section{Resumo}

Celere, A. L. (2008). Método para a avaliação do ganho empregado pelo piloto em ensaios de PIO. Tese (Doutorado), Escola de Engenharia de São Carlos, Universidade de São Paulo, São Carlos, 2008.

Um método para avaliação do uso de ganho adequado em ensaios de verificação de PIO (Pilot Induced Oscillations) é apresentado. As Tarefas de Manobra Sintética (Synthetic Tracking Task) são utilizadas para a demonstração. A teoria é baseada no conceito de entropia estatística proveniente da teoria da informação e no modelo estrutural do piloto humano. O método é apresentado para manobras executadas no eixo lateral e oferece uma medida do ganho humano utilizado durante a sua execução em malha-fechada. Para a modelagem da planta é utilizado modelo black-box com equacionamento de espaço de estados e identificação de parâmetros. Dados de ensaios em vôo provenientes de uma aeronave de transporte certificada FAR-25 são utilizados para medir a razão entre o tempo gasto pelo piloto humano em uma malha fechada em posição versus o tempo em uma malha de derivada da posição (roll vs. roll rate). Esta medida é proposta como validadora da execução correta do ensaio.

Palavras-chave: PIO. Pilot induced oscillations. Oscilações com piloto no loop. Malha-fechada. Entropia estatística. Ensaios em vôo. Aeronáutica. Qualidades de vôo. Mecânica de vôo. 



\section{Abstract}

Celere, A. L. (2008). Method to evaluate pilot gain in PIO flight test. Thesis (PhD), Escola de Engenharia de São Carlos, Universidade de São Paulo, São Carlos, 2008.

A method is proposed to verify closed-loop adequate flight test piloting gain in PIO aircraft certification. The Synthetic Tracking Task PIO flight test is used. The theory is based on the entropy concept from information theory and on the structural pilot model of the human pilot. The method is presented for single axis pilot tracking maneuvers and offers a measure of the human pilot gain employed during its execution. A black-box, state-space, parameter-identified model is used for the plant. Flight test data from a FAR-25 transport aircraft is used to verify the theory of how to determine a measure of the ratio between time spent by the human pilot in the error loop versus in the error rate loop to control the aircraft. This measure is proposed as a test point validation method for PIO flight testing.

Keywords: PIO. Pilot induced oscillations. Pilot in the loop oscillations. Closedloop. Statitical entropy. Synthetic task. Flight test. Aeronautics. Atmospheric flight mechanics. Flying qualities. 


\section{Lista de Símbolos}

$A x(t) \quad$ Matriz da equação de espaço de estados

$B u(t) \quad$ Matriz da equação de espaço de estados

$C x(t) \quad$ Matriz da equação de espaço de estados

$D u(t) \quad$ Matriz da equação de espaço de estados

$D_{\alpha}\left(P_{z} \| Q_{z}\right) \quad$ Entropia relativa de Renyi com grau $\alpha$

$D_{3} 21 \quad$ Entropia de Renyi de ordem 3, calculada entre os sinais 2 e 1

$D_{3} 31 \quad$ Entropia de Renyi de ordem 3, calculada entre os sinais 3 e 1

$D\left(P_{z} \| Q_{z}\right) \quad$ Entropia relativa, ou divergência de Kullback-Leibler

$e(t) \quad$ Ruído (sinal)

$G(q) \quad$ Matriz de resposta ao impulso (impulse response)

$H_{\alpha}(z) \quad$ Entropia de Renyi

$H(z) \quad$ Entropia de Shannon

$K_{\dot{e}} \quad$ Ganho da malha de derivada do erro do modelo de Hess

$K_{c} \quad$ Ganho da planta controlada no modelo de Crossover

$K_{e} \quad$ Ganho da malha de erro do modelo de Hess

$K_{p} \quad$ Ganho do piloto no modelo Crossover

$l_{r} \quad$ Razão de probabilidade (likelihood ratio)

$N_{z} \quad$ Fator de carga

$P_{z}, Q_{z} \quad$ Distribuições de prob.

$p\left(w_{\text {alto }} \mid x\right) \quad$ Prob. de um ponto de ensaio pertencer à classe de alto ganho, dado que o evento x ocorreu

$p\left(w_{\text {alto }}\right) \quad$ Prob. de um ponto de ensaio ter sido executado com alto ganho

$p\left(w_{\text {baixo }} \mid x\right) \quad$ Prob. de um ponto de ensaio pertencer à classe de baixo ganho, dado que o evento x ocorreu

$p\left(w_{\text {baixo }}\right) \quad$ Prob. de um ponto de ensaio ter sido executado com baixo ganho

$p\left(x \mid w_{\text {alto }}\right) \quad$ Prob. de um evento $\mathrm{x}$, dado que o mesmo

pertence à classe de alto ganho

$p\left(x \mid w_{\text {baixo }}\right) \quad$ Prob. de um evento $\mathrm{x}$, dado que o mesmo

pertence à classe de baixo ganho

$\mathrm{s}$

Variável de Laplace

S1 Chave seletora entre a malha de erro e derivada do erro no modelo de Hess 
Lista de Símbolos

\begin{tabular}{|c|c|}
\hline$T_{1}$ & Constante de tempo de washout do sistema neuromuscular \\
\hline$T_{2}$ & Constante de tempo no modelo de sistema de controle manual \\
\hline$u(t)$ & Sinal de entrada em um sistema \\
\hline$v(t)$ & Ruído (sinal) \\
\hline$w_{\text {alto }}$ & Classe de separação de dados (alto ganho) \\
\hline$w_{\text {baixo }}$ & Classe de separação de dados (baixo ganho) \\
\hline$Y_{d e}$ & Dinâmica do display no modelo de Hess \\
\hline$Y_{p n}$ & Forma em malha aberta da dinâmica neuromuscular \\
\hline$Y_{c}$ & Dinâmica da Planta \\
\hline$Y_{f}$ & $\begin{array}{l}\text { Washout do sist. neuromuscular, devido à ligação alfa-gama } \\
\text { dos músculos e tendões da mão }\end{array}$ \\
\hline$Y_{m}$ & Uma representação interna do sist. de controle manual utilizado pelo piloto \\
\hline$Y_{p}$ & Função de Transferência Aproximada do Piloto \\
\hline$Y_{p} l$ & Lógica pulsativa do sistema nervoso central \\
\hline$Y_{p} Y_{c}$ & Forma Combinada \\
\hline$y(t)$ & Sinal de saída em um sistema \\
\hline$Z$ & Variável randômica \\
\hline$z$ & Evento \\
\hline$\alpha$ & ordem da entropia de Renyi \\
\hline$\beta$ & Ângulo de derrapagem \\
\hline$\delta_{\text {comando }}$ & Movimento do inceptor \\
\hline$\Delta \mathrm{D}$ & Diferença entre entropias \\
\hline$\gamma$ & Ângulo de planeio \\
\hline$\mu$ & Média \\
\hline$\omega_{c}$ & Freqüência de crossover do sistema (modelo crossover) \\
\hline$\omega$ & freqüência \\
\hline$\phi$ & Atitude de rolamento \\
\hline$\sigma$ & Desvio padrão \\
\hline$\tau_{0}$ & Atraso de processamento de sinais do sistema nervoso central \\
\hline
\end{tabular}


Lista de Símbolos

\begin{tabular}{ll}
\hline \hline$\tau_{1}, \tau_{2}, \tau_{3}, \tau_{4}$ & Atrasos puros \\
$\tau_{e}$ & Atraso total do sistema piloto + planta \\
$\theta_{d o t}$ & Razão de arfagem \\
$\theta$ & Atitude - arfagem \\
\hline \hline
\end{tabular}




\section{Lista de Abreviaturas e Siglas}

1P Piloto humano no lado esquerdo da cabine de pilotagem

2P Piloto humano no lado direito da cabine de pilotagem

A-PC Airplane-pilot coupling

AG Alto Ganho

AOA Ângulo de ataque

BG Baixo Ganho

CAT II Aproximação por instrumentos com mínimos de 100 pés

CDF Função distribuição cumulativa (cumulative distribution function)

cfd Computational fluid dynamics

D1 e D2 Configurações de decolagem da aeronave ensaiada

FAA Federal aviation administration

FBW Fly-by-wire

FTI Instrumentação de ensaios (flight test instrumentation)

IRU Inertial reference unit

LCD Liquid crystal display

LH Lado esquerdo

LVDT Linear variable differential transformer

MLW Peso máximo de pouso (maximum landing weight)

N1_AC Rotação do rotor primário (fan) de um turboreator

P1 e P2 Configurações de pouso da aeronave ensaiada

PC Probabilidade Condicional

PCM Pulse coded modulation

pdf Função densidade de probabilidade

PFD Primary fnction display

PIO Pilot-induced oscillations

PSD Densidade espectral

PSS Rotina de identificação do Matlab

QDV Qualidade de vôo

R.V. Variável randômica (random variable)

RH Lado direito

RMU Remote monitoring unit 
Lista de Abreviaturas e Siglas

\begin{tabular}{ll}
\hline \hline Sinal 1 & Atitude controlada por humano \\
Sinal 2 & Atitude simulada na malha de erro \\
Sinal 3 & Atitude simulada na malha de derivada do erro \\
Syntask & Synthetic Tracking Task \\
\hline \hline
\end{tabular}




\section{Capítulo 1}

\section{Introdução}

A certificação de uma aeronave de transporte civil moderna é uma atividade complexa e extensa, requerendo comprovações de requisitos que abrangem desde itens estruturais até estudos de confiabilidade de sistemas e as conseqüências de suas falhas. Neste universo há vários requisitos que têm sua demonstração de maneira determinística, porém há também aqueles que exigem uma avaliação subjetiva, especialmente da tripulação de ensaio.

Nas últimas duas décadas, há, cada vez mais, eletrônica embarcada nas aeronaves, visando desde a automação de tarefas a serem executadas pela tripulação até a obtenção de estabilidade artificial para problemas aerodinâmicos de resolução custosa. É tendência nos projetos modernos a utilização de computadores para auxiliar o piloto na condução da aeronave, atuando não raramente em malha-fechada, diretamente no sistema de controle de vôo.

A verificação da qualidade de vôo dessas aeronaves modernas exige maior foco em fenômenos de acoplamento entre a pilotagem humana, seus sistemas sensoriais e a aeronave. Esse é o objeto de estudo proposto.

\subsection{Objetivo e Motivação}

O objetivo é apresentar um método para validar a execução de pontos de ensaios em vôo para verificação de PIO (pilot-induced oscillations) utilizando a técnica de tarefa sintética, e a motivação vem da experiência adquirida na participação de diversas 
certificações junto à EMBRAER como engenheiro de ensaios em vôo, especialmente como especialista (focal point) da área de ensaios em qualidades de vôo.

A execução de tais ensaios é baseada em uma hipótese fundamental de que o piloto executará a tarefa com o mais alto ganho possível, mimetizando uma condição real de PIO. A experiência nas certificações mostrou que essa hipótese fundamental não é cumprida sempre e está sujeita ao próprio elemento subjetivo inerente ao ser humano, como sua variação de humor, cansaço físico e mental, dentre outros fatores.

O interesse e a vontade de minimizar a influência desses elementos subjetivos sobre os resultados de ensaio são os grandes motivadores desta tese.

\subsection{Justificativa e Relevância}

Vários métodos foram criados pela indústria ao longo dos anos para testar as qualidades de vôo das aeronaves, porém o peso de julgar como fiel da balança se os resultados estão aceitáveis para toda a gama de pilotos existentes na operação da aeronave ainda está só com a tripulação de ensaios. É uma responsabilidade grande e um exercício difícil abstrair-se antes, durante e após a realização de um ensaio para, mentalmente, avaliar se os resultados obtidos seriam aceitáveis para aqueles que utilizarão a aeronave na prática. Uma opção seria executar avaliações múltiplas, com tripulações de ensaio diversas, cobrindo uma diversidade melhor das variações humanas, porém o custo e o prazo tornam-se proibitivos rapidamente. Justamente por ser esta uma tarefa difícil, não é rara a necessidade de repetição de ensaios para se "ter certeza"do resultado.

Esta é a justificativa para a busca de um método que auxilie a tripulação na tomada de decisões, minimizando aspectos subjetivos e tornando os ensaios mais rápidos e eficientes.

Tal método não teria relevância se a aviação civil não estivesse em franco crescimento, como é o cenário atual. Há recordes de vendas de aeronaves, e certificações de novos produtos estão se tornando cada vez mais freqüentes. 


\subsection{Contribuições da Tese}

A partir dos resultados apresentados, pode-se concluir que o método proposto para verificar ensaios de PIO, realizados com ganho inadequado, utilizando a técnica de tarefa sintética é válido. O método poderá reduzir o tempo de ensaios e a repetição de pontos, gerando ganhos para a indústria, além de introduzir conceitos da Teoria da Informação no ambiente de certificação de aeronaves.

Há, no entanto, uma necessidade de aplicar o método em vários outros cenários (outras aeronaves, tripulações, configurações, etc), para que as conclusões estatísticas tenham maior confiabilidade.

\subsection{Histórico e Avanços da Pesquisa no Setor}

A seguir, um breve histórico dos primórdios da aviação e a construção gradual dos critérios de aeronavegabilidade.

A aviação civil iniciou-se com Santos Dumont e seu histórico vôo ao redor da torre Eiffel, demonstrando, pela primeira vez, que era possível controlar veículos aéreos. Em seguida, já levava passageiros e, poucos anos após, distribuía plantas de seu modelo Demoiselle para divulgar a aviação e permitir que os interessados tivessem acesso a essa tecnologia, de maneira irrestrita.

Poucos anos depois, a sociedade civil já contava com serviços de correio aéreo e transporte de passageiros, e, conseqüentemente, acidentes aeronáuticos eram notícia nos jornais.

Muitas eram as falhas iniciais: meteorologia, falhas estruturais, falhas humanas, falhas de motor (sistemas), e, com o aumento do número de vôos e da exposição à esses riscos, houve uma pressão da opinião pública para que fossem definidos requisitos mínimos de aeronavegabilidade. Um dos primeiros requisitos determinados pelo governo americano regulava a operação e listava itens do tipo (UNITED STATES ARMY AIR CORPS, 1920):

No original em Inglês:

- Don't take the machine into the air unless you are satisfied it will fly; 
- Never leave the ground with the motor leaking;

E a tradução em Português:

- Não vá voar na máquina a não ser que você esteja convencido de que ela voará;

- Não saia do chão com o motor vazando;

É importante ressaltar que, historicamente, os Estados Unidos sempre estiveram na vanguarda da utilização do meio aeronáutico e, conseqüentemente, na sua regulamentação. Foi no ano de 1926 que o primeiro requisito oficial foi publicado sob o título de Air Commerce Act - (FEDERAL AVIATION ADMINISTRATION, 2007a). Nele havia as primeiras exigências sobre a segurança das aeronaves, já com vistas na crescente utilização comercial. Com a crescente utilização do meio aéreo para as diversas transações comerciais (aí incluído o transporte de passageiros), o governo americano publicou o primeiro conjunto de requisitos para garantir a aeronavegabilidade: o CAR-04 de 1936 (BUREAU OF AIR COMMERCE, 1936). Em 1938, foi publicado o Civil Aeronautics Act, criando agências e órgãos reguladores com mais força e responsabilidade, e emitindo o primeiro conjunto de requisitos

Já no período pós-segunda grande guerra, houve a emissão dos primeiros códigos nos Estados Unidos: CAR-3 e CAR-4, contendo os requisitos mínimos de aeronavegabilidade para a comercialização de aeronaves civis (CIVIL AERONAUTICS BOARD, 1949), sendo o foco principal garantir confiabilidade à estrutura. Na década de 50, com a aprovação no congresso americano do Federal Aviation Act de 1958, os requisitos evoluíram para um conjunto mais maduro e completo, complementados com a experiência dos vários anos de operação de aeronaves e com a conseqüente exposição às intempéries diárias (FEDERAL AVIATION ADMINISTRATION, 1965). As principais disciplinas abordadas são:

- Desempenho - determinação de mínimos aceitáveis, já com alguns casos de falha previstos, como falha de motor.

- Qualidades de Vôo (ou QDV) - determinação dos mínimos de estabilidade e controle.

- Sistemas - adequabilidade e estabilidade dos sistemas embarcados. 
- Estruturas - margens de segurança para as cargas conhecidas na época.

Há, desde então, uma constante corrida entre o avanço tecnológico incorporado pelos fabricantes e a rapidez da comunidade (por meio das autoridades certificadoras) em atualizar os requisitos. Assim, a certificação civil de aeronaves foi sempre conduzida com foco principal nas 4 áreas descritas acima, apresentando certo atraso principalmente em relação às novas tecnologias empregadas nas aeronaves modernas.

Nas últimas décadas, o projeto aeronáutico mundial passou por grandes avanços. Estruturas, propulsão, aerodinâmica e conforto são apenas algumas das áreas que evoluíram significativamente, mas nenhuma se compara ao avanço da eletrônica embarcada. Uma aeronave moderna possui hoje incontáveis microprocessadores a bordo: computadores de vôo, disjuntores virtuais, controles de ar-condicionado, atuadores inteligentes chegando até a cafeteiras microprocessadas. Esse fácil acesso à eletrônica possibilitou uma enorme evolução no automatismo dos sistemas embarcados, bem como a implementação de comandos de vôo eletricamente comandados - FBW, ou (Fly-by-Wire). As leis de controle iniciaram uma evolução já na década de 60 com a introdução pela Boeing da lei C* (TOBIE; ELLIOT; MALCOLM, 1966; FIELD, 1993), e hoje estão implementadas em vários modelos de sucesso comercial, como o Airbus A320 e o Boeing 777 (FIELD, 1995).

Um outro aspecto relevante para projetos modernos é uma série de fatores (ou requisitos) de projeto que precisam ser levados em consideração, além dos mínimos de aeronavegabilidade estabelecidos pelas autoridades certificadoras:

- conforto interno;

- limitações construtivas;

- requisitos extras de qualidades de vôo;

- tempo disponível para projeto (time-to-market);

- limitantes econômicos;

- e outros.

Cada vez mais há pressões opostas: de um lado, a necessidade de desempenho excepcional do produto e, do outro, as soluções são limitadas pelo custo. Ainda mais: 
essa grande gama de requisitos induz a uma espiral de projeto complexa, com vários ciclos, e que necessita engenharia simultânea para não exceder o tempo para entrada no mercado (time-to-market). Os grandes ciclos se iniciam com o anteprojeto, onde o formato externo básico (aerodinâmica) e a configuração são determinados, ou congelados na terminologia da área. Em seguida, prossegue-se com os ensaios em túnel de vento, necessários para verificar se as projeções matemáticas (computational fluid dynamics cfd) de estabilidade e desempenho estão corretas. Em paralelo, avançam estruturas e sistemas.

Ao término dos ensaios em túnel, o projeto das linhas de sistema já está razoavelmente congelado e, então, prossegue-se para os ciclos dos sistemas em si. Os comandos de vôo estão aqui incluídos, dando início a uma série de estudos em que os requisitos de desempenho, estabilidade e controle deverão ser atendidos pelo projeto. Neste ponto há uma mudança no paradigma original para os comandos de vôo: onde antes as limitações construtivas do sistema formavam a barreira para o projeto aerodinâmico e de comandos, hoje controles em malha fechada conseguem eliminá-las, provendo estabilidade aparente ao piloto, mesmo que sem estabilidade inerente. Essa evolução veio criar uma lacuna entre o modus operandi projetado e aquele realmente utilizado, pois os métodos tradicionais de análise de qualidades de vôo não levam em consideração a malha fechada piloto-aeronave, que tem sido alvo de vários estudos das últimas 4 décadas.

Para projetos FBW, o resultado deste ciclo é a definição da estratégia dos comandos de vôo, que é a espinha dorsal do controle da aeronave.

Nota-se que o aumento da percepção da importância de qualidade, da cadeia de valor e o barateamento dos equipamentos geraram forte concorrência entre os provedores de serviços aéreos (linhas, charter, carga). Esse é mais um motivo pelo qual os fabricantes tentam implementar rapidamente os avanços tecnológicos disponíveis em suas aeronaves . Em especial, a disponibilidade cada vez maior de poder computacional barato tem provocado mudanças de paradigma na construção aeronáutica, avançando por áreas não cobertas pelos requisitos de aeronavegabilidade.

Esta análise rápida tenta entender como a certificação civil de aeronaves tem se ajustado (ou não) à tecnologia de comandos de vôo FBW, especialmente no tocante à garantia da aeronavegabilidade quanto ao fenômeno de oscilações com o piloto na malha, ou PIO - Pilot Induced Oscillation. Vale lembrar que essa tecnologia não é nova: 
já no início da década de 70, as aeronaves militares iniciaram sua utilização em caças. $\mathrm{Na}$ época, os problemas associados a essa mudança de paradigma emergiram de maneira contundente com eventos de PIO, e o volume de estudos iniciados ainda na década de 60 em aeronaves com comandos hidráulicos (T-38A, X-15) (MCRUER, 1995) foram fortemente incrementados. Mas torna-se necessário definir PIO com mais precisão. Há inúmeras referências que definem esse fenômeno, porém, dentre as pesquisadas, uma das melhores definições é:

PIO são oscilações sustentadas ou não-controláveis resultantes de uma ação direta do piloto para controlar a aeronave (DEPARTMENT OF DEFENSE INTERFACE STANDARD, 1990).

Há definições mais recentes (MITCHELL; KLYDE, 2008), porém são, em geral, variações sobre a idéia central já apresentada anteriormente.

Outro fator importante para a ocorrência do fenômeno PIO é a presença da tríade piloto-veículo-gatilho observada em várias referências. Um PIO somente irá ocorrer em um sistema operando em malha fechada (pilot+veículo) e quando houver um fator surpresa que desencadeie (gatilho) um modo de pilotagem agressivo (alto ganho). O termo gatilho também é referido na literatura como abismo (cliff) ou fator surpresa startle factor) (CALSPAN, 1998; KLYDE; MITCHELL, 2005).

Vários estudos foram realizados para identificar as causas e definir critérios para projeto, de maneira a tentar garantir uma inibição do fenômeno (ANANTHKRISHNAN; SHAH; UNNIKRISHNAN, 2004; COOPER; HARPER, 1969; MCRUER; KRENDEL, 1974; MCRUER; MYERS, 1988). O cume de tais estudos está nas definições de critérios de projeto, como a própria norma MIL1797A e os critérios de Phase Delay Bandwidth - (HOH; MITCHELL; HODGKINSON, 1982), Gibson (GIBSON, 1999), Neil-Smith (NEAL; ROGERS, 1970), Smith-Geddes (SMITH, 1993), dentre outros. Como o foco eram os caças de última geração (de cada época), todo o esforço foi concentrado neste tipo de aeronave, com suas peculiaridades de operação. Uma ótima análise dos prós e contras de cada critério foi apresentada por (GAUTREY, 1998).

Os dados dos mais variados experimentos realizados pela NASA são todos relacionados a esse tipo de aeronave (SHAFER; STEINMETZ, 2001). Além disso, foi verificado que o fator humano é de fundamental importância e extremamente difícil de mode- 
lar (CHIGNELL; HANCOCK, 1986; DEY, 1972; HESS, 2003; KELLY; KLAPP, 1986; JEX; ALLEN; MAGDALENO, 1972; REPA; ALBERS; POTVIN, 1972).

Transportando esse histórico dos estudos voltados à área militar para a aviação civil, verifica-se que não foram realizadas mais pesquisas para determinar critérios de projeto que pudessem guiar o projeto de novas aeronaves, permitindo um mínimo de robustez a esse fenômeno. A leitura completa dos requisitos de aeronavegabilidade revela a falta de um tratamento específico relacionado a PIO Federal Aviation Regulations - FAR part 25 (FEDERAl AVIATION ADMinistration, 1965). Porém, há evidências de que essa tecnologia aplicada a aeronaves de transporte civis não está imune aos mesmos problemas enfrentados pelos caças. Um exemplo pode ser verificado na aeronave C-17, que, apesar de ser militar, é bastante análoga às aeronaves de transporte civil (o C-17 é uma aeronave de transporte de cargas e tropas) (WELTZ; SHWEYK; MURRAY, 2007). Outro exemplo é o esforço dispendido pelo Departamento de Transporte (DoT) americano, promovendo estudos quanto às qualidade de vôos de aeronaves com estabilidade relaxada (HOH; MITCHELL, 1982; MCRUER; MYERS, 1982).

Resumidamente, pode-se dizer que a variabilidade do fator humano é de tal monta que inviabiliza um critério de projeto capaz de declarar uma aeronave livre de PIO (PIO Free). No máximo, pode-se declarar que a aeronave não é suscetível a PIO (non PIO prone). Exemplos de aeronaves civis que presenciaram algum tipo de PIO são o MD-11 (NATIONAL TRANSPORTATION SAFETY BOARD, 1993), A320; 321, Boeing 767; 777 e Dassault Falcon 900, entre outros (FIELD, 1995; MCRUER, 1995). A maneira de minimizar a probabilidade de ocorrência de PIOs em aeronaves civis é aplicar, em seus projetos, critérios desenvolvidos para aeronaves militares, mesmo com as distorções provenientes de empregos tão diferentes.

Novamente, citando o histórico, as aeronaves civis modernas e providas desse tipo de tecnologia tiveram suas bases de certificação normais acrescentadas de condições especiais, ou Issue Papers como esses documentos são referenciados pelo FAA - Federal Aviation Administration (DEPARTMENT OF TRANSPORTATION, 2007a). São documentos que colocam requisitos de aeronavegabilidade adicionais ao projeto sendo certificado, devido a alguma característica inovadora - novel feature - e que, no entendimento da autoridade certificadora, não está contemplada nos requisitos comuns. As condições especiais relativas a PIO tratam especificamente das avaliações sobre a sus- 
ceptibilidade a PIO em uma campanha de ensaios de certificação (CENTRO TÉCNICO AEROESPACIAL, 2002). Porém não há consenso sobre o método para se declarar que um projeto novo tem aeronavegabilidade suficiente para apresentar uma probabilidade extremamente remota de encontrar eventos de PIO ao longo da sua vida útil.

A prática atual para se verificar o atendimento aos requisitos de aeronavegabilidade de aeronaves de transporte público descritos na norma de certificação (FEDERAL AVIATION ADMINISTRATION, 1965) é a adoção do guia de ensaios publicado pelas próprias autoridades reguladoras AC-25-7A (FEDERAL AVIATION ADMINISTRATION, 1999). No entanto, conforme explanado acima, este conjunto requisito+guia é muito bom quando se trata das quatro áreas básicas (desempenho, qualidade de vôo, sistemas e estruturas). Uma análise mais detalhada deles, especialmente do 25.143(a) e (b), demonstra um estado incipiente no tocante ao fornecimento de um guia eficaz na condução de ensaios com o objetivo de demonstrar cumprimento de um requisito que também não é específico e nem objetivo sobre o problema da existência de PIOs. A afirmativa a seguir é um exemplo: "There are no certification tests or objective measures to specifically assess the airplane's susceptibility to pilot overcontrol or out-of-phase induced pitch oscillations [...]", ou em português "Não há ensaios de certificação ou medidas objetivas para avaliar especificamente a susceptibilidade de uma aeronave a sobrecontrole ou oscilações fora-de-fase induzidas em arfagem [...]"(NATIONAL TRANSPORTATION SAFETY BOARD, 1993).

Dessa maneira, torna-se imprescindível a realização de ensaios em vôo, principalmente pela falta de um modelo suficientemente completo para capturar as características humanas nas várias fases de vôo e, assim, conseguir demonstrar a aeronavegabilidade apenas por análise (CALSPAN, 1998; MCRUER, 1995). Além do mais, há um forte elemento subjetivo nessa avaliação, que leva as autoridades certificadoras a terem a necessidade de participarem da realização dos ensaios e não aceitarem substanciações que utilizem modelagem matemática. No máximo, esse tipo de modelagem e aplicação de critérios leva apenas a uma redução da matriz de pontos de ensaios em vôo (EMPRESA BRASILEIRA DE AERONÁUTICA, 2005).

As recomendações modernas sobre as técnicas de ensaio para uma campanha de verificação quanto à susceptibilidade a PIO estabelecem manobras dinâmicas como propostas de excitadores (ou gatilho) (CALSPAN, 1998, 1999; FEDERAL AVIATION 
ADMINISTRATION, 1999). Foi observado na literatura um forte direcionamento das pesquisas para a área militar.

É importante ressaltar que as aeronaves civis têm uma utilização fundamentalmente diferente daquela das aeronaves de combate (em especial as aeronaves de transporte FAR 25), porém os eventos de PIO relatados e, principalmente o piloto humano, são análogos. Desta forma, introduzindo-se modificações nas manobras propostas para os ensaios que tentam evidenciar a predisposição de uma aeronave a PIO, pode-se chegar a um conjunto que, ao mesmo tempo, proporcione as excitações (gatilhos) e também se assemelhe mais ao emprego civil. Essas modificações incluem adequação do conteúdo de freqüência, das amplitudes e das tarefas excitadoras, contando com níveis adequados das fases de aquisição (gross aquisition) e controle fino (fine tracking). Dentre as manobras propostas, as que melhor demonstraram potencial resultado para a certificação civil são o pouso de precisão e as tarefas sintéticas (MITCHELL; KLYDE, 2004; SHAFER; STEINMETZ, 2001).

Por outro lado, a modelagem do piloto executando uma tarefa é objeto de estudos há pelo menos 50 anos, porém, devido ao alto potencial do ser humano de se adaptar e utilizar informações periféricas, como o sistema vestibular, visão periférica, sistema olfativo, tato, etc para modificar a estratégia de controle, um modelo único ainda não foi formulado. Vários modelos específicos estão disponíveis, destacando-se os propostos por (MCRUER; JEX, 1967; MCRUER; KRENDEL, 1974; MCRUER; MYERS, 1988) e por (HESS, 1981; HESS; STOUT, 1997).

Um dos principais é (MCRUER; GRAHAM, 1964), que inicia as publicações sobre modelos matemáticos do comportamento humano em controle manual. Na mesma década iniciam-se os estudos sobre modelos não-lineares, interferências, influências de múltiplos eixos e a criação do conceito de remnant ${ }^{1}$ (MCRUER; JEX, 1967; SWALLWOOD, 1967; WIERWILLE; CAGN; KNIGHT, 1967; TODOSIEV, 1967). Vale ressaltar que esses estudos foram movidos pela corrida espacial russo-americana da década de 60 . Já na década de 70, os estudos de influência de mostradores/telas (displays) são ini-

\footnotetext{
${ }^{1}$ remnant é o conceito criado na década de 60 . Enquanto pesquisando modelos matemáticos do piloto humano, McRuer identificou que o piloto humano mudava de estratégia conforme a dinâmica da planta (veja detalhes no capítulo 4.1.1) para formar, junto com a planta, um modelo invariante. Esse modelo explica bastante bem como se comporta o conjunto homem +planta, a menos de um ruído, geralmente de mais alta freqüência. À esse ruído foi dado o nome de remnant.
} 
ciados (JEX; ALLEN; MAGDALENO, 1972) e é publicado um dos pilares das teorias (MCRUER; KRENDEL, 1974) sobre o comportamento de sistemas operados por humanos. Esta publicação é considerada uma das melhores sobre modelos matemáticos de pilotos humanos.

A década de 80 já traz estudos mais aplicados a casos práticos, como os casos do ônibus espacial (POWERS, 1984; SMITH, 1981). Foi também publicado estudo sobre uso de manobras discretas (HEFFLEY, 1982), marcando uma quebra com os estudos até então vigentes, que usavam manobras contínuas; Hess introduz o modelo estrutural com duas malhas (HESS, 1978, 1980, 1981) e abre espaço para estudos dos aspectos fisiológicos do controle (JOHNSTON; MCRUER, 1986). Um dos primeiros estudos brasileiros sobre o assunto de modelagem de pilotos surge também (PEDREIRO, 1989). E por último, a década de 90 e 2000 tem algumas publicações que fazem apanhados gerais sobre as teorias sobre PIO (MCRUER, 1995; MCRUER; MYERS, 1988) e uma excelente coletânea do estado da arte publicada pela NASA (SHAFER; STEINMETZ, 2001).

Dos modelos pesquisados, o escolhido para ser utilizado nesta tese é o último citado: o modelo estrutural de Hess, que apresenta duas variáveis principais nas malhas de controle.

Esse modelo foi extensamente estudado e demonstrou que há uma alteração na estratégia de controle quando ocorre a transição de uma situação confortável de pilotagem para outra onde há considerável atraso de fase entre a variável que está sendo controlada e o set point do controlador, que no caso é o piloto. Inicialmente, apenas o eixo de controle lateral será estudado e, portanto, essas variáveis referem-se ao ângulo de rolamento da aeronave e ao ângulo de rolamento que o piloto deseja manter (ou ir para). A teoria preconiza que a estratégia de controle migra de um controle angular (posição, ou roll) para velocidade angular (velocidade, ou roll rate) (JAGACINSKI; HAH, 1988; ROBBINS, 1999).

É baseando-se nesta teoria que será proposta uma tese para determinar em qual modo de controle o piloto está operando durante a execução de ensaios em vôo utilizando a técnica de manobra sintética.

Os dados de ensaio em vôo de uma aeronave de transporte FAR-25 serão utilizados 
para validar o método proposto. Inicialmente será feita a identificação de parâmetros da aeronave (planta) em cada condição de vôo ensaiada. Os dados da execução de tarefas sintéticas realizadas em rolamento serão utilizados como entrada em simulações em malha fechada com o modelo estrutural para o piloto humano proposto por Hess. Os resultados das simulações serão comparados com os dados de ensaio utilizando entropia estatística de Renyi, verificando a validade da tese. 


\section{Capítulo 2}

\section{Requisitos de Aeronavegabilidade}

Conforme colocado no capítulo 1.4, os requisitos de aeronavegabilidade para aeronaves civis são bastante genéricos e não tratam especificamente do assunto PIO.

O requisito do FAR 25 (FEDERAL AVIATION ADMINISTRATION, 1965), e seu equivalente europeu CS 25 (EUROPEAN AVIATION SAFETY AGENCY, 2003), que abrange questões de controle é o §25.143, porém sem menção específica a PIO's. É feita, a seguir, uma leitura crítica dos requisitos e seus documentos anexos, sendo que o anexo A contém uma transcrição dos trechos importantes para referência rápida do leitor. É inevitável traçar uma comparação com os requisitos militares, que sempre deram atenção aos fenômenos relacionados à qualidades de vôo, também porque as pesquisas nessa área sempre foram encabeçadas por órgãos governamentais buscando solucionar dificuldades relacionadas à linha de frente do desenvolvimento aeronáutico. Houve uma evolução da compreensão e conseqüentemente dos requisitos de qualidade de vôo (MITCHELL et al., 2004), e a utilização de análises com sistemas equivalentes foi também testada pela indústria militar (HODGKINSON, 2005), análise esta presente há tempos em projetos militares porém pouco utilizada até hoje em projetos civis.

O foco do §25.143 é uma definição dos mínimos exigidos para a controlabilidade e a manobrabilidade que a aeronave deve exibir em cada fase de vôo, definida de maneira genérica para abranger justamente qualquer aeronave de transporte comercial, de qualquer tamanho e configuração. E, por ser tão abrangente, o requisito delega a avaliação à tripulação de ensaio. Essa delegação torna a avaliação subjetiva para determinar se é necessário ou não utilizar no controle da aeronave "habilidades excepcionais, 
força excessiva ou alerta excessivo do piloto e sem exceder os limites de carga - exceptional piloting skill, alertness, or strength, and without danger of exceeding the airplane limit-load factor"

Não há qualquer menção específica à problemática do controle em malha fechada, sendo que há sugestão explícita de alguns autores, como por exemplo (FIELD, 1995; GAUTREY, 1998), para uma revisão dos requisitos de maneira a incorporar aspectos modernos de controle. Via de regra, os organismos certificadores se atêm ao fato de o requisito declarar como mandatório que a aeronave seja controlável e manobrável de maneira segura (safely controllable and maneuverable) e, desta forma, interpretam o requisito como abrangente o suficiente para demandar ensaios que comprovem que o tipo não é susceptível a PIO (non-PIO prone) - ("tipo" - ou type em Inglês - refere-se à aeronave sendo certificada).

Como qualquer norma, o FAR-25 é abrangente, seu conteúdo é passível de interpretação e, portanto, os resultados de suas demonstrações são interpretados de maneiras diferentes por pessoas diferentes. Faz parte da natureza humana. Porém, via de regra, interpretações mais rígidas provocam efeitos econômicos bastante pronunciados nos fabricantes. Especialmente na fase de certificação de uma aeronave, que é a última etapa antes do início das entregas para os clientes. É o ponto na linha do tempo onde a soma do investimento para o desenvolvimento completo é maior, portanto dias de atraso no início das entregas acarretam perdas financeiras consideráveis.

Visando equalizar os custos de certificação entre fabricantes e harmonizar as interpretações dos requisitos, é publicado um guia contendo meios para demonstrar os requisitos (os chamados means of compliance ou MOC) pré-aceitos, explicações de condições mais críticas e, em alguns casos, a motivação do requisito. Normalmente, esses guias são utilizados pelos fabricantes para poupar tempo e eliminar um pouco o fator interpretativo da fase de certificação. Porém, para certificações FAR 25, a parte específica de PIO não era contemplada, em seu respectivo guia de ensaios até sua penúltima edição, com quaisquer interpretações ou meios pré-aceitos de demonstração do requisito até a última revisão.

Visando esclarecer um pouco a comunidade e também tentar padronizar os ensaios, foi emitida revisão do guia AC25-7A - (FEDERAL AVIATION ADMINISTRATION, 1999; THIEL, 2001). Sua adoção, apesar de ele conter uma referência de boas práticas 
e métodos pré-aceitos para a demonstração de requisitos, não é obrigatória, tendo o fabricante liberdade para apresentar novas idéias e métodos para demonstrar o cumprimento com os requisitos. Nessa revisão, foi incluído o §20. GENERAL - 25.143 section d, que trata especificamente de ensaios de PIO (ou A-PC Airplane-Pilot Coupling na nomenclatura utilizada na época). Antes de emitir essa revisão, foi promovido um debate com a comunidade para tentar aglutinar sob um mesmo documento as várias linhas de pesquisa e suas diferentes visões sobre o assunto. Participaram das discussões representantes da indústria, dos organismos certificadores e de algumas instituições de pesquisa, sendo a principal pergunta no debate:

Como testar uma nova aeronave quanto à susceptibilidade a PIO?

O texto resultante reconhece que as aeronaves modernas podem ser susceptíveis a PIO - $§ 1$ (a) (i) - "A história de eventos em serviço indica que aeronaves de transporte modernas podem ser susceptíveis a acoplamento aeronave-piloto (A-PC ou PIO) sob certas condições operacionais e não atenderiam às intenções do requisito." - e define a sua ocorrência "clássica" como sendo uma resposta defasada de 180 graus em relação ao comando do piloto. Reconhece, também, que os requisitos não contemplam nem a definição e nem a necessidade explícita de demonstração de aeronavegabilidade com relação a este aspecto; que até então estavam sendo feitos quase exclusivamente através de ensaios em malha aberta - $\S 1$ (a) (iv) "o cumprimento somente com os requisitos quantitativos, em malha aberta (piloto fora do loop) não garante que os níveis de qualidade de vôo sejam atingidos."

Antes de descrever os ensaios sugeridos para a demonstração de aeronavegabilidade, o documento faz algumas considerações especiais, dentre as quais destaca-se: cada programa de ensaio deverá ser desenhado especificamente para o Tipo que está sendo certificado. E sugestões para programas específicos de ensaio visando verificar a susceptibilidade a PIO são tema de publicações recentes, como (GAUTREY, 1997; MITCHELL; KLYDE, 2005), onde é proposto que seja feita "uma quebra de filosofia, incluindo ensaios específicos para avaliação de PIO em programas de desenvolvimento futuro" e definindo novos critérios para os aspectos de qualidades de vôo de aeronaves de transporte civil.

O método proposto para demonstrar o aspecto PIO do requisito de aeronavegabi- 
lidade é a execução de tarefas em malha fechada. Essa é a principal contribuição do documento, pois reconhece ser o modo de pilotagem em que o fenômeno ocorre. Recomenda, de maneira geral, que a execução das tarefas não seja atrelada a uma medida de desempenho (por exemplo: porcentagem de acerto da tarefa); que o programa de ensaios seja projetado especificamente para cada aeronave; e que as tarefas sejam baseadas em situações operacionais, manobras de ensaios, ou dificuldades em serviços que tenham produzido eventos de PIO. Recomenda-se também que tenham características em comum com esses eventos e sirvam para evidenciar aspectos diferentes de quaisquer áreas problemáticas de PIO que possam existir. Enfim, é uma tarefa perfeita para evidenciar PIO's. Porém não é fornecida a fórmula para sua criação, apenas seus requisitos. Essas exigências contribuíram para uma diminuição da credibilidade do guia na indústria, gerando a necessidade de criação, por parte de cada fabricante, de novos meios para demonstrar os requisitos. Ou seja, a eficácia do guia não atingiu níveis adequados, e o problema da interpretação voltou.

O documento ainda faz sugestões específicas sobre o uso de tarefas sintéticas, considerando que as seqüências devam ter os comandos de rolamento e arfagem como combinações de degraus e rampas, e serem longas e complexas o suficiente para o piloto não aprender e antecipar os comandos (aprendizado). O fator aprendizado já havia sido identificado como importante desde a década de 60 (PREYSS; MEIRY, 1967), sendo o objetivo de eliminar essa familiaridade manter o ganho do piloto de ensaios alto e afastar o risco de compensação inadvertente durante a execução da tarefa.

O esvaziamento na utilização direta do guia pela indústria nas demonstrações FAR25 §25.143 continuou causando debate, e a própria autoridade certificadora (no caso, o FAA americano) não é fiel na aplicação dos preceitos do guia de ensaios e aceita (até fomenta) discussões a respeito de alternativas para demonstração de tendências a PIO. As primeiras discussões ocorreram em 1996 no workshop "Calspan PIO Fly Shop", de que participaram representantes de vários escritórios do FAA nos Estados Unidos (os escritórios são regionais). O workshop recomendou aos pilotos certificadores do FAA treinamento com uma parte prática na aeronave de estabilidade variável da CALSPAN. As primeiras sessões ocorreram em 1998, de onde são citados excertos da publicação briefing paper $^{1}$ :

\footnotetext{
${ }^{1}$ engenheiro de ensaios chefe do FAA/LA ACO na época - J. Ashley
} 
Um entendimento significativamente maior sobre o fenômeno de PIO precisa ser desenvolvido pelo FAA. A susceptibilidade a PIO somente pode ser avaliada por pilotos de ensaio em alto ganho, i.e., voando tarefas demandantes de grande concentração e controle preciso - operar com alto ganho em um ambiente controlado exige prática de ensaios (CALSPAN, 1999).

Foi publicado um livro (NATIONAL RESEARCH COUNCIL, 1997) contendo os conceitos discutidos neste workshop, que é bastante ilustrativo sobre o assunto PIO. Foram realizadas novas discussões acerca do tema, culminando com outro workshop promovido pela empresa americana CALSPAN, entre 15 e 19 de novembro de 1999 (CALSPAN, 1999). Vários conceitos foram revisitados, e uma revisão da proposta apresentada por Mel Rogers (documento FWP 599-3) como revisão da AC25-7A, seção 3, parágrafo 20 (d) foi consensada. Porém, o processo não evoluiu, provavelmente devido à baixa demanda da indústria, que passava por um período em que novos projetos com tecnologia FBW estavam apenas em estudo preliminar. Dessa maneira, o guia de ensaios já publicado prevaleceu como único documento oficial a orientar a certificação civil no tocante a PIO. Com o passar dos anos, a cada projeto de tipo novo, os debates acerca desse tema revelam que o assunto realmente não ficou adequadamente delimitado no guia de ensaios e que há uma necessidade de complementação, efetuada por meio de regras especiais (special conditions). Inclusive com sugestões de ensaios (MITCHELL; KLYDE, 2005), e reforço na sugestão de treinamento dos pilotos certificadores (A'HARRAH, 2001). Infelizmente, essas regras especiais são restritas para cada tipo (para cada projeto novo) e não são publicadas integralmente. Somente as formas finais são públicas, por exemplo, (DEPARTMENT OF TRANSPORTATION, 2007a, 2007b). Torna-se, portanto, conhecimento e diferencial de mercado, para cada fabricante de aeronaves, envolver-se em debates com autoridades certificadoras sobre esse tema e propor ensaios que contemplem de facto uma verificação sobre a susceptibilidade a PIO do tipo. O estado atual do avanço dos regulamentos nessa área é um projeto do FAA americano intitulado Software Digital Systems Safety Project, que reconhece a dificuldade de avaliar a susceptibilidade a PIO e estuda meios para avaliar essas características :

A história de projetos FBW, certificação e operação em serviço mostra como é difícil projetar e garantir qualidades de vôos satisfatórias em todo o envelope de vôo. Vários relatos de dificuldades em serviços e ocorrência de PIOs 
podem ser encontrados (FIELD, 1995). O resultado tem sido (FEDERAL AVIATION ADMINISTRATION, 2007B):

1. Susceptibilidade a PIO, particularmente durante os primeiros anos dos programas FBW;

2. Interação adversa entre tarefas normais de controle e funções de proteção de envelope.

Esta tarefa busca, primeiro, documentar as lições aprendidas durante programas anteriores de FBW nessa área e depois identificar:

- falhas nos requisitos de qualidades de vôo para métodos de projeto e avaliação que precisam ser verificados (e endereçados em programas subseqüentes);

- guias importantes de projeto preliminar e avaliações que possam ajudar dificuldades de certificação custosas e demoradas, encontradas tardiamente no projeto ou na entrada em serviços.

O futuro dos requisitos certamente deverá lançar algum tipo de discussão a respeito do tema, haja vista o constante aumento do grau de automação na cabine dos aviões. Os tipos mais recentes a receberem certificação e terem que demonstrar cumprimento com condições especiais foram o Dassault Falcon 7X, que tem seu FBW derivado do caça Rafale, o Airbus A380 e o Gulfstream G650 (DEPARTMENT OF TRANSPORTATION, 2007b, 2006). Projetos ainda não certificados, como o Boeing 787, também incorporam tecnologia FBW e estão sujeitos às condições especiais - (DEPARTMENT OF TRANSPORTATION, 2007a). 


\section{Capítulo 3}

\section{Ensaios em Vôo - Prática Atual e Colocação da Tese}

\subsection{Histórico dos Ensaios}

A evolução rápida dos sistemas embarcados, conforme descrito no capítulo 1.4, propiciou um vazio no catálogo oficial (guia de ensaios) de manobras de ensaios em vôo para verificação da susceptibilidade a PIO. De certa maneira, verifica-se uma evolução também lenta das técnicas de ensaios, porém significativamente mais rápida que a evolução dos requisitos de aeronavegabilidade.

As pesquisas por soluções que pudessem desvendar possíveis PIOs na fase de desenvolvimento (tanto em critérios de projeto quanto em critérios práticos) avançaram quase que exclusivamente por fomento das agências governamentais a pesquisas militares.

Historicamente, essas pesquisas provenientes da área militar migraram mais lentamente para a área civil devido ao alto custo envolvido em validá-las para aeronaves intrinsecamente diferentes (um caça versus uma aeronave de transporte de passageiros) e à lentidão da evolução dos requisitos de aeronavegabilidade, que seria, sem dúvida, o principal motivador para o avanço das pesquisas na indústria. Dessa maneira, para cada instante no tempo, há um atraso praticamente constante entre o grau do avanço do conhecimento sobre o assunto PIO encontrado na pesquisa militar, na prática dos ensaios civis e nos requisitos de aeronavegabilidade civis. 
Analisando o histórico dos ensaios em vôo para permitir a verificação da susceptibilidade a PIO de aeronaves civis, verifica-se este atraso, que pode ser visto na tabela 3.1, onde é apresentada essa evolução das técnicas de ensaio.

\subsection{Descrição das Manobras e a Prática Atual}

A prática atual de ensaios em vôo para verificação de PIO em aeronaves civis está calcada, conforme já exposto, na experiência proveniente das pesquisas militares que migraram para este setor e que foram adaptadas para se adequarem aos tipos de aeronave que o mercado civil utiliza. Além disso, vários estudos já demonstraram a necessidade de desenhar tarefas específicas para testar sistemas FBW - (FIELD, 1995; GAUTREY, 1998). A seguir, as principais manobras utilizadas para certificação de aeronaves civis serão brevemente descritas em ordem crescente de acordo com o grau de risco para a realização. O grau de risco é analisado levando-se em conta a probabilidade de um acidente causado durante os ensaios por três motivos principais:

1. Falha de algum sistema da aeronave durante a execução do ponto de ensaio;

2. Erro do piloto devido à dificuldade inerente à execução da manobra;

3. Expansão inadvertida do envelope de vôo.

Desses três motivos, os dois primeiros são os principais fatores; haja vista a premissa que a realização de um ensaio para a verificação de PIO ocorre após a abertura de envelope da aeronave a ser testada.

As principais manobras são:

- Simulação com Piloto - base fixa ou base móvel

Os mais variados tipos de simuladores (desde PCs até simuladores com movimento completo da cabine (full motion simulators) são utilizados para fazer avaliações do sistema conjugado piloto-aeronave durante o desenvolvimento de um projeto. Basicamente, são voadas missões, de maneira a permitir uma avaliação rápida, barata e sem risco. Geralmente inicia-se a utilização de simuladores em base fixa nos primeiros estágios de um projeto novo, principalmente devido à rapidez em se prototipar os modelos e ao custo reduzido. Uma vez que o projeto avança, são 
Tabela 3.1: Evolução das Técnicas de Ensaio para Verificação de PIO

\begin{tabular}{|c|c|c|c|c|c|c|}
\hline & .............. Década »» & 60 & 70 & 80 & 90 & 2000 \\
\hline $\begin{array}{l}\text { Pesq. } \\
\text { Militar }\end{array}$ & $\begin{array}{l}\text { Vôos a baixa altura } \\
\text { Tarefas de captura } \\
\text { Vôos em formatura } \\
\text { Pouso com desvio lat.* } \\
\text { Simulação com piloto } \\
\text { Simulação em vôo } \\
\text { Tarefas sintéticas }\end{array}$ & $\begin{array}{l}X \\
X \\
X\end{array}$ & $\begin{array}{l}\mathrm{X} \\
\mathrm{X} \\
\mathrm{X} \\
\mathrm{X} \\
\mathrm{X} \\
\mathrm{X}\end{array}$ & $\begin{array}{l}\mathrm{X} \\
\mathrm{X} \\
\mathrm{X} \\
\mathrm{X} \\
\mathrm{X} \\
\mathrm{X}\end{array}$ & $\begin{array}{l}\mathrm{X} \\
\mathrm{X} \\
\mathrm{X} \\
\mathrm{X} \\
\mathrm{X} \\
\mathrm{X}\end{array}$ & $\begin{array}{l}X \\
X \\
X \\
X \\
X \\
X\end{array}$ \\
\hline Ens. civis & $\begin{array}{l}\text { Vôos a baixa altura } \\
\text { Tarefas de captura } \\
\text { Vôos em formatura } \\
\text { Pouso com desvio lat. } \\
\text { Simulação com piloto } \\
\text { Simulação em vôo } \\
\text { Tarefas sintéticas }\end{array}$ & & $\mathrm{X}$ & $\begin{array}{l}\mathrm{X} \\
\mathrm{X}\end{array}$ & $\begin{array}{l}\mathrm{X} \\
\mathrm{X} \\
\mathrm{X} \\
\mathrm{X} \\
\mathrm{X} \\
\mathrm{X} \\
\mathrm{X}\end{array}$ & $\begin{array}{l}X \\
X \\
X \\
X \\
X \\
X\end{array}$ \\
\hline $\begin{array}{l}\text { Req. } \\
\text { aeronavg. }\end{array}$ & $\begin{array}{l}\text { Vôos a baixa altura } \\
\text { Tarefas de captura } \\
\text { Vôos em formatura } \\
\text { Pouso com desvio lat. } \\
\text { Simulação com piloto } \\
\text { Simulação em vôo } \\
\text { Tarefas sintéticas }\end{array}$ & & & & $\mathrm{X}$ & $\begin{array}{l}\mathrm{X} \\
\mathrm{X}\end{array}$ \\
\hline
\end{tabular}

utilizados simuladores cada vez mais sofisticados, chegando a um equipamento com base móvel somente nas últimas etapas. Cada etapa tem seu valor no desenvolvimento para eliminar erros de projeto e com o aumento de complexidade dos simuladores, busca-se melhorar a precisão da modelagem, culminando com a integração entre percepções visuais diretas, visuais periféricas e sensoriais de movimento nos simuladores de base móvel. Estes possuem grande diferencial sobre os simuladores de base fixa, tanto construtivo e de engenharia como de resultados. Um dos problemas das simulações é que há, nas primeiras fases de um projeto, uma falta de fidelidade entre o modelo matemático da aeronave (planta) e a aeronave em si, principalmente devido à incorreção dos dados aerodinâmicos disponíveis. Outro problema é a falta de acelerações no sistema sensorial do piloto, provocando reações (controle) durante a execução das manobras que não têm boa correlação com a realidade. Principalmente em situações extremas, quando um PIO ocorreria. Os simuladores são ótimas ferramentas para verificar grandes problemas em estágios iniciais do desenvolvimento de uma aeronave. Se o PIO aparece nos simuladores, então ele aparecerá na aeronave; porém, se não aparece 
no simulador, não significa que não aparecerá na aeronave. ${ }^{1}$

- Tarefas de Captura

São capturas de proa, atitude - arfagem $(\theta)$ e rolamento $(\phi)$, ângulo de planeio $(\gamma)$, ângulo de ataque $(\alpha)$ e capturas de fator de carga $\left(N_{z}\right)$ comandadas abruptamente a partir de uma condição estabilizada e compensada, com emprego de alto ganho. Podem ser executadas em simuladores durante os estágios iniciais de avaliação de um projeto novo, mas é durante ensaios em vôo que apresentam resultados satisfatórios. Geralmente executadas em altitude segura (longe do chão) e por isso são de grande aceitação entre as autoridades certificadoras. Porém são bem pouco eficazes em desvendar tendências a PIO, uma vez que sua execução apresenta resultados apenas para a fase de captura de uma tarefa em malha fechada e dá, portanto, somente uma impressão geral sobre as qualidades de vôo da aeronave. Um exemplo dos resultados dessa manobra pode ser visto na figura 3.1.

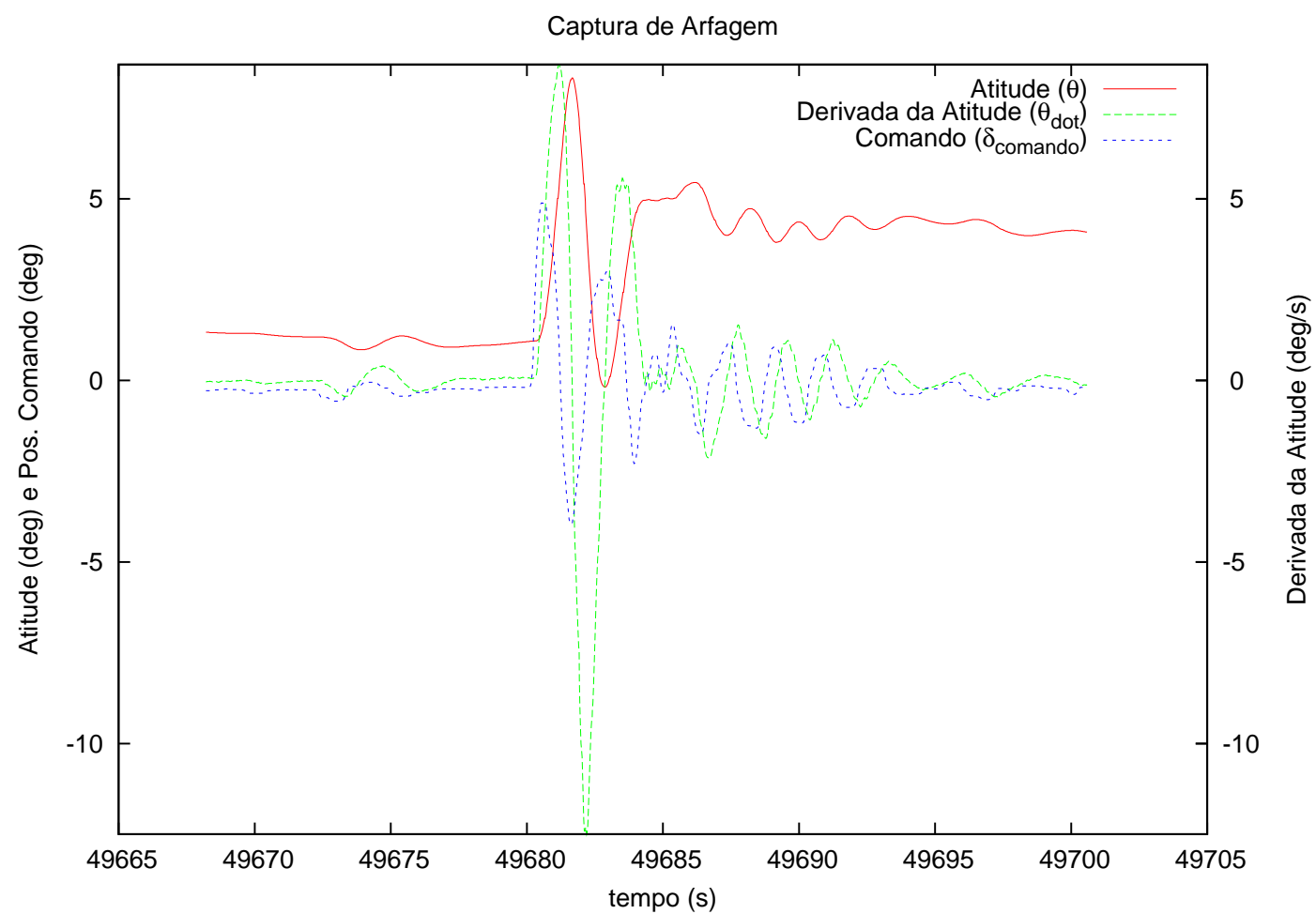

Figura 3.1: Manobra de Captura de Atitude de Arfagem - A manobra é bastante simples: inicia-se com uma atitude estabilizada, em vôo reto e nivelado, e busca-se estabilizar em uma nova atitude o mais rapidamente possível.

\footnotetext{
${ }^{1}$ afirmativa emitida por Mike Parrag, instrutor da Calspan, durante o curso "EMBRAER/CTA PIO Flight Test Training- 1998
} 
- Simulação em Vôo

Este ensaio requer uma aeronave hospedeira com características aerodinâmicas muito bem conhecidas. Além disso, ela deve ser altamente modificada para ter a capacidade de servir como hospedeira de um modelo matemático. A idéia é que se possa ter essa aeronave hospedeira controlada por computador, que executa duas tarefas: para cada entrada (input) feita pelo piloto, é calculada a resposta que a aeronave hospedeira daria; então a essa resposta é somado um comando oposto, de maneira a anulá-la. Em seguida, essa entrada do piloto é simulada através de modelo matemático do avião que se está querendo simular. Esse método foi inicialmente empregado pela empresa americana Calspan (WEINGARTEN, 2005). A mecanização se dá com uma aeronave de características aerodinâmicas conhecidas (hospedeiro), sendo modificada para servir como se fosse a nova aeronave que se está querendo ensaiar (hóspede) (PARRAG, 2001). O método consiste em anular matematicamente as características da aeronave hospedeira, através de um modelo matemático inverso, e produzir saídas (outputs) que se assemelhem à aeronave hóspede. O aparato exige um modelo matemático bastante preciso da aeronave hospedeira e do modelo matemático da aeronave hóspede, geralmente proveniente de ensaios de túnel de vento. O modelo do sistema de controle da aeronave hóspede, incluindo aí as latências das informações, é também fundamental para resultados aceitáveis. Uma vez sintonizados ambos modelos, são executadas tarefas de pouso, de captura e manobras sintéticas para avaliar as respostas. Sempre com possibilidades de reversão para as características da aeronave hospedeira (reversão para manual), minimizando risco de acidentes.

A vantagem desse tipo de ensaio é a fidelidade em termos de acelerações e de realimentação visual (feedback), sem o atraso dos simuladores em terra (CELERE; FERNANDEZ; OLIVEIRA, 2000). A desvantagem é o alto custo.

Um exemplo de aeronave com capacidade para executar simulações em vôo é o Learjet da Calspan, empresa americana especializada em pesquisas de PIO. Uma foto dessa aeronave pode ser vista na figura 3.2.

- Tarefas Sintéticas

É um sistema específico de guiagem para o piloto, possibilitando comandos de rolamento e arfagem via um diretor de vôo colocado na cabine de pilotagem (MIT- 


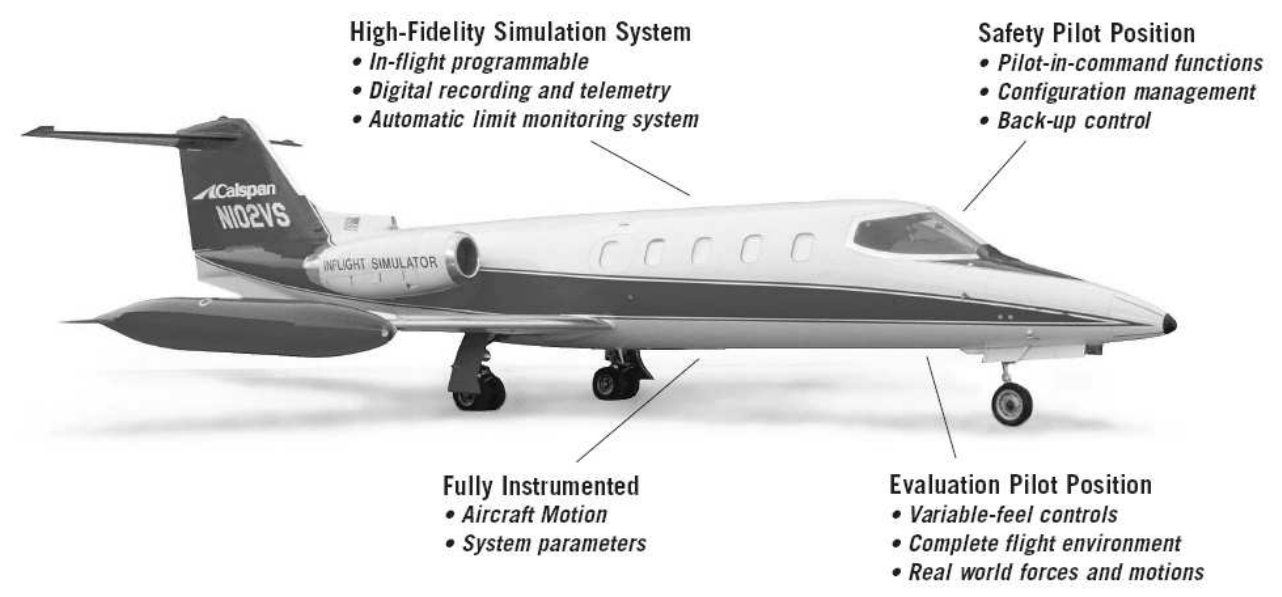

\section{calspan}

Figura 3.2: figura ilustrativa extraída do catálogo da empresa americana Calspan. A aeronave tem um sistema de estabilidade variável e é utilizada como plataforma para simulações em vôo - Learjet Calspan.

Fonte: (CALSPAN, 2007)

CHELL; KLYDE, 2001). O objetivo desse aparato é induzir entradas (inputs) no sistema aeronave-piloto. As tarefas (séries de comandos enviados a esse diretor de vôo e que o piloto deve seguir com o mais alto ganho possível) são construídas a partir do conteúdo de freqüência desejado e também por meio de um balanceamento entre as etapas de aquisição (fine tracking) e manutenção (gross acquisition) de atitude.

Esse método é bastante seguro, haja vista que se pode regular as tarefas de maneira a não exceder limites da aeronave, bem como executá-las em altitudes confortáveis.

A principal vantagem é a segurança proporcionada. A principal desvantagem é que só se pode executá-las na própria aeronave sendo desenvolvida, não deixando margem para alterações grandes de projeto sem um alto custo elevado. Uma descrição mais detalhada dessa manobra segue na seção 3.4.1 e será parte fundamental deste trabalho, uma vez que esta é a principal manobra escolhida para a realização dos ensaios de PIO.

- Vôos a baixa altura

Consiste na utilização de uma referência no solo (geralmente uma pista de pouso) 
para execução de manobras de captura e manutenção. Vide figura 3.3. A manobra inicia-se a uma altitude de aproximadamente 3 envergaduras, com o centro da pista deslocado para um dos lados. Já em vôo estabilizado e nivelado, a captura do centro da pista é executada com alto ganho (com inclinações de asa que chegam a 45 graus). A captura é feita com o auxílio de uma marca no pára-brisa, que deve ser alinhada com a faixa central. Uma vez capturado, o alinhamento é mantido por 5 a 10 segundos. Outro tipo de captura é o chamado de curva em S, ou $S$ Turn, onde as laterais esquerda e direita da pista são alternadamente capturadas mantendo-se uma altitude bastante pequena (50 pés) (LEE, 2001; PONCELET; ALONSO, 2001). Para que haja eficácia nesta manobra, é necessário que o ganho

\section{Desvio Lateral}

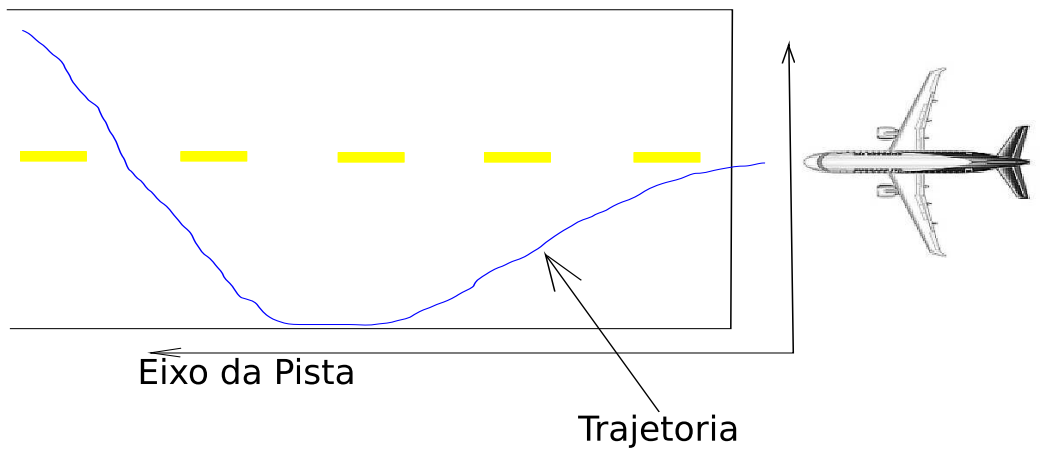

Figura 3.3: S-Turns

Esquema para execução da manobra $S$-Turn, onde o piloto procura voar sobre a pista em altitudes cada vez menores, indo de um lado para outro, capturando as laterais no seu campo visual

empregado pelo piloto seja alto (como em qualquer ensaio de PIO). Porém a própria condição de baixa altura gera desconforto e induz à utilização de ganhos menores. Outro aspecto prático a se considerar é o espaço lateral necessário. Não pode haver construções ao redor da pista para não comprometer a segurança. Por último, caso haja ocorrência de algum evento, existe pouca margem para manobras evasivas. Desta maneira, apesar de ser considerada eficaz, essa manobra é pouco utilizada na certificação civil.

-Vôo em Formatura

Consiste em se executar tarefas de precisão utilizando-se uma aeronave externa como referência (líder). As tarefas são geralmente captura de alguma parte da aeronave líder (como, por exemplo, ponta da asa do líder no canto superior da 
janela do piloto) (LEE, 2001) e posterior manutenção de posição sob as várias intempéries de vôos em formatura. Há, também, a versão de simulação de abastecimento em vôo ( ou probe-and-drogue maneuver), que é bastante eficiente em evidenciar PIOs (KLYDE; MITCHELL; LATTIMER, 1999). A vantagem é ser simples de executar. As desvantagens são custo elevado e risco de colisão em vôo. Fotos deste tipo de ensaio podem ser vistas nas figuras 3.4, 3.5 e 3.6.

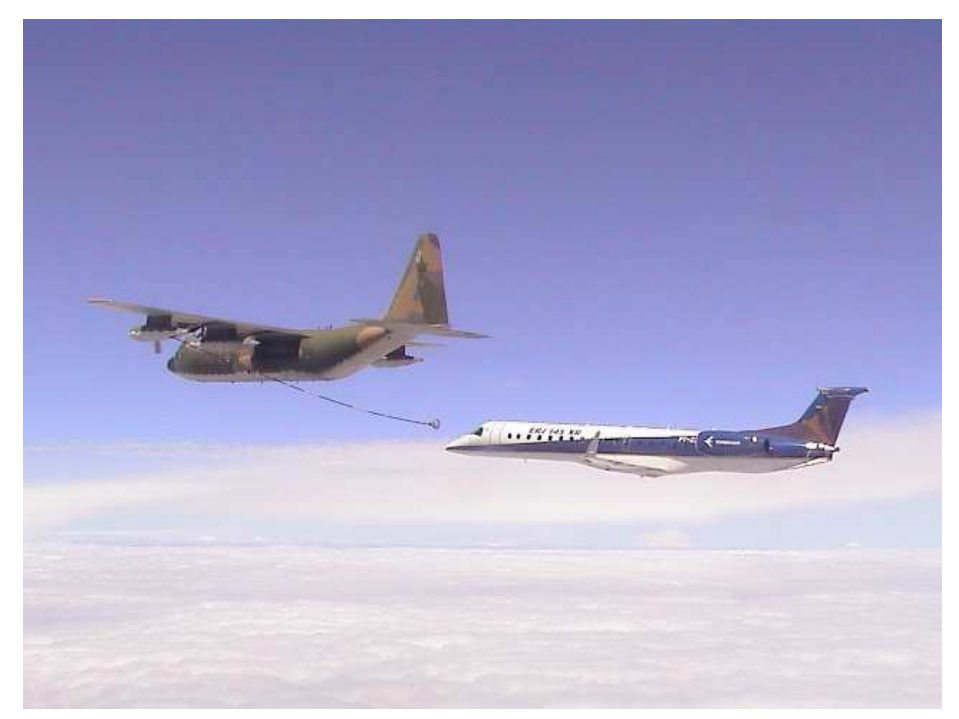

Figura 3.4: Vôo em Formatura - 01 - foto do ensaio de simulação de abastecimento em vôo e vôo em formatura. A aeronave à frente reboca uma mangueira com uma cesta na ponta. A aeronave mais atrás tenta se posicionar para encaixar a cesta em uma haste fictícia desenhada no pára-brisa.

Fonte: arquivo Ensaio em Vôo - EMBRAER 


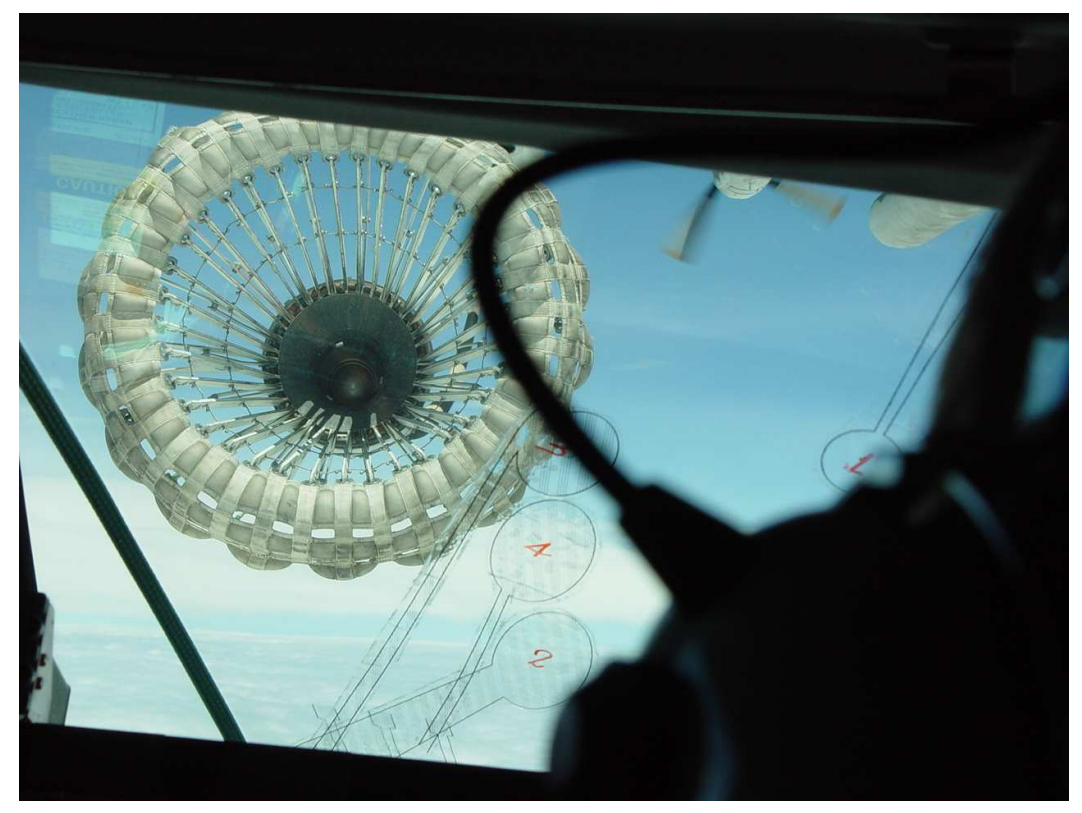

Figura 3.5: Vôo em Formatura - 02 - foto de dentro da aeronave sendo ensaiada, mostrando a cesta sendo puxada pela aeronave da frente e as hastes fictícias desenhadas no pára-brisa. Cada posição representa uma haste sendo ensaiada.

fonte: arquivo Ensaio em Vôo - EMBRAER

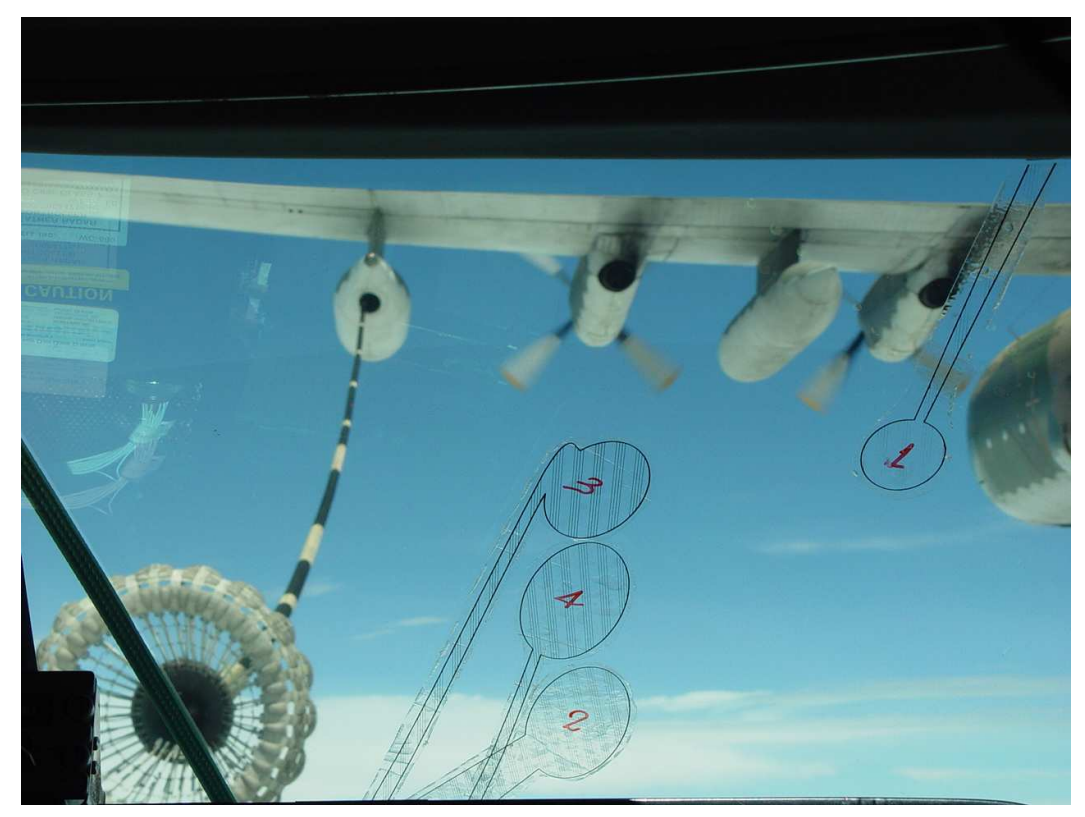

Figura 3.6: Vôo em Formatura - 03 - detalhe das hastes fictícias desenhadas no párabrisa da aeronave sendo ensaiada.

Fonte: arquivo Ensaio em Vôo - EMBRAER 


\section{- Pouso com Desvio Lateral, ou Offset Landing}

Consiste um executar um pouso de precisão, partindo de uma situação desalinhada com a pista (geralmente uma a duas envergaduras fora do eixo) e, geralmente, mantendo uma rampa de 3 graus para toque na cabeceira. A correção lateral se

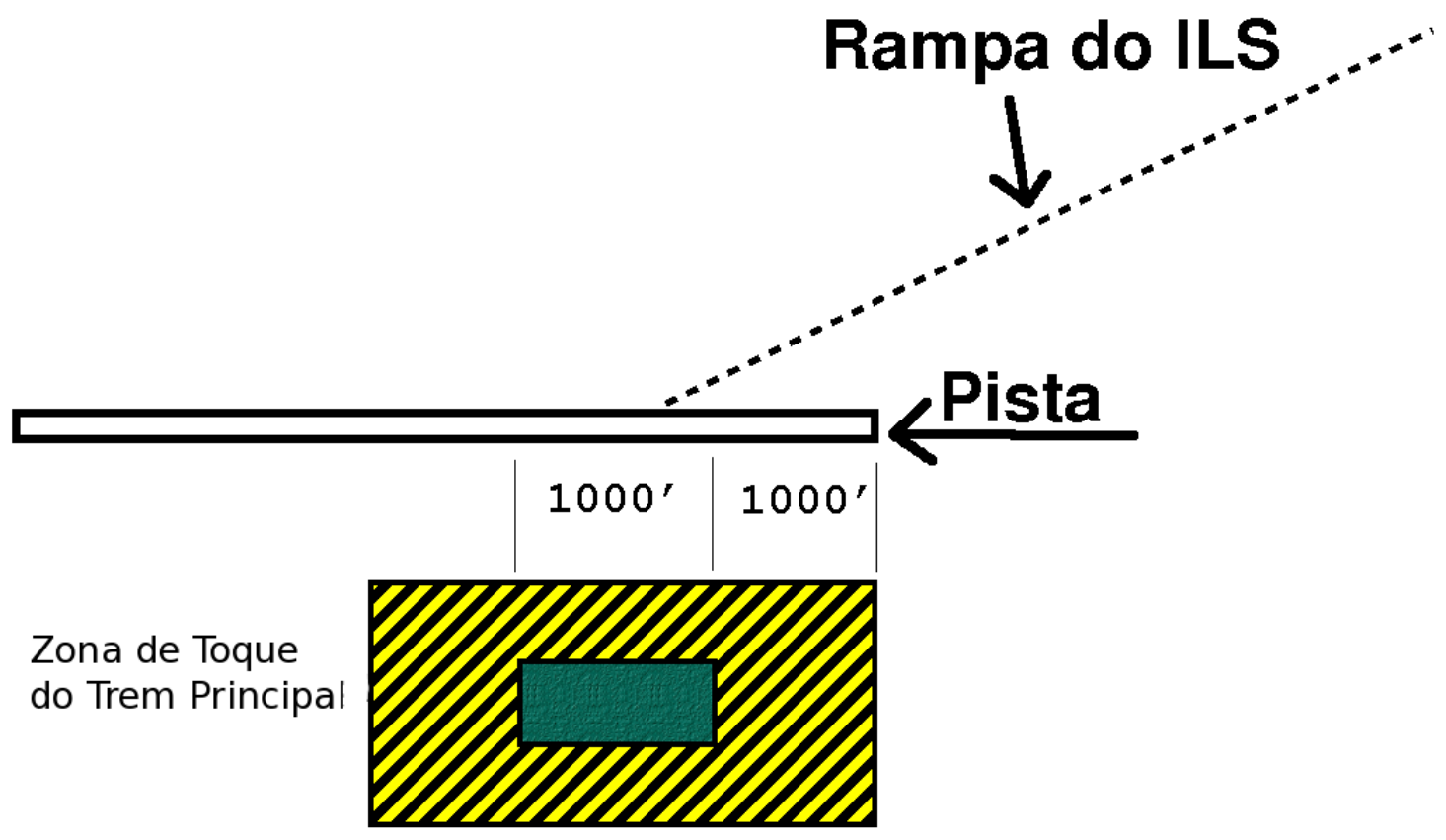

Figura 3.7: Esquema para execução da manobra de pouso com desvio lateral, ou Offset Landing - Notar que há duas áreas hachuradas definidas na figura. Uma maior, com 3000 pés de comprimento e 60 pés de largura, que é a zona considerada aceitável para o pouso. Uma segunda, menor e contida dentro da maior, de 1000 pés de comprimento e 20 pés de largura, dentro da qual um pouso é definido como desejável. O piloto deve esforçar-se para pousar na área menor, sendo que o alinhamento com a pista é dificultado pelo desvio lateral.

dá entre 200 e 100 pés de altura, e o pouso necessariamente deve ser executado em espaço confinado, tipicamente um retângulo imaginário de 100 por 20 metros, em algum local próximo à cabeceira. A vantagem é ser uma tarefa de altíssimo ganho e, portanto, considerada uma das melhores manobras para evidenciar PIOs. A desvantagem é a justa margem para erros, devido à proximidade com o solo e, também, às atitudes extremas envolvidas nas correções de proa. 


\subsection{Método de Validação Proposto - Tese}

Em todos os ensaios descritos no item anterior, há uma hipótese muito forte associada: O piloto executará a tarefa com o mais alto ganho possível, excitando uma possível condição real de PIO. Essa hipótese é fundamental para que, enquanto controla a aeronave, o piloto aja de maneira similar a uma situação onde há uma defasagem significativa entre seus comandos e as respostas da aeronave. Sem uma pilotagem de alto ganho, não é possível identificar um PIO. Porém, nenhum dos ensaios descritos tem como condição validadora a garantia de que o piloto está realmente atuando com ganho alto. Inclusive há relatos de que o simples conhecimento de que se trata de um ensaio, e não da situação real, leva o piloto a modificar o gatilho do mecanismo de início do PIO (CORD, 2001). A hipótese é simplesmente assumida como verdadeira, e a única providência para se tentar garanti-la é um briefing ${ }^{2}$ bem executado, cuja condição de pilotar realmente com alto ganho é enfatizada para o piloto participante do ensaio. A literatura admite que essa hipótese não é sempre verdadeira. Há relatos da dificuldade de pilotos de ensaios mimetizarem uma operação de linha aérea ou uma situação de PIO:

$[\ldots]$ também foi encontrado que era difícil um piloto de ensaios treinado fechar a malha da mesma maneira que um piloto em serviço o faria. Foi a experiência de trabalhar com pilotos de ensaio que evidenciou dúvidas na cabeça deste apresentador quanto a avaliações de qualidades de vôo. Este [pensamento] tem a raiz na variabilidade e subjetividade da visão de cada piloto e ainda é possível obter uma faixa de comentários de um piloto individual (SMITH, 1995).

Há também recomendações para que o desempenho do piloto seja monitorado durante os ensaios e que uma variabilidade entre pilotos deve ser esperada (MITCHELL, 2001). Coloca-se, pois, a tese deste trabalho: um ensaio de PIO deveria ser validado primariamente quanto ao ganho do piloto. É proposto um método para verificar a execução de pontos de ensaio para verificação de PIO utilizando-se a técnica de tarefa

\footnotetext{
${ }^{2}$ briefing é o nome utilizado para a reunião que antecede uma missão ou um ensaio, onde todos os envolvidos revisam toda a seqüência a ser executada. O objetivo é eliminar quaisquer dúvidas e sincronizar a comunicação.
} 
sintética. Uma segunda hipótese sobre ensaios de PIO é que o piloto é capaz de se abstrair do ensaio e perceber, durante a execução da manobra, se há descontinuidade entre os comandos propostos pelo cérebro e a resposta da aeronave, mimetizando a situação em que um eventual PIO ocorreria. A experiência nos programas de certificação FAR 25 dos modelos EMB-135BJ, ERJ-170/175/190 e 195 demonstrou que essa hipótese é bastante razoável e, portanto, não será o foco deste trabalho.

\subsection{Técnica de Manobras Sintéticas}

\subsubsection{Descrição e História}

Desde o início das pesquisas com controles manuais, há uma tentativa de reproduzir dentro do laboratório as situações verificadas no uso prático, que seguem até a atualidade (DUPPEN et al., 2007). As primeiras experiências com computadores analógicos mostrando pontos e traços para um operador humano seguir na tela de um osciloscópio datam da década de 50 e sofreram bastante avanço durante a corrida espacial da década de 60 (BEKEY; ANGLE, 1966; PREYSS; MEIRY, 1967). Uma miríade de experiências foi produzida e com o acúmulo desse conhecimento, aliado ao refinamento da precisão das medidas, chegando até a se construir uma simulação que utiliza uma maquete de pista de pouso e câmera de televisão para realizar a filmagem e prover uma imagem simulada para o piloto através de uma televisão (CHASE, 1967), a primeira metade da década de 70 mostrou que os experimentos em laboratório traziam sérias limitações:

1. Falta de feedback da dinâmica da aeronave (acelerações), o que causa comandos excessivos. Esse tipo de desvio da situação real provou-se bastante importante na compreensão do padrão cognitivo do piloto humano, revelando que as informações adicionais utilizadas no processamento do controle são bastante relevantes;

2. Atraso no sistema visual, entre o comando e a resposta do sistema, gerando falta de fidelidade e atrapalhando a visão periférica, conseqüentemente inserindo um fator de erro a mais no processamento das informações feito pelo piloto (uma informação errada);

3. Efeitos de turbulência e variações atmosféricas não realistas; 
4. Ambiente de laboratório (em solo) que não consegue disparar uma atuação de alto ganho adequada no piloto. A literatura mostra que há uma tendência a se efetuar uma pilotagem que é agressiva porém, como o ambiente de laboratório em solo não implica em risco de acidente e também não traz elementos como barulho, visão periférica, vibrações e acelerações presentes em uma aeronave real, a pilotagem fica agressiva em demasia, sem que o piloto possa relacionar esses testes em solo com a experiência em ensaios em vôo.

Buscando uma solução que suplantasse essas dificuldades, foi inventado o conceito de tarefa sintética pela empresa americana Calspan. A base para a idéia vem das manobras de reabastecimento em vôo, que são notoriamente exigentes do ponto de vista de pilotagem e já desvendaram vários PIOs em aeronaves militares.

\subsubsection{Aparato Experimental}

Com o lançamento do programa de desenvolvimento tecnológico para projeto de controles fly-by-wire na EMBRAER em 1998, foi necessário desenvolver ferramentas que dessem suporte aos ensaios requeridos para posterior certificação. Visando atender os requisitos para ensaios de PIO, este autor liderou o desenvolvimento do sistema de tarefas sintéticas da EMBRAER, chamado Syntask, com o mesmo conceito daquele apresentado pela Calspan, em que uma tarefa (compensatory) é apresentada ao piloto para que ele a siga com o mais alto ganho possível. Inicialmente foram pesquisadas várias interfaces, aparato computacional, interface de entrada de dados e análises em tempo real simplificadas. Após várias revisões do projeto, contando com ensaios de desenvolvimento, congelou-se o sistema conforme a arquitetura mostrada na figura 3.8.

O seu funcionamento ocorre da seguinte forma:

- É definida uma tarefa em que as atitudes desejadas (target attitudes) para cada instante de tempo são listadas em um arquivo;

- Este arquivo é lido durante o ensaio e sincronizado com os sensores de atitude da aeronave, sendo, então, computada a diferença entre a atitude em que a aeronave está e a atitude desejada;

- As informações compiladas são mostradas para o piloto na forma de um diretor 
de vôo;

- As ações do piloto e as atitudes resultantes são gravadas no sistema de aquisição de dados.

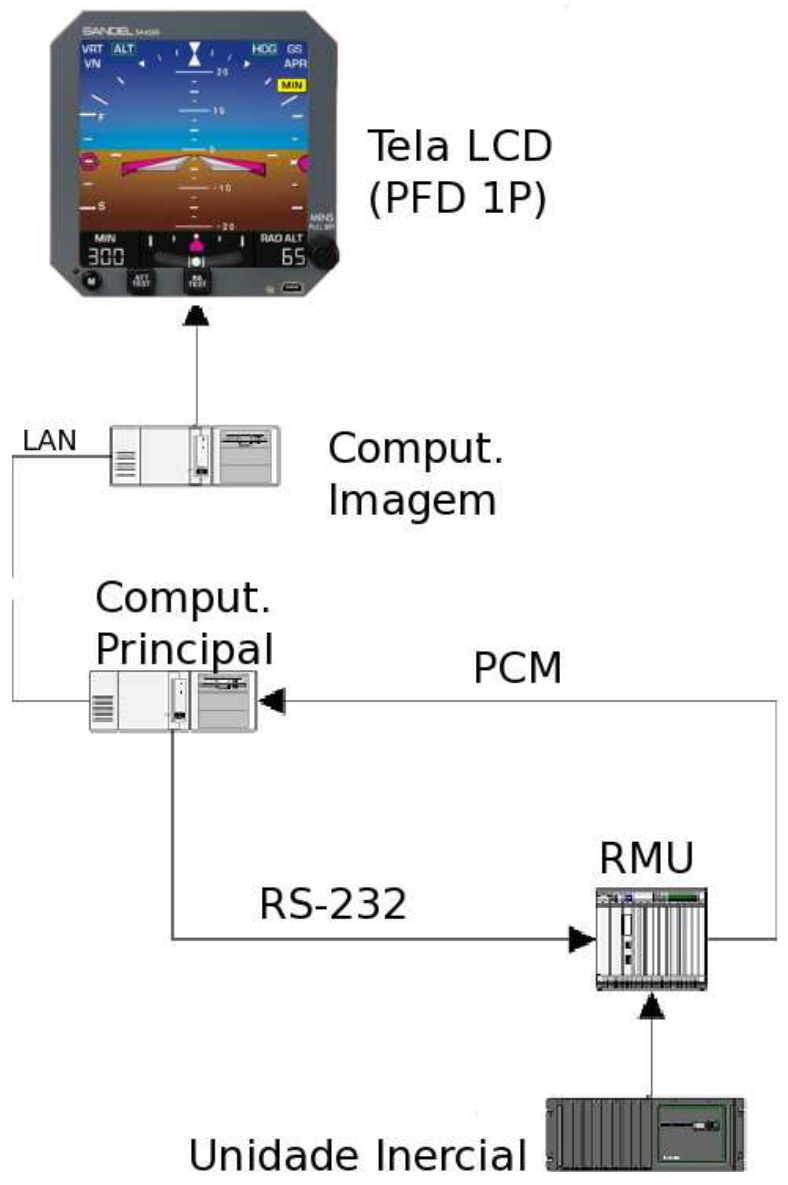

Figura 3.8: Arquitetura Sistema Syntask da EMBRAER - a unidade inercial fornece informações de atitude, que são recebidas pela RMU. Os dados são enviados ao computador principal por sinal PCM (pulse code modulated). Este insere os dados da tarefa sintética no sinal e remete o conjunto completo para o computador de imagem. As imagens são geradas e mostradas ao piloto via tela LCD (liquid crystal display) do lado esquerdo (1P) na posição principal - PFD (primary function display).

As funções dos componentes listados naquela figura são definidas na tabela 3.2. Um ponto muito importante para este tipo de ensaio é manter o menor atraso possível, haja vista a sensibilidade dos resultados com relação a este parâmetro. O sistema utilizado neste trabalho tem as características de atraso máximo especificado em 140ms, e os detalhes podem ser verificados na figura 3.9.

Este atraso introduzido pelo sistema é conservativo, uma vez que qualquer atraso 
Tabela 3.2: Função dos Componentes do Sistema Syntask

\begin{tabular}{|c|l|}
\hline Componente & Função \\
\hline IRU & Sistema inercial para medir atitudes \\
RMU & Sistema de aquisição de dados \\
Main computer & Computador onde é gerada a tarefa sintética (target attitudes) \\
Syntask computer & Computador onde é gerada a imagem para o piloto \\
\hline
\end{tabular}

Diagrama de Tempo do Sistema Syntask

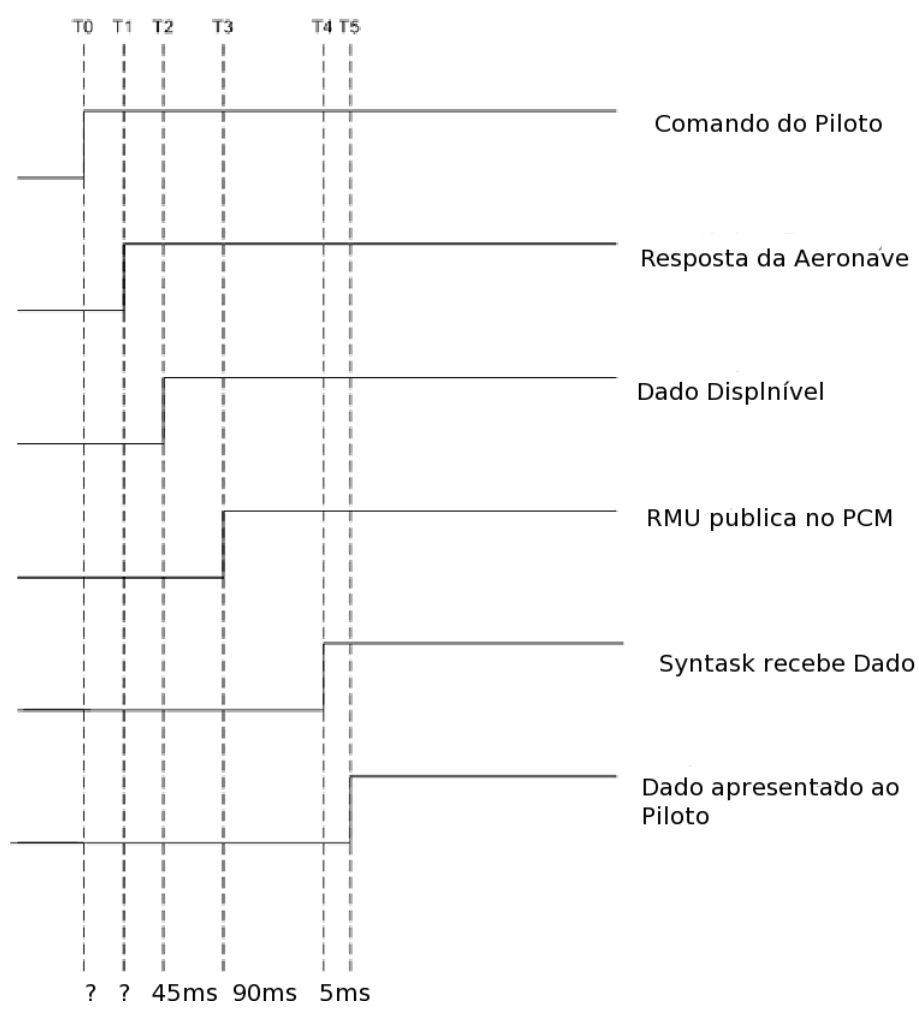

Figura 3.9: Atrasos do Sistema Syntask

adicional nesses experimentos leva a uma maior susceptibilidade a PIO. Decorrente da preocupação de não introduzir um novo fator no experimento, especialmente no tocante ao processamento de informações pelo piloto, foi utilizado o formato-padrão para vôos por instrumento como interface homem-máquina, conhecido como diretor de vôo $V$-Bar. Trata-se de um pictóreo básico e padronizado na indústria aeronáutica, com que um piloto habilitado para o tipo necessariamente está familiarizado. Portanto, considerouse que o tempo de processamento da informação pelo piloto é igual ao tempo gasto no processamento natural de informações de vôo em operação comercial. O formato deste pictóreo pode ser visto na figura 3.10 . 


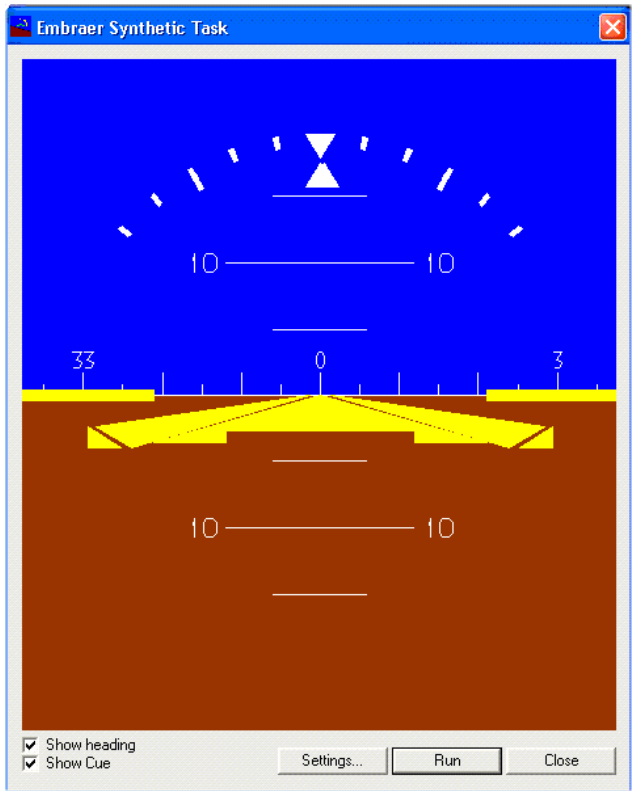

Figura 3.10: Pictóreo Utilizado como Interface Homem-Máquina - Diretor de Vôo no padrão V-Bar

Fonte: Arquivo Ensaio em Vôo - EMBRAER

Uma outra preocupação existente no projeto do dispositivo foi tentar dar ao piloto a melhor condição para que houvesse precisão na pilotagem. Dessa maneira, foi escolhida uma tela grande para a fácil leitura e para que a resolução, principalmente em rolamento, fosse ampliada. $\mathrm{O}$ arranjo físico na cabine de pilotagem pode ser visto na figura 3.11. 


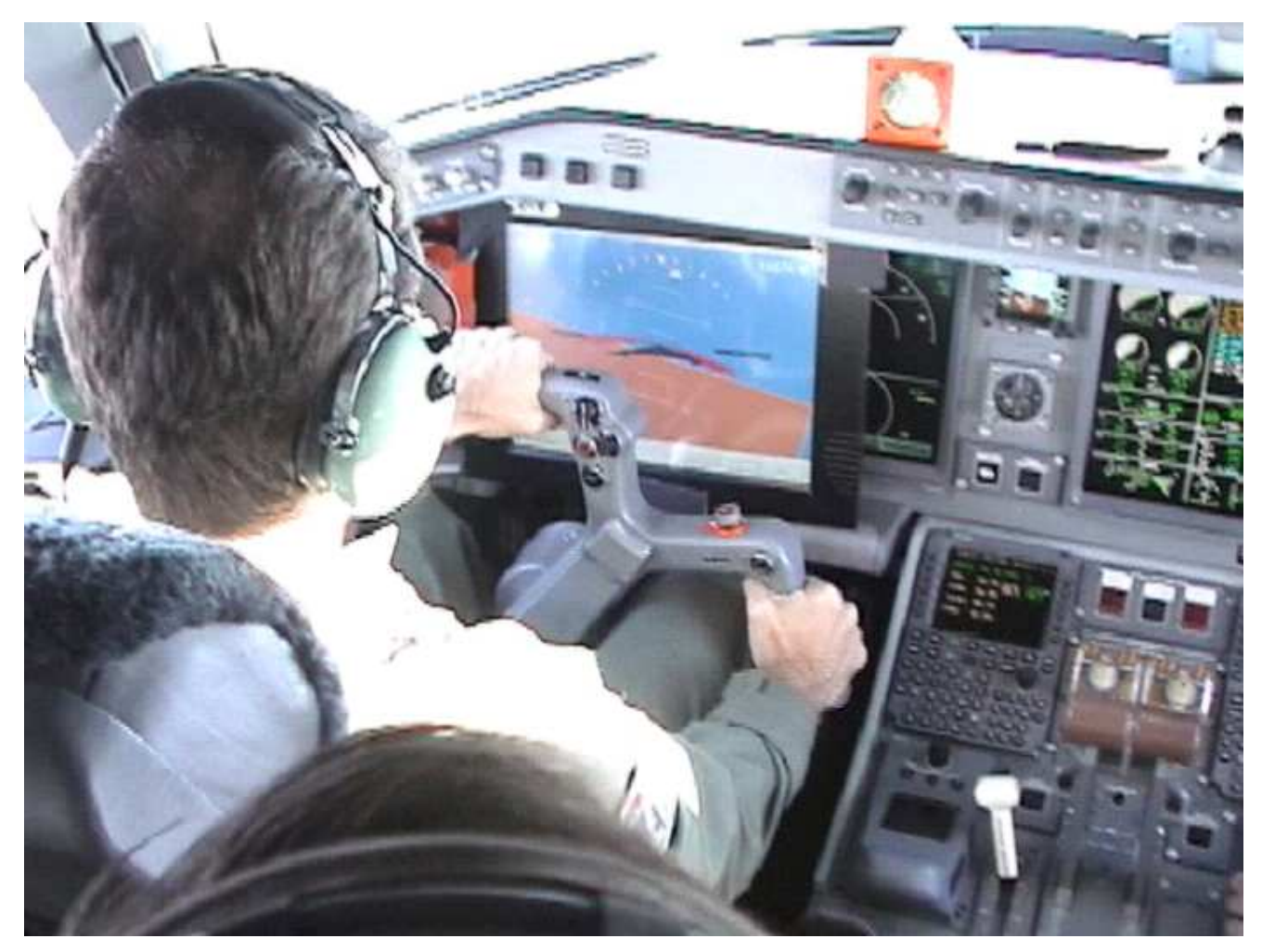

Figura 3.11: Arranjo Físico do Display no Cockpit

Fonte: Arquivo Ensaio em Vôo - EMBRAER 


\title{
3.4.3 Definição das Tarefas
}

A definição das tarefas sintéticas (a seqüência de comandos no tempo que será enviada para o piloto seguir) é bastante polêmica (VAN DEN BERG et al., 2007). De um lado, é necessário que elas tenham um conteúdo em freqüências que seja representativo de PIOs. Por outro, não podem ser desconexas com o tipo de aeronave em questão, contendo manobras que sejam agressivas em demasia ou que ultrapassem os limites do envelope operacional.

As tarefas desenvolvidas para serem utilizadas neste trabalho são resultado de vários ensaios em simulador e em vôo realizadas pela EMBRAER, e foram julgadas representativas de uma aproximação CAT II por instrumentos com bastante turbulência, conforme descrito em (CELERE, 2002). Em adição, o conteúdo em freqüência foi ajustado de maneira a contemplar a faixa de interesse. Um exemplo de tarefa utilizada e de seu conteúdo em freqüência pode ser visto nas figuras 3.12 e 3.13; as outras tarefas têm formas parecidas e serão apresentadas na seção de resultados. A quantidade e a duração dos patamares de atitude constante também foi dimensionado. O critério neste caso foi dar condições para o piloto verificar as duas etapas de uma tarefa:

\author{
- Aquisição (Gross Acquisiton) \\ - Manutenção (Fine Tracking)
}




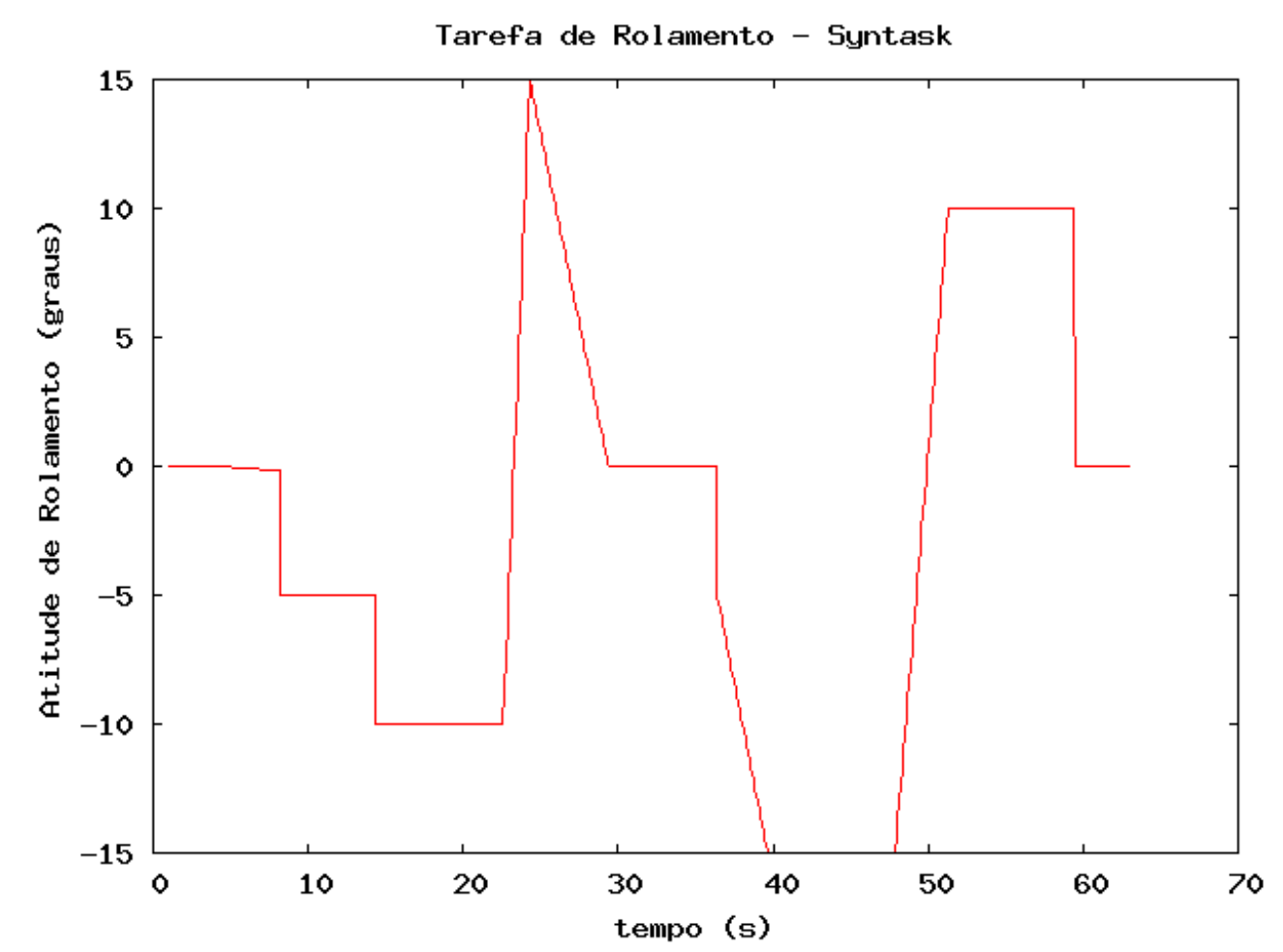

Figura 3.12: Tarefa de Rolamento

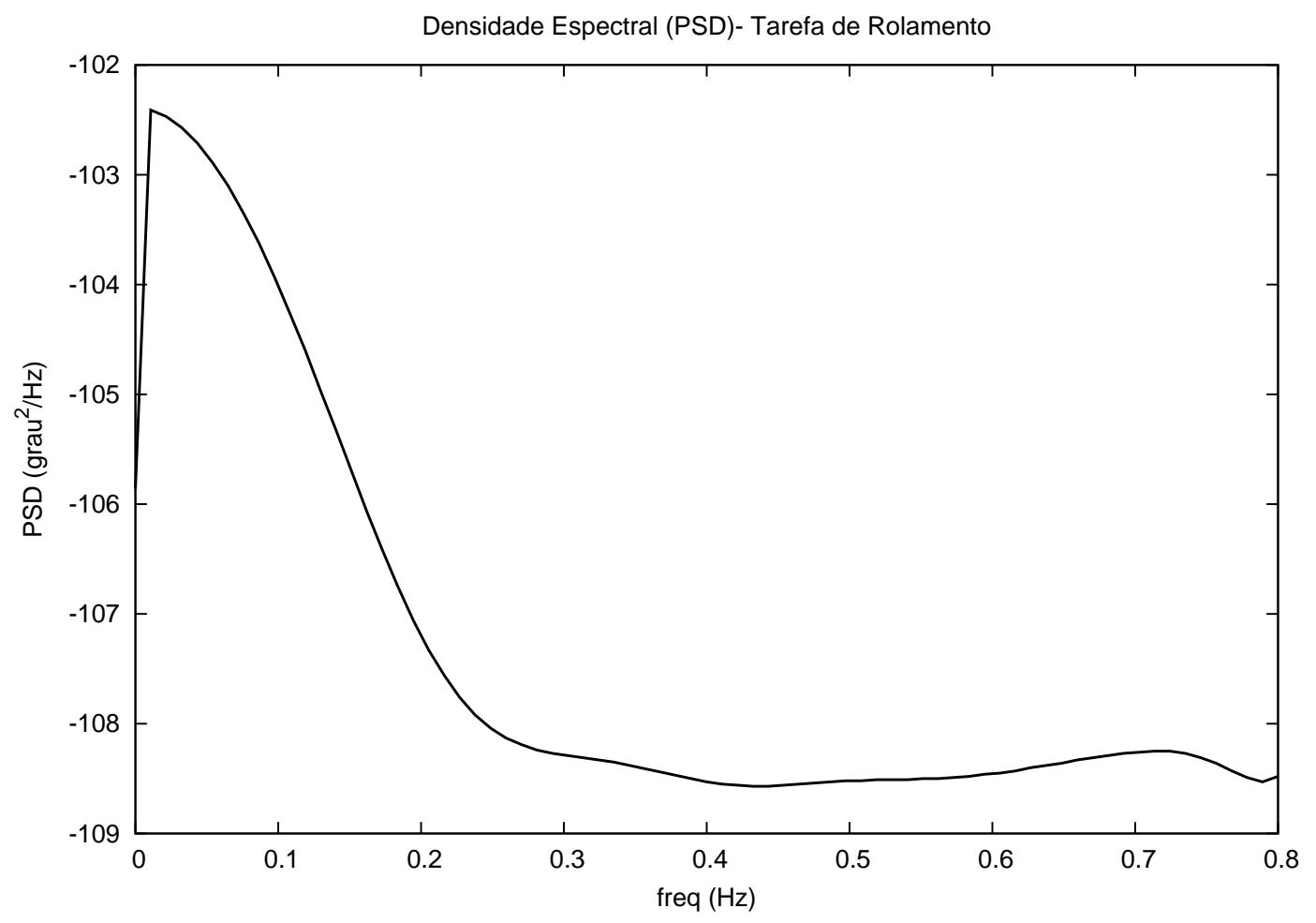

Figura 3.13: Densidade Espectral de Potência da Tarefa de Rolamento 
Um outro aspecto importante na definição das tarefas é a capacidade de aprendizado do ser humano. Por mais aleatória que pareça uma tarefa sintética apresentada ao piloto pelo diretor de vôo, foi verificado que há uma retenção e, conseqüentemente, uma mudança no modo de executar a manobra, passando a ser pré-cognitiva e modificando os resultados (MCRUER, 1995). Para tentar minimizar esse efeito, as tarefas envolvidas nos ensaios desta tese foram multiplicadas por meio de inversão e/ou espelhamento. A técnica é simples e não altera o conteúdo em freqüência. Na inversão, a tarefa é apresentada de trás para a frente e, no espelhamento, a atitude é multiplicada por (-1). Os efeitos podem também ser combinados, e um exemplo pode ser visto na figura 3.14.

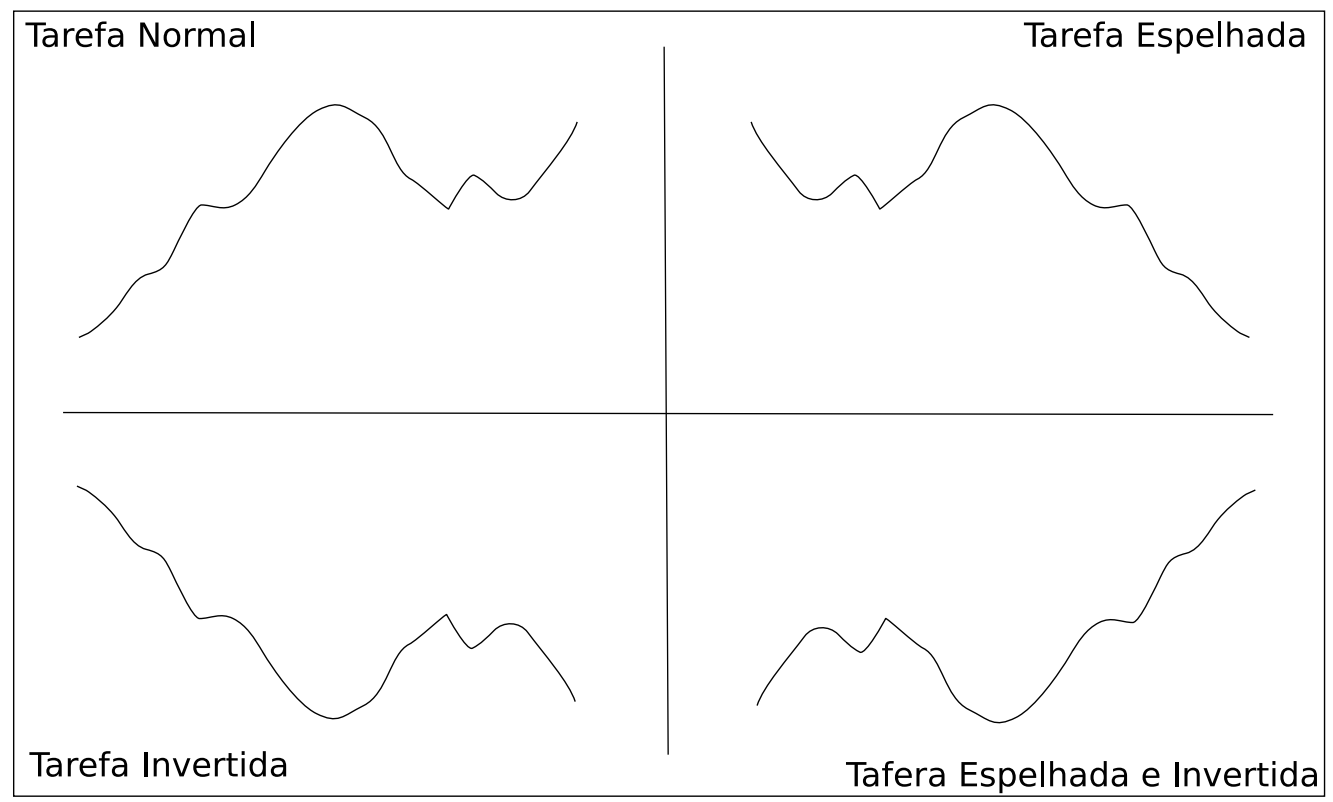

Figura 3.14: Inversão e Espelhamento das Tarefas

Por último, há de se considerar a saturação dos canais de arfagem e rolamento quando se desenham as tarefas. Há uma tendência natural de se priorizar o canal de arfagem na pilotagem humana, em detrimento das correções do canal de rolamento (CLIFF, 1972). Esse argumento é utilizado em favor da separação dos canais, ao efetuar tarefas que excitam apenas arfagem e outras apenas para rolamento. As tarefas com excitação em ambos canais são utilizadas apenas para verificar acoplamento entre arfagem e rolamento, e as avaliações com maior ganho são realizadas com os canais em separado. 
A execução do ensaio requer uma preparação especial da aeronave, com a instalação de todo o aparato, da instrumentação, que exige amostragem alta para minimizar o atraso dos sinais e da tripulação, que pressupõe treinamento e um alto grau de abstração, principalmente do piloto. É necessário que, durante o ensaio, o piloto utilize alto ganho (conforme descrito na seção 3.3). Além disso, é necessário que ele se abstraia e consiga perceber suas ações para poder traçar um paralelo a atuação de um piloto com experiência mediana exposto à uma situação parecida com a do ensaio. Ele deve perceber se está empregando qualquer tipo de compensação na execução da tarefa, anotando mentalmente seus movimentos e o modo com que está operando. Exemplos de compensação verificados em vôos são:

- Pilotar com malha aberta, amortecendo oscilações;

- Pilotar com comportamento pré-cognitivo, antecipando-se à tarefa;

- Pilotar com baixo ganho, principalmente por já antecipar a resposta da aeronave.

Conforme colocado na seção 3.3, o objetivo deste trabalho é propor um método para garantir, principalmente, o último item: que os ensaios foram executados com ganho adequado.

\subsection{Escala PIOR}

Qualquer ensaio de PIO envolve a avaliação subjetiva do piloto executante. Ele é o controlador que está fechando a malha e que tem todos os elementos para perceber e medir a influência do comportamento (e das qualidades de vôo) da aeronave em seu desejo de modificar a trajetória.

De maneira geral, as avaliações de qualidade de vôo sofrem de um problema de padronização das opiniões subjetivas advindas de vários pilotos diferentes. Muitas vezes, sobre um mesmo ensaio em uma mesma aeronave.

Várias tentativas de padronizar uma saída para essas impressões subjetivas foram testadas, e uma das mais bem sucedidas é a escala de Cooper-Harper (COOPER; HARPER, 1969). Para a utilização dessa classificação, inicialmente é definida uma tarefa na qual se tenham resultados desejáveis e aceitáveis bem definidos. Um exemplo de tal 
tarefa seria a execução de um pouso com desvio lateral, conforme mostra a figura 3.7 já apresentada. Notar que há duas áreas hachuradas definidas na figura. Uma maior, com 3000 pés de comprimento e 60 pés de largura, que é a zona considerada aceitável para o pouso. Uma segunda, menor e contida dentro da maior, de 1000 pés de comprimento e 20 pés de largura, dentro da qual um pouso é definido como desejável.

Uma vez bem definidos os parâmetros da tarefa, então torna-se possível aplicar a escala de Cooper-Harper. Seus valores encontram-se na figura 3.15, extraída da própria referência. A escala em seu formato e linguagem originais pode ser encontrada no anexo F. 


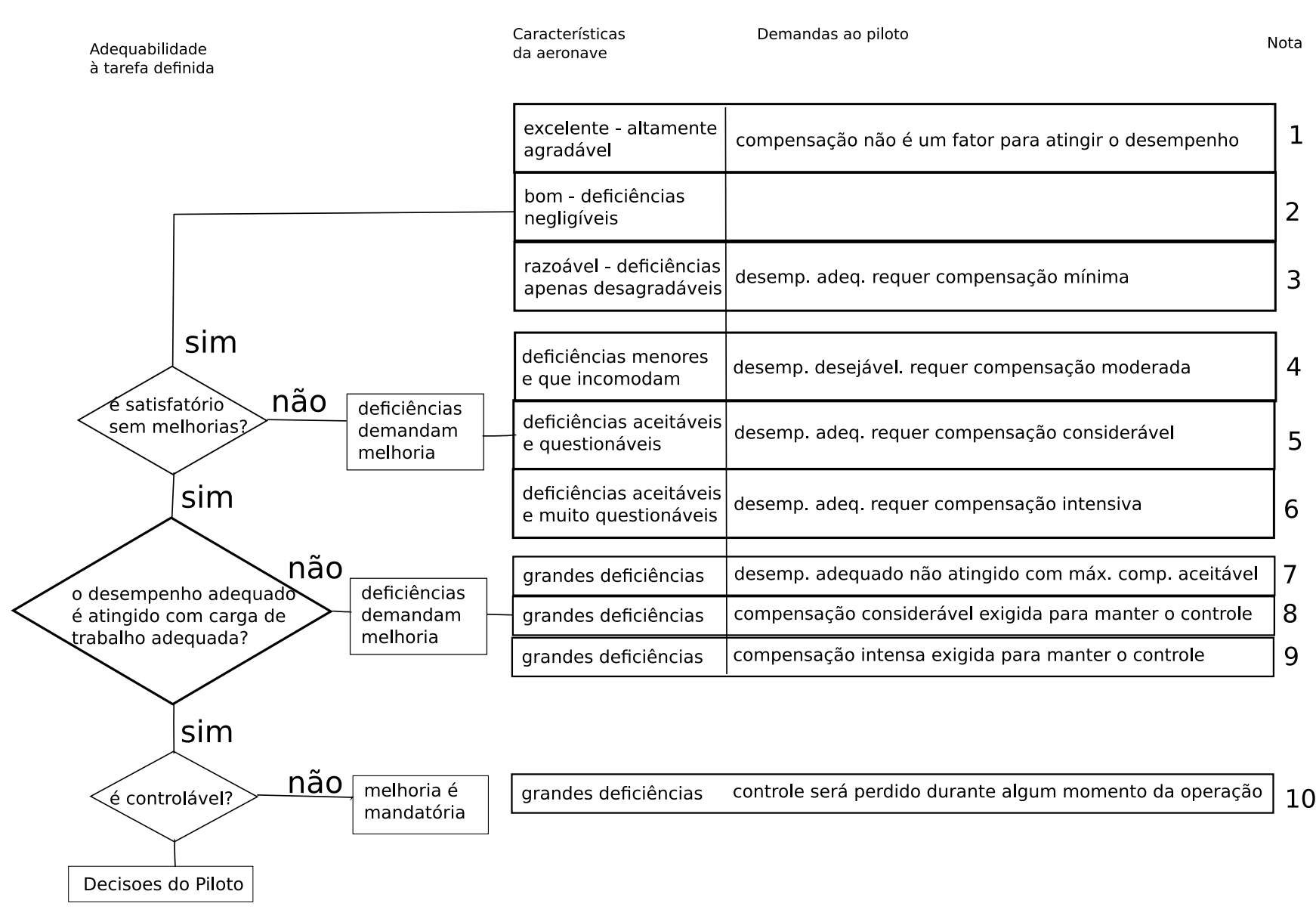

Fonte: (COOPER; HARPER, 1969) - tradução do autor. 
Historicamente, essa escala foi a primeira a ser utilizada com freqüência nos ensaios de qualidades de vôo e, naturalmente, foi a primeira tentativa para os ensaios de PIO. Porém, por ser genérica, os resultados nos ensaios específicos de verificação de PIO não foram bons, gerando dúvidas e não conseguindo padronizar a linguagem utilizada pela larga gama de pilotos.

A escala Cooper-Harper serviu de base para uma outra, desenvolvida para os testes de aceitação do F-4H (Phantom II). A idéia principal da escala é focar a atenção do piloto (após a execução do ensaio) nos movimentos da aeronave e, assim, atribuir uma graduação numérica. O foco é diferente daquele privilegiado pela escala Cooper-Harper, em que o piloto deve prestar atenção naquilo que ele mesmo está fazendo. A escala de PIO (ou PIOR) pode se vista na figura 3.16 traduzida para Português. Ela é a escala utilizada neste trabalho para as avaliações de PIO realizadas. A escala em seu formato e linguagem originais pode ser encontrada no anexo F. 


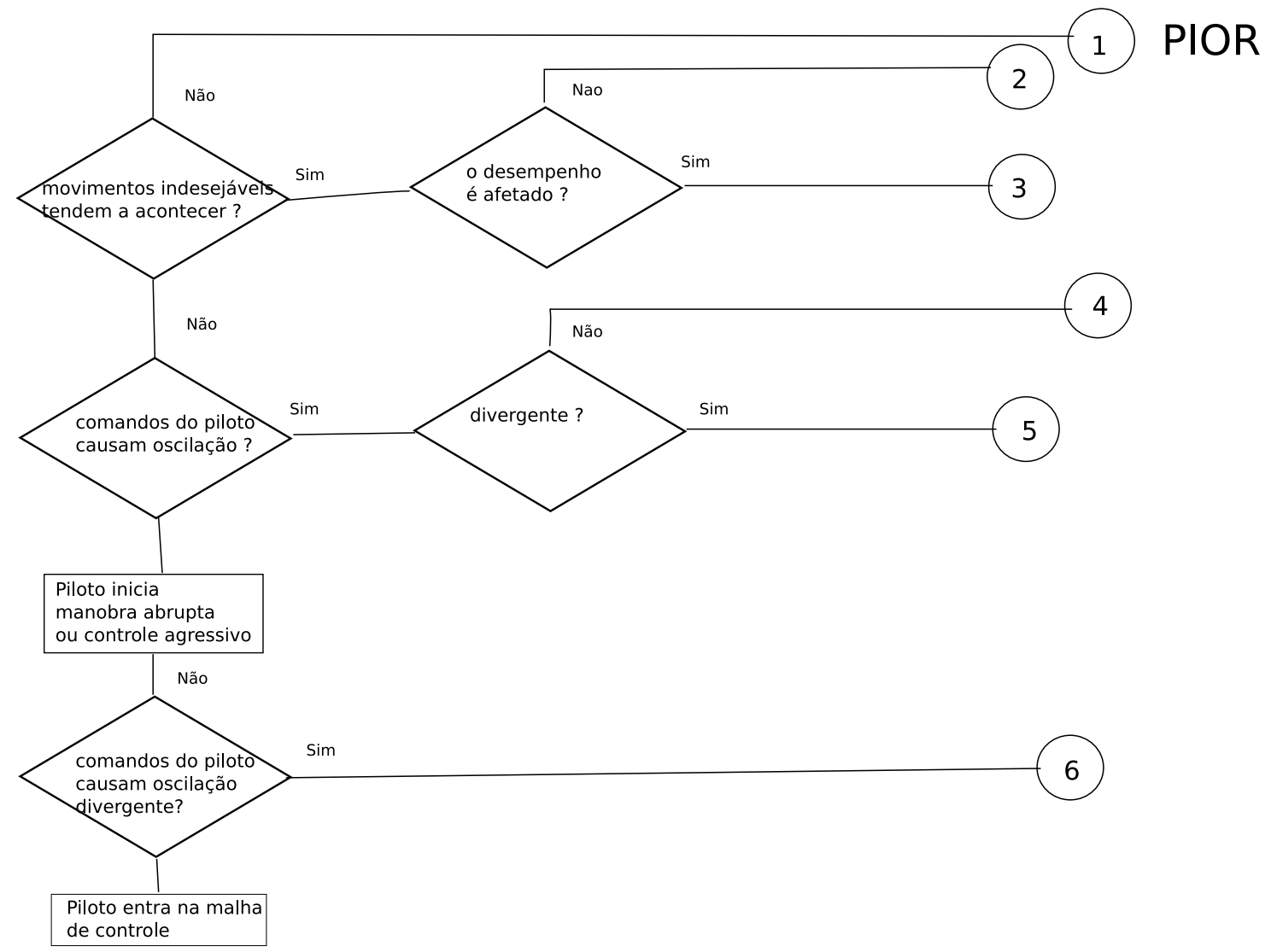

Figura 3.16: Escala de PIO

Fonte: (US NAVY, 2007) - tradução do autor. 



\section{Capítulo 4}

\section{Modelagem Analítica}

\subsection{O Modelo de Piloto Humano}

Neste capítulo, será feita uma revisão dos dois principais modelos de piloto propostos na literatura. A pesquisa na área é ampla e iniciou-se durante a Segunda Guerra Mundial, com a introdução de canhões e torretas acionadas eletricamente. Essas armas eram operadas remotamente e desvendaram os desafios de atuadores com atraso e com limitação de velocidade (ou rate limit). As pesquisas avançaram lentamente até a década de 60, quando novamente houve grande afluxo de esforço, alimentado pela corrida espacial e pela guerra fria. Outros modelos serão apenas citados. McRuer possui uma das melhores definições da utilidade de modelos do piloto humano (MCRUER; JEX, 1967):

[...] o objetivo dos modelos é resumir dados comportamentais, para melhorar a base de racionalização e entendimento de ações de controle de pilotos, e, entender essas ações com a dinâmica do veículo na formação de predições ou em modelos de engenharia de controle que satisfaçam essas necessidades. São, na melhor da hipóteses, representações do comportamento do piloto ao invés de analogias mecânicas da estrutura fisiológica do piloto [...] o piloto humano é um controlador que aprende, multimodal e adaptativo capaz de exibir uma variedade enorme de comportamentos, que incluem:

1. organização do sistema; 
2. mecanização do feedback: seleção e uso de movimentos particulares do veículo (de todos aqueles possíveis de serem sentidos) que melhor servem como feedback (ou retroalimentação) para as necessidades de guiagem e controle;

3. detecção de coerência.

Com o avanço das pesquisas, várias teorias foram desenvolvidas, porém há consenso de que um modelo único e universal para o piloto não é algo viável:

Uma coisa é determinar o que o piloto fez em cada um dos exemplos de PIO, e uma outra bem diferente é desenvolver um modelo teórico do piloto capaz de predizer o seu comportamento antes de observar o evento. As não linearidades e irregularidades fazem o sucesso ser extremamente improvável [...] (GIBSON, 1995).

Colocadas essas restrições, é possível afirmar que os modelos propostos na literatura têm geralmente uma aplicação específica e não genérica. A busca por um modelo que pudesse atender à necessidade colocada pela tese descrita na seção 3.3 percorreu basicamente duas categorias distintas:

\section{Modelos Funcionais}

São modelos pensados para capturar funcionalmente o piloto humano. Tentam mimetizar as saídas por meio de funções de transferência que não necessitam ter correlação. São mais simples e largamente utilizados em simulações, justamente pela facilidade de implementação e pelos bons resultados apresentados. Porém, geralmente, são ajustados para uma situação específica, sendo necessários novos ajustes (tunning) para cada nova condição.

\section{Modelos Estruturais}

São modelos que tentam desvendar a estrutura de processamento de sinais interna à pessoa humana. São, geralmente, modelos mais complexos e elaborados, e as malhas de controle geralmente possuem correlação física com a estrutura de uma pessoa (visão, tato, etc.). São menos utilizados que os modelos funcionais.

A seguir, os principais modelos pesquisados: 


\subsubsection{Modelo Crossover}

O modelo Crossover (MCRUER; GRAHAM, 1964), de longe, é o mais consagrado nas pesquisas e usos da literatura ocidental e demonstra simplicidade e boa correlação para situações em que a dinâmica da planta é razoavelmente constante. McRuer e Jex (1967) trazem uma ótima revisão do modelo que é bastante citada pelas referências posteriores (é considerada um pilar do conhecimento)(MCRUER; JEX, 1967). McRuer pesquisou detalhadamente esse modelo por mais de 10 anos, publicando vários estudos posteriores a 1964 e culminando com a publicação de um tratado sobre o assunto (MCRUER; KRENDEL, 1974), que contém uma análise bastante completa da teoria. Esta referência, por se aprofundar, por aumentar a abrangência e por trazer explanações de clareza ímpar, é o trabalho mais citado no assunto de modelos de piloto humano.

O principal conceito do modelo crossover estabelece que o piloto humano adapta a sua função de transferência de acordo com a dinâmica da planta, de tal forma que mantém constante a freqüência de crossover. A formulação advém de verificação experimental, em que foram testadas plantas com diferentes dinâmicas e, por meio da resposta em freqüência, inferiu-se o modelo do piloto que se adequava à saída. A questão da nãolinearidade foi tratada de maneira simples: historicamente, verifica-se que os sistemas não-lineares podem razoavelmente ser aproximados por sistemas quase-lineares equivalentes (HODGKINSON, 2005). Esses sistemas consistem em uma parte linear chamada de função descritiva, ou describing function e em um resto, ou remnant, que é interpretado como se fosse um ruído colorido injetado no sistema, porém refere-se a distúrbios no controle inseridos involuntariamente pelo controlador humano.

A tabela 4.1 resume as principais plantas verificadas e os modelos inferidos para o piloto. Os modelos matemáticos para o piloto humano decorrentes de cada planta ensaiada resultaram em algo surpreendente. Foi verificado que a resposta total do sistema (planta + piloto) apresentava características que não variavam muito, resultando na teoria segundo a qual o piloto alterava a estratégia de controle de acordo com a dinâmica da planta, de maneira a gerar uma função de transferência conforme a equação 4.1 .

$$
Y_{p}(j \omega) Y_{c}(j \omega) \doteq \frac{\omega_{c} e^{-j \omega \tau_{e}}}{j \omega}
$$

Sendo: $Y_{p}$ a função de transferência aproximada do piloto; $Y_{c}$ a função de transferência 
Tabela 4.1: Modelo Crossover - Principais dinâmicas Testadas.

\begin{tabular}{|l|l|l|l|}
\hline $\begin{array}{l}\text { Dinâmica da } \\
\text { Planta }\left(Y_{c}\right)\end{array}$ & $\begin{array}{l}\text { Função de } \\
\text { Transferência } \\
\text { Aproximada do } \\
\text { Piloto }\left(Y_{p}\right)\end{array}$ & $\begin{array}{l}\text { Forma Combi- } \\
\text { nada }\left(Y_{p} Y_{c}\right)\end{array}$ & Atraso Efetivo $\left(\tau_{e}\right)$ (sec.) \\
\hline$K_{c}$ & $\frac{K_{p} e^{-\tau_{1} s}}{s}$ & $\frac{\omega_{c} e^{-\tau_{e} s}}{s}$ & NA \\
\hline$\frac{K_{c}}{s}$ & $K_{p} e^{-\tau_{2} s}$ & $\frac{\omega_{c} e^{-\tau_{e} s}}{s}$ & 0.14 \\
\hline$\frac{K_{c}}{s(s+\alpha)}$ & $K_{p}(s+\alpha) e^{-\tau_{3} s}$ & $\frac{\omega_{c} e^{-\tau_{e} s}}{s}$ & 0.16 \\
\hline$\frac{K_{c}}{s^{2}}$ & $K_{p} s e^{-\tau_{3} s}$ & $\frac{\omega_{c} e^{-\tau_{e} s}}{s}$ & 0.43 \\
\hline$\frac{K_{c}}{(s-\lambda)}$ & $K_{p} e^{-\tau_{2} s}$ & $\frac{\omega_{c} e^{-\tau_{e} s}}{(s-\lambda)}$ & 0.07 \\
\hline$\frac{K_{c}}{(s+\alpha)(s-\lambda)}$ & $K_{p}(s+\alpha) e^{-\tau_{4} s}$ & $\frac{\omega_{c} e^{-\tau_{e} s}}{(s-\lambda)}$ & 0.20 \\
\hline
\end{tabular}

Fonte: (MCRUER; KRENDEL, 1974)

da planta ou controlled element; $\omega_{c}$ a freqüência de crossover e $\tau_{e}$ o atraso total do sistema piloto+planta. O nome Crossover Model advém do fato de o sistema combinado piloto + planta possuir uma freqüência máxima definida onde a margem de ganho cruza zero db. Notar que essa freqüência não é o cruzamento em margem de fase igual a zero. Esta é a chamada freqüência de crossover, conforme pode ser observado na figura 4.1. Um outro conceito apresentado por este modelo é uma classificação "quase-linear", advinda do fato de a função de transferência estar sob a forma linear, com a parte nãolinear da resposta sendo introduzida na forma de um sinal auxiliar chamado remnant. Esta simplificação possibilitou uma formulação mais simples e também a aplicação de toda a teoria clássica de análise de sistemas lineares. O formato do sistema fica, então, conforme a figura 4.2 . 


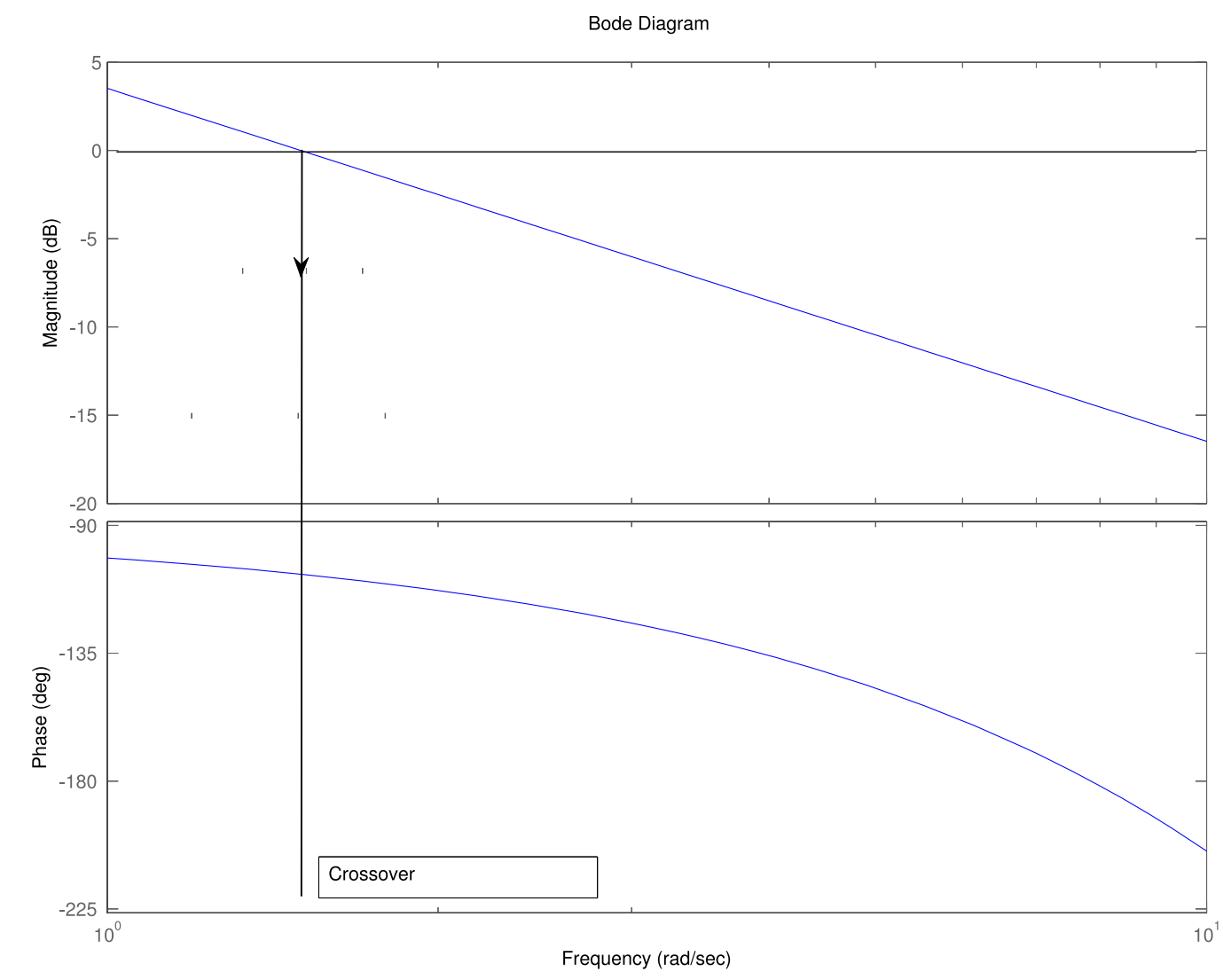

Figura 4.1: Gráfico de Bode para o sistema $\frac{\omega_{c} e^{-\tau s}}{s}$

Gráfico de Bode para a função de transferência combinada piloto-planta resultado do modelo crossover

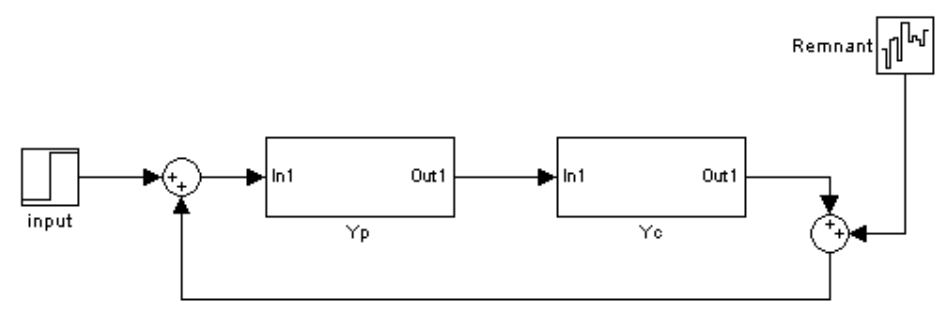

Figura 4.2: Sistema Piloto-Planta Quase-Linear

Sistema completo piloto-quase-linear + planta com parte não linear concentrada na componente remnant 


\subsubsection{O Modelo Estrutural}

No final dos anos 70, foi introduzido o primeiro modelo (HESS, 1978) de uma série que culminou com o modelo estrutural de Hess (HESS, 1980). Mais tarde, esse modelo foi revisto e ampliado (HESS, 1989, 1997), porém sem alteração de conceitos. Apesar da revisão de 1997*, será analisado e utilizado o modelo mais simples proposto em 1980. Esse modelo nasceu da observação de que os modelos de piloto postulados até então estavam balizados ou pela teoria clássica de controle, resultando em servomodelos ou pela teoria de controle moderno, resultando em modelos de controle ótimo. Hess afirma que:

apesar de ambas abordagens terem bastante sucesso, nenhuma conseguia descrever a estrutura interna, que contribui sobremaneira para as características dinâmicas do piloto humano.

A partir de então, foi postulado o Modelo Estrutural, que:

provê uma representação mais realista da estrutura de processamento de sinais interna do piloto humano.

Mais importante ainda, e objeto principal desta tese, é a habilidade do modelo proposto em capturar as adaptações feitas pelo piloto humano às diferentes dinâmicas dos veículos e, assim, identificar modus operandi diferentes para as diversas situações a que o conjunto piloto+planta (ou piloto+veículo) estarão expostos.

Foram realizados vários estudos de aplicação deste modelo para modelagem de PIO (HESS; SUNYOTO, 1985; HESS; STOUT, 1997; VAN DER VORST, 2001). Em geral, os resultados obtidos foram razoáveis, sendo que os modelos foram capazes de capturar a dinâmica do piloto. Como característica principal, o modelo possui duas malhas de controle internas: uma relativa ao sistema nervoso central e outra relativa ao sistema neuromuscular. Essas duas malhas de controle explicitam e tentam modelar a natureza adaptativa dos pilotos humanos de maneira sistemática. Assim, a adaptação à planta

*Não há mudança fundamental na revisão de 1997, tratando-se apenas de uma evolução para tratar do senso primário para mudança de estratégia de controle. O modelo de 1980 propõe que a informação visual é que comandada a alteração da estratégia de controle da malha de erro para a malha de derivada do erro. Já o modelo revisado em 1997 propõe que a informação proprioceptiva seja a responsável por essa mudança de estratégia. 
postulada por McRuer em seu modelo crossover, apresentado no item 4.1.1, ficaria explícita e poderia ser estudada. A parametrização estaria completa e as malhas internas de realimentação sofreriam apenas pequenos ajustes dependendo de cada condição de aplicação do modelo. No entanto, essencialmente, o poder adaptativo do piloto humano estaria capturado na diagramação do modelo matemático.

O diagrama de blocos pode ser visto na figura 4.3, já com os grandes núcleos delimitados por cores. As malhas apresentam as seguintes funções:

- modelar a realimentação de força utilizada pelo sistema neuromuscular, proveniente dos sistemas musculares do braço e antebraço - sentidos proprioceptivos $\left(Y_{f}\right)$

- montar uma representação interna do sistema de controle manual que é utilizado pelo piloto $\left(Y_{m}\right)$.

O modelo foi idealizado para sistemas Single Input, Single Output (ou SISO), e as análises considerarão o canal de rolamento de uma aeronave. O piloto é considerado em uma tarefa em que tenta controlar ativamente o canal de rolamento por meio de entradas visuais e saídas por meio do sistema de controle manual da aeronave. 


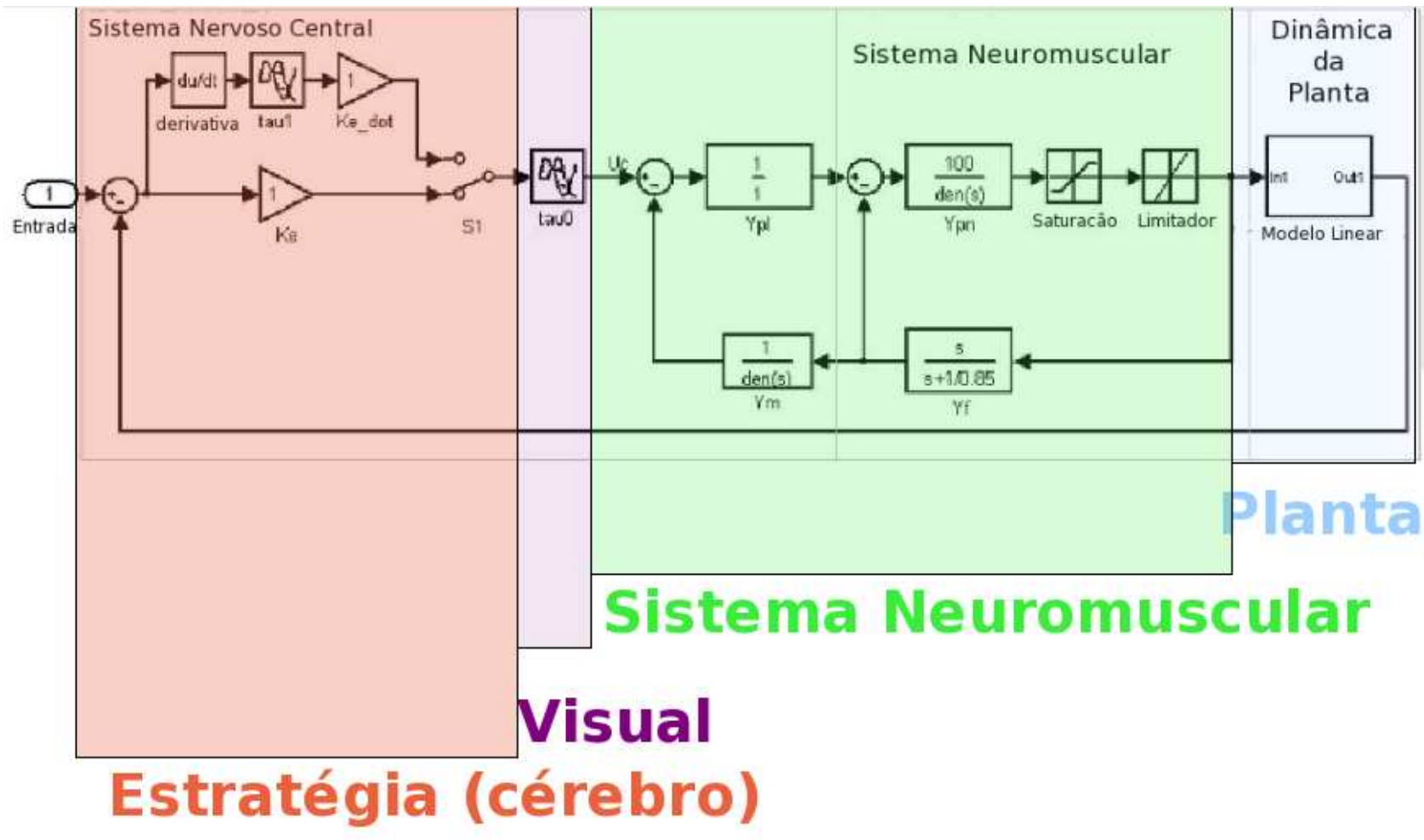

Figura 4.3: Desmembramento do Modelo Estrutural

Para facilitar a compreensão, o modelo pode ser desmembrado conforme ilustrado. A dinâmica da planta é modelada no último bloco à direita (em azul): O sistema neuromuscular vem ao lado, contendo a parte proprioceptiva (em verde); O sistema visual é modelado como um atraso (em roxo) e para manter coerência com a publicação original de Hess, permaneceu após a chave S1 e não logo na entrada. Essa alteração não influencia o resultado; A estratégia selecionada pelo cérebro (inconscientemente) está na entrada, à esquerda (em vermelho) 
O sinal de erro (atitude de rolamento atual menos a atitude desejada) é percebido pelo sistema de visão humana por meio de uma tela (display) com dinâmica $Y_{d e}$. Essa dinâmica já contém todos os atrasos de processamento do display, mas não inclui o atraso entre a informação ser apresentada na tela e o cérebro humano compreendê-la. Já no sistema nervoso central, o sinal segue dois caminhos: no primeiro é multiplicado por um ganho simples $\left(K_{e}\right)$ e forma a malha de controle de erro; no segundo, o sistema nervoso central aplica uma operação de derivação com atraso $\tau_{1} \mathrm{e}$, em seguida, é multiplicado por um ganho $K_{\dot{e}}$ simples para formar a malha de controle por derivada do erro (error rate).

Além dessas duas malhas de controle, há uma chave $\mathbf{S 1}$ colocada na entrada da malha do sistema nervoso central, que é responsável por alterar a estratégia de controle adotada pelo piloto. Esta característica é um dos pilares centrais desta tese: o modelo postula que o piloto humano, na essência, fecha a malha em erro e na derivada do erro da grandeza que é controlada. Porém, não simultaneamente. A estratégia de controle é alterada durante a execução de uma manobra, de maneira que o piloto muda o controle para adaptar-se à tarefa. Assim, a chave S1 no diagrama, alterna entre as malhas com uma probabilidade de estar em uma ou outra posição. O modelo ainda postula que quanto maior a probabilidade da chave S1 estar fechando a malha na derivada do erro, maior será o ganho empregado pelo piloto e portanto mais próximo de um PIO. É importante notar que o valor não é absoluto: a situação de PIO não ocorre somente com essa prioridade igual a 1. O valor varia com a dinâmica da planta e para dinâmicas do tipo $\frac{K}{s}$, rolamento em aeronaves de transporte, essa probabilidade gira em torno de $5 \%$.

Em seguida, há um atraso $\left(\tau_{0}\right)$ para modelar a latência no processamento de sinais pelo sistema nervoso central (visual, táctil e auditivo). Este atraso é aplicado a ambas malhas. O sinal resultante entra, então, nas malhas de controle posteriores que consiste em 4 elementos:

- $Y_{p l}=1.0-$ Lógica pulsativa do sistema nervoso central, teorizada de maneira análoga aos controladores bang-bang (HESS, 1979). A implementação nesta tese está conforme descrito em Hess, (1980);

- $Y_{m}=\frac{k_{2}}{\left(\frac{s+1}{T_{2}}\right)^{k-1}}-$ É uma representação interna do sistema de controle manual 
(manipulator);

。 $Y_{p n}=\frac{\omega_{n}^{2}}{s^{2}+2 \zeta_{n} \omega_{n} s+\omega_{n}^{2}}-$ Forma em malha aberta da dinâmica neuromuscular;

- $Y_{f}=\frac{k_{1} s}{\frac{s+1}{T_{1}}}-$ washout do sistema neuromuscular, devido à ligação alfa-gama dos músculos e tendões da mão.

Os valores numéricos para esses parâmetros utilizados na implementação do modelo são os mesmos publicados em sua forma original (HESS, 1980) e estão na tabela 4.2. Os únicos valores a serem ajustados de acordo com a estabilidade da malha são os ganhos $K_{e}$ e $K_{e \_} d o t$.

Tabela 4.2: Modelo Estrutural de Hess - Principais Parâmetros.

\begin{tabular}{|c|c|c|c|c|c|c|c|c|c|c|}
\hline Dinâmica da Planta $\left(Y_{c}\right)$ & $\mathrm{k}$ & $K_{e}$ & $K_{\dot{e}}$ & $K_{2}$ & $T_{1}$ & $K_{1}$ & $\tau_{0}$ & $\tau_{1}$ & $\zeta_{n}$ & $\omega_{n}$ \\
\hline rolamento: $\frac{K}{s}$ & 3 & 2 & 2 & 1 & 0.85 & 1 & 0.14 & 0.2 & 0.707 & 10 \\
\hline
\end{tabular}

Fonte: (HESS, 1980)

O modelo ainda prevê a inserção de um sinal com características de ruído colorido para contabilizar os efeitos não-lineares observados em experimentos. Esse sinal é chamado de remnant. Para os dados desta tese, o ruído foi naturalmente introduzido nos dados obtidos em vôos (apresentados no capítulo 7). As simulações matemáticas não contemplam a injeção de ruído em suas corridas, por isso, a entrada do ruído não é apresentada na figura 4.3 .

\subsubsection{Análise e Escolha do Modelo}

A busca por modelos que pudessem apresentar condições de explicitar o modo de controle empregado pelo piloto incluiu alguns outros modelos, porém nenhum deles tinha a capacidade de prever mudanças de estratégia empregada pelo piloto como o modelo estrutural. É possível que um modelo que não prevê essa mudança de estratégia (por exemplo, crossover em certa frequência) seja capaz de determinar uma pilotagem com alto ganho, porém o método mais evidente é através de um modelo que aponte essa característica explicitamente, daí a escolha do modelo estrutural. A avaliação de outros modelos fica como sugestão de continuidade do trabalho. O modelo escolhido para o método proposto nesta tese foi o postulado por Hess, 1980, uma vez que as características daquele modelo tornam viáveis a detecção de uma mudança na estratégia empregada 
pelo piloto por meio da alteração da malha de controle de erro para a derivada do erro. A idéia geral por trás do método proposto é: se for possivel descobrir em qual modo o piloto está operando, então talvez seja possível validar a utilização de ganho adequado na execução do ensaio. Uma estratégia similar está sendo estudada pela Universidade de Nova Iorque (ZAYCHIK; CARDULLO, 2007; ZAYCHIK; CARDULLO; GEORGE, 2006).

\subsection{Modelo da Planta}

\subsubsection{Interlúdio}

O raciocínio lógico para montar um método de verificação do ganho empregado pelo piloto durante a execução de um ensaio para a verificação de PIO que utiliza tarefas sintéticas (tese) seguiu a seqüência:

1. Inicia-se por identificar o modelo da planta sendo ensaiada, por meio de manobras em malha aberta;

2. Com a planta, identifica-se os parâmetros essenciais da modelagem do piloto, por meio de tarefas que possam evidenciar a estratégia de controle em caso de baixo ganho;

3. Prossegue-se para a realização da tarefa sintética;

4. Analisa-se a tarefa realizada, observando-se a semelhança do traço com as duas estratégias de controle possíveis e determinando-se uma medida para o ganho empregado durante a execução da tarefa.

Para a parte experimental deste trabalho, foi escolhido o eixo lateral de uma aeronave de transporte FAR 25.

\subsubsection{Modelo Laterodirecional}

O modelo clássico para uma aeronave parte das equações de inércia para movimentos Newtonianos, com 6 graus de liberdade (movimento nos 3 eixos e rotações nos 3 
eixos). O modelo completo pode ser desacoplado, permitindo que se separe os eixos laterodirecionais do eixo longitudinal. A derivação completa deste modelo laterodirecional desacoplado pode ser verificada no anexo E.

Seria ideal que a planta fosse perfeitamente modelada para cada condição de ensaio, eliminando-se a sua influência no modelo total (planta+piloto). Obviamente, isto é inviável na prática. Para que a influência do modelo da planta fosse a menor possível, originalmente optou-se por uma modelagem completa, não-linear, dos modos laterodirecionais. A idéia inicial era fazer a identificação de parâmetros clássica, para cada uma das derivadas de estabilidade ${ }^{\dagger}$ do modelo apresentado no anexo E e previa a utilização de um software dedicado, específico da EMBRAER para a identificação de parâmetros (software SYSID) daquele modelo para cada condição de vôo, porém a sua utilização se demonstrou inviável por limitações na documentação do modelo interno utilizado por aquele software, resultando em parâmetros identificados que não condiziam com a realidade. Estratégia análoga a essa já é utilizada pela NASA na identificação de parâmetros de diversas aeronaves (MORELLI; WARD, 2007). Os resultados obtidos não puderam ser correlacionados com os dados de ensaio e, em face desse problema, não foi possível desenvolver tal técnica, e passou-se a utilizar uma identificação black-box, que usa internamente um modelo no formato de espaço de estados, e está disponível como pacote no Matlab, conforme descrito na seção 4.2.3. A utilização de redes neurais seria também uma opção bastante razoável, porém a pronta disponibilidade das ferramentas para identificação do modelo de espaço de estados foi decisiva na escolha deste tipo de modelo. A utilização do SYSID para a identificação fica como sugestão para a continuidade deste trabalho. Essa solução mostrou-se aceitável, com resultados que não introduziram erros de modelagem. No entanto, a identificação clássica de parâmetros permite que sejam feitos estudos paramétricos de variação das derivadas de estabilidade. Um desenvolvimento futuro poderá evoluir para o uso de ferramenta com essa capacidade de capturar o modelo da planta, conforme um equacionamento explícito (modelo do anexo E).

\footnotetext{
${ }^{\dagger}$ são provenientes da modelagem matemática de uma aeronave como um corpo movendo-se no espaço, com 6 graus de liberdade. As derivadas de estabilidade relacionam as influências de forças, momentos e velocidades com as reações apresentadas pela aeronave. Por exemplo, $N_{\beta}$ relaciona a força lateral $(N)$ com o angulo de derrapagem $(\beta)$
} 


\subsubsection{Identificação de Parâmetros da Planta}

\subsubsection{Descrição do Modelo}

O modelo utilizado para a identificação da planta foi do tipo caixa preta com equacionamento em espaço de estados - (black box - state-space model). O problema que está sendo modelado é mostrado na figura 4.4, conforme descrito no manual da ferramenta matemática que faz parte do software comercial Matlab (system identification toolbox) - (LJUNG, 2006).

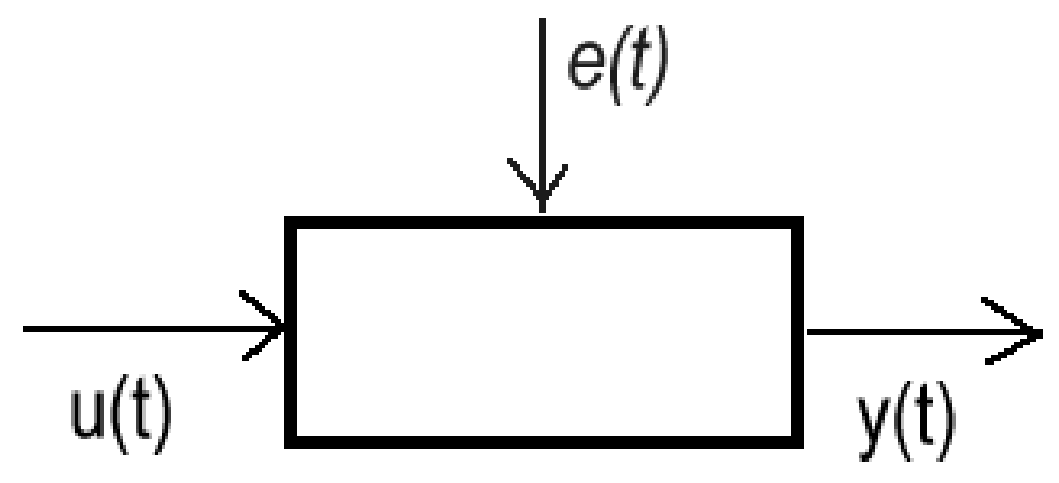

Figura 4.4: Sistema Espaço de Estados que está sendo Identificado

$u(t)$ é o sinal de entrada com dados amostrados nos tempos $t=1,2, \ldots, N$;

$y(t)$ é o sinal de saída amostrado nos mesmos tempos $t=1,2, \ldots, N$;

O equacionamento em espaço de estados assume uma relação linear entre entrada e saída, conforme a equação 4.2

$$
y(t)=G(q) u(t)+v(t)
$$

sendo

$$
G(q) u(t)=\sum_{k=1}^{\infty} g(k) u(t-k)
$$

e

$$
\begin{gathered}
G(q)=\sum_{k=1}^{\infty} g(k) q^{-k} \\
q^{-1} u(t)=u(t-1)
\end{gathered}
$$


e por último, $v(t)$ é um ruído.

As equações arranjadas no formato de espaço de estados resultam em 4.4

$$
\begin{array}{r}
x(t+1)=A x(t)+B u(t) \\
y(t)=C x(t)+D u(t)+v(t)
\end{array}
$$

Se $G(q)=C\left(q I_{n x}-A\right)^{-1} B+D$, e se $v(t)=H(q) e(t)$ for definido como um ruído filtrado, então a equação 4.2 pode ser escrita ainda no formato da equação 4.5.

$$
\begin{array}{r}
x(t+1)=A x(t)+B u(t)+K e(t) \\
y(t)=C x(t)+D u(t)+e(t)
\end{array}
$$

Este é o formato utilizado para a identificação dos parâmetros, e o número de estados internos do sistema (ordem do vetor x) é chamado de ordem do sistema. Notar que não há relação entre a ordem dos vetores u e y com a ordem do vetor x.

\subsubsection{Método de Identificação do Modelo}

O método utilizado pelo Matlab para a identificação das matrizes A, B, C, D e K na equação 4.5 é chamado de subespaços e é identificado dentro do programa como "método N4SID". Não é o foco deste trabalho detalhar a identificação de parâmetros da planta, sendo esta técnica utilizada apenas como ferramenta para a defesa da tese. Maiores detalhes estão nos manuais dos programas (HIERNAUX; JEREZ; CASALS, 2005; LJUNG, 1999, 2006; MATHWORKS, 2009)

A seguir, apenas o conceito geral do método será apresentado.

Por meio dos dados de saída, é encontrada uma base neste subespaço que forma os preditores do vetor de estado $x(t)$. Os estados são, então, utilizados conjuntamente com as entradas $(u(t))$ e saídas $(y(t))$ para resolver o sistema linear da equação $y(t)=$ $C x(t)+D u(t)+e(t)$ e encontrar estimativas de $C$ e $D$ via método de mínimos quadrados. O termo $e(t)$ é encontrado no resíduo do sistema linear e tratado como uma variável conhecida na equação $x(t+1)=A x(t)+B u(t)+K e(t)$. Com esta equação, novamente por meio de mínimos quadrados, encontra-se uma estimativa para $A$ e $B$, sendo $K$ calculado pela solução da equação de Ricatti (LJUNG, 1999). Trata-se de um método 
bastante robusto numericamente. Foi utilizada a implementação do toolbox System Identification do Matlab versão 7.

\subsubsection{Identificação do Modelo}

O procedimento utilizado para a identificação do modelo foi simples. Inicialmente, foi escolhida uma amostragem de $20 \mathrm{~Hz}$ como padrão para os dados. Esse valor é, pelo menos, duas vezes maior que a freqüência de crossover $(1-8 \mathrm{rad} / \mathrm{s}=0.16 \mathrm{a} 1.2 \mathrm{~Hz})$.

Os parâmetros escolhidos encontram-se na tabela 4.3, e uma descrição detalhada de cada parâmetro encontra-se no apêndice D.

Tabela 4.3: Lista de Parâmetros Medidos durante os Ensaios

\begin{tabular}{|l|l|}
\hline \#FTIL* & Descrição \\
A1 & PCM Time \\
A280 & Beta Vane Angle \\
A297 & Aileron LH Position \\
A1094 & IRU 1 Pitch Angle \\
A1095 & IRU 1 Pitch Rate \\
A1096 & IRU 1 Roll Angle \\
A1097 & IRU 1 Roll Rate \\
A1105 & IRU 1 Y Body Acceleration \\
A1106 & IRU 1 Yaw Rate \\
A1204 & Airspeed 1 \\
A1207 & Baro Altitude 1 \\
A2733 & Engine LH Ch A N1_AC \\
A3271 & Engine RH Ch A N1_AC \\
A6279 & Rudder Upper SURFACE LVDT PoSITION can 4 - 1 \\
A10116 & AOA body filtered 1A \\
A12306 & Synthetic Task Target Pitch \\
A12307 & Synthetic Task Target Roll \\
A12308 & Synthetic Task Event Command \\
A20676 & Aileron LH LVDT Va \\
A20677 & Aileron LH LVDT Vb \\
A20678 & Aileron RH LVDT Va \\
A20679 & Aileron RH LVDT Vb \\
*número de referência do parâmetro-Flight Test Instrumentation List \\
\hline
\end{tabular}

Uma vez gerado o arquivo texto contendo esses parâmetros, eles foram carregados para variáveis na memória do ambiente Matlab. Foram criadas duas variáveis auxiliares, contendo os valores de posição de leme e posição de aileron (posição do aileron esquerdo menos o direito). Essas variáveis formam a matriz $u(t)$ de entrada no sistema modelado por meio de espaço de estados, conforme a seção 4.2.3.1. Como saídas (matriz $y(t)$ ), foram utilizados os parâmetros de razão de rolamento (roll rate), razão de guinada (yaw 
rate) e rolamento roll angle).

Em seguida, foi criado um objeto que contém esses dados, para que o pacote de identificação fosse utilizado. Já dentro do pacote (comando ident), várias ordens do sistema foram testadas, de maneira a identificar a menor ordem que resultasse em boa correlação entre os dados de entrada e saída e os dados de saída já simulados. Um exemplo em que, para um mesmo conjunto de dados foram testadas 3 ordens diferentes, pode ser visto na figura 4.5 .

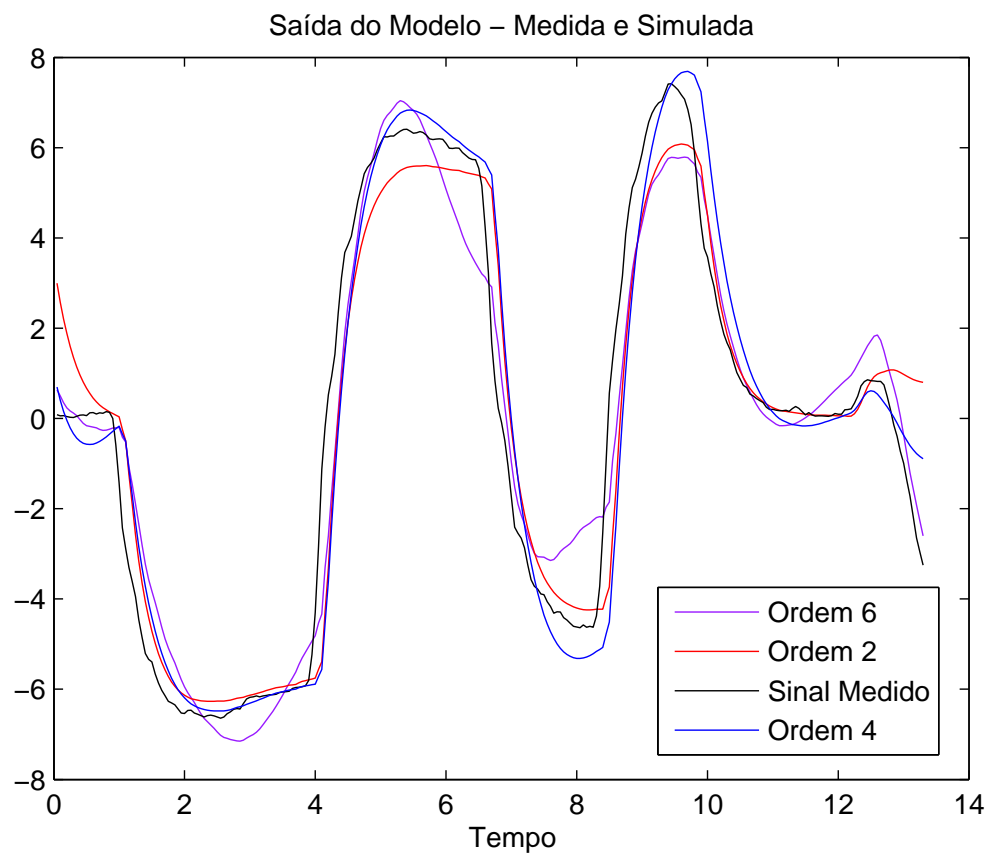

Figura 4.5: Rolamento - Medido e Simulado

O critério para a escolha da ordem seguiu o roteiro:

1. início e fim da manobra sem apresentação de divergências - principalmente de derivada do sinal

2. dados simulados que não apresentem oscilações

3. overshoots e undershoots controlados

4. menor erro quadrático

5. menor ordem possível 
Com a melhor ordem do modelo estabelecida, via de regra foi tentado um refinamento na identificação por meio da rotina PSS da própria ferramenta de identificação do Matlab (sysid toolbox). Em alguns casos esse refinamento resultou em uma identificação com mais precisão (diminuição do erro), porém em outros casos, os resultados apresentaram divergência. Com os parâmetros identificados, o próximo passo era executar a simulação com o modelo do piloto operando em malha fechada, ou piloto no loop, a ser descrita no capítulo 5.

Os modelos identificados para cada configuração estão listados no capítulo 7.1.2. 



\section{Capítulo 5}

\section{Simulações em Malha Fechada - Teoria}

Neste capítulo, serão descritas as simulações executadas com os dados provenientes de ensaios em vôo, utilizando-se o modelo do piloto descrito no capítulo 4.1 e da planta identificada conforme descrito no capítulo 4.2.3. Será focada a teoria, e os resultados serão apresentados no capítulo 7. O objetivo das simulações realizadas é determinar como seria a pilotagem humana no caso de sua malha de controle interna estar operando para zerar o erro da atitude e, num segundo caso, operando para zerar a derivada do erro. O modelo completo (piloto+planta) foi construído em Matlab/Simulink por meio da união de ambos modelos e do fechamento da malha pela realimentação da atitude de rolamento. Uma figura deste modelo pode ser vista na 5.1. 


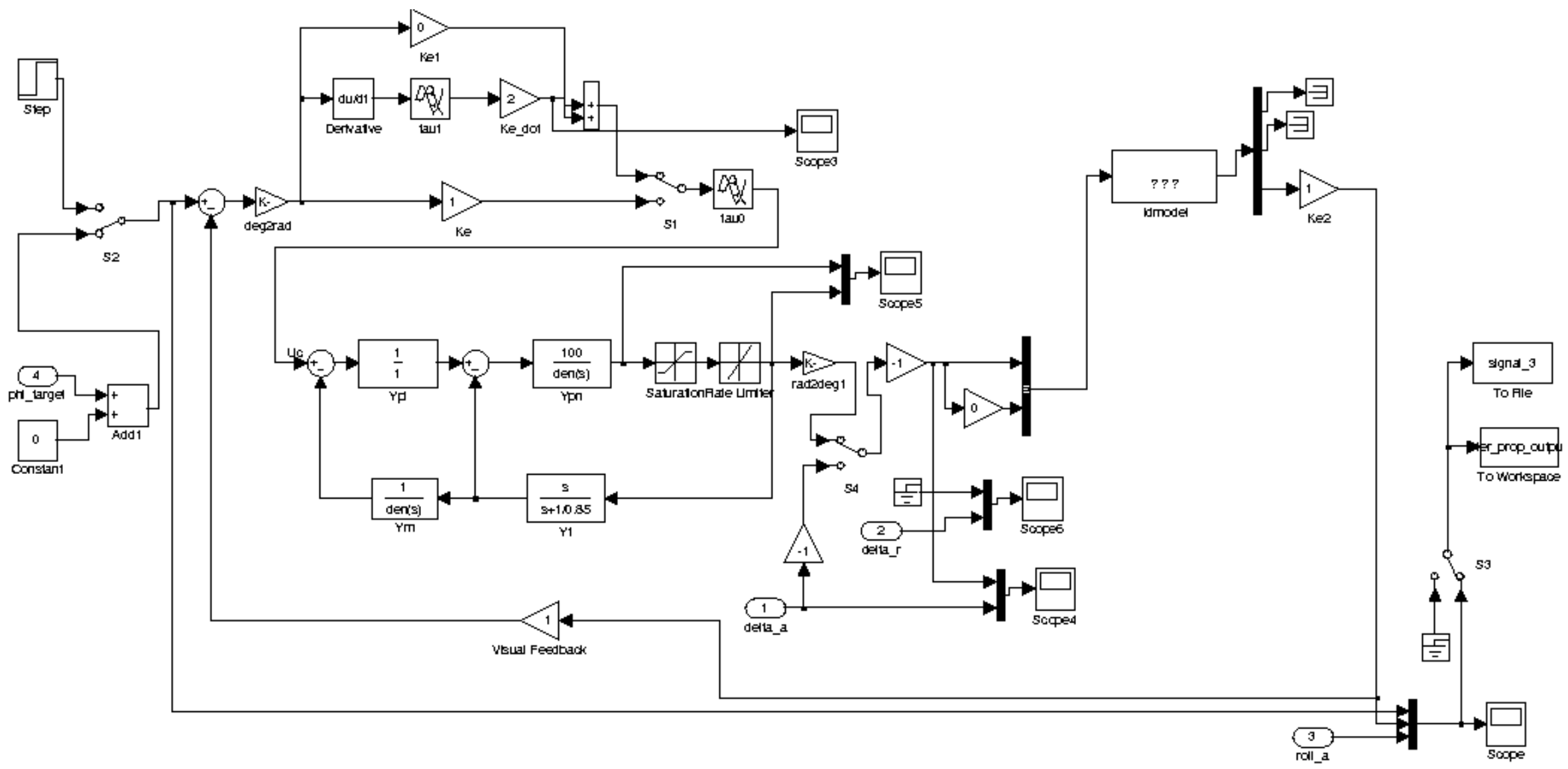

Figura 5.1: Modelo de Simulação Completo - (piloto + planta) 
Para cada manobra de ensaio realizada na aeronave, os dados de excitação (inputs) e os resultados (outputs) foram gravados na mesma base de tempo, garantindo sincronia. Os dados do sinal da tarefa sintética (phi_target) são provenientes destas gravações e garantem que os dados simulados estão sendo comparados com dados de ensaio provenientes da mesma função forçante apresentada ao piloto. Para fazer a simulação completa (modelo completo), foi necessário fazer pequenas adaptações aos modelos puros do piloto e da planta apresentados nas seções 4.1 e 4.2.3. Essas modificações foram introduzidas para facilitar a utilização do modelo completo e não apresentam qualquer prejuízo ou desvio dos modelos individuais já apresentados. Seguindo o fluxo dos sinais (vide figura 5.1), tem-se:

1. O sinal de phi_target pode ser acrescido de um bias (constant1), caso a aeronave não esteja compensada e apresente tendência a rolamento. Normalmente, esse valor é zero;

2. O valor da atitude atual da aeronave é subtraído da atitude target para formar o valor do erro;

3. O valor é transformado em radianos (deg2rad) e segue, pelo caminho inferior, através de um ganho simples $\left(K_{e}\right)$;

4. No caminho superior, o sinal é derivado, passa por um atraso $\left(\tau_{1}\right)$ e por um ganho $\left(K_{\dot{e}}\right)$. O ganho $K_{e 1}$ tem valor zero e não influencia na malha de controle. Este ganho foi introduzido apenas para testes;

5. O sinal entra, então, na malha neuromuscular, já discutida na seção 4.1;

6. A transformação de radianos em graus (rad2deg) é executada para o sinal de comando de aileron entrar no modelo da planta, que usou o sinal em graus para a identificação dos parâmetros;

7. A chave $\mathrm{S} 4$ foi utilizada apenas para verificar o modelo identificado por meio da aplicação direta dos comandos provenientes do ensaio com o piloto humano no loop. Para as simulações, essa chave é mantida na posição conforme mostrado na figura 5.1.

8. É necessário inverter o sinal de saída do modelo do piloto para compatibilidade com o modelo da planta, o que é feito através do ganho -1 colocado no modelo; 
9. É feita uma derivação do sinal de comando do aileron para servir de sinal de leme, porém, neste caso, o ganho é mantido em zero e o sinal de leme é ignorado, assim como ocorreu na identificação de parâmetros, que não levou em consideração os inputs do leme.

10. O sinal de comando do aileron entra no bloco que contém o modelo da planta (idmodel), o qual fornece, na saída, o sinal de atitude de rolamento resultante (em graus);

11. Este sinal é realimentado na entrada do modelo, terminando o ciclo;

12. A parte à direita do modelo (chave S3) refere-se apenas à gravação dos resultados em disco.

Os resultados da simulação foram ajustados para rodar em $20 \mathrm{~Hz}$, com passo fixo (fixedstep), e foi escolhido o integrador com o método de Euler (MATLAB ODE1) pois trata-se de um modelo simples. Como as simulações são curtas (pequeno intervalo de tempo), a adoção de integradores mais elaborados não apresenta vantagens numéricas. A rapidez na simulação foi o fator de decisão. As seqüências de simulação foram sempre iniciadas com tempo zero e terminadas com um segundo a mais do que os dados disponíveis. Para cada conjunto de dados (para cada ponto de ensaio disponível), foram feitas duas rodadas. Uma com a chave $\mathbf{S 1}$ na posição inferior (malha de controle que utiliza erro), e outra, na posição superior (malha da derivada do erro). Cada resultado foi gravado em arquivo independente, contendo a atitude de rolamento simulada, a atitude de rolamento observada em vôo com o piloto humano no loop e a função forçante (tarefa sintética).

As tarefas foram divididas em dois tipos:

- Alto Ganho: tarefas com conteúdo em freqüência considerado elevado, chegando a $2 \mathrm{rad} / \mathrm{s}$ com potência razoável;

- Baixo Ganho: conceito oposto, conteúdo em freqüência considerado baixo e portanto de fácil execução. Serve de base para uma pilotagem conhecidamente com ganho baixo.

Os ganhos $K_{e}$ e $K_{e}$ dot foram ajustados segundo (HESS, 1980), onde ambos devem "ser o maior possível, mantendo a estabilidade da malha". Eles foram ajustados através 
da observação de estabilidade do modelo em malha fechada, executando a simulação, e são os maiores ganhos que ainda assim mantiveram o sistema estável.

A tabela 5.1 contém um resumo das seqüências e dos ganhos utilizados, lembrando que os resultados das seqüências estão listados e analisados no capítulo 7.

Tabela 5.1: Listagem das Seqüências de Simulação

\begin{tabular}{|c|c|c|c|c|c|c|}
\hline Vôo & Seqüência & Ponto de Ensaio & Tarefa & Tempo de Sim. & $K_{e}$ & $K_{e} \quad d o t$ \\
\hline \multirow[t]{13}{*}{1} & 14 & 28.1 & $B G$ & 42.7 & 2 & 2 \\
\hline & 15 & 29.1 & $\mathrm{AG}$ & 89.2 & 2 & 2 \\
\hline & 16 & 32.2 & $\mathrm{AG}$ & 65.6 & 2 & 2 \\
\hline & 17 & 33.1 & $\mathrm{AG}$ & 73.4 & 2 & 2 \\
\hline & 18 & 7.1 & $B G$ & 61.0 & 2 & 1 \\
\hline & 19 & 8.1 & $B G$ & 82.0 & 2 & 1 \\
\hline & 20 & 12.1 & $\mathrm{AG}$ & 82.0 & 2 & 1 \\
\hline & 22 & 14.1 & $B G$ & 90.0 & 2 & 2 \\
\hline & 23 & 17.1 & $\mathrm{AG}$ & 65.0 & 2 & 2 \\
\hline & 24 & 18.1 & $\mathrm{AG}$ & 52.0 & 2 & 1 \\
\hline & 26 & 22.1 & $\mathrm{AG}$ & 74.0 & 2 & 2 \\
\hline & 27 & 23.1 & $\mathrm{AG}$ & 58.0 & 2 & 2 \\
\hline & 28 & 24.1 & $\mathrm{AG}$ & 28.0 & 2 & 2 \\
\hline \multirow[t]{6}{*}{2} & 1 & 29.1 & $\mathrm{AG}$ & 91.0 & 2 & 2 \\
\hline & 2 & 26.1 & $\mathrm{AG}$ & 95.0 & 2 & 2 \\
\hline & 3 & 9.1 & $\mathrm{AG}$ & 103.0 & 2 & 2 \\
\hline & 4 & 14.1 & $\mathrm{AG}$ & 96.0 & 2 & 2 \\
\hline & 5 & 15.1 & AG & 95.0 & 2 & 2 \\
\hline & & & $\begin{array}{l}\mathrm{AG}=\text { Alto Ganho } \\
B G=\text { Baixo Ganho }\end{array}$ & & & \\
\hline \multicolumn{6}{|c|}{ ganho proporcional da malha de controle de erro $=K_{e}$} & \\
\hline
\end{tabular}





\section{Capítulo 6}

\section{Comparação de Sinais -}

\section{Introduzindo o Conceito de Entropia Estatística}

Neste capítulo, será descrita a teoria utilizada na análise dos dados obtidos nas simulações. A idéia principal contida na tese descrita na seção 3.3 é a determinação do modo de pilotagem empregado pelo piloto durante a execução do ensaio de tarefa sintética, verificando-se se o ganho empregado foi adequado. Conforme visto na seção 5 , os dados obtidos nos ensaios e simulações foram:

- Atitude Controlada por Humano - referenciada como sinal 1 - é o valor da atitude de rolamento da aeronave, conforme uma tarefa sintética é executada num ensaio em vôo.

- Atitude Simulada na malha de Erro - referenciada como sinal 2 - atitude de rolamento obtida pela simulação com o piloto operando exclusivamente na malha de controle por erro;

- Atitude Simulada na malha de Derivada do Erro - referenciada como sinal 3 - atitude de rolamento obtida pela simulação com o piloto operando exclusivamente na malha de controle por razão do erro (ou roll rate). 


\subsection{Análise de Sinais}

O desafio de analisar os sinais obtidos durante os ensaios realizados e as simulações com o modelo do piloto na malha foi complexo. Sempre com o objetivo de determinar quão próximo de uma pilotagem de alto ganho estava o piloto. Foram analisadas várias soluções possíveis a priori:

- Cálculo da correlação, quantificando a relação entre os sinais;

- Cálculo da transformada wavelet para identificar a variação em cada instante;

- Cálculo do erro médio quadrático direto entre sinais;

- Cálculo da incerteza (conteúdo de informação) associada com uma variável aleatória - Entropia Estatística;

Além dessas soluções, mais algumas menos importantes foram consideradas. Após uma análise qualitativa das opções, as mais promissoras foram o cálculo da correlação, e o cálculo da entropia estatística. Seria ideal que ambas vias fossem testadas para que a melhor fosse escolhida, porém por restrições de tempo, apenas a mais promissora foi implementada: o cálculo da entropia estatística. A verificação da correlação como método fica como sugestão para trabalhos futuros.

\subsection{Entropia Estatística}

Cada conjunto de dados é também referenciado no texto simplesmente por "sinal", apenas para brevidade. Além dos dados de atitude de rolamento utilizados nas comparações, também foram utilizados dados de comando do piloto e dados de atitude desejada (a tarefa sendo executada) para a realização das simulações, conforme descrito no capítulo 5. De maneira a comparar os dados de ambas malhas de controle simuladas com os dados obtidos diretamente da execução com o piloto humano no loop (sinal 1 versus 2 e sinal 1 versus 3), foram utilizados os conceitos de entropia estatística (SHANNON, 1948), entropia relativa (KULLBACK; LEIBLER, 1951) e entropia relativa posteriormente incrementados por (RENYI, 1961). Todos provenientes da Teoria da Informação. 
A grandeza entropia (em sua concepção estatística, diferente do conceito clássico termodinâmico) mede quanto há de informação em um sinal (ou de um conjunto de dados), ou quanto do sinal é conhecido. A definição original visava determinar a capacidade de transmissão de informação de um canal de comunicação, porém sua maior abrangência foi logo notada, sendo expandida a aplicação para outras áreas. A definição estabelece que, dada uma variável randômica (R.V.) $Z$ em um alfabeto $\mathcal{A}$ e dada a probabilidade de um evento $z$ ocorrer,

$$
P_{z}(z)=\operatorname{probabilidade}(Z=z), z \in \mathcal{A}
$$

a entropia de Shannon é definida como:

$$
H(z)=-\sum_{x \in \mathcal{A}} P_{z}(z) \log _{2}\left(P_{z}(z)\right)
$$

e por definição:

$$
0 \log _{2}(0)=0
$$

A unidade de entropia é, quando utiliza-se $\log _{2}$, bits.

Uma outra maneira de interpretar essa grandeza é como uma medida da incerteza da probabilidade do evento $z$ ocorrer na distribuição de probabilidade $P_{z}$. Mas esse conceito precisa ser expandido para ser aplicado na comparação de sinais. Foi exatamente a contribuição apresentada na proposta de uma medida para :

um problema estatístico de discriminação, considerando uma medida da "distância"* ou "divergência" entre populações estatísticas, em termos de nossa medida da informação (KULLBACK; LEIBLER, 1951).

Dessa maneira, o conceito de Entropia Relativa (também conhecido como Distância de Kullback-Leibler, Distância K-L ou Divergência K-L) é uma medida da ineficiência de considerar que a distribuição de uma R.V. é $Q_{z}$, quando, na verdade, ela é $P_{z}$. A definição é:

$$
D\left(P_{z} \| Q_{z}\right)=\sum_{x \in \mathcal{A}} P_{z}(z) \log _{2}\left(\frac{P_{z}(z)}{Q_{z}(z)}\right)
$$

\footnotetext{
*O termo "distância" é utilizado na literatura, porém o conceito não é o mesmo da distância Euclidiana. A distância K-L não é simétrica $\left(D\left(P_{z} \| Q_{z}\right) \neq D\left(Q_{z} \| P_{z}\right)\right)(\mathrm{COVER}, 1990)$.
} 
com: $Q_{z}(z) \neq 0$

$$
0 \log _{2}\left(\frac{0}{Q_{z}(z)}\right)=0
$$

e para $P_{z}(z) \neq 0$,

$$
P_{z}(z) \log _{2}\left(\frac{P_{z}(z)}{0}\right)=\infty
$$

Essas definições têm uma aplicação interessante na comparação de sinais, pois torna-se possível medir quão longe estão dois sinais um do outro (ou quão diferentes são suas distribuições de probabilidade). Assim, pode-se medir quão provavelmente o piloto estava operando na malha fechada em erro de posição versus na fechada em derivada do erro. No caso, os sinais (ou dados) simulados (sinal 2 - malha de erro e sinal 3 derivada do erro) são considerados como conhecidos a priori (ou $P_{z}(z)$ na definição). Os dados medidos no ensaio com o piloto no loop (sinal 1) são considerados de conteúdo desconhecido e serão comparados aos sinais conhecidos a priori para se determinar as distâncias (ou $Q_{z}(z)$ na definição) entre eles. É importante ter em mente que a tese proposta tenta estabelecer uma métrica para determinar se o ensaio foi realizado com ganho adequado ou não, funcionando como um validador de manobra.

Há uma definição mais abrangente e mais recente para o cálculo da divergência entre duas distribuições (RENYI, 1961). A teoria parte da definição de entropia de ordem $\alpha$ :

$$
H_{\alpha}(z)=\left(\frac{1}{1-\alpha}\right) \log _{2}\left(\sum_{x \in \mathcal{A}} P_{z}(z)^{\alpha}\right)
$$

que é válida para inteiros $\alpha>0$ e $\alpha \neq 1$, sendo o $\lim _{\alpha \rightarrow 1} H_{\alpha}\left(P_{z}\right)=H_{1}\left(P_{z}\right)=H\left(P_{z}\right)$ (entropia de Shannon).

Expandindo o conceito, chega-se à definição da entropia relativa de ordem $\alpha$ (RENYI, 1961):

$$
D_{\alpha}\left(P_{z} \| Q_{z}\right)=\left(\frac{1}{\alpha-1}\right) \log _{2} \sum_{x \in \mathcal{A}}\left(\frac{P_{z}(z)^{\alpha}}{Q_{z}(z)^{\alpha-1}}\right)
$$

que é válida para $\alpha \neq 1$, sendo o cálculo de $\lim _{\alpha \rightarrow 1} D_{\alpha}\left(P_{z} \| Q_{z}\right)=D_{1}\left(P_{z} \| Q_{z}\right)=D\left(P_{z} \|\right.$ $Q_{z}$ ) (definição da entropia relativa de K-L).

A grande vantagem em se utilizar 6.8 ao invés de 6.4 está na estabilidade do cálculo a partir de uma função densidade de probabilidade estimada (que contém erros de aproximação e numéricos). Principalmente porque se passa a ter o cálculo do logaritmo fora do somatório. Essa é a definição que será usada a seguir. 


\subsection{Algoritmo Utilizado para Cálculo da Entropia}

O conceito de entropia apresentado na seção 6.2 utiliza, como base de cálculo, a probabilidade de um evento ocorrer dentro de um universo conhecido (chamado alfabeto, ou espaço amostral). A seguir, serão apresentadas as definições formais de probabilidade e densidade de probabilidade (GRAY; DAVISSON, 2004).

Para uma variável aleatória (V.A.), o espaço amostral $(\mathcal{A})$ é definido como o universo de todos os possíveis eventos (para essa variável) e pode ser limitado em valores definidos. Se, por exemplo, definirmos um evento como "o valor da atitude de rolamento da aeronave", os valores possíveis podem ser estabelecidos entre $\Phi \in[-60,+60]$ graus. Atitudes fora dessa faixa não pertencem ao espaço amostral e não são considerados.

Para uma variável aleatória $e$, a função distribuição de probabilidade é definida para $\forall x \in \mathcal{A}$ como:

$$
F(x)=P\{e \leq x\}
$$

Essa função, por vezes, também é chamada de distribuição de probabilidade acumulada e quantifica a probabilidade de um evento ocorrer entre o extremo inferior do espaço amostral e um ponto definido (x) (PAPOULIS, 1991).

A função densidade de probabilidade (pdf) é definida por (PAPOULIS, 1991):

$$
f(x)=\frac{d F(x)}{d x}
$$

A aplicação desses conceitos para os dados simulados (sinais 2 e 3 ) e obtidos via ensaio (sinal 1) é direta, pois é necessário determinar a função densidade de probabilidade para cada um deles. A atitude da aeronave obtida no ensaio (sinal 1) é um sinal contínuo no tempo. Porém, ele é amostrado pelo sistema de aquisição de dados e passa, então, para o domínio discreto. Os dados provenientes da simulação numérica já são discretos por natureza.

A função densidade de probabilidade dos sinais é obtida de maneira aproximada, com um algoritmo que tem as seguintes etapas e baseia-se na obtenção de histogramas:

1. Estabelece-se uma gama para varredura do número de classes (bins), nais quais 
os sinais serão discretizados;

2. Para cada discretização, ou número de classes (bins) no histograma, determina-se a largura da classe;

3. O sinal no tempo é projetado no eixo das ordenadas para cada instante da simulação (step no tempo), e uma unidade é acrescida na classe (bin) correspondente;

4. É feita a normalização para que a soma de todas as classes (equivalente à integral do histograma) seja igual a um.

Os histogramas normalizados são utilizados como uma aproximação da função de distribuição de densidade de probabilidade (pdf), que será utilizada diretamente no cálculo da entropia.

A fim de eliminar possíveis distorções devidas às bordas das faixas das classes (bins), que é um erro de discretização, o algoritmo foi repetido diversas vezes, variando-se o número de classes entre 64 até 127. Para número de classe, foi realizado o cálculo da entropia. O resultado final foi obtido calculando-se a média do valor de entropia. Esse procedimento, além de diminuir distorções, traz maior estabilidade ao método.

A figura 6.1 mostra o fluxograma simplificado da rotina. 


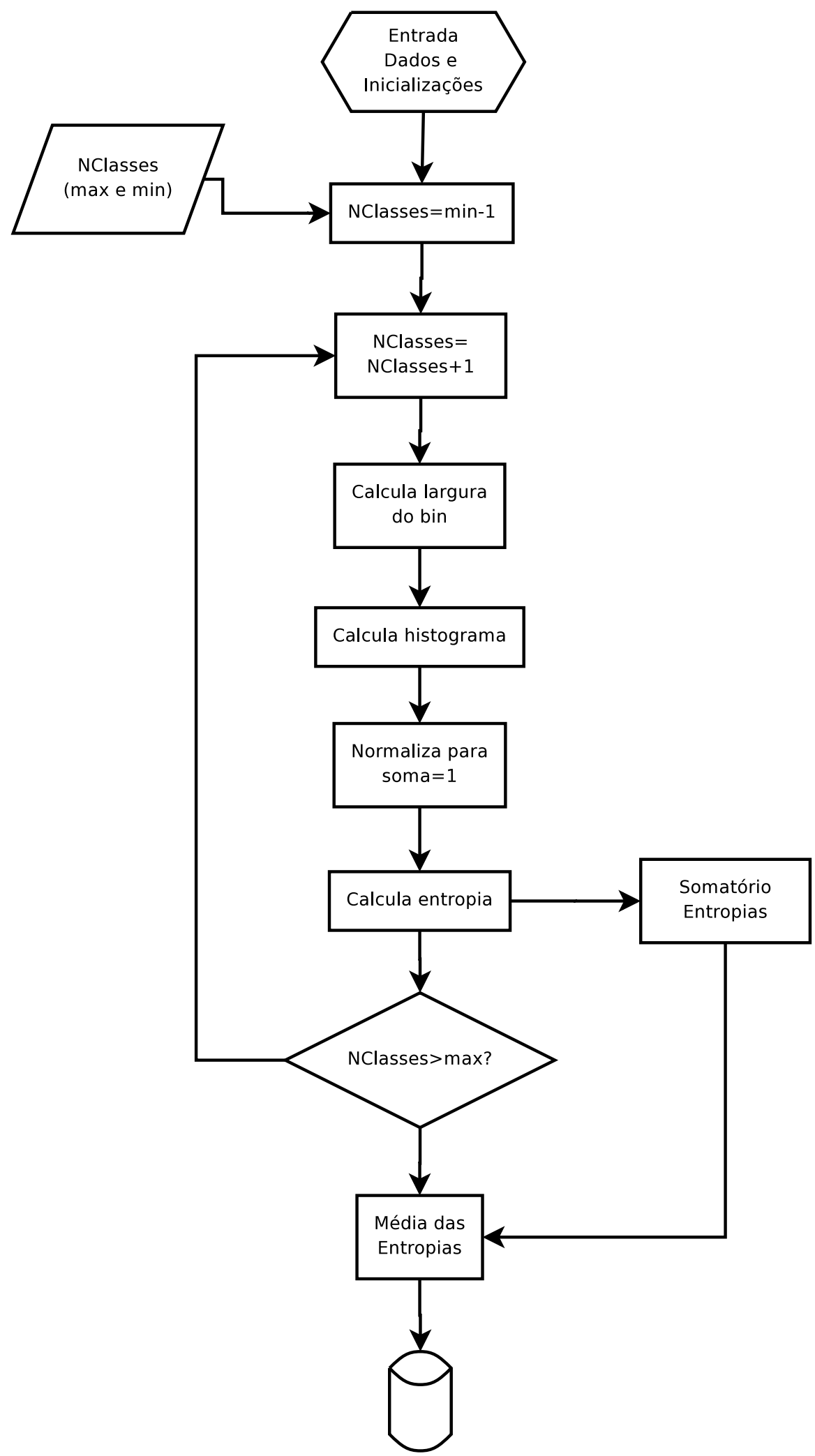

Figura 6.1: Algoritmo simplificado da rotina de cálculo dos histogramas e da entropia 
A figura 6.2 mostra como, para os valores de entropia calculados para vários números de classes, variam. Também é mostrada a diferença entre as entropias e a média calculada.

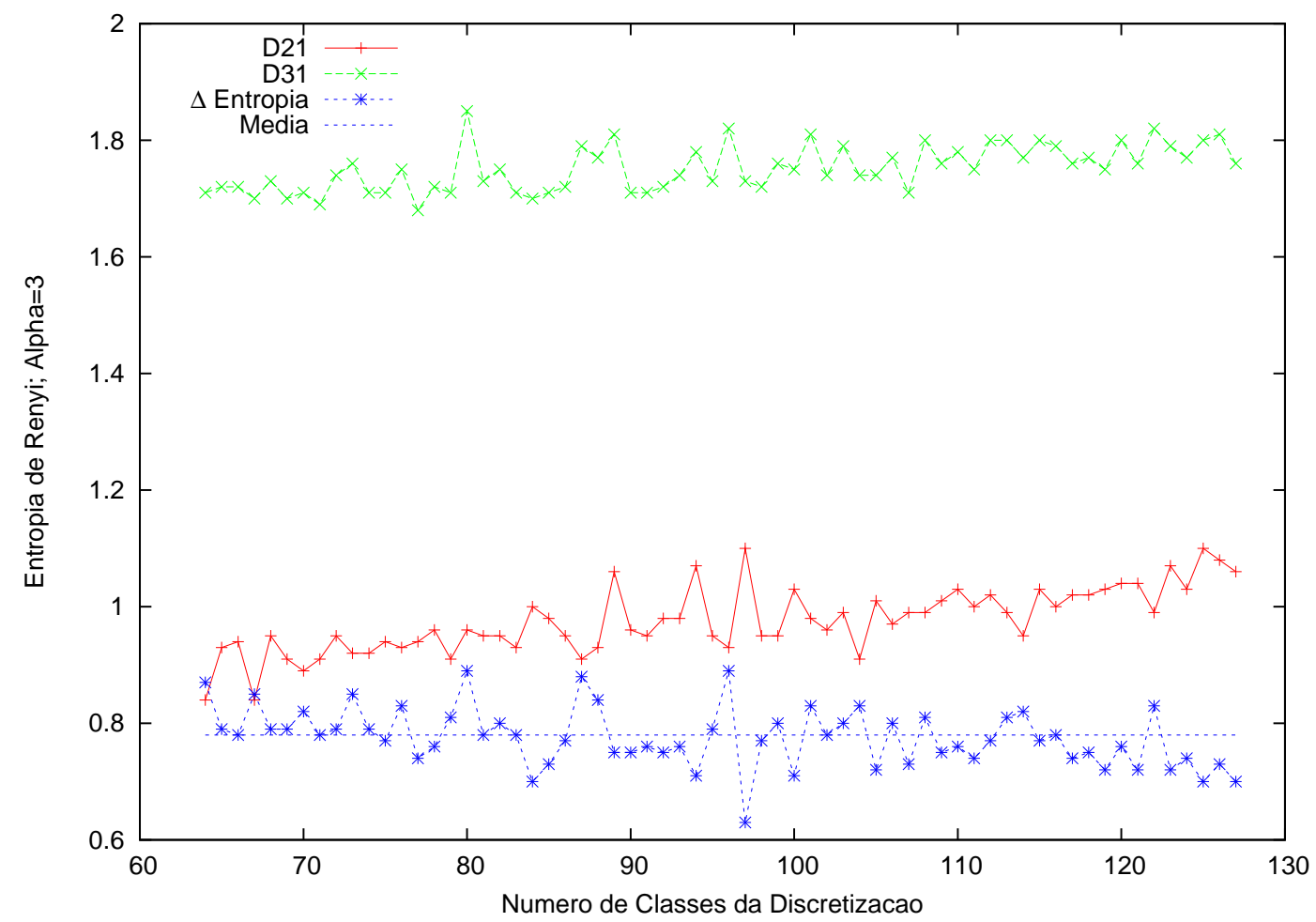

Figura 6.2: Influência do número de classes (ou bins) utilizadas na discretização dos histogramas no cálculo do valor das entropias - Nota-se que há variação nas entropias calculadas, porém, sem grande variação na diferença entre as entropias. Conseqüentemente, o valor da média é bastante estável.

Há também, o fator de distorção presente quando o valor da pdf é zero, pois a definição de entropia trata esses eventos pela definição (vide equações 6.5 e 6.6). Quanto mais discretizados forem os bins, maior será a chance de haver um valor zero na pdf, aumentando a distorção. Portanto, para o cálculo da entropia relativa (equação 6.8), faz-se necessário tratar as descontinuidades quando $Q_{z}=0$; caso contrário, o valor resultaria em $\infty$. Para que o erro total seja pequeno (da ordem de 1.0\%), um $\epsilon$ é somado ao histograma toda vez que seu valor é zero. Após percorrer todo o histograma novamente, todos os valores são normalizados de maneira que a soma total seja igual a 1. O valor adotado foi de $\epsilon=1 \cdot 10^{-6}$. Finalmente, o valor de $D_{\alpha}\left(P_{z} \| Q_{z}\right)$ é obtido pela soma $\left(\frac{1}{\alpha-1}\right) \log _{2}\left[\sum\left(P_{z}(z)^{\alpha} * Q_{z}(z)^{1-\alpha}\right)\right]$, que equivale à equação 6.8.

O algoritmo para o cálculo da entropia foi desenvolvido em C. Foi utilizada a bi- 
blioteca GNU Scientific Library versão 1.8-3 para manipulação de vetores, cálculo de mínimos e máximos e cálculo de histogramas. O código dessa biblioteca é aberto e pode ser verificado acessando-se um dos sites fonte (FREE SOFTWARE FOUNDATION, 2007). A compilação foi realizada em sistema operacional Linux com o compilador GCC 4.1.2, e diretivas de compilação -lm -lgsl -lgslcblas. Uma listagem do programa encontra-se no anexo C.1. 



\section{Capítulo 7}

\section{Resultados de Ensaios,}

\section{Simulações e Análise}

Neste capítulo, serão apresentados os resultados dos ensaios práticos realizados em vôo, das simulações com as malhas em atitude de rolamento (roll angle) e razão de rolamento (roll rate), bem como dos cálculos de entropia.

A intenção é obter um método onde seja possível avaliar uma manobra proveniente de um ensaio, comparando os dados de atitude da aeronave com dados simulados logo após a execução, ainda em vôo. O objetivo é usar os resultados da entropia estatística para validar a manobra, logo após a sua execução. Ao final, uma análise.

\subsection{Ensaios}

Para verificar a tese apresentada no capítulo 3.3, foram realizados ensaios em uma aeronave de porte regional, certificada FAR-25. A aeronave foi instrumentada com um sistema especialista, consistindo principalmente de:

- instrumento inercial com girômetro a laser, capaz de fornecer medições de aceleração, velocidade e posição angulares nos 3 eixos;

- sensor de altitude e velocidade indicada do tipo pitot-estático com compensação de erro de posição e MACH; 
- sistema gerador de trajetórias (SYNTASK), conforme descrito no capítulo 3.4.1;

- sistema de aquisição de dados multiplexado com codificação PCM e com velocidade de 2 Mbits/s.

Todos os instrumentos estavam calibrados e controlados pelo sistema EMBRAER de controle de calibração de FTI (SIGECAL). Os ensaios foram realizados nos dias 05 e 11 de novembro de 2005 a partir do aeródromo privado de Gavião Peixoto (SBGP).

A preparação dos ensaios levou em consideração as preocupações com a variabilidade do ganho utilizado pelo piloto (citada no capítulo 3.4.1). Antes de cada vôo de ensaio, as boas práticas preconizam a realização de uma reunião de coordenação com toda a tripulação para dirimir quaisquer dúvidas sobre os aspectos de segurança, a seqüência de ações e execução dos pontos de ensaio. Essa reunião é chamada de briefing. Para os ensaios realizados, o briefing da tripulação foi absolutamente explícito em relação às conseqüências da utilização do ganho adequado durante a execução das tarefas sintéticas. Também incluiu uma explicação de que alguns pontos de ensaio estariam sendo utilizados como experimento para esta tese e, portanto, a utilização do máximo ganho possível era de suma importância. Cuidado especial e atenção redobrada foram solicitadas nesse sentido.

A escolha dos pilotos de prova foi criteriosa e levou em consideração a experiência anterior no tipo de aeronave e em ensaios de PIO já realizados. Além disso, os vôos foram dimensionados para que a quantidade de pontos de ensaio fosse aquém da quantidade de um vôo de ensaios normal, resultando, portanto, num vôo considerado curto. Foi mais uma preocupação importante para minimizar o risco de o piloto utilizar um ganho menor devido ao cansaço proporcionado por um vôo longo.

Essas foram as precauções utilizadas para tentar garantir o emprego correto dos ganhos pelos pilotos durante a execução das manobras, porém é, sem dúvida, uma hipótese que não pode ser garantida com $100 \%$ de certeza.

É importante apontar que o custo de cada ensaio é elevado (da ordem dos US\$15 mil) e, por essa razão, o número de pontos é limitado. 


\subsubsection{Condução do Ensaio}

A tripulação dos ensaios foi composta por um piloto de provas no comando da aeronave, um segundo piloto na função de segurança (safety pilot) e de um engenheiro de ensaios na condução geral. Os ensaios iniciaram-se com decolagens no centro de gravidade (C.G.) já na posição traseira, peso máximo de pouso ( $M L W$ - maximum landing weight) e prosseguiram direto para o nível de vôo projetado para o ensaio. Esta configuração de massa e C.G. foi a considerada crítica para o tipo de aeronave. A sua escolha foi baseada em critérios analíticos de estabilidade, tais como os descritos na norma de qualidades de vôo MIL1797A (DEPARTMENT OF DEFENSE INTERFACE STANDARD, 1990).

Para cada configuração ensaiada (posição de flap, trem-de-pouso e velocidade), foi executada uma manobra para a identificação de parâmetros da aeronave, seguindo o método exposto no capítulo 4.2.3. Essa manobra consistiu na introdução de uma excitação em malha aberta por meio do aileron (canal lateral), e seu formato é consagrado na literatura (AGARD Working Group 23, 2000) e nos ensaios de identificação de parâmetros. A manobra chama-se 3211 e herda o nome do formato da excitação, conforme apresentado na figura 7.1. O seu uso foi também uma recomendação direta dos especialistas em identificação de parâmetros da EMBRAER. Uma comparação entre a potência espectral (PSD) de algumas entradas excitadoras possíveis revela, também, que o uso da manobra 3211 é o que proporciona maior largura de banda, oferecendo um melhor custo/benefício. Ver a fig. 7.2.

Os dados resultantes das manobras 3211 foram utilizados como dados de entrada na rotina de identificação de parâmetros a fim de obter um modelo matemático da planta (aeronave) ajustado especificamente para as condições de cada configuração ensaiada. Com esse procedimento, o erro de modelagem da planta foi minimizado uma vez que o ajuste do modelo foi realizado para a condição específica, sem extrapolação. Há, claro, uma perda de generalidade, mas que, neste caso, não tem conseqüências devido ao uso específico do modelo apenas para a função de simulação nas mesmas condições em que a identificação foi realizada. O modelo não é utilizado para extrapolar dados fora destas condições específicas.

Na seqüência, foram realizados os ensaios de tarefa sintética para aquela configuração, e o procedimento específico para a execução dos pontos foi o seguinte: 


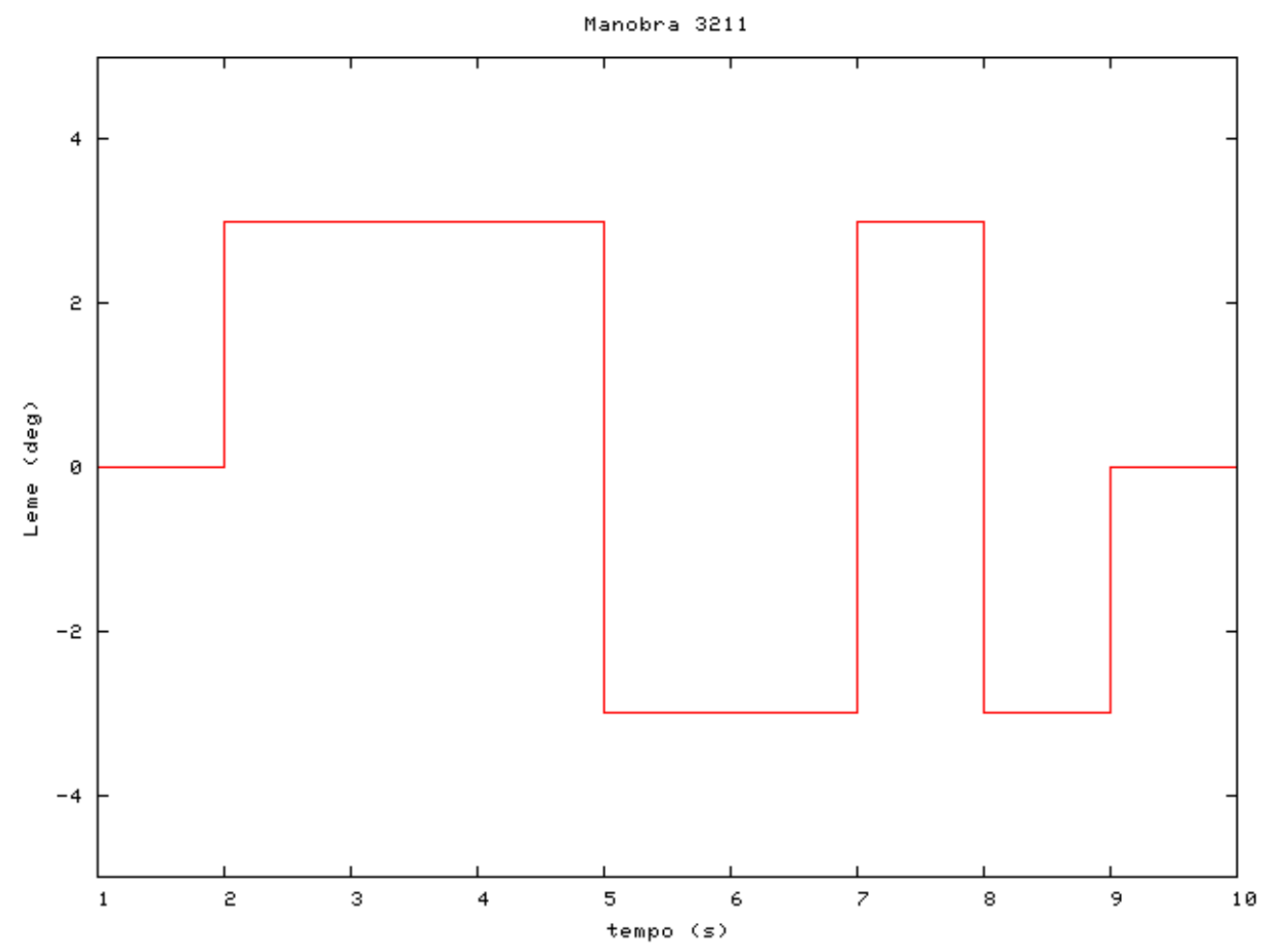

Figura 7.1: Manobra 3211 - manobra utilizada como entrada na planta (aeronave) para excitação em malha aberta. Os dados de entrada e saída são utilizados pela ferramenta de identificação de parâmetros para a obtenção do modelo matemático da planta.

- compensar a aeronave em vôo reto e nivelado, com um período de estabilização de 10s (trim shot), sem interferência do piloto (hands-off);

- iniciar a apresentação da tarefa sintética para o piloto com uma contagem regressiva;

- ao final da contagem regressiva, perseguir a tarefa sintética com o maior ganho possível, tentando manter o erro em zero e pilotar sem compensações;

- após o término da tarefa sintética, descrever quaisquer aspectos relevantes, tais como conectividade do controle à resposta da aeronave, atrasos excessivos, sobre valores significativos (overshoots) e oscilações percebidas;

- verificar na tabela de PIOR a classificação adequada;

- após escolher a classificação, justificar as razões da escolha.

Os comentários pós-ponto de ensaio são os de mais alta relevância, pois as impressões recém-colhidas sobre a conectividade entre o desejo do piloto (quanto ao controle 


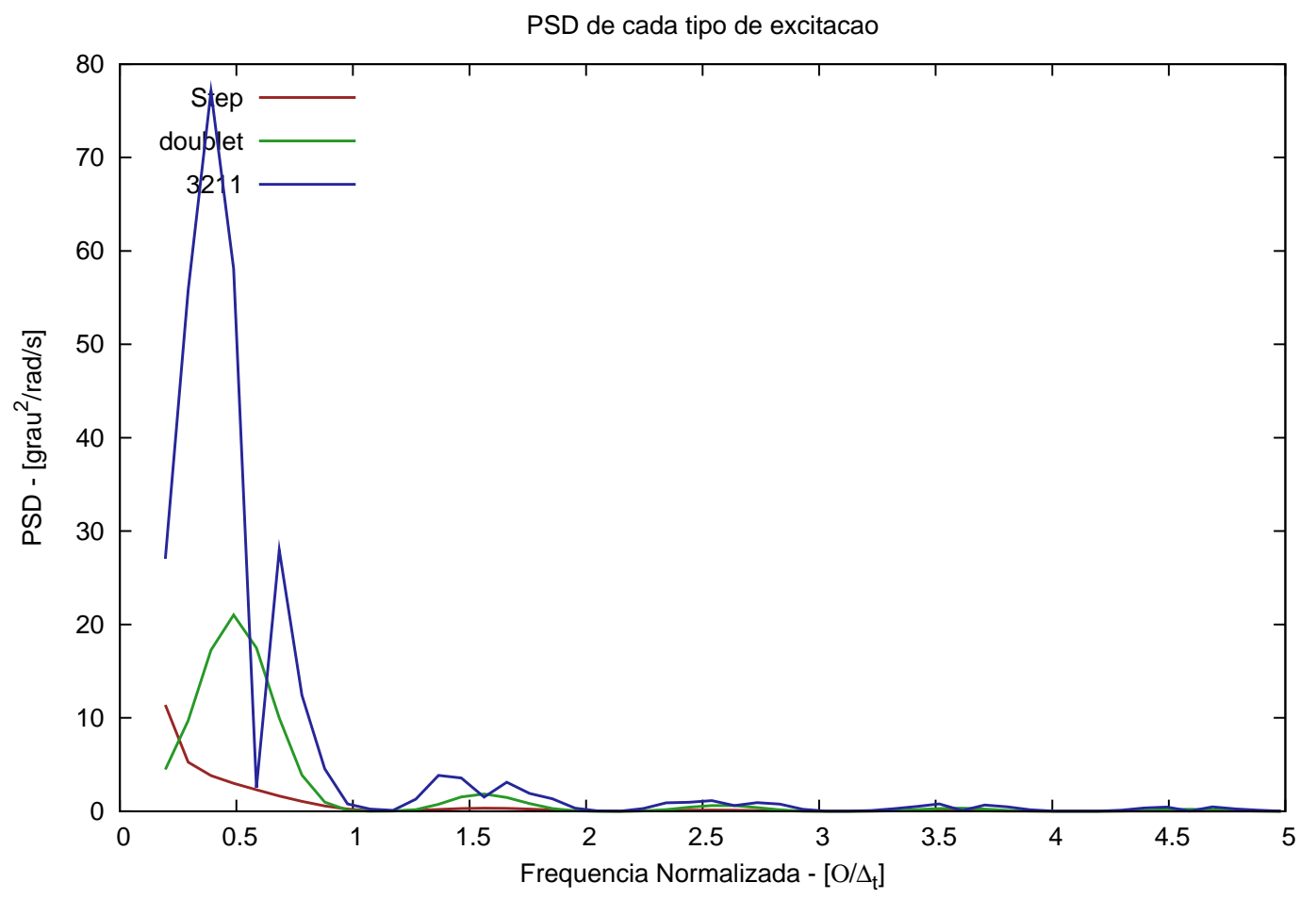

Figura 7.2: Comparação da densidade de potência espectral de cada manobra excitadora proposta para obtenção de dados de entrada para a ferramenta de identificação de parâmetros da planta - verifica-se que a potência nas freqüências de interesse (até 1.5 $\omega / \delta t)$ para a manobra 3211 é bastante superior, indicando a escolha.

de trajetória) e as respostas da aeronave estão claras e recentes para ele. Em experiências passadas, tentativas de colher essas impressões e/ou comentários adicionais após o término do ensaio (pouso da aeronave) resultaram em confusão e incapacidade de discernimento entre as situações enfrentadas. A boa prática de ensaio em vôo preconiza que os comentários sejam colhidos após cada ponto de ensaio e é, inclusive, o que recomenda Smith (1995).

Os dados colhidos nestes pontos são os dados referidos como sinal 1 no capítulo 6 e serão testados para verificar a entropia relativa contra os sinais simulados de rolamento (sinal 2) e razão de rolamento (sinal 3).

\subsubsection{Configurações Ensaiadas e Modelos Ajustados}

Foram ensaiadas duas configurações de decolagem (Decolagem $1 \gg$ D1 e Decolagem $2 » \mathrm{D} 2$ ) e outras duas de pouso (Pouso $1 » \mathrm{P} 1$ e Pouso $2 » \mathrm{P} 2$ ). Foram realizados 
dois vôos distintos, sendo eles conduzidos por pilotos diferentes. As configurações de decolagem estavam com o trem-de-pouso recolhido, e a diferença entre D1 e D2 é a posição do flap (D1 com flap menos defletido que D2). As configurações de pouso estavam com o trem-de-pouso baixado, e a diferença entre P1 e P2 é também a posição do flap (P1 com flap menos defletido). Ambos vôos contaram com a participação do mesmo engenheiro de ensaios (o presente autor).

Como será mostrado a seguir, cada configuração ensaiada teve mais de um modelo matemático da planta identificado por meio de rotina de identificação de parâmetros (primeiro modelo para configuração D1 é denotado por D1A, o segundo por D1B, etc.). Cada modelo identificado (D1A, D1B, etc.) corresponde à uma configuração (pouso ou decolagem) em uma condição específica (altitude, velocidade, etc.). Porém, é importante explicitar que, uma vez mantidas as condições de contorno (configuração, altitude, velocidade), foram realizados múltiplos pontos de ensaio. À esses pontos dá-se o nome de seqüência. A tabela 7.1 contém as combinações modelo utilizado vs. seqüência. A única excessão é a seqüência número 05 (configuração de pouso), que utilizou um modelo identificado para uma configuração de asa idêntica (flap e ângulo de ataque), porém com o trem-de-pouso recolhido. Essa diferença foi julgada não significativa, haja vista a experiência de certificação desta aeronave, que não verificou grandes alterações aerodinâmicas entre as duas situações. A influência do trem-de-pouso é relacionada mais com o arrasto da aeronave, que, neste caso, está compensado pelo motor.

Tabela 7.1: Listagem dos Modelos vs. Seqüência\#

\begin{tabular}{|c|c|c|l|}
\hline Vôo & Configuração & Modelo & Seqüência\# \\
\hline 1 & D1 & D1A & $26,27,28$ \\
& & D1B & $18,19,20,22,23,24$ \\
& P1 & P1A & $14,15,16,17$ \\
\hline 2 & D2 & D2A & 02 \\
& & D2B & 03 \\
& P2 & P2A & 01 \\
& & P2B & 04 \\
& P1 & D2A & 05 \\
\hline
\end{tabular}

A validação dos modelos é apresentada a seguir, contendo a excitação (manobra 3211 no aileron $)$ e as saídas simulada $\left(\phi_{\text {simulado }}\right)$ e real $\left(\phi_{\text {real }}\right)$ da aeronave. 


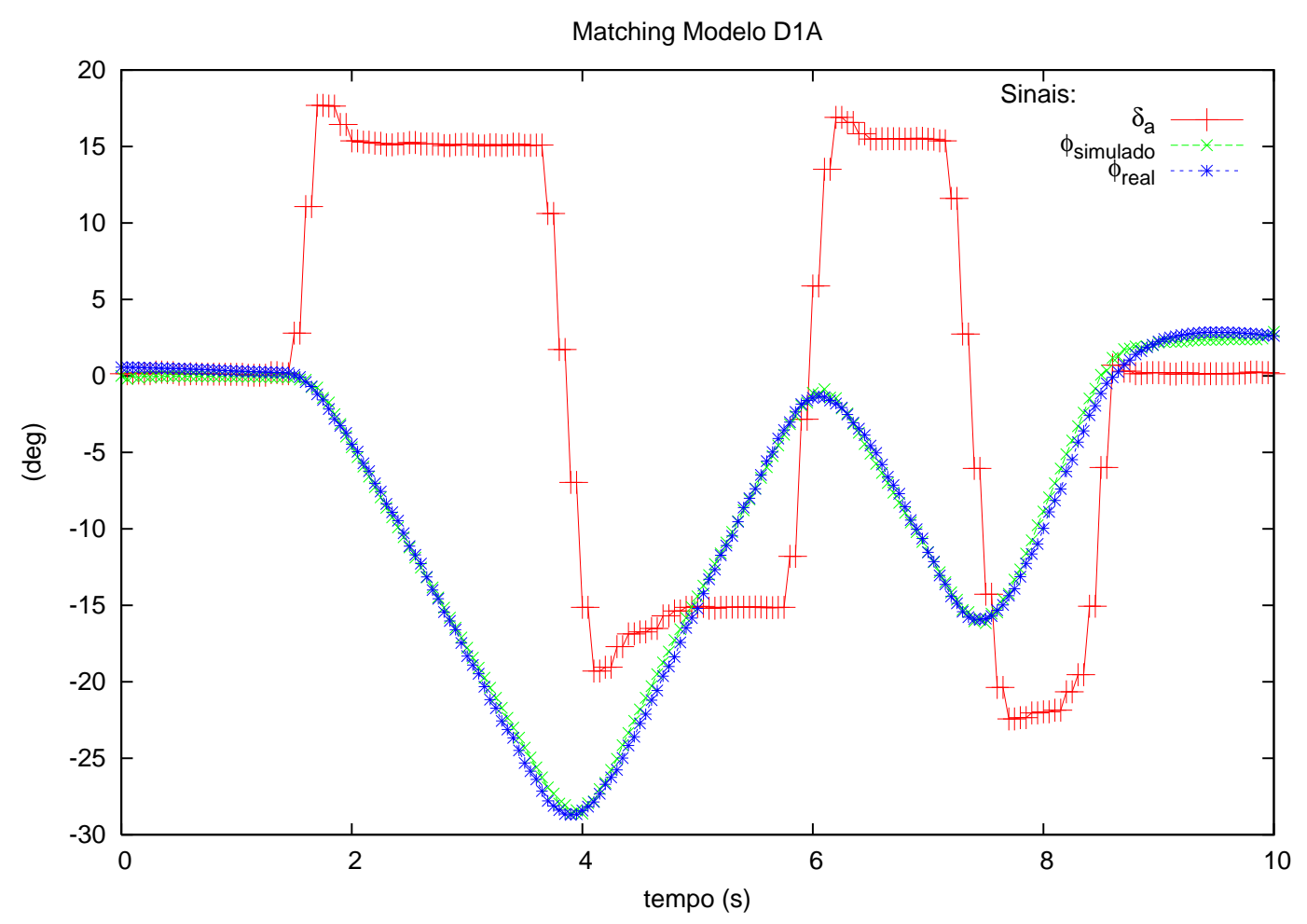

Figura 7.3: Validação (Matching) do Modelo D1 - versão A 


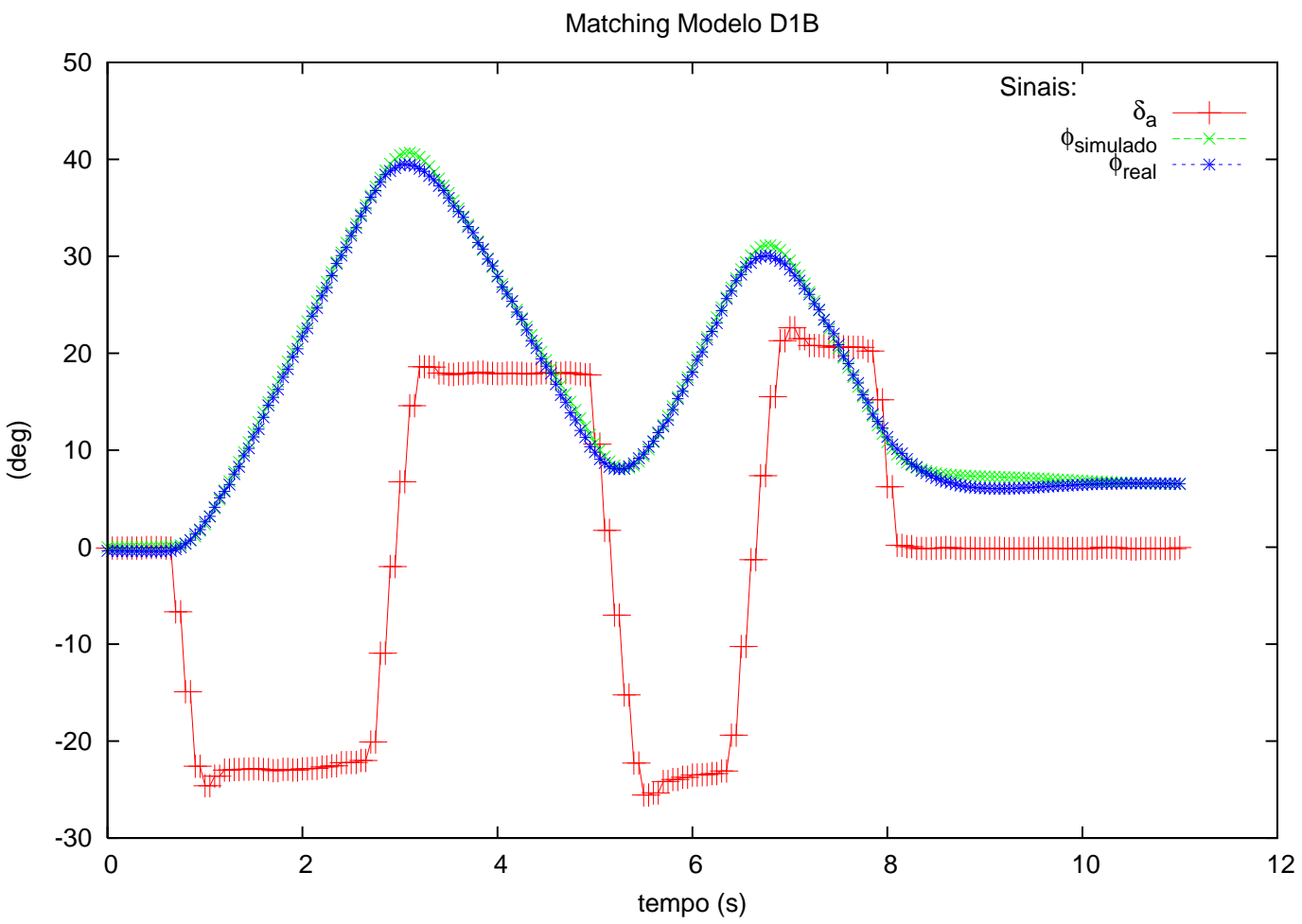

Figura 7.4: Validação (Matching) do Modelo D1 - versão B

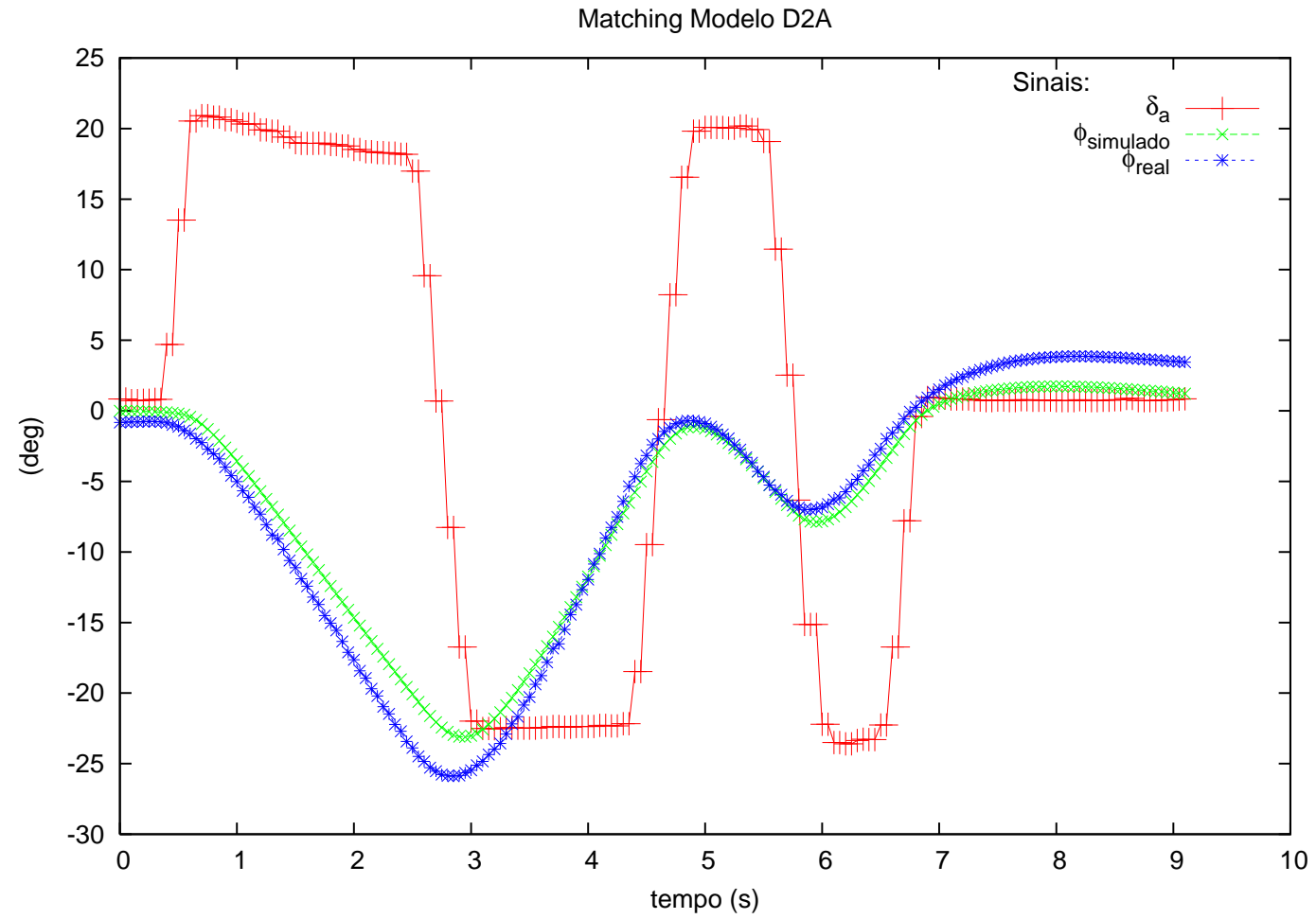

Figura 7.5: Validação (Matching) do Modelo D2 - versão A 


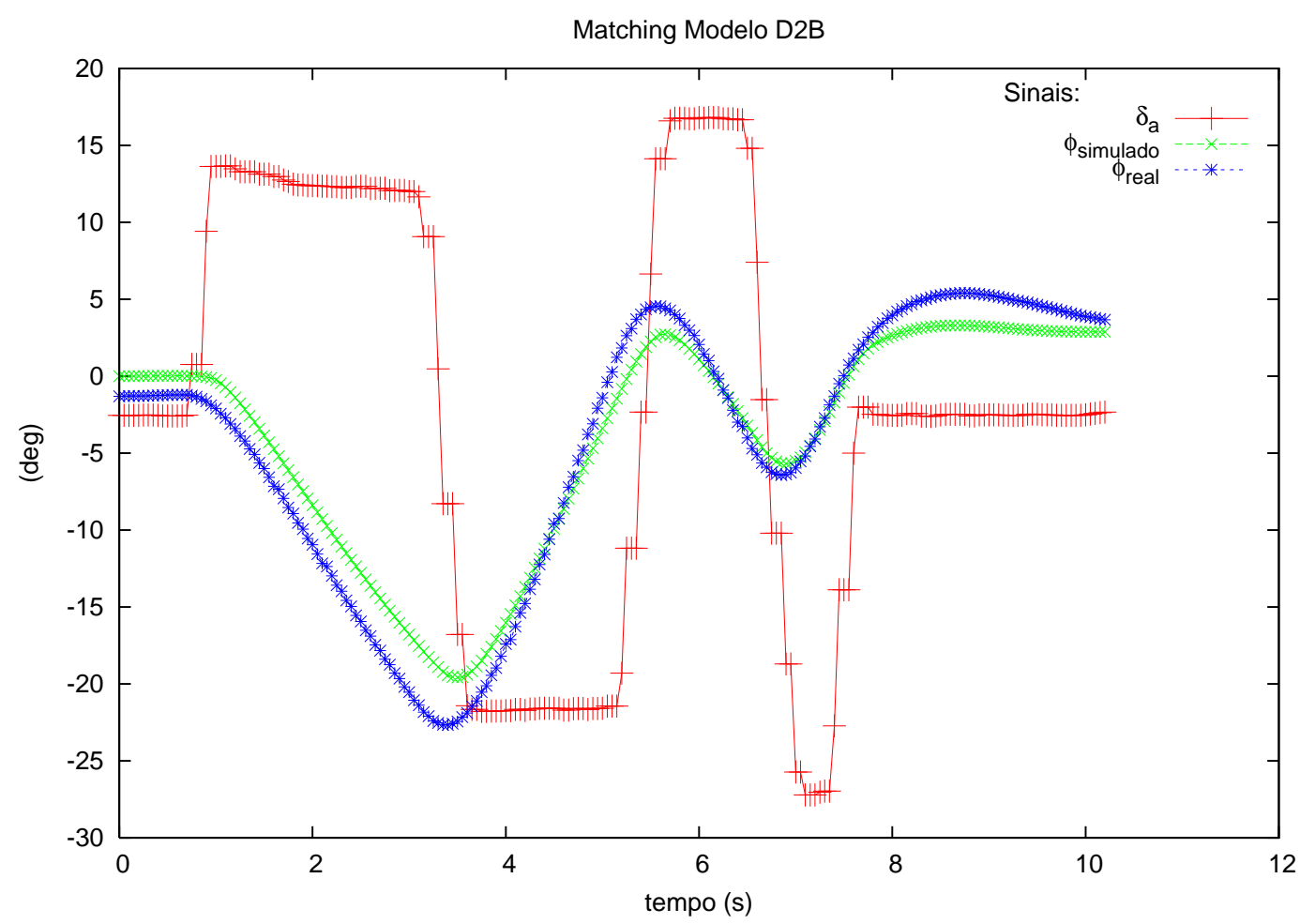

Figura 7.6: Validação (Matching) do Modelo D2 - versão B

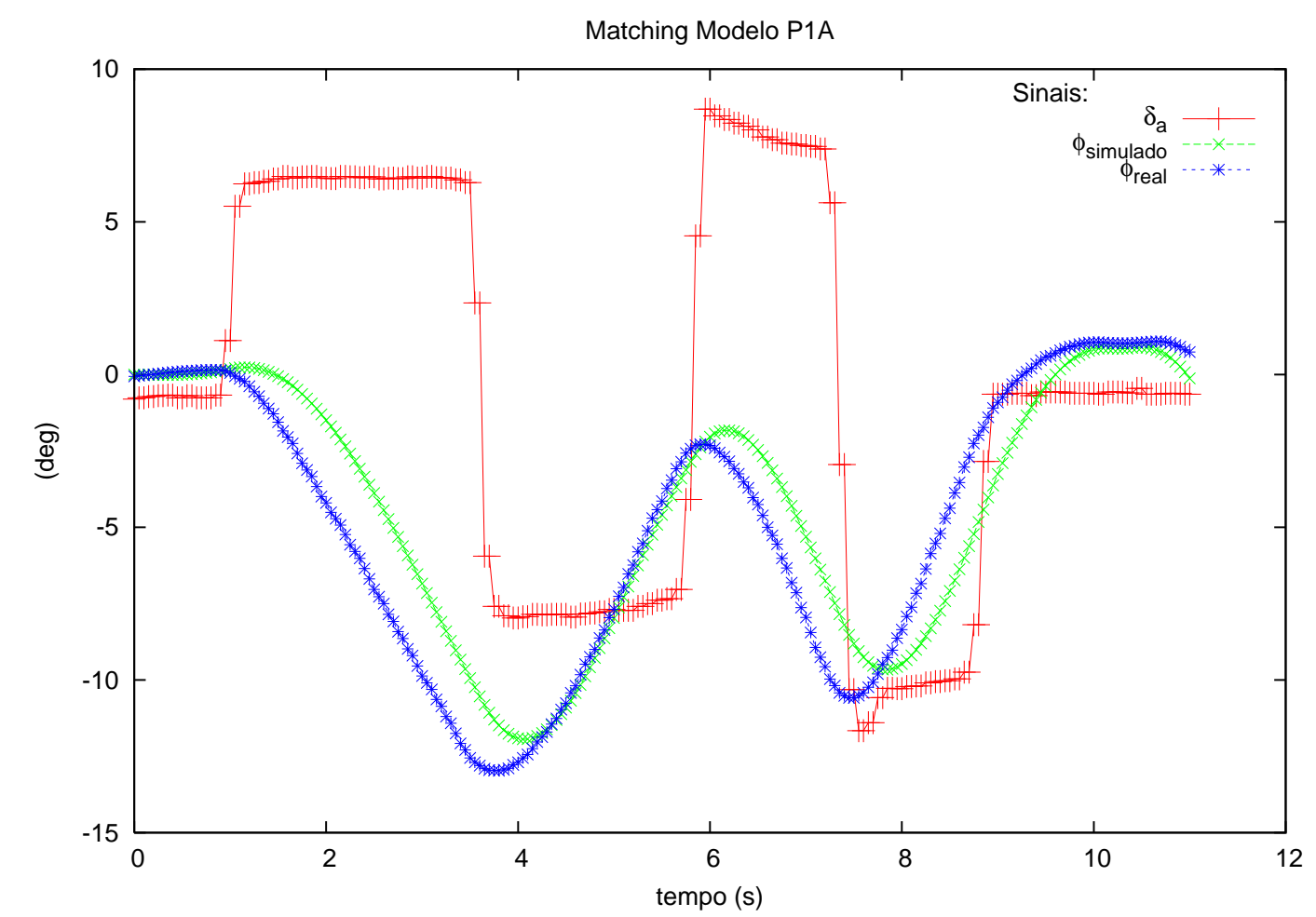

Figura 7.7: Validação (Matching) do Modelo P1 - versão A 


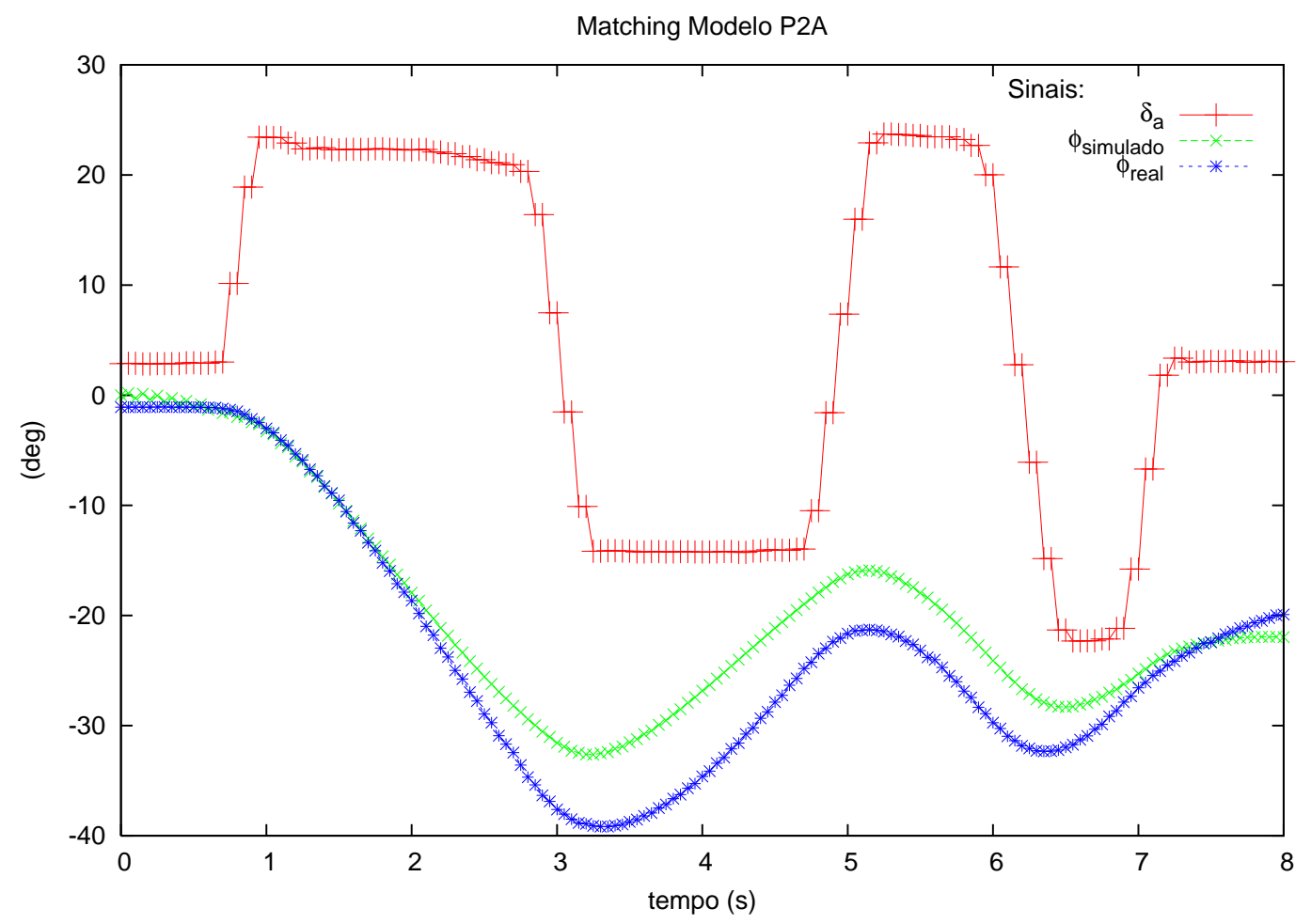

Figura 7.8: Validação (Matching do Modelo P2 - versão A

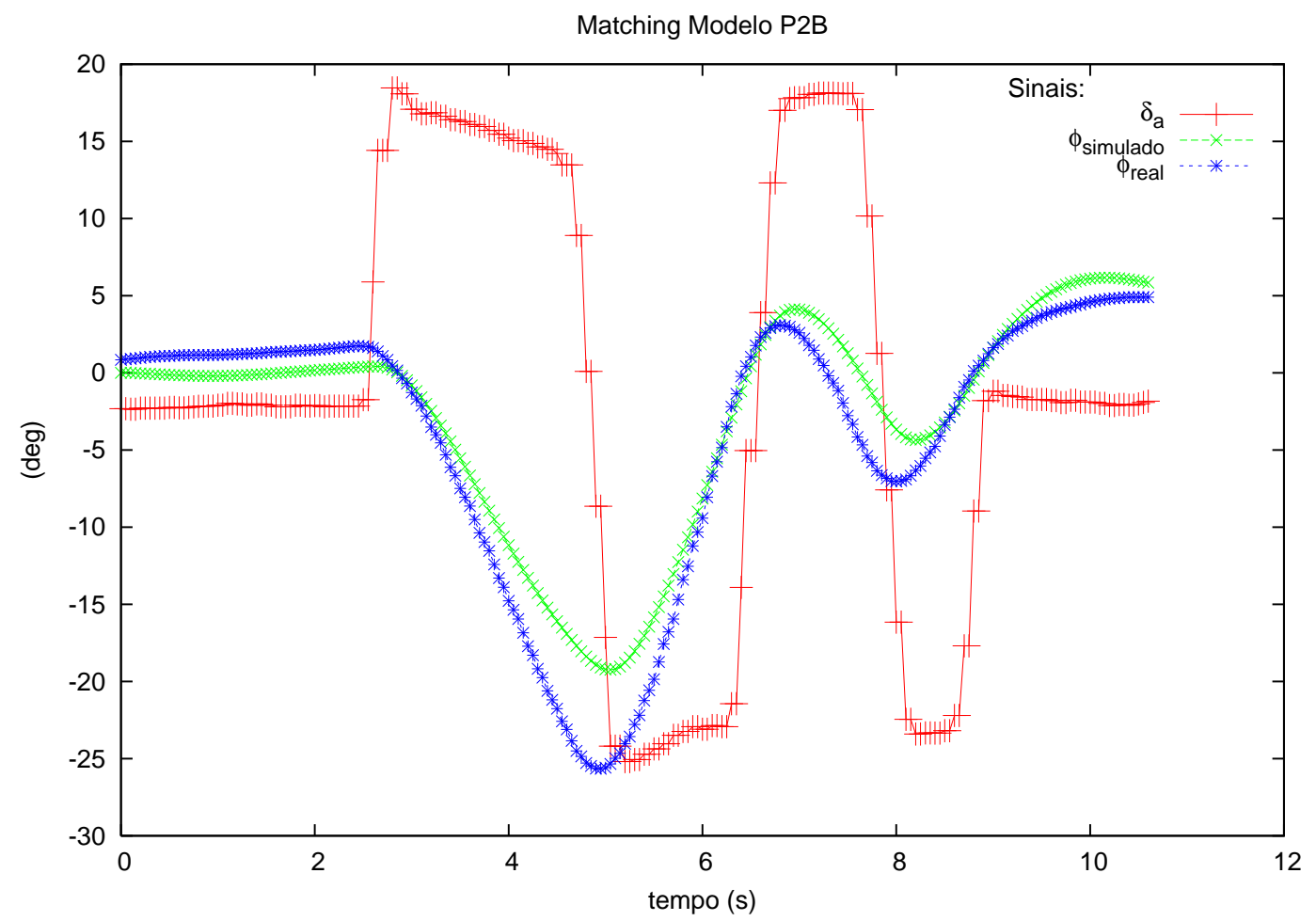

Figura 7.9: Validação (Matching do Modelo P2 - versão B 
Analisando-se as figuras de 7.3 a 7.9, é possível verificar que a identificação de parâmetros das várias plantas resultou em modelos bastante próximos dos traços reais. Os modelos D1A e D1B obtiveram os melhores resultados, sendo praticamente imperceptível a diferença entre os traços. Nota-se que o traço do modelo P1A sofreu um deslocamento (offset), que, se removido, reduz drasticamente o erro. Os modelos D2A e D2B obtiveram resultados bons, havendo uma pequena variação na resposta em freqüência e resultando em um pequeno atraso do modelo comparado ao traço real. $\mathrm{O}$ último conjunto composto pelos modelos P1A, P2A e P2B é o que apresentou resultado menos preciso, porém ainda considerado satisfatório. A maior variação foi uma amplitude menor quando comparada ao traço real. Os modelos foram considerados válidos e satisfatórios para a utilização nas simulações.

As excitações 3211 para identificação dos modelos foram realizadas pouco antes de cada ponto de ensaio de Syntask. Dessa maneira, garantiu-se que o modelo da planta para cada condição ensaiada fosse o mais fiel possível, diminuindo a influência de elementos externos, como alterações das condições atmosféricas.

Após a identificação das plantas, as simulações descritas no capítulo 5 foram realizadas para a obtenção dos dados para cada uma das malhas de controle, com sinais contendo 20 amostras/segundo, gerando sinais de atitude de rolamento. Conforme descrito no capítulo 6, os sinais no tempo foram transformados em histogramas aproximados, que podem ser vistos nas figuras B.3 a B.36.

\subsection{Resultados do Cálculo de Entropia}

Os dados numéricos das simulações e aqueles coletados diretamente da aeronave com a pilotagem humana foram submetidos ao algoritmo para cálculo da entropia relativa, conforme descrito no capítulo 6.

Os dados foram separados em dois grupos:

1. O primeiro foi formado para que o critério de separação entre pontos executados com baixo ganho versus com alto ganho fosse definido (formação do critério).

2. A segunda é a figura testemunho, utilizado para testar o critério (avaliação do critério). 
Os pontos e suas separações por grupos encontram-se na tabela 7.2.

Tabela 7.2: Grupos dos Pontos de Ensaio

\begin{tabular}{|c|l|c|}
\hline Vôo/Grupo & Tarefa & Seqüência \# \\
\hline 1/Grupo formação critério & Alto Ganho & 15 \\
& & 16 \\
& & 17 \\
& & 20 \\
& & 23 \\
& & 24 \\
& & 26 \\
& & 27 \\
\cline { 2 - 3 } & & 28 \\
\hline $2 /$ Grupo Gano testemuno & 14 \\
& & 18 \\
& & 19 \\
& & 22 \\
\hline & & 1 \\
& & 2 \\
& & 3 \\
& & 4 \\
\hline
\end{tabular}

\subsubsection{Formação do Critério - Análise Direta}

Após estabelecidos os grupos e a separação dos pontos, partiu-se para o cálculo das entropias relativas. Para a formação do critério, serão utilizados somente os dados do primeiro grupo e uma vez estabelecido o mesmo, os dados do segundo grupo serão a ele submetidos, verificando sua validade. Isso será feito na seção 7.2.3.

Em se tratando de um ambiente de ensaio controlado e, assumindo-se por hipótese que os testes foram realizados de acordo com o previsto (piloto operando realmente em alto ganho nas tarefas de alto ganho e baixo ganho nas tarefas correspondentes), podese procurar um valor de corte para a diferença de entropia que corresponda aos valores ensaiados/observados. Esta é uma hipótese forte, pois, como não há padrão absoluto para o ensaio, é necessário assumir que os pontos executados estavam de acordo com este preceito. A hipótese é, no entanto razoável, haja vista a preparação dedicada a comprometer a tripulação com o ensaio. Vide detalhes no capítulo 3.3 e no capítulo 7.1.

Inicialmente, valores entre 1 e 4 para $\alpha$ da entropia de Renyi foram utilizados nos cálculos para verificar a influência na aderência e na estabilidade do método, e, a partir 
destes, buscou-se um valor de corte para separar os pontos realizados com baixo ganho daqueles realizados com alto ganho. Os resultados numéricos encontram-se na tabela 7.3 .

Tabela 7.3: Entropias do vôo 1 para vários $\alpha$ 's

\begin{tabular}{|l|l|c|c|c|c|}
\hline Ganho & Seq. & $\Delta \mathrm{D} \mathrm{p} / \alpha=1$ & $\Delta \mathrm{D} \mathrm{p} / \alpha=2$ & $\Delta \mathrm{D} \mathrm{p} / \alpha=3$ & $\Delta \mathrm{D} \mathrm{p} / \alpha=4$ \\
\hline Baixo & 14 & 0.52 & 0.51 & 0.47 & 0.42 \\
\hline Alto & 15 & 0.39 & -2.07 & -3.94 & -4.51 \\
\hline Alto & 16 & 0.8 & 0.65 & 0.11 & -0.05 \\
\hline Alto & 17 & 0.78 & 0.78 & 0.78 & 0.76 \\
\hline Baixo & 18 & 0.76 & 0.86 & 0.94 & 1 \\
\hline Baixo & 19 & 0.59 & 1 & 1.25 & 1.38 \\
\hline Alto & 20 & 0.37 & 0.44 & 0.46 & 0.46 \\
\hline Alto & 21 & 0.54 & 0.12 & -0.41 & -0.62 \\
\hline Baixo & 22 & 0.75 & 1.29 & 1.52 & 1.55 \\
\hline Alto & 23 & 0.52 & 0.49 & 0.24 & 0.13 \\
\hline Alto & 24 & 0.58 & -1.33 & -2.74 & -3.24 \\
\hline Alto & 26 & 1.34 & 1.72 & 1.81 & 1.74 \\
\hline Alto & 27 & 2.72 & 4.23 & 3.44 & 3.11 \\
\hline
\end{tabular}

Uma vez calculadas as entropias para vários $\alpha$ 's, passou-se à busca de um valor de corte para separar os pontos de alto ganho dos de baixo. Vários valores foram experimentados, procurando-se maximizar o número de acertos. Trata-se de uma otimização bidimensional: em $\alpha$ e no valor do corte. Para auxiliar na tomada de decisão, foi montada uma tabela dinâmica onde as várias combinações pudessem ser simuladas e analisadas. O resultados dessas simulações, para alguns dos valores de corte experimentados, podem ser vistos nas tabela 7.4.

Dos vários resultados das simulações, os valores de $\alpha=3$ e $\alpha=4$ para cortes de 0.86 e 1.0 bit foram os que apresentaram melhor resultado. Dentre eles, foram escolhidos o de menor corte e menor $\alpha$. As razões foram apresentar a maior separação possível (menor corte) e o menor expoente possível (menor $\alpha$ ), o que, teoricamente, apresenta menor erro numérico em cálculos com precisão limitada (sistemas computacionais). Os valores finais para $\alpha=3$ podem ser vistos na tabela 7.5.

Os resultados passa/não-passa podem ser vistos de forma gráfica na figura 7.10, já com o limiar (ou threshold em Inglês) de 0.86 bit. Na mesma figura é possível notar os pontos que ficaram fora da faixa prevista (marcados como outlier na figura). 
Tabela 7.4: Porcentagem de Acertos vs. Corte

\begin{tabular}{|l|c|c|c|c|}
\hline & $\alpha=1$ & $\alpha=2$ & $\alpha=3$ & $\alpha=4$ \\
\hline \multicolumn{4}{|c|}{ Corte =0.5 } \\
\hline Acertos Alto Ganho & $27 \%$ & $55 \%$ & $73 \%$ & $73 \%$ \\
Acertos Baixo Ganho & $100 \%$ & $100 \%$ & $75 \%$ & $75 \%$ \\
Erros Alto Ganho & $73 \%$ & $45 \%$ & $27 \%$ & $27 \%$ \\
Erros Baixo Ganho & $0 \%$ & $0 \%$ & $25 \%$ & $25 \%$ \\
\hline \multicolumn{5}{|c|}{ Corte =0.86 } \\
\hline Acertos Alto Ganho & $82 \%$ & $82 \%$ & $82 \%$ & $82 \%$ \\
Acertos Baixo Ganho & $0 \%$ & $50 \%$ & $75 \%$ & $75 \%$ \\
Erros Alto Ganho & $18 \%$ & $18 \%$ & $18 \%$ & $18 \%$ \\
Erros Baixo Ganho & $100 \%$ & $50 \%$ & $25 \%$ & $25 \%$ \\
\hline \multicolumn{5}{|c|}{ Corte =1.0 } \\
\hline Acertos Alto Ganho & $82 \%$ & $82 \%$ & $82 \%$ & $82 \%$ \\
Acertos Baixo Ganho & $0 \%$ & $25 \%$ & $50 \%$ & $75 \%$ \\
Erros Alto Ganho & $18 \%$ & $18 \%$ & $18 \%$ & $18 \%$ \\
Erros Baixo Ganho & $100 \%$ & $75 \%$ & $50 \%$ & $25 \%$ \\
\hline \multicolumn{5}{|c|}{ Corte =1.5 } \\
\hline Acertos Alto Ganho & $91 \%$ & $82 \%$ & $82 \%$ & $82 \%$ \\
Acertos Baixo Ganho & $0 \%$ & $0 \%$ & $25 \%$ & $25 \%$ \\
Erros Alto Ganho & $9 \%$ & $18 \%$ & $18 \%$ & $18 \%$ \\
Erros Baixo Ganho & $100 \%$ & $100 \%$ & $75 \%$ & $75 \%$ \\
\hline
\end{tabular}

Tabela 7.5: Entropias dos Pontos de Ensaio para $\alpha=3$

\begin{tabular}{|l|c|c|c|c|}
\hline Tarefa & Seqüência \# & $\begin{array}{c}D_{3} 21 \\
\text { [bits] }\end{array}$ & $\begin{array}{c}D_{3} 31 \\
\text { [bits] }\end{array}$ & $\begin{array}{c}\Delta D_{3} \\
\text { [bits] }\end{array}$ \\
\hline Alto Ganho & 15 & 5.27 & 1.33 & -3.94 \\
& 16 & 2.26 & 2.37 & 0.11 \\
& 17 & 0.98 & 1.75 & 0.78 \\
& 20 & 0.65 & 1.11 & 0.46 \\
& 23 & 2.05 & 2.29 & 0.24 \\
& 24 & 4.26 & 1.52 & -2.74 \\
& 26 & 0.7 & 2.51 & 1.81 \\
& 27 & 4.26 & 7.7 & 3.44 \\
& 28 & 6.62 & 6.98 & 0.36 \\
\cline { 2 - 5 } Baixo Ganho & 14 & 0.76 & 1.23 & 0.47 \\
& 18 & 0.25 & 1.19 & 0.94 \\
& 19 & 0.82 & 2.07 & 1.25 \\
& 22 & 1.16 & 2.68 & 1.52 \\
\hline
\end{tabular}




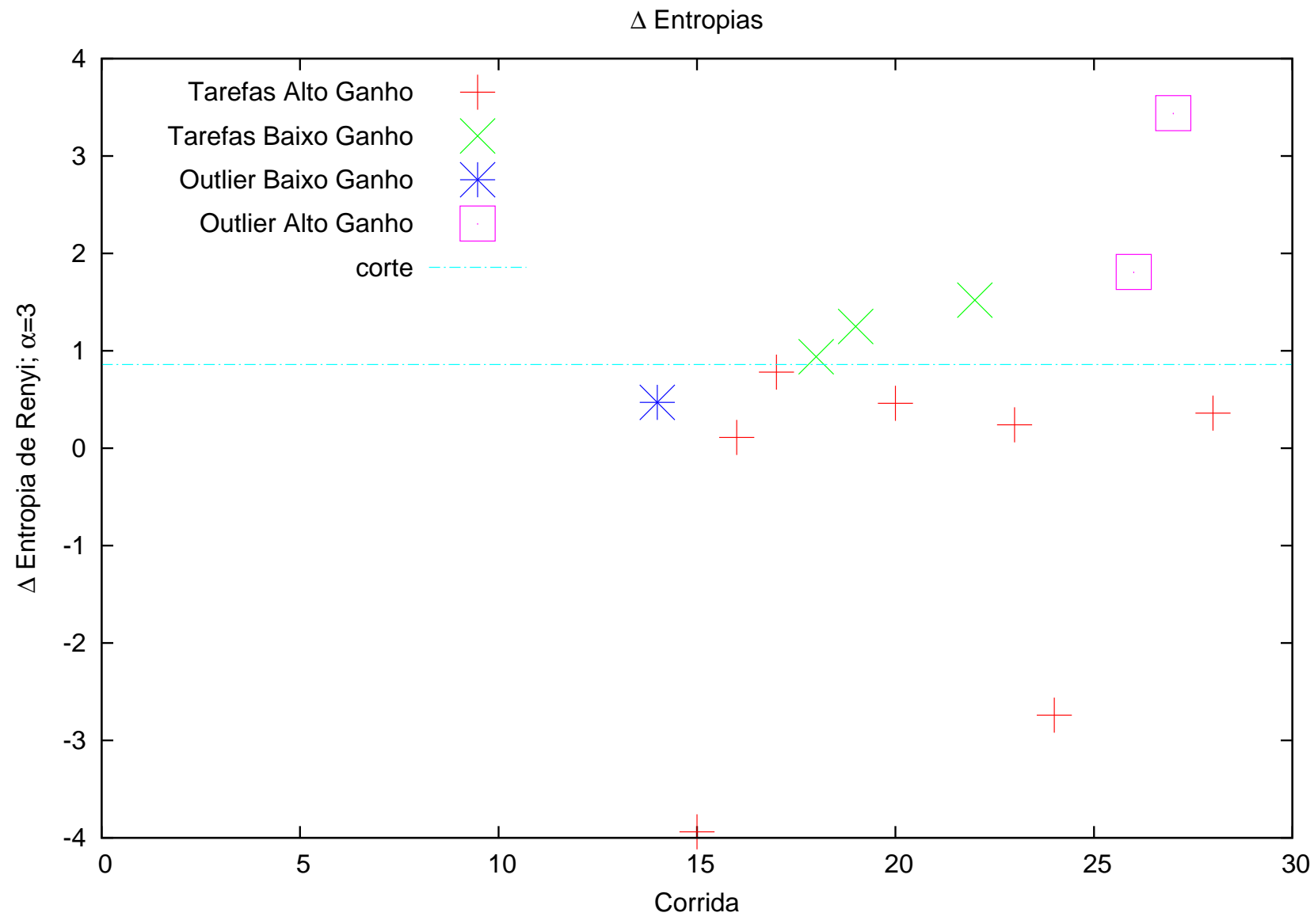

Figura 7.10: Resultados do cálculo da Entropia de Renyi para $\alpha=3$ com os pontos do primeiro grupo. A linha de corte está posicionada em 0.86 bit. Os pontos denotados como outlier não atendem à essa linha de corte. 
Analisando-se os resultados da figura 7.10, é possível ver uma boa correlação entre o critério estabelecido (0.86 bit de diferença entre as entropias de Renyi, ou $\Delta D_{3}=0.86$ bit) e os pontos de ensaio realizados com alto e baixo ganho. Há, no entanto, 3 pontos que não atendem o critério.

\subsubsection{Formação do Critério - Análise Estatística}

Para os pontos de ensaio apresentados (primeiro grupo, formação do critério), podese considerar que o método é bastante razoável na missão de separar pontos realizados com alto ganho daqueles realizados com baixo ganho. Apesar de não apresentar 100\% de acerto, a ocorrência de pontos que não atendem ao critério é aceitável, haja vista a natureza subjetiva existente na tarefa de pilotagem e a imperfeições nos modelos matemáticos.

É possível, no entanto, estender a análise por meio de ferramentas estatísticas. Para tal, os valores das seqüências foram ordenados por $\Delta D_{3}$ crescente, obtendo-se a tabela 7.6. A coluna "ID" é apenas uma identificação crescente e a coluna "Seqüência" referencia-se aos pontos de ensaio originais, já apresentados na tabela 7.5.

Tabela 7.6: Seqüências Ordenadas por $\Delta D_{3}$ crescente

\begin{tabular}{|c|c|c|}
\hline ID & $\Delta D_{3}$ & Seqüência \\
\hline alto ganho & \multicolumn{2}{|c|}{} \\
\hline 1 & -3.94 & 15 \\
2 & -2.74 & 24 \\
3 & 0.11 & 16 \\
4 & 0.24 & 23 \\
5 & 0.36 & 28 \\
6 & 0.46 & 20 \\
7 & 0.78 & 17 \\
8 & 1.81 & 26 \\
9 & 3.44 & 27 \\
\hline \hline baixo ganho & \multicolumn{2}{|c|}{} \\
\hline 10 & 0.47 & 14 \\
11 & 0.94 & 18 \\
12 & 1.25 & 19 \\
13 & 1.52 & 22 \\
\hline
\end{tabular}

Antes de proceder aos cálculos estatísticos, é importante recolocar que o objetivo é a obtenção de um critério que consiga separar os pontos executados com alto e baixo ganho. Dessa maneira, é justificável a remoção dos valores discrepantes do critério pri- 
mário, observações estatísticas notadamente diferentes das outras, feitas sobre a mesma amostra. Esses pontos são chamados de outliers na literatura estatística. A remoção desses pontos visa melhorar a precisão do indicador passa/não-passa para a execução do ponto de ensaio, colocando as médias entre baixo e alto ganho um pouco mais distantes. Notar também que os dados analisados até o momento contêm apenas o primeiro grupo - formação do critério. O critério ainda passará pelo crivo do segundo conjunto de dados - avaliação do critério apresentado posteriormente.

A provável razão para que os pontos seqüência 26 e 27 tenham valores de $\Delta D_{3}$ altos é um desbalanceamento na tarefa sintética. Uma análise dos gráficos B.21 e B.23 mostra que há um descolamento bastante grande entre os sinais resultantes das simulações nas malhas de erro e derivada do erro. Esse descolamento ocorre em tarefas que não têm uma média zero na atitude de rolamento, ou seja, a aeronave fica mais tempo inclinada para um dos lados durante a execução da tarefa. Essa hipótese necessita de mais ensaios para ser verificada e fica como sugestão para trabalhos futuros.

Com essas alterações e assumindo-se distribuições Gaussianas, obtém-se a tabela 7.7, que é apresentada graficamente na figura 7.11 com um traço mostrando a média e outros dois traços em média + desvio padrão $(\mu+\sigma)$ e média-desvio padrão $(\mu-\sigma)$.

Tabela 7.7: Estatística das Seqüências

\begin{tabular}{|c|c|c|c|c|}
\hline ID & Seqüência & $\Delta$ & Média $(\mu)$ & Desvio Padrão $(\sigma)$ \\
\hline alto ganho & \multicolumn{5}{|c|}{} \\
\hline 1 & 15 & -3.94 & -0.68 & 1.86 \\
2 & 24 & -2.74 & & \\
3 & 16 & 0.11 & & \\
4 & 23 & 0.24 & & \\
5 & 28 & 0.36 & & \\
6 & 20 & 0.46 & & \\
7 & 17 & 0.78 & & \\
\hline 8 & 26 & 1.81 & eliminados da formação do critério \\
9 & 27 & 3.44 & & \\
\hline baixo ganho & \multicolumn{3}{|l|}{} \\
\hline 10 & 14 & 0.47 & eliminado da formação do critério \\
\hline 11 & 18 & 0.94 & 1.24 & 0.29 \\
12 & 19 & 1.25 & & \\
13 & 22 & 1.52 & & \\
\hline
\end{tabular}




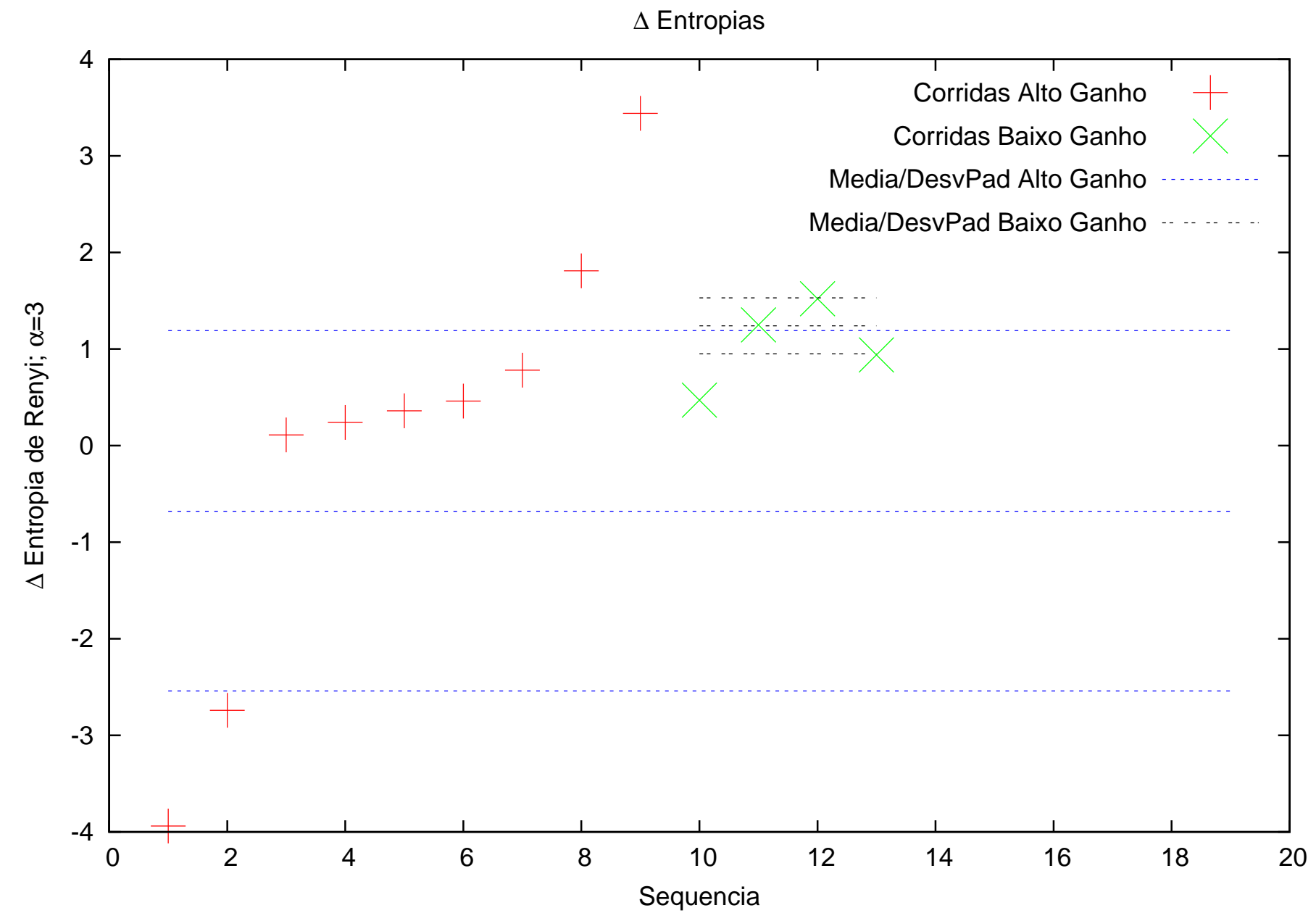

Figura 7.11: Entropia, Média e Desvio Padrão dos dados do grupo de pontos utilizados para a formação do critério 
A figura 7.11 mostra uma superposição entre a banda inferior (média menos desvio padrão) dos pontos executados com baixo ganho e a banda superior (média mais desvio padrão) dos pontos executados com alto ganho. Há uma zona de incerteza na interface entre as duas regiões.

Fica claro que quanto mais positiva for a diferença de entropia entre as duas condições, mais próxima de uma operação de baixo ganho estará a execução da tarefa.

Pode-se obter uma leitura mais direta da probabilidade de um ponto ter sido executado em alto ou baixo ganho, dado um valor de $\Delta D_{3}$. Esses valores são obtidos pela probabilidade combinada, mostrada na figura 7.12.

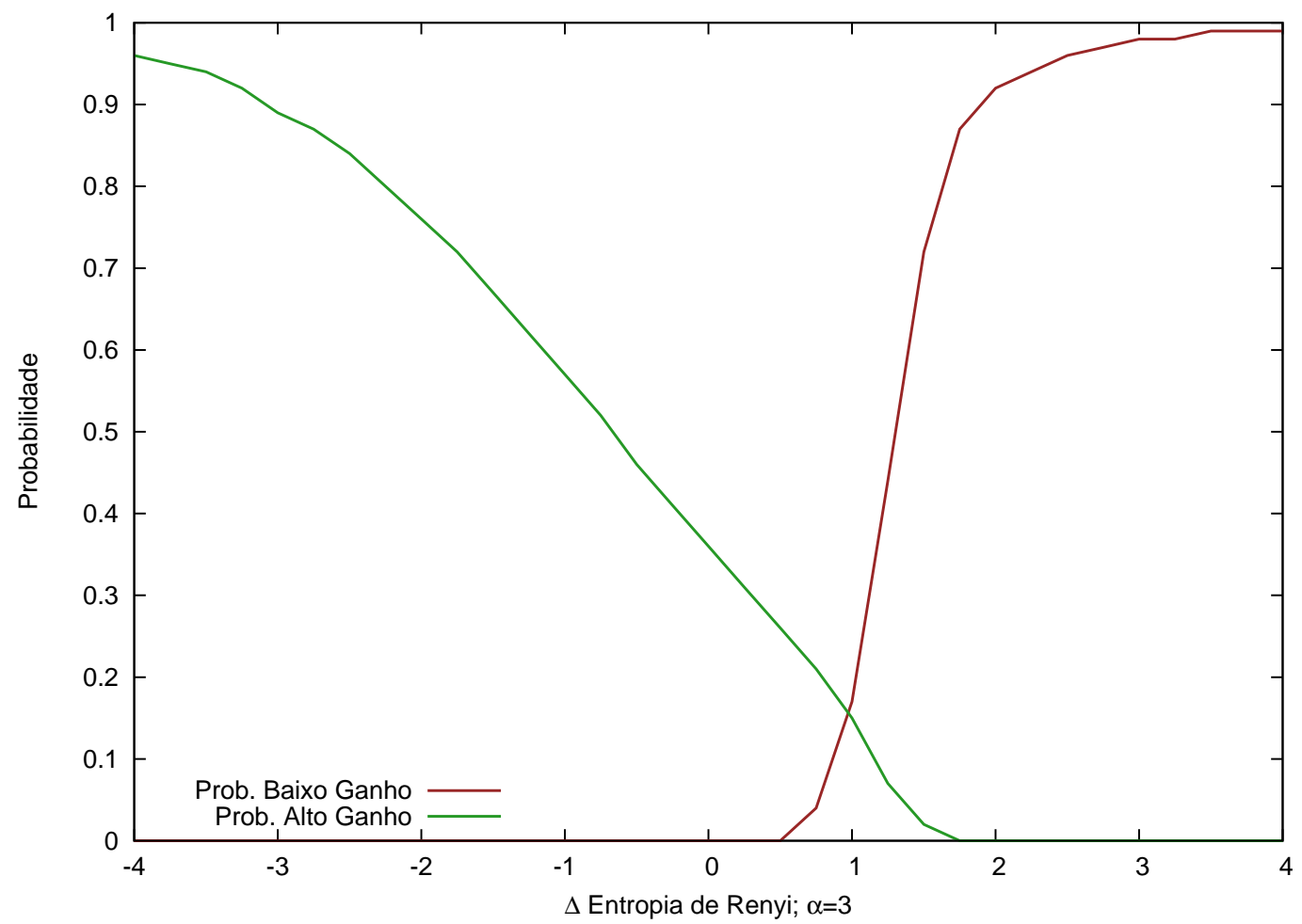

Figura 7.12: Probabilidade de execução em alto e baixo ganho em função da diferença de entropia de Renyi para $\alpha=3$.

A figura 7.12 mostra a probabilidade que um ponto seja executado em baixo ganho e sua probabilidade condicional combinada para alto ganho. A partir da média e desvio padrão de distribuição de probabilidade (alto e baixo ganho), calcula-se a distribuição 
normal gaussiana.

$$
p\left(x \mid w_{\text {alto/baixo }}\right)=\frac{1}{\sigma \sqrt{2 \pi}} \exp \left(-\frac{(x-\mu)^{2}}{2 \sigma^{2}}\right)
$$

e destas, obtém-se as funções de distribuição cumulativa (CDF):

$$
C D F_{(\text {alto } / \text { baixo })}=\int_{-\infty}^{x} p\left(x \mid w_{\text {alto } / \text { baixo }}\right)
$$

As probabilidades condicionais são obtidas por:

$$
P C_{\text {alto }}=C D F_{(\text {alto })} *\left(1-C D F_{(\text {baixo })}\right)
$$

e

$$
P C_{\text {baixo }}=C D F_{(\text {baixo })} *\left(1-C D F_{(\text {alto })}\right)
$$

A área acima de ambas curvas é a incerteza. Por exemplo, para um $\Delta D_{3}=-1.0$, a probabilidade do ponto ter sido executado com alto ganho é de aproximadamente $57 \%$; com baixo ganho é zero; restando $43 \%$ de incerteza.

Com a capacidade de obter valores de probabilidade para cada $\Delta D_{3}$, pode-se definir um novo critério passa/não-passa como limite entre alto e baixo ganhos. Para tal, a regra de decisão de Bayes para erro mínimo será utilizada (WEBB, 2002). Essa regra irá determinar o ponto ótimo para se separar um evento em duas classes (no caso, alto e baixo ganhos), levando em consideração as distribuições de probabilidade para cada classe. É um critério que minimiza os erros de classificação.

Considere-se duas classes $w_{\text {baixo }}$ e $w_{\text {alto }}$ nas quais os pontos de ensaio executados serão classificados. Ambas possuem probabilidades a priori iguais: $p\left(w_{\text {baixo }}\right)=0.5 \mathrm{e}$ $p\left(w_{\text {alto }}\right)=0.5$, o que significa que o piloto, ao executar a manobra, tem $50 \%$ de chance de executá-la conforme planejado (com alto ganho) e $50 \%$ de maneira fora do esperado (baixo ganho). Essa hipótese é razoável pois não se sabe a priori qual será o resultado.

Com a entropia relativa calculada $\left(x=\Delta D_{3}\right)$, a probabilidade a posteriori para cada classe é dada por $p\left(w_{\text {baixo }} \mid x\right)$ e $p\left(w_{\text {alto }} \mid x\right)$, que pode ser obtida usando-se o teorema 
de Bayes com as funções de densidade de probabilidade condicionais: (WEBB, 2002)

$$
p\left(w_{\text {baixo }} \mid x\right)=\frac{p\left(x \mid w_{\text {baixo }}\right) * p\left(w_{\text {baixo }}\right)}{p(x)}
$$

e

$$
p\left(w_{\text {alto }} \mid x\right)=\frac{p\left(x \mid w_{\text {alto }}\right) * p\left(w_{\text {alto }}\right)}{p(x)}
$$

As funções de densidade de probabilidade condicionais $p\left(x \mid w_{\text {baixo }}\right)$ e $p\left(x \mid w_{\text {alto }}\right)$ são as Gaussianas com média e desvio padrão já apresentados na tabela 7.7 e na figura 7.11.

A regra para decisão pode ser estabelecida então por: classificar o ponto de ensaio realizado com $x=\Delta D_{3}$ como $w_{\text {alto }}$ se

$$
p\left(x \mid w_{\text {alto }}\right) * p\left(w_{\text {alto }}\right)<p\left(x \mid w_{\text {baixo }}\right) * p\left(w_{\text {baixo }}\right)
$$

senão, classificar o ponto como $w_{\text {baixo }}$.

A regra pode também ser escrita de maneira mais compacta por:

$$
l_{r}(x)=\frac{p\left(x \mid w_{\text {alto }}\right)}{p\left(x \mid w_{\text {baixo }}\right)}<\frac{p\left(w_{\text {baixo }}\right)}{p\left(w_{\text {alto }}\right)}
$$

A equação (ou função) 7.8 é chamada de razão de probabilidade (likelihood ratio) e é apresentada graficamente na figura 7.13. Essa função resulta em 2 regiões desconexas para a classificação como alto ganho: para valores de $\Delta D_{3}$ menores que 0.66 , a regra classifica os pontos de ensaio realizados como alto ganho; para valores de $\Delta D_{3}$ maiores que 1.95, a função volta a classificar como alto ganho. No entanto, isso pode ser simplificado para apenas uma região, uma vez que valores decrescentes de $\Delta D_{3}$ produzem crescente similaridade entre a pilotagem humana e a simulação com a malha na derivada do erro. Esse é o conceito apresentado pela entropia relativa e uma aproximação da malha de derivada do erro sinaliza uma pilotagem de alto ganho (modelo de Hess). Um valor alto de $\Delta D_{3}$ (maior que 1.95) leva à conclusão que as distribuições de probabilidade da pilotagem humana estão cada vez mais longe das da malha de derivada do erro, o que sinaliza baixo ganho. A distorção deve-se, principalmente, ao fato da distribuição de probabilidade obtida para alto ganho ( $\mu=-0.68$ e $\sigma=1.86)$ ter um desvio padrão alto. É necessário executar mais pontos de ensaio para melhorar a confiabilidade das estatísticas e essa é uma recomendação para continuidade deste trabalho. 
O resultado prático da regra de decisão é um limite pass/não-passa igual a $\Delta D_{3}=0.66$ bits, que separa pontos de ensaio realizados com alto e baixo ganho.

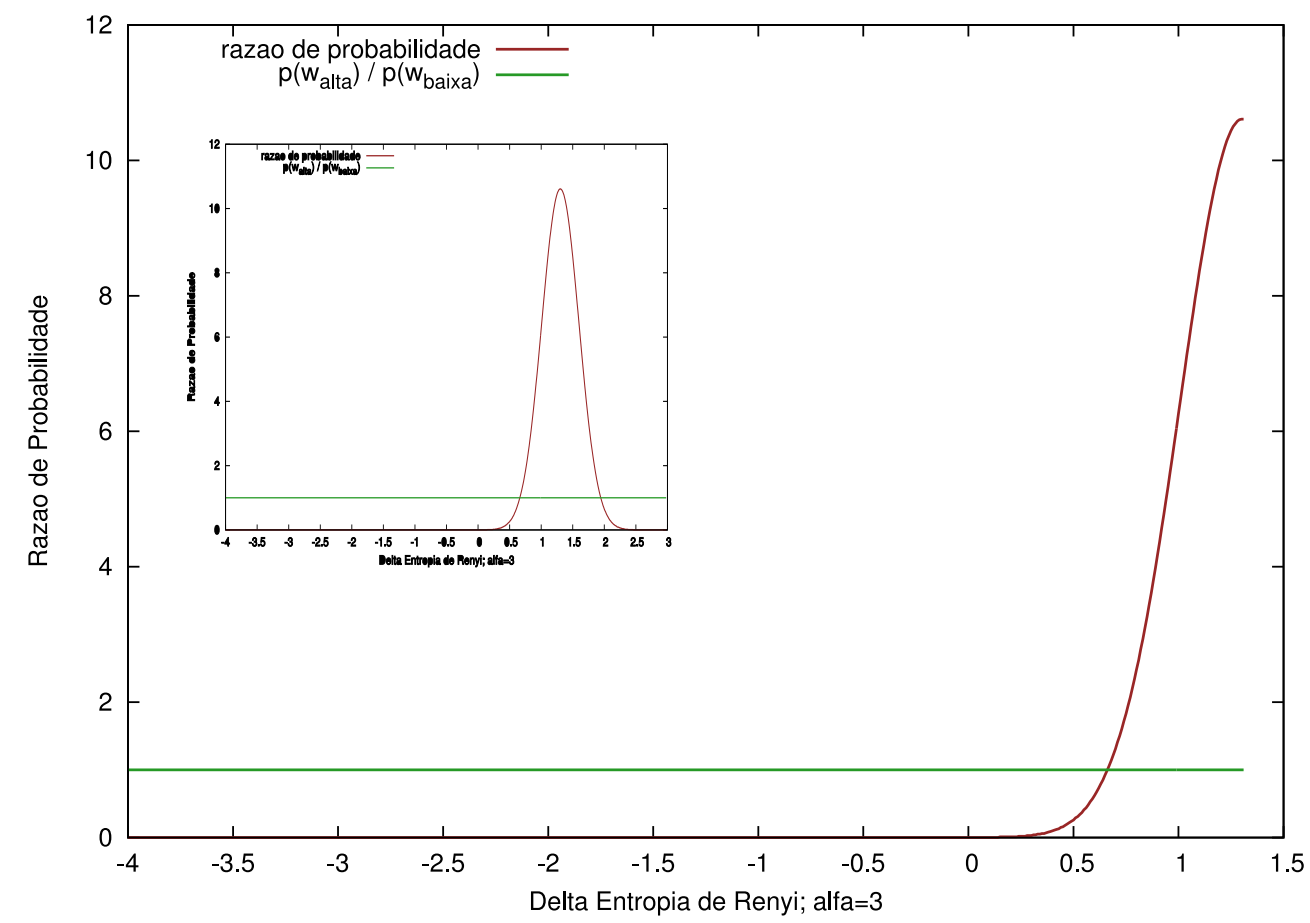

Figura 7.13: Função razãoçç de probabilidade (Likelihood ratio function) resultante da regra de decisão de Bayes. A figura menor, no canto esquerdo mostra duas regiões desconexas: valores entre $\Delta D_{3}<0.66$ e $\Delta D_{3}>1.95$ para classificação como alto ganho). A figura principal mostra uma regra de decisão simplificada, considerando apenas $\Delta D_{3}<0.66$ como critério para pontos executados com alto ganho. Tal simplificação é feita baseando-se no fato experimental observado de que quanto menor $\Delta D_{3}$, maior a probabilidade do ponto ter sido executado com alto ganho.

O erro, ou, a probabilidade de classificar um ponto de ensaio erroneamente, pode ser também obtido. Há 2 tipos de erro: o primeiro é a classificação de um ponto como alto ganho, quando na realidade ele foi executado como baixo ganho; vice-versa para o segundo. Os erros são obtidos por meio da integração parcial das densidades de probabilidade condicionais abaixo e acima do limite estabelecido pela regra $\left(\Delta D_{3}=\right.$ $0.66)$ - vide a figura 7.14, resultando em:

- Erro de classificar um ponto de baixo ganho como alto ganho $=\int_{0.66}^{+\infty} p\left(w_{\text {alto }} \mid x\right) d x$ $=23 \%$

- Erro de classificar um ponto de alto ganho como baixo ganho $=\int_{-\infty}^{0.66} p\left(w_{\text {baixo }} \mid x\right) d x$ $=1 \%$ 
A classificação errônea como baixo ganho é conservativa e forçará a rejeição de um ponto executado de maneira correta (com alto ganho). A classificação errônea como alto ganho classificará como válido um ponto de ensaio mal-executado.

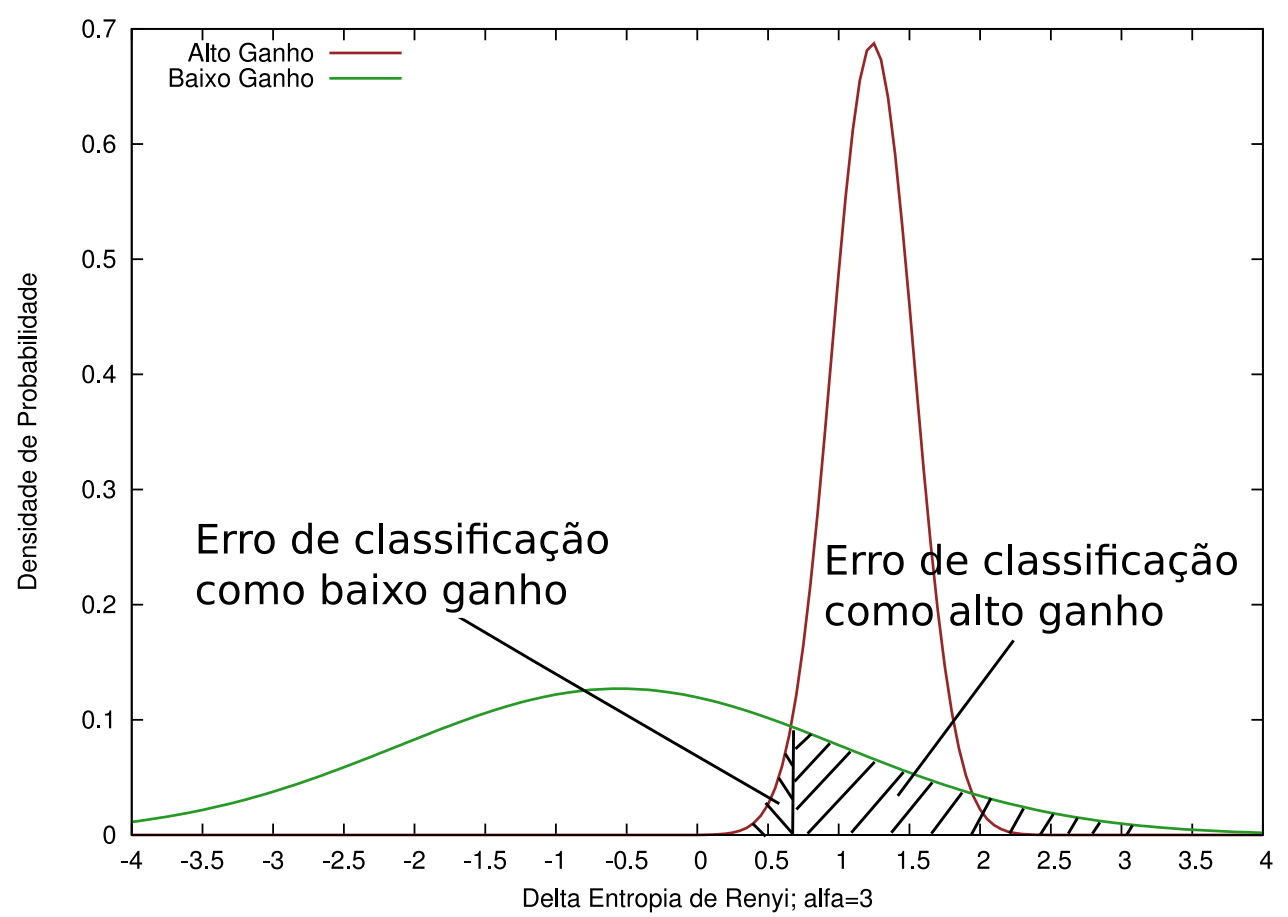

Figura 7.14: Erros de classificação. A área hachurada mais à esquerda representa a probabilidade da regra classificar como alto ganho um ponto que foi realizado como baixo ganho. A área hachurada mais à direita representa a probabilidade da regra classificar como baixo ganho um ponto que foi realizado como alto ganho.

\subsubsection{Avaliação do Critério - Utilizando a Análise Estatística}

Com a regra estabelecida na seção 7.2.2, prossegue-se para sua avaliação com a utilização do conjunto de dados anteriormente separado, os testemunhos, que não participaram da formação do critério.

Os dados da seqüência 1 do vôo 2 (listado na tabela 7.2 ) serão utilizados para ilustrar o método completo. Inicialmente, a aeronave foi excitada em malha aberta para obtenção de dados para serem utilizados na identificação de parâmetros. A figura 7.15 (já apresentada anteriormente na seção 7.1.2 e aqui recolocada para conveniência) mostra o modelo P2A identificado. 
Matching Modelo P2A

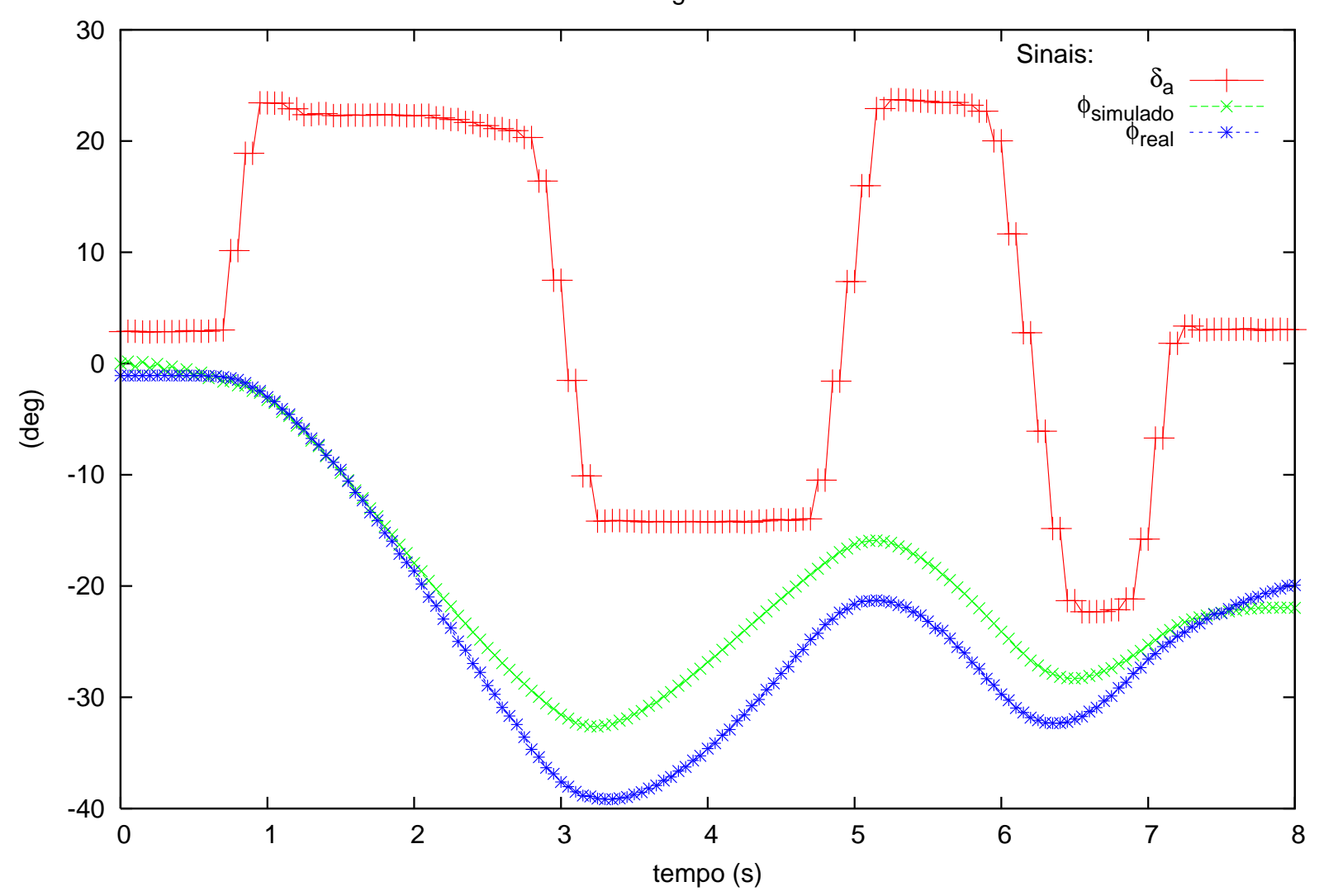

Figura 7.15: modelo utilizado na seqüência 1 do vôo 2 (ponto testemunho)- figura já apresentada anteriormente na seção 7.1.2 - reapresentada para conveniência apenas. 
A figura 7.16 mostra o bloco correspondente ao modelo identificado apontado com uma seta vermelha, dentro do diagrama de blocos do modelo de simulação completo:

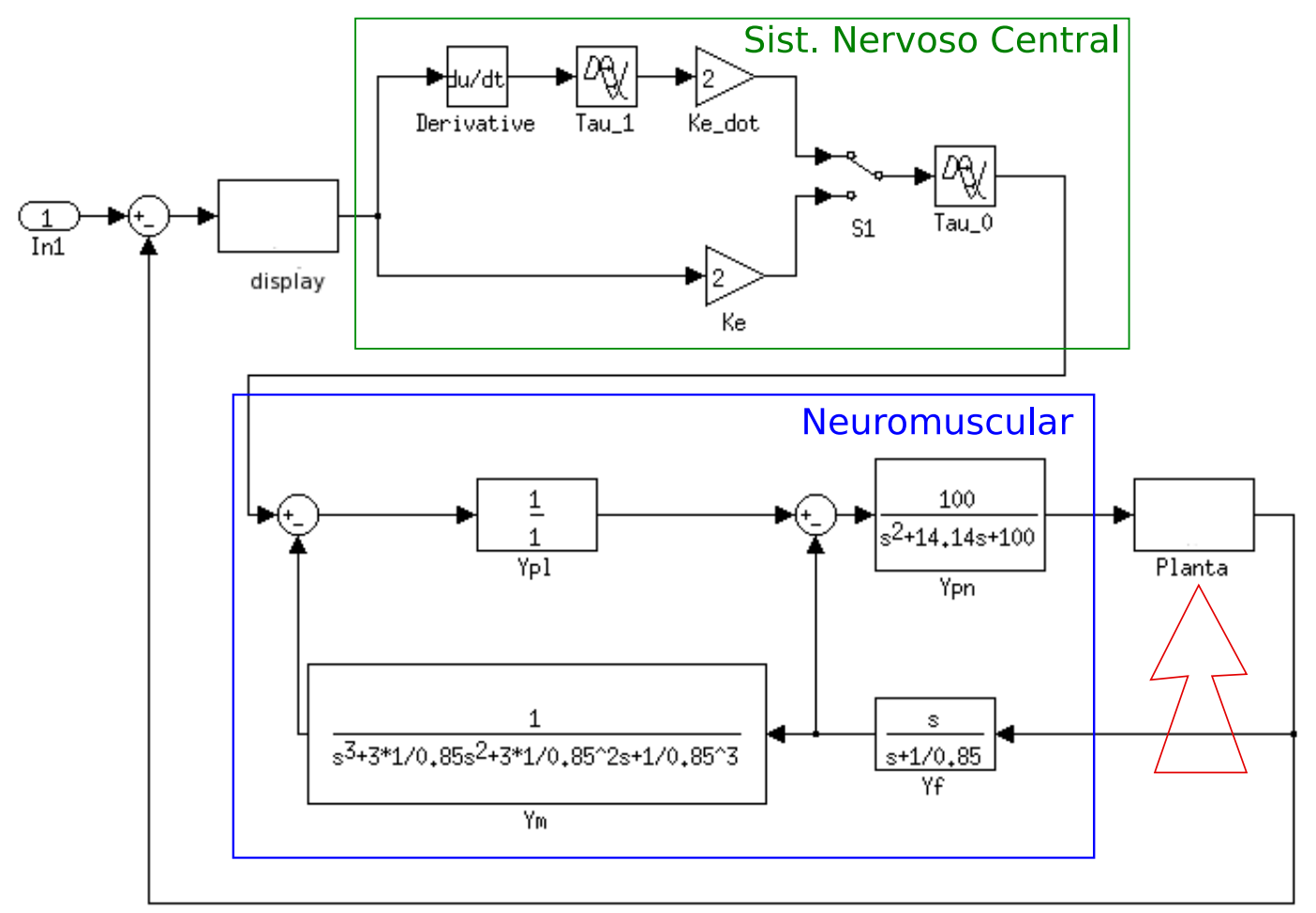

Figura 7.16: diagrama de blocos do modelo completo, ressaltando com uma seta vermelha o bloco da planta onde os dados do modelo identificado são inseridos

Os parâmetros utilizados dentro dos blocos do sistema nervoso central e do sistema neuromuscular apresentados na figura 7.16 são os já apresentados no capítulo 5 .

Utilizando a mesma configuração na aeronave (flape, posição do trem-de-pouso, peso e centro de gravidade), foi realizado o ponto de ensaio em vôo com a tarefa sintética, obtendo-se os resultados da figura 7.17.

Com o modelo da planta identificado (figura 7.15) e os dados obtidos do ensaio (figura 7.17), foram feitas as simulações em malha fechada (modelo da figura 7.16), obtendo-se os dados apresentados na figura 7.18.

Os dados no tempo apresentados na figura 7.18 foram condensados em histogramas, conforme descrito na seção 6.3, obtendo-se os resultados apresentados na figura 7.19.

Com os histogramas, obtém-se as entropias de Renyi:

A regra para classificação do ponto de ensaio como alto ou baixo ganho é: classificar 


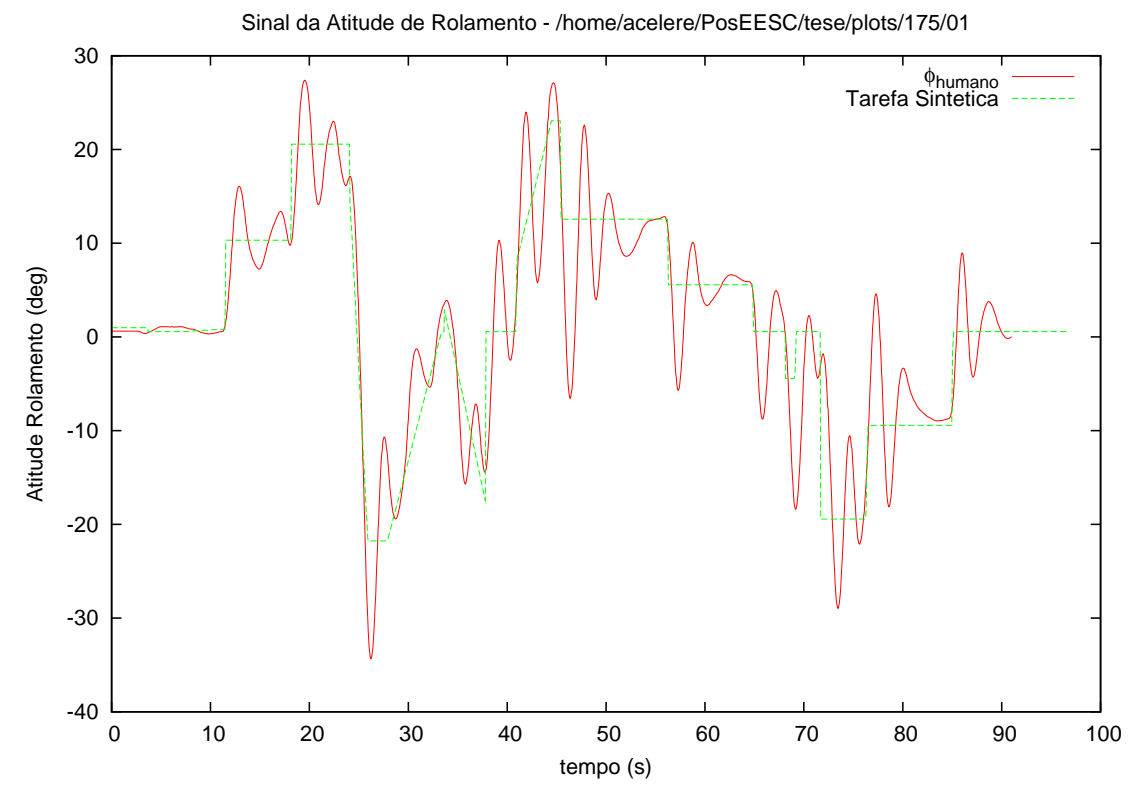

Figura 7.17: tarefa sintética e resultado apresentado pelo piloto humano - seqüência 1 do vôo 2 - ponto testemunho

Tabela 7.8: Entropias de Renyi para $\alpha=3$ e seqüência 1 do vôo 2 - ponto testemunho

\begin{tabular}{|c|c|c|}
\hline$D_{3}(21)$ & $D_{3}(31)$ & $\Delta D_{3}$ \\
\hline 3.22 & 1.14 & -2.08 \\
\hline
\end{tabular}

como alto ganho se $\Delta D_{3}<0.66$; portanto, o ponto é considerado como alto ganho pelo método. As anotações referentes ao ensaio confirmam se tratar de um ponto de alto ganho, portanto o método obteve êxito em classificar o ponto de ensaio corretamente.

Os erros de classificação são obtidos da figura 7.14:

- Erro de classificar um ponto de baixo ganho como alto ganho $0 \%$

- Erro de classificar um ponto de alto ganho como baixo ganho $0 \%$

Este processo foi aplicado para cada um dos pontos testemunhos e somente um ponto falhou à regra, resultando em:

- 80\% classificação correta como Alto Ganho

• 20\% classificação incorreta como Baixo Ganho 


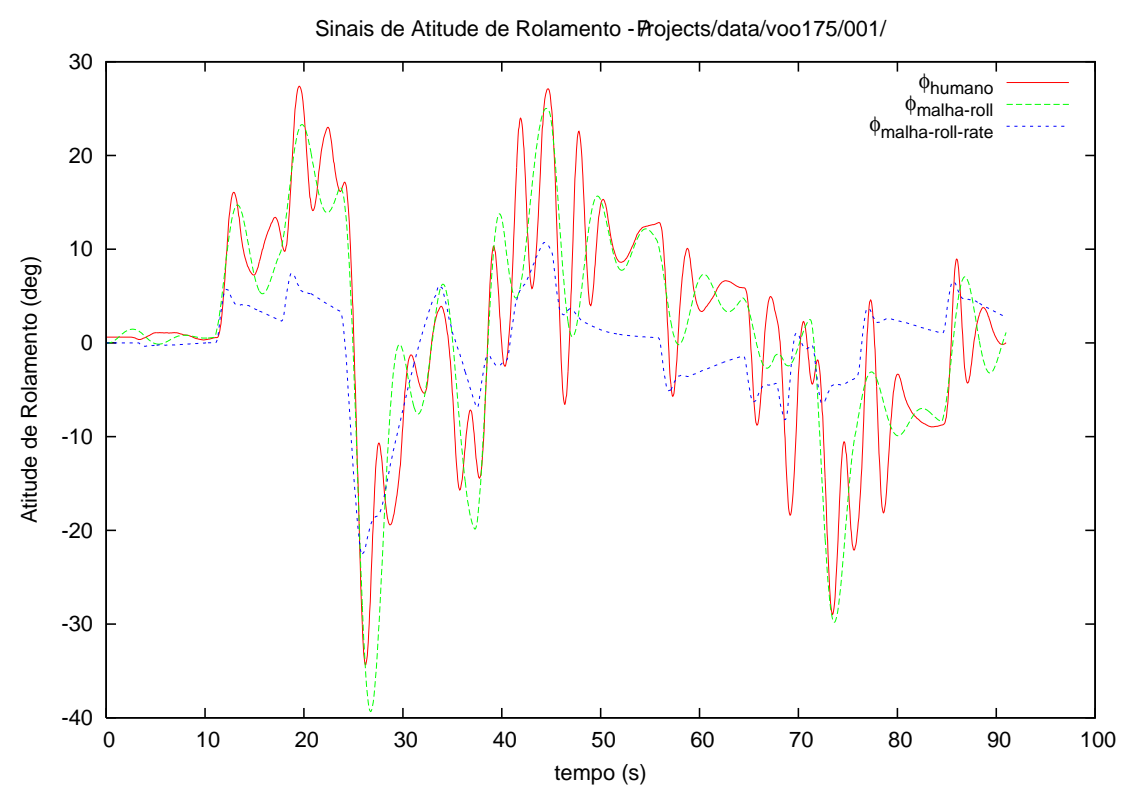

Figura 7.18: Resultados da seqüência 1 do vôo 2 (ponto testemunho). Em vermelho, está o traço no tempo da atitude da aeronave, quando pilotada pelo piloto humano, durante a execução do ponto de ensaio. Em verde, o resultado da simulação com a malha de erro. Em azul, o resultado da simulação com a malha na derivada do erro

Os valores numéricos para cada ponto de ensaio encontram-se na tabela 7.9, bem como o resultado da classificação, já utilizando a denominação passa/não-passa para o critério.

Tabela 7.9: Entropia dos pontos testemunhos para $\alpha=3$ Verificação do Critério

\begin{tabular}{clrrc}
\hline \hline Grupo & Ganho Real & Seq. $\#$ & $\begin{array}{c}\Delta D_{3} \\
{[\mathrm{bits}]}\end{array}$ & Criterio \\
\hline 2/Testemunho & Alto & 1 & -2.08 & passa \\
& & 2 & 0.85 & falha \\
& & 3 & 0.22 & passa \\
& 4 & 0.34 & passa \\
& & 5 & -1.24 & passa \\
\hline \hline
\end{tabular}

Todos os gráficos de resultados (traços no tempo e histogramas) podem ser vistos no anexo B. É importante notar que o modelo proposto por Hess não é absoluto, no sentido de que a estratégia empregada pelo piloto esteja $100 \%$ malha de controle derivativo para que haja uma pilotagem de alto ganho. Hess mostra que esse valor, na realidade, é bastante baixo (da ordem de $5 \%$ ), justificando assim que, apesar dos histogramas do modelo operando na malha derivativa estarem menos próximos dos histogramas com o piloto humano na malha, ainda assim eles indicam uma pilotagem de alto ganho. 


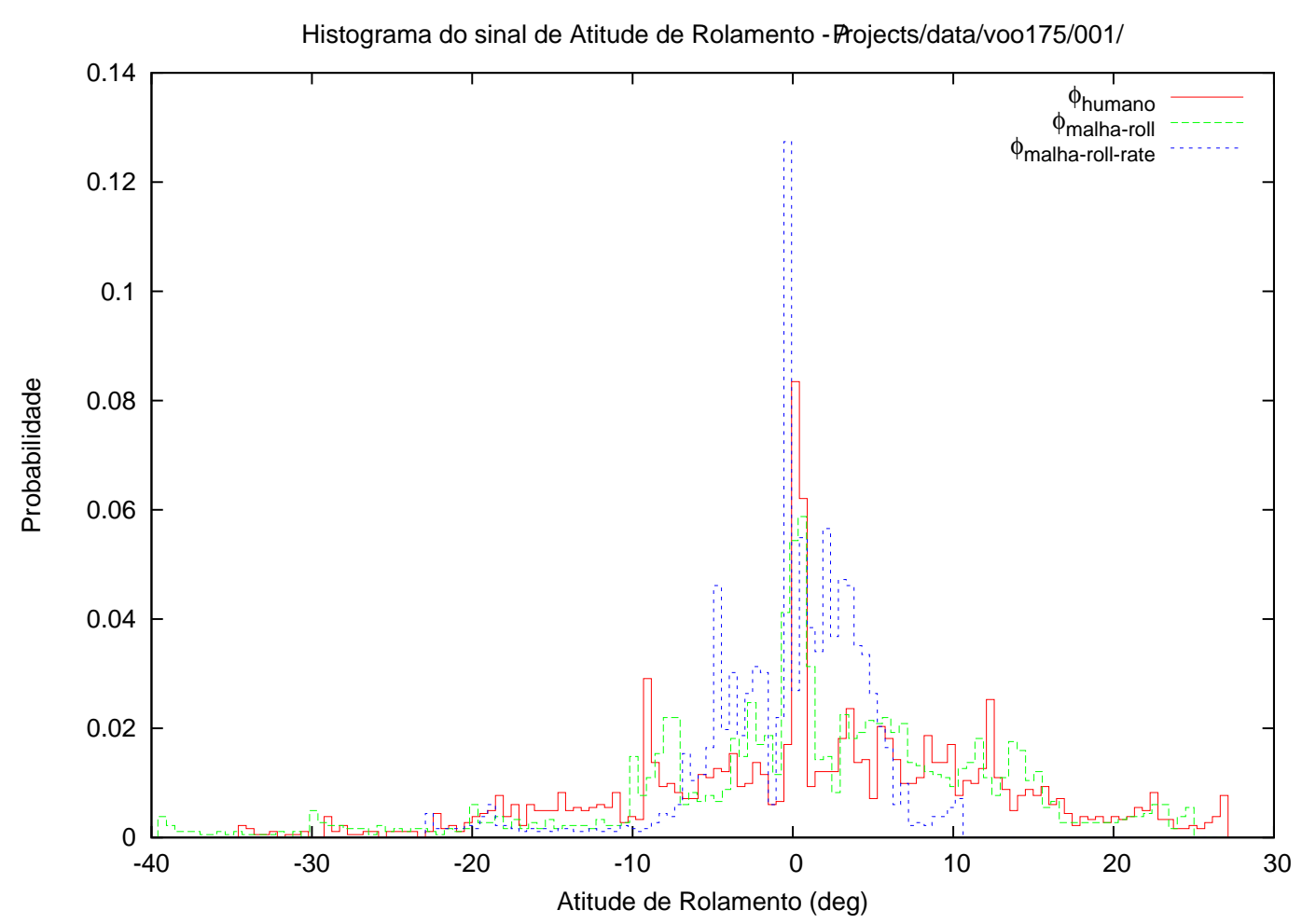

Figura 7.19: histogramas dos resultados das simulações em malha fechada da seqüência 1 do vôo 2 (ponto testemunho)

A boa prática de ensaios em vôo preconiza que os ensaios de qualidade de vôo (no qual o ensaio de PIO se enquadra) possui mesmo um resultado onde há variações de acordo com a avaliação subjetiva da tripulação de ensaio.

Há alguns cenários de influência nos resultados:

1. Tripulação realiza o ensaio conforme preconizado, não gerando influência nos resultados e o método apresenta desvio na detecção dos ganhos. Este cenário necessita de uma avaliação por método independente para ser verificado. Porém, não foi identificado um método alternativo durante a revisão da literatura, permanecendo esta verificação como sugestão para continuidade de pesquisa.

2. Tripulação erra na realização do ensaio, gerando resultados falsos. Esta é uma influência que foi minimizada com máximo esforço durante a realização dos ensaios deste trabalho, haja vista se tratar de uma hipótese fundamental. As mitigações incluíram treinamento, briefing completo antes do ensaio, briefing antes da realização de cada ponto de ensaio, entrevista com o piloto logo após a realização 
de cada ponto e finalmente vôos com duração curta para evitar cansaço. Não há como verificar essa hipótese.

3. Uma combinação de ambos

Os dados apresentados nas figuras 7.12 a 7.14 devem ser avaliados e utilizados levando em consideração essas variações devidas à subjetividade; não há um critério absoluto; para pontos de ensaio onde o método resulta em incerteza de classificação e a tripulação também não consegue classificar o ganho adequadamente, o ponto de ensaio deverá ser repetido.

Essa forma de pensar é perfeitamente aceitável dentro do ambiente de ensaios em vôo, e um método com $100 \%$ de acerto, especialmente para ensaios de qualidade de vôo, estão fora de cogitação. É, no entanto, relevante lembrar que a proposta do método é servir como um filtro para os pontos de ensaio realizados fora dos parâmetros de ganho do piloto, apresentando ganhos grandes para cada ponto identificado como insatisfatório. Pontos de ensaio que estejam em dúvida (conflito entre opinião da tripulação e resultado do método) devem ser repetidos, sendo que a opinião da tripulação ainda é o fiel da balança no aceite do ensaio realizado. 



\section{Capítulo 8}

\section{Conclusões e Recomendações para Pesquisas Futuras}

Neste capítulo, serão apresentadas as conclusões do método e também uma lista de possibilidades para que seja dada continuidade ao estudo e à sua utilização prática.

\subsection{Conclusões}

A partir dos resultados apresentados, pode-se concluir que o método proposto para identificar ensaios de PIO utilizando a técnica de tarefa sintética realizados com ganho inadequado é válido. O método apresentou boa correlação entre os pontos ensaiados e os resultados analíticos, com $80 \%$ de acerto para o conjunto de pontos dedicados à sua avaliação (pontos testemunhos). A variabilidade presente nos resultados é considerada aceitável para ensaios de qualidade de vôo, uma vez que a natureza subjetiva na avaliação dos resultados é uma constante neste tipo de ensaio. O método, porém, foi razoável em separar a execução correta do ensaio.

A formação do critério utilizou 10 pontos de ensaio. Para aumentar a confiabilidade do método e obter resultados mais estatisticamente significativos para as médias e desvios padrão mostrados na tabela 7.7, é sugerida a realização de mais ensaios.

Levando-se em consideração a simplicidade da regra final $\left(\Delta D_{3}<0.66\right)$ e as probabilidades de acerto e erro apresentadas na Figura 7.12, conclui-se que é possível fornecer 
ao engenheiro de ensaios uma ferramenta capaz de propiciar um indicativo razoável sobre a correta execução dos pontos. E, para sua utilização eficaz, é recomendado que a aplicação seja feita com critério, sendo que os pontos na área de interface das probabilidades, onde a incerteza de classificação é grande, sejam repetidos. Esse julgamento deverá levar em consideração o resultado do método e a opinião do piloto, conjuntamente.

Apesar dos dados terem utilizado apenas um tipo de aeronave, a execução do ensaio e a dinâmica das aeronaves da mesma categoria (aeronaves de transporte - FAR25) não variam. O método pode ser considerado válido para aplicação em qualquer aeronave da mesma categoria, com o mesmo valor de corte $\left(\Delta D_{3}<0.66\right)$ para classificação como alto ganho.

\subsection{Recomendações para Implementação}

O método proposto necessita de várias etapas, enumeradas a seguir:

1. Execução das manobras 3211 de identificação de parâmetros;

2. Identificação dos parâmetros através de rotina matemática;

3. Validação do modelo identificado;

4. Execução das Manobras de Tarefa Sintética (SYNTASK);

5. Execução do modelo com os Inputs realizados pelo piloto como entrada na malha de posição (error);

6. Execução do modelo com os Inputs realizados pelo piloto como entrada na malha de derivada da posição (error rate);

7. Cálculo das entropias

8. Verificação passa/não-passa pelo critério

A utilização desse método em ambiente de ensaio real irá requerer um alto grau de automatismo dessas etapas. Uma boa meta de tempo é: 
- 1 minuto para os identificar a planta e validá-la; ou utilizar um método recursivo para se obter o modelo da planta simultaneamente com a realização do ensaio;

- 1 minuto para rodar os modelos em ambas malhas;

- 10 segundos para o cálculo da entropia e apresentação no critério

Esse automatismo é necessário devido ao dinamismo do ambiente de ensaios, porém os tempos sugeridos são bastante viáveis, haja vista a experiência adquirida durante o desenvolvimento desta pesquisa.

\subsection{Recomendações para Pesquisas Futuras}

O método proposto necessita ser exposto a uma variedade maior de pilotos e aeronaves e, portanto, fica a recomendação para que os programas futuros se utilizem dessa técnica. Infelizmente, não é possível aplicar diretamente o método em dados passados, haja vista que a maioria dos ensaios não contém manobras de identificação de parâmetros para que a planta possa ser devidamente sintonizada. Uma outra saída seria desenvolver ferramentas de identificação da planta que não fossem dependentes de manobras específicas (como a 3211 utilizada) e que pudessem determinar o modelo da planta a partir de manobras comuns, como curvas e outras manobras operacionais que não sejam executadas em malha fechada pelo piloto. Essa opção abriria enormes possibilidades para a utilização do grande volume de pontos de ensaio já realizados. Essa pesquisa poderia utilizar a versão mais nova do software SYSID da EMBRAER.

Outra recomendação relevante é fazer uma comparação com resultados obtidos por meio do cálculo da freqüência de crossover (apresentado no capítulo 4.1.1). A idéia de Mitchell e Klyde * é que se verifique se os pontos de ensaio identificados como sendo executados com baixo ganho pelo método proposto apresentam também algum tipo de alteração na freqüência de crossover do piloto. Na visão deles, deverá haver uma alteração, levando a freqüência para um patamar inferior (menor bandwidth).

É necessário testar a hipótese levantada no capítulo 7.2.2 sobre a influência do desbalanceamento da tarefa sintética no resultado. Uma comparação direta entre tarefas

*apresentada como sugestão por David Mitchell e David Klyde durante exposição na conferência da AIAA em Hilton Head, SC (CELERE; VAROTO; MACIEL, 2007). 
balanceadas e desbalanceadas seria o suficiente.

A utilização de modelo black-box para a planta é, sem dúvida, uma limitação grande da implementação utilizada e a migração para a utilização de um software capaz desfazer a identificação das explícitas das derivadas de estabilidade seria bastante contribuinte para o avanço da utilização do método proposto. A obtenção das derivadas de estabilidade trazem robustez ao modelo, que pode ser utilizado com uma gama maior de condições (velocidades, altitudes, etc.).

Como alternativa ao uso da entropia estatística para comparar os sinais oriundos dos ensaios em vôo e aqueles produzidos pelas simulações, o cálculo da correlação poderia ser utilizado. Esta pesquisa poderá utilizar os mesmos dados já obtidos e produzir uma comparação. 


\section{Referências}

AGARD Working Group 23. Flight control design: best practices. França: Research and Technology Organization of North Atlantic Treaty Organization, 2000.

(RTO-NATO-TR-029).

A'HARRAH, R. Mitigating the apc threat - a work in progress. In: SHAFER, M.;

STEINMETZ, P. O. (Ed.). Pilot-induced oscillation research: status at the end of the century. Washington, D.C.: NASA, 2001. v. 1. (NASA/CP-2001-210389).

ANANTHKRISHNAN, N.; SHAH, P.; UNNIKRISHNAN, S. Approximate analytical criterion for aircraft wing rock onset. Journal of Guidance, Control and Dynamics, Washington, v. 27, n. 2, p. 304-307, 2004.

BABISTER, A. W. Aircraft flight control and response. Oxford: Pergamon, 1980.

BEKEY, G. A.; ANGLE, E. S. Assynchronous finite state models of manual control systems. In: Proceedings of the Second Annual NASA-University Conference on Manual Control. Cambridge, MA: National Aeronautics ans Space Administration, Washington, D.C., 1966. (NASA SP-128).

BUREAU OF AIR COMMERCE. CAR04: Civil airworthiness requirements. Washington, D.C.: [s.n.], 1936.

CALSPAN. Flight syllabus and sackground material for EMBRAER/CTA flight test training program. Buffalo, NY: [s.n.], 1998.

CALSPAN. Veridian engineering (CALSPAN) FAA/Industry PIO training workshop. Buffalo, NY: [s.n.], 1999.

CALSPAN. Calspan learjet inflight simulator handout sheet. Buffalo, NY: [s.n.], 2007. Disponível em <http://www.calspan.com/variable.htm>. Acesso em 18Sept.2008. 
CELERE, A.; FERNANDEZ, F. E. P.; OLIVEIRA, L. F. T. Erj 170 flight controls development. In: Proceedings of the AIAA Modeling and Simulation Technologies Conference. 2000, Denver: AIAA, Reston, 2000. (AIAA-2000-4578).

CELERE, A.; VAROTO, P. S.; MACIEL, M. Verifying pilot gain in pio flight test. In: Proceeding of the AIAA Atmospheric Flight Mechanics Conference and Exhibit. Hilton Head: AIAA, Reston, 2007. (AIAA-2007-6640).

CELERE, A. L. Relatório Interno de Resultado de Ensaios, Relatório do Engenheiro de Ensaio em Vôo ECJ-002-021\%. São José dos Campos, SP: [s.n.], 2002. São José dos Campos: EMBRAER - Relatório Interno de Resultado de Ensaios.

CENTRO TÉCNICO AEROESPACIAL. Ficha de controle de assuntos relevantes: Hde-018 - pilot induced oscillations airplane pilot coupling. São Jose dos Campos, SP: [s.n.], 2002. Documento emitido pelo instituto de fomento industrial.

CHASE, W. D. Piloted simulator display system evaluation: effective resolution and pilot performance in the landing approach. In: Proceedings of the Third Annual NASA-University Conference on Manual Control. Los Angeles, CA: NASA, Washington, D.C., 1967. (NASA SP-144).

CHIGNELL, M. H.; HANCOCK, P. A. Knowledge based load levelling and task allocation in human-machine systems. Washington, D.C., 1986. 9.1-9.11 p. (Contractor Report, CP-2428).

CIVIL AERONAUTICS BOARD. CAR3: Airplane airworthiness requirements normal, utility, acrobatic and restricted purpose categories. Washington, D.C.: [s.n.], 1949.

CLIFF, R. C. The effects of attention sharing in a dynamic dual-task environment. In: Proceedings of the Seventh Annual NASA-University Conference on Manual Control. Los Angeles, CA: NASA, Washington, D.C., 1972. (NASA SP-281).

COOPER, G.; HARPER, R. The use of pilot rating in the evaluation of aircraft handling qualities. Washington, D.C., 1969. (NASA Technical Note, TN D-5153).

CORD, T. Comparison from pio severity from flight and simulation. In: SHAFER, M.; STEINMETZ, P. O. (Ed.). Pilot-induced oscillation research: status at the end of the century. Washington, D.C.: NASA, 2001. v. 2. (NASA/CP-2001-210389). 
COVER, T. M. Elements of information theory. New York: John Wiley \& Sons, 1990.

DEPARTMENT OF DEFENSE INTERFACE STANDARD. Mil Standard, MIL1797A: Flying qualities of piloted airplpanes. Washington, D.C., 1990.

DEPARTMENT OF TRANSPORTATION. Federal Register, Special Conditions: Airbus model A380-800 airplane, design roll maneuver. 2006. 38513-38515 p. Disponível em: <http://frwebgate1.access.gpo.gov/cgibin $/$ waisgate.cgi? WAISdocID $=653085445339+14+2+0 \&$ WAISaction $=$ retrieve $>$. Acesso em: 5Mar.2006.

DEPARTMENT OF TRANSPORTATION. Federal Register, Special Conditions: Boeing model 787-8 airplane and interaction of systems and structures, electronic flight control system-control surface awareness, etc. 2007. 41428-41433 p. Disponível em: <http://frwebgate1.access.gpo.gov/cgibin $/$ waisgate.cgi? WAISdocID $=652387442379+1+2+0 \&$ WAISaction $=$ retrieve $>$. Acesso em: 5Mar.2006.

DEPARTMENT OF TRANSPORTATION. Federal Register, Special Conditions: Dassault Aviation model falcon 7x airplane and side stick controllers, electronic flight control system: Lateral-directional and longitudinal stability, etc. april 2007. 18365-18372 p. Disponível em: <http://frwebgate1.access.gpo.gov/cgibin $/$ waisgate.cgi? WAISdocID $=652387442379+3+2+0 \&$ WAISaction $=$ retrieve $>$. Acesso em: 5Mar.2006.

DEY, D. The influence of a prediction display on the quasi-linear describing function remnant measured with an adaptve analog-pilot in a closed loop. In: Proceedings of the Seventh Annual NASA-University Conference on Manual Control. Los Angeles, CA: NASA, Washington, D.C., 1972. (Special Publication). (NASA SP-281).

DUPPEN, M. et al. Effects of motion on pilot behavior in target, disturbance and combined tracking tasks. In: Proceedings of the AIAA Atmospheric Flight Mechanics Conference and Exhibit. Hilton Head: AIAA, Reston, 2007. (2007). (AIAA-2007-6894). EMPRESA BRASILEIRA DE AERONÁUTICA. ERJ190-100 airplane pilot coupling flight test proposal. São José dos Campos: [s.n.], 2005. (EMBRAER - 190FTP041). 
ETKIN, B.; REID, L. Dynamics of flight - stability and control. New York: John Wiley and Sons, 1996.

EUROPEAN AVIATION SAFETY AGENCY. Standard, CS-25 - Certification specification for large aeroplanes. Bruxelas, 2003.

FEDERAL AVIATION ADMINISTRATION. Code of Federal Regulantions, FAR-25: airworthiness standards: transport category airplanes. Washington, D.C., 1965.

FEDERAL AVIATION ADMINISTRATION. Code of Federal Regulations, Advisory Circular AC25-7A: Flight test guide for certification for transport category airplanes. Washington, D.C., 1999.

FEDERAL AVIATION ADMINISTRATION. A brief history of the federal aviation administration. Disponível em: <http://www.faa.gov/about/history/brief_history/>. Acesso em: 10Jan.2007. 2007a.

FEDERAL AVIATION ADMINISTRATION. Software and digital systems safety project. Disponível em: $<$ http://aar400.tc.faa.gov/Programs/FlightSafety/sdss/AudManContSys.htm>. Acesso em: 17May2007. 2007B.

FIELD, E. J. The application of a $C^{*}$ flight control law to large civil transport aircraft. Cranfield, Bedford, Inglaterra, 1993. 35 p. (College of Aeronautics Report, 9303).

FIELD, E. J. Flying qualities of transport aircraft. Tese (Doutorado) - College of Aeronautics, Cranfield University, Cranfield, 1995.

FREE SOFTWARE FOUNDATION. programa de computador, GNU Scientific Library. Boston: [s.n.], 2007. Disponível em: <http://directory.fsf.org/project/gsl/>. Acesso em: 10Dec.2007.

GAUTREY, J. E. Generic regional aircraft flying qualities for the approach and landing task. Cranfield, Bedford, Inglaterra, 1997. 112 p. (College of Aeronautics Report, 9701).

GAUTREY, J. E. Flying qualities and flight control system design for a fly-by-wire transport aircraft. Tese (Doutorado) - College of Aeronautics, Cranfield University, Cranfield, 1998. 
GIBSON, J. C. Looking for the simple pio model. In: . Flight vehicle integration panel workshop on pilot induced oscillations. Neuilley-Sur-Seine: NATO-AGARD, 1995. (AR, AGARD-AR-335), p. 5.1-5.11.

GIBSON, J. C. Development of a methodology for excellence in handling qualities design for fly by wire. Amsterdam: Delft University, 1999.

GRAY, R. M.; DAVISSON, L. D. An Introductin to statistical signal processing. Cambridge: Cambridge University Press, 2004.

HEFFLEY, R. Pilot models for discrete maneuvers. In: Proceedings of the AIAA XXth Guidance and Control Conference. San Diego, CA: AIAA, Reston, 1982. (AIAA Conference). (AIAA-1982-1519).

HESS, R. A. Dual-loop model of the human controller. Journal of Guidance, Control and Dynamics, Washington, D.C., v. 1, n. 4, p. 254-260, 1978.

HESS, R. A. A rationale for human operator pulsive control behavior. Journal of Guidance, Control and Dynamics, Washington, D.C., v. 2, n. 3, p. 221-227, 1979.

HESS, R. A. Structural model of the adaptive human pilot. Journal of Guidance, Control and Dynamics, Washington, D.C., v. 3, n. 5, p. 416-423, 1980.

HESS, R. A. Pursuit tracking and higher levels of skill development in the human pilot. IEEE Transactions on Systems, Man and Cybernetics, New York, v.SMC-11, n. 4, p. 262-273, 1981.

HESS, R. A. Theory for aircraft handling qualities based upon a structural pilot model. Journal of Guidance, Control and Dynamics, Washington, D.C., v. 12, n. 6, p. 792-797, 1989.

HESS, R. A. Unified theory for aircraft handling qualitities and adverse aircraft-pilot coupling. Journal of Guidance, Control and Dynamics, Washington, D.C., v. 20, n. 6, p. 1141-1148, 1997.

HESS, R. A. Human performance group chairman's factual report, An inquiry into whether a pilot-induced oscillation was a factor in the crash of american airlines flight 58\%. Washington, D.C.: [s.n.], 2003. 
HESS, R. A.; STOUT, P. W. NASA Contractor Report. Assessing aircraft susceptibility to nonlinear aircraft-pilot coupling/pilot-induced oscillations. Washington, D.C.: NASA, 1997. (NASA/CR-97-207296).

HESS, R. A.; SUNYOTO, I. Toward a unified theory for aircraft handling qualitities. Journal of Guidance, Control and Dynamics, Washington, D.C., v. 8, n. 3, p. 440-446, 1985.

HIERNAUX, A.; JEREZ, M.; CASALS, J. Fast estimation methods for time and series models in state-space form. [S.l.], 2005. Disponível em: $<$ http://ideas.repec.org/p/ucm/doicae/0504.html>. Acesso em: 10Dec.2006. Também disponível em: <http://www.ucm.es/BUCM/cee/icae/doc/0504.pdf>. Acesso em: 18Sept.2008.

HODGKINSON, J. History of low-order equivalent systems for aircraft flying qualities. Journal of Guidance, Control and Dynamics, Washington, D.C., v. 28, n. 4, p. 577-583, 2005.

HOH, R.; MITCHELL, D. Flying qualities of relaxed static stability aircraft. Hawthorne, CA, 1982. v. 1, n. (DOT/FAA/CT-82/130-I).

HOH, R. H.; MITCHELL, D. G.; HODGKINSON, J. Bandwidth - a criterion for highly augmented airplanes. In: AGARD. Criteria for handling qualities of military aircraft. Neuilley-Sur-Seine: NATO-AGARD, 1982. (CP, AGARD-CP-333), p. 9.1-9.11.

JAGACINSKI, R. J.; HAH, D. Progression-regression effects in tracking repeated patterns. Journal of Experimental Psychology: Human Perception and Performance, Washington, D.C., v. 14, n. 1, p. 77-88, 1988.

JEX, H. R.; ALLEN, R. W.; MAGDALENO, R. E. Effects of display format on pilot describing function and remnant. In: Proceedings of the Seventh Annual NASAUniversity Conference on Manual Control. Los Angeles, CA: NASA, Washington, D.C., 1972. (NASA SP-281).

JOHNSTON, D.; MCRUER, D. Investigation of interactions between limb-manipulator dynamics and effective vehicle roll control characteristics. Washington, D.C., 1986. 
KELLY, P. A.; KLAPP, S. T. The use of a battery of tracking tests in the quantitative evaluation of neurological function. In: Proceedings of the Twenty-first Annual NASA-University Conference on Manual Control. Moffett Field, CA: NASA, Washington, D.C., 1986. (NASA-CP-2428).

KLYDE, D.; MITCHELL, D. G.; LATTIMER, K. J. Development of the probe-anddrogue handling qualities demonstration maneuver. Journal of Guidance, Control and Dynamics, Washington, D.C., v. 22, n. 4, p. 528-531, 1999.

KLYDE, D. H.; MITCHELL, D. G. A pio case study - lessons learned through analysis. In: AIAA. Proceedings of the AIAA Atmosferic Flight Mechanic Conference and Exhibit. San Francisco: AIAA, Reston, 2005. (AIAA-2005-5813).

KULLBACK, S.; LEIBLER, R. A. On information and sufficiency. Annals of Mathematical Statistics, Ann Arbor, v. 22, p. 79-86, MAR 1951.

LEE, B. Pio flight test experience at boeing (puget sound): and the need for more research. In: SHAFER, M.; STEINMETZ, P. O. (Ed.). Pilot-induced oscillation research: status at the end of the century. Washington, D.C.: NASA, 2001. v. 1. (NASA/CP-2001-210389).

LJUNG, L. System identification theory for the user. 2nd. ed. Upper Saddle River: Prentice Hall, 1999.

LJUNG, L. System identification toolbox for use with Matlab. version 6. Natick, MA: The Mathworks, 2006.

MATHWORKS. Documentation: system identification toolbox: N4sid page. Disponível em: $<$ http://www.mathworks.com/access/helpdesk/http://www.mathworks.com/access /helpdesk/help/toolbox/ident/index.html?/access/helpdesk/help/toolbox /ident/ug/bq2fhgj.htmlhelp/toolbox/ident/index.html?/access /helpdesk/help/toolbox/ident/ug/bq2fhgj.html>. Acessado em: 05June2009. 2009.

MCRUER, D. Pilot-induced oscillations and human dynamic behavior. Washington, D.C.: NASA, 1995. (NASA-CR-4683). 
MCRUER, D.; KRENDEL, E. Mathematical models of human pilot behavior.

London: AGARD - Advisory Group for Aerospace Research and Development, 1974. (AGARDograph AG 188).

MCRUER, D.; MYERS, T. Flying qualities of relaxed static stability aircraft. Hawthorne, CA, 1982. v. 2, n. DOT/FAA/CT-82/130-II.

MCRUER, D.; MYERS, T. Advanced piloted aircraft flight control system design methodology: knowledge base. Washington, D.C.: NASA, 1988. (NASA-CR-181726). MCRUER, D. T.; GRAHAM, D. Pilot-vehicle control systems analysis. Guidance and Control, Reston, v. 2, n. 3, p. $603-621$, June 1964.

MCRUER, D. T.; JEX, H. R. A review of quasi-linear pilot models. IEEE Transactions on Human Factors in Electronics, New York, v.HFE-8, n. 3, p. 231-249, 1967.

MITCHELL, D. Criteria for simulation to flight test - and vice-versa. In: SHAFER, M.; STEINMETZ, P. O. (Ed.). Pilot-induced oscillation research: status at the end of the century. Washington, D.C.: NASA, 2001. v. 3. (NASA/CP-2001-210389).

MITCHELL, D.; KLYDE, D. The need for pio demonstration maneuvers. In: SHAFER, M.; STEINMETZ, P. O. (Ed.). Pilot-induced oscillation research: status at the end of the century. Washington, D.C.: NASA, 2001. v. 2. (NASA/CP-2001-210389).

MITCHELL, D. G. et al. Evolution, revolution, and challenges of handling qualities. Journal of Guidance, Control and Dynamics, Washinton, D.C., v. 27, n. 1, p. 12-28, 2004.

MITCHELL, D. G.; KLYDE, D. H. Recommended practices for exposing pilot-induced oscillations or tendencies in the development process. In: AIAA. Proceedings of the AIAA USAF Developmental Test and Evaluation Summit. Woodland Hills: AIAA, Reston, 2004. (AIAA-2004-6810).

MITCHELL, D. G.; KLYDE, D. H. Testing for pilot-induced oscillations. In: AIAA. Proceedings of the AIAA Atmospheric Flight Mechanics Conference and Exhibit. San Franscisco, CA: AIAA, Reston, 2005. (AIAA-2005-5811).

MITCHELL, D. G.; KLYDE, D. H. Identifying a pio - new techniques applied to an old problem. Journal of Guidance, Control and Dynamics, Washinton, D.C., v. 31, n. 1 , p. $215-224,2008$. 
MORELLI, E. A.; WARD, D. G. Automated simulation updates based on flight data. In: AIAA. Proceedings of the AIAA Atmospheric Flight Mechanics Conference and Exhibit. Hilton Head: AIAA, Reston, 2007. (AIAA-2007-6714).

NATIONAL RESEARCH COUNCIL. Aviation safety and pilot control: understanding and preventing unfavorable pilot-vehicle interactions. Washington, D.C.: National Academies Press, 1997. Committee on the Effects of Aircraft-Pilot Coupling on Flight Safety.

NATIONAL TRANSPORTATION SAFETY BOARD. Accident Report, Inadvertent in-flight slat deployment China Eastern Airlines flight 583. Washington, D.C., 1993. (Accident Report pb93-910408).

NEAL, T. P.; ROGERS, E. S. An In-Flight Investigation to Develop Control System Design Criteria for Fighter Airplanes. [S.l.: s.n.], 1970. (Technical Report AFFDL-TR-70-74).

PAPOULIS, A. Probability, random variables and stochastic processes. 3rd. ed. Boston: McGraw Hill, 1991.

PARRAG, M. Use of in-flight simulators for pio susceptibility testing and flight test training. In: SHAFER, M.; STEINMETZ, P. O. (Ed.). Pilot-induced oscillation research: status at the end of the century. Washington, D.C.: NASA, 2001. v. 2. (NASA/CP-2001-210389).

PEDREIRO, N. Aplicação de um modelo matemático do piloto humano na estimativa da qualidade de vôo. 64 p. Dissertação (Mestrado) - Instituto Tecnológico de Aeronáutica, São José dos Campos, SP, 1989.

PONCELET, P.; ALONSO, F. Flight testing for apc: current practices at airbus. In: SHAFER, M.; STEINMETZ, P. O. (Ed.). Pilot-induced oscillation research: status at the end of the century. Washington, D.C.: NASA, 2001. v. 2. (NASA/CP-2001-210389).

POWERS, B. G. Space shuttle pilot-induced-oscillation research testing. Washington, D.C., 1984. (NASA Technical Memorandum, 86034).

PREYSS, A. E.; MEIRY, J. L. Stochastic modeling of human learning behavior. In: Proceedings of the Third Annual NASA-University Conference on Manual Control. Los Angeles, CA: NASA, Washington, D.C., 1967. (NASA SP-144). 
RENYI, A. On measurements of information and entropy. In: Proceedings of the 4 th Berkeley Symposium on Mathematics, Statistics and Probability. Berkley: University of Berkley, 1961. p. 547-561.

REPA, B. S.; ALBERS, J. W.; POTVIN, A. R. The use of a battery of tracking tests in the quantitative evaluation of neurological function. In: Proceedings of the Seventh Annual NASA-University Conference on Manual Control. Los Angeles, CA: NASA, Washington, D.C., 1972. (NASA SP-281).

ROBBINS, A. Pilot variability during pilot-induced oscillation. Dissertação (Mestrado) — Virginia Polytechnic, Blacksburg, 1999.

SHAFER, M.; STEINMETZ, P. O. Pilot-induced oscillation research: status at the end of the century. Washington, D.C., 2001. (NASA Conference Publication). (NASA/CP-2001-210389).

SHANNON, C. E. A mathematical theory of communication. Bell System Technical Journal, New York, v. 27, p. 379-423, 1948.

SMITH, J. Analysis of a longitudinal pilot-induced oscillation experienced on the approach and landing test of the space shuttle. Washington, D.C., 1981. (Technical Memorandum, 81366).

SMITH, R. H. The smith-geddes criteria. In: Proceedings of the SAE Aerospace Control and Guidance Systems Committee Meeting. Reno, NV: SAE, New York, 1993.

SMITH, R. H. Observations on pio. In: Flight vehicle integration panel workshop on pilot induced oscillations. Neuilley-Sur-Seine: NATO-AGARD, 1995. p. 3.1-3.11. (AGARD-AR-335).

SWALLWOOD, R. D. Internal models and the human instrument monitor. IEEE Transactions on Human Factors in Electronics, New York, v.HFE-8, n. 3, p. 181-187, 1967.

THIEL, G. Faa`s history with apc. In: SHAFER, M.; STEINMETZ, P. O. (Ed.). Pilot-induced oscillation research: status at the end of the century. Washington, D.C.: NASA, 2001. v. 1. (NASA/CP-2001-210389). 
TOBIE, H.; ELLIOT, E.; MALCOLM, L. A new longitudinal handling qualities criterion. In: Proceeding of the National Aerospace Electronics Conference. Dayton, OH: [s.n.], 1966.

TODOSIEV, E. P. Human performance in a cross-coupled tracking system. IEEE Transactions on Human Factors in Electronics, New York, v.HFE-8, n. 3, p. 210-217, 1967.

UNITED STATES ARMY AIR CORPS. website. 1920 regulations for operation of aircraft: something about everything military. [S.l.: s.n.], 1920. Disponível em: $<$ http://www.jcs-group.com/military/armyac.html>. Acesso em: 24July2008.

US NAVY. Navy tps resources home page. Disponível em: $<$ http://flighttest.navair.navy.mil/resources.cfm>. Acesso em: 19Apr.2007. 2007.

VAN DEN BERG, P. et al. Conducting multi-modal pilot model identification - results of a simulator experiment. In: Proceedings of the AIAA Atmospheric Flight Mechanics Conference and Exhibit : (2007: Hilton Head, South Carolina);: Hilton Head: AIAA, Reston, 2007. (2007). (AIAA-2007-6892).

VAN DER VORST, J. A pilot model for helicopter maneuvers. Amsterdam, 2001. (Relatório baseado em apresentação no 24th European Rotorcraft Forum, NLR-TP-98448).

WEBB, A. Statistical pattern recognition. Hoboken: John Wiley and Sons, 2002.

WEINGARTEN, N. C. History of in-flight simulation \& flying qualities research at calspan. Journal of Aircraft, New York, v. 42, n. 2, p. 290 - doi: 10.2514/1.4663, 2005.

WELTZ, G.; SHWEYK, K. M.; MURRAY, D. M. Application of new and standard pilot-induced oscillation (pio) analysis methods to flight test data of the c-17 transport aircraft. In: Proceedings of the AIAA Atmospheric Flight Mechanics Conference and Exhibit. Hilton Head: AIAA, Reston, 2007. (2007). (AIAA-2007-6387).

WIERWILlE, W.; CAGN, G.; KNIGHT, J. R. An experimental study of human operator models and closed-loop analysis method for high-speed automobile driving. IEEE Transactions on Human Factors in Electronics, New York, v.HFE-8, n. 3, p. 187-201, 1967. 
ZAYCHIK, K. B.; CARDULLO, F. M. Genetic algorithm based approach for parameters estimation of the hess operator model. In: Proceedings of the AIAA Atmospheric Flight Mechanics Conference and Exhibit. Hilton Head: AIAA, Reston, 2007. (AIAA-2007-6893).

ZAYCHIK, K. B.; CARDULLO, F. M.; GEORGE, G. A conspectus on operator modeling: Past, present and future. In: Proceedings of the AIAA Atmospheric Flight Mechanics Conference and Exhibit. Keystone: AIAA, Reston, 2006. (AIAA-2006-6625). 


\section{Apêndice $A$}

\section{Excertos FAR-25 e AC-25-7A}

\section{A.1 FAR 25}

$\S 25.143$ - General. CONTROLLABILITY AND MANEUVERABILITY

(a) The airplane must be safely controllable and maneuverable during: (1) Takeoff; (2) Climb; (3) Level flight; (4) Descent; and (5) Landing.

(b) It must be possible of making a smooth transition from one flight condition to any other flight condition without exceptional piloting skill, alertness, or strength, and without danger of exceeding the airplane limit-load factor under any probable operating conditions, including cluindo [... ] $[\ldots]$

\section{A.2 AC 25-7A}

Segue excertos da AC:

$\S 25.143$ - Geral. CONTROLABILIDADE E MANOBRABILIDADE

(a) A aeronave deverá ser controlável e manobrável, de maneira segura, durante: (1) Decolagem; (2) Subida; (3) Vôo nivelado; (4) Descida; e (5) Pouso.

(b) Deverá ser possível fazer a transição de uma para qualquer outra condição de vôo, sem habilidades excepcionais, força excessiva ou alerta excessivo do piloto e sem exceder os limites de carga sob quaisquer condições operacionais prováveis, in- 
(1) Explanation. (i) Sections 25.143(a) and (b) require that the airplane be safely controllable and maneuverable without exceptional piloting skill and without danger of exceeding the airplane limiting load factor under any probable operating conditions. Service history events have indicated that modern transport category airplanes can be susceptible to airplane-pilot coupling under certain operating conditions and would not meet the intent of this requirement.

(ii) The classic airplane-pilot coupling (APC) situation, commonly referred to as pilot-induced oscillations (PIO), is considered to occur when some airplane's response metric is approximately 180 degrees out of phase with the pilot's control input $\cdots$

(iv) This service experience has shown that compliance with only the quantitative, open-loop (pilot-out-of-the loop) requirements does not guarantee that the required levels of flying qualities are achieved. Therefore, in order to ensure that the airplane has achieved the flying qualities required by $\S \S 25.143(\mathrm{a})$ and (b), the airplane must be evaluated by test pilots conducting high-gain (wide-bandwidth), closed-loop tasks to determine that the potential of encountering adverse A-PC tendencies is minimal.
(1) Explanação. (i) As seções 25.143(a) e (b) requerem que a aeronave seja controlável e manobrável de maneira segura sem habilidades excepcionais de pilotagem e sem o perigo de exceder o fator de carga sob qualquer condição operacional provável. A história de eventos em serviço indica que aeronaves de transporte modernas podem ser susceptíveis a acoplamento aeronave piloto (A-PC ou PIO) sob certas condições operacionais e não atenderiam às intenções do requisito.

(ii) A situação clássica de acoplamento aeronave piloto (A-PC), comummente referida como oscilações induzidas pelo piloto (PIO), é considerada como ocorrendo quando alguma medida da resposta da aeronave está aproximadamente a 180 graus fora de fase com o sinal de controle do piloto $[\ldots]$

(iv) Esta experiência em serviço mostrou que o cumprimento somente com os requisitos quantitativos, em malha aberta (piloto fora do loop) não garante que os níveis de qualidade de vôo sejam atinjidos. Portanto, para garantir que a aeronave tenha atinjido os requisitos de qualidade de vôo dos $\S \S 25.143(\mathrm{a})$ e (b), a aeronave necessita ser avaliada por pilotos de ensaio conduzindo tarefas de alto ganho (banda larga) e malha-fechada para determinar que o potencial para encontrar tendências adversas de A-PC são mínimas. 
(v) For the most part, these tasks must be performed in actual flight ...

(2) Special Considerations. ...

(iv) The certification flight test program should be tailored to the specific airplane design and to evaluate the airplane in conditions that were found to be critical during its development program and A-PC analytical assessment. ...

(vi) Since the evaluation of flying qualities under $\S 25.143(\mathrm{a})$ and (b) is basically qualitative, especially evaluations of A-PC susceptibility, the high-gain tasks discussed herein should be accomplished by at least three test pilots...

(3) Procedures (Flight Test)

(i) Evaluation of the actual task performance achieved... is not recommended ... The tasks are used only to increase the pilot's gain, which is a prerequisite for exposing A-PC tendencies...

(ii) Tasks for a specific certification project should be based on operational situations, flight testing maneuvers, or service difficulties that have produced A-PC events... (iii) ...capture tasks and fine tracking tasks share many common characteristics but serve to highlight different aspects of any A-PC problem areas that may exist ... (v) Para a maior parte, estas tarefas deverão ser executadas em vôo [...]

(2) Considerações Especiais. [...]

(iv) O programa de ensaios em vôo de certificação deverá ser desenhado para o projeto de tipo específico e para avaliar a aeronave em condições que tenham sido consideradas críticas durante os ensaios de desenvolvimento e avaliação analítica de A-PC. $[\ldots]$

(vi) Como a avaliação das qualidades de vôo descrita nos $\S \S 25.143(a)$ e (b) é basicamente qualitativa, especialmente avaliações de susceptibilidade a A-PC, as tarefas de alto ganho discutidas aqui deviam ser realizadas por, pelo menos, três pilotos de ensaio. $[\ldots]$

(3) Procedimentos (Ensaios de Vôo) (i) A avaliação do desempenho alcançado para efetuar a tarefa [...] não é recomendado [...] As tarefas são usadas para aumentar o ganho do piloto, que é um pré-requisito para expor as tendências a A-PC [...] (ii) Tarefas para um projeto de certificação específico deverão ser baseadas em situações operacionais, manobras de ensaios, ou dificuldades em serviços que tenham produzido eventos de A-PC [...] (iii) [...] tarefas de captura e tarefas finas têm algumas características em comum mas servem para evidenciar aspectos diferentes de quaisquer áreas problemáticas de A-PC que possam existir $[\ldots]$ 
(4) Capture Tasks. ...

(5) Fine Tracking Tasks. ...

The pitch and roll commands should be combinations of steps and ramps. ... The sequence should be long enough and complex enough that the pilot cannot learn to anticipate the commands. The unfamiliarity is intended to help keep the test pilot's gain high and to preclude inadvertent pilot compensation while accomplishing the task. Such compensation, along with reduced gains, could mask any A-PC tendencies ...
(4) Tarefas de Captura. [...]

(5) Tarefa Finas. [...]

Os comandos de rolamento e arfagem devem ser combinações de degraus e rampas [... A A seqüência longa e complexa o suficiente para o piloto não aprender e antecipar os comandos. Esta não-familiaridade tem a intensão de ajudar a manter o ganho do piloto de ensaios alto e afastar o risco de compensação inadvertente pelo piloto durante a execuçaõ da tarefa. Tal compensação, junto com uma atuação com ganho reduzido, pode mascarar tendencias a A$\mathrm{PC}[\ldots]$ 
Apêndice $B$

Gráficos dos Resultados 
Os dados apresentados neste anexo foram gentilmente cedidos para publicação pela EMBRAER. Os dados referentes às tarefas enviadas para o piloto foram, no entanto, retidas por motivos de sigilo industrial. 


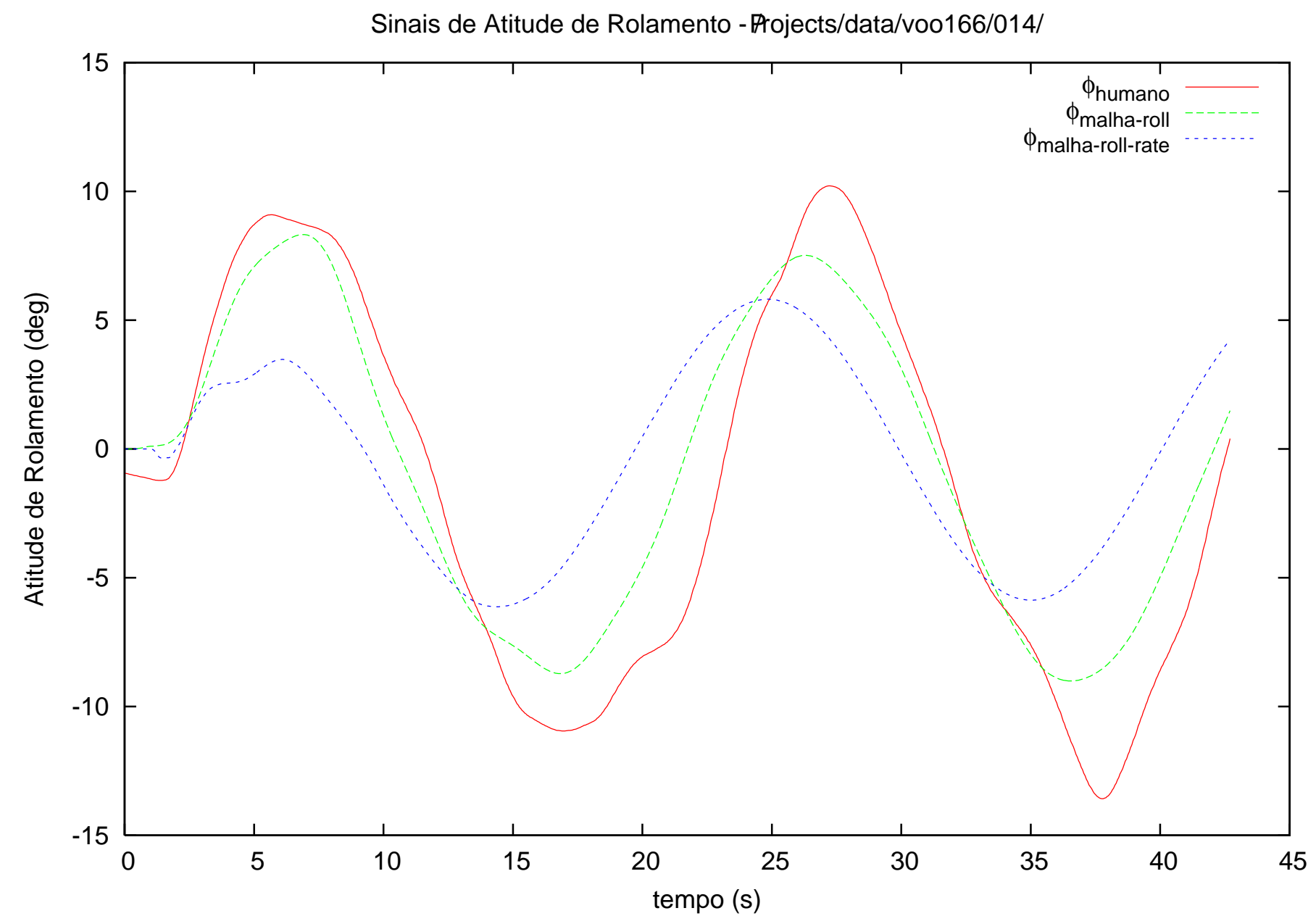

Figura B.1: Vôo 1 - Seqüência \#14 - Configuração P1A - dados do ensaio e das simulações 


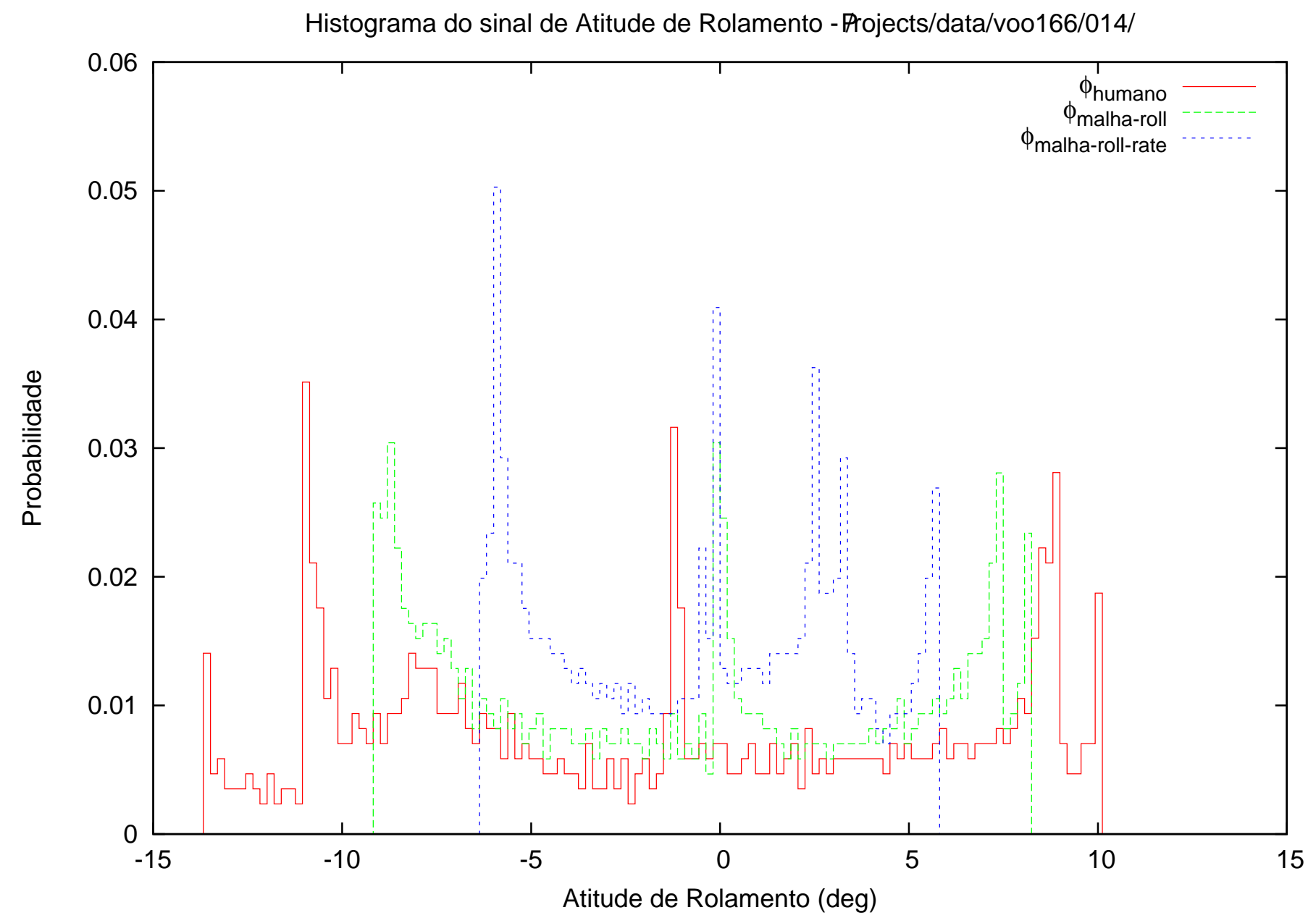

Figura B.2: Vôo 1 - Seqüência \#14 - Configuração P1A - histogramas dos dados 
Sinais de Atitude de Rolamento - Projects/data/voo166/015/

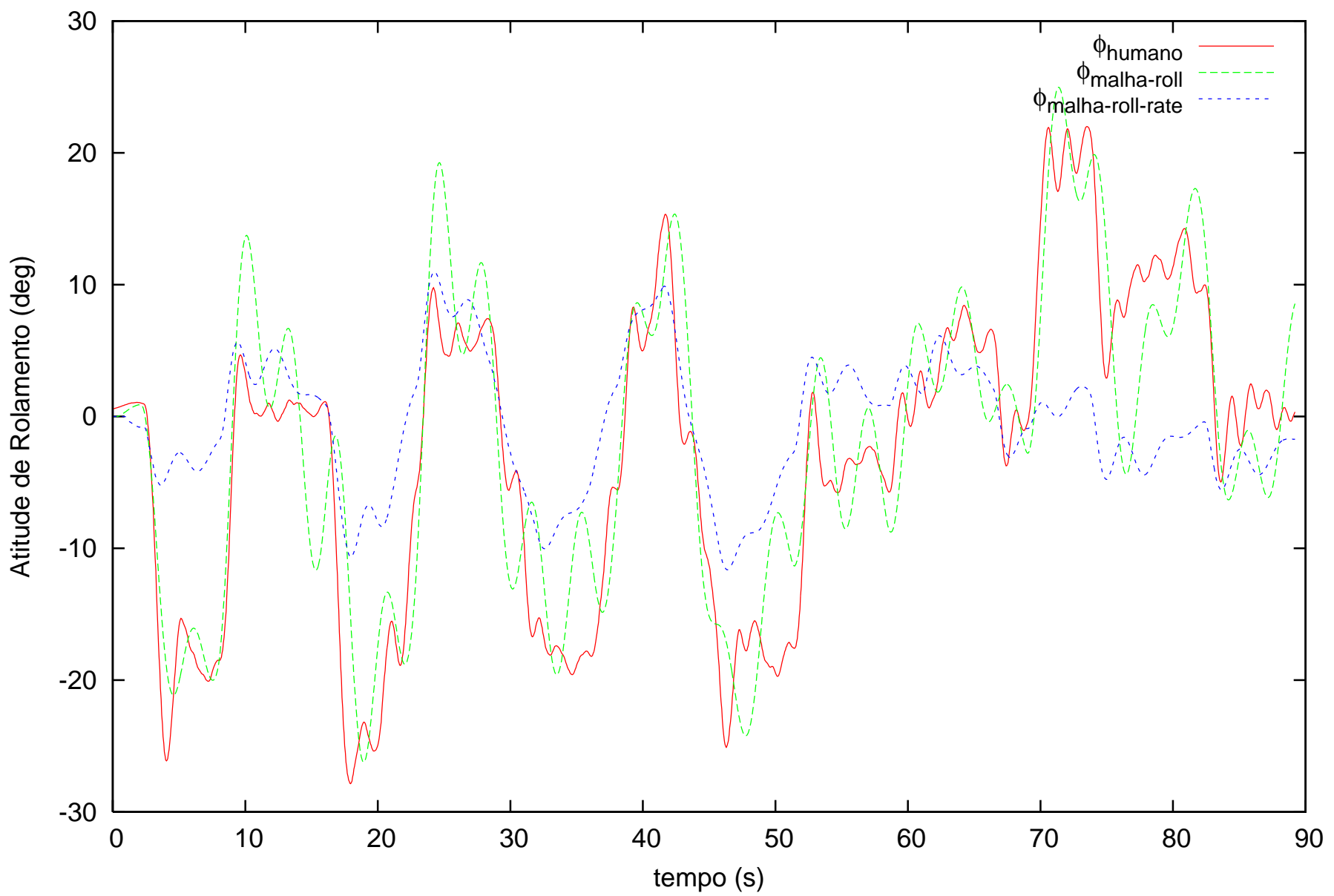

Figura B.3: Vôo 1 - Seqüência \#15 - Configuração P1A - dados do ensaio e das simulações 


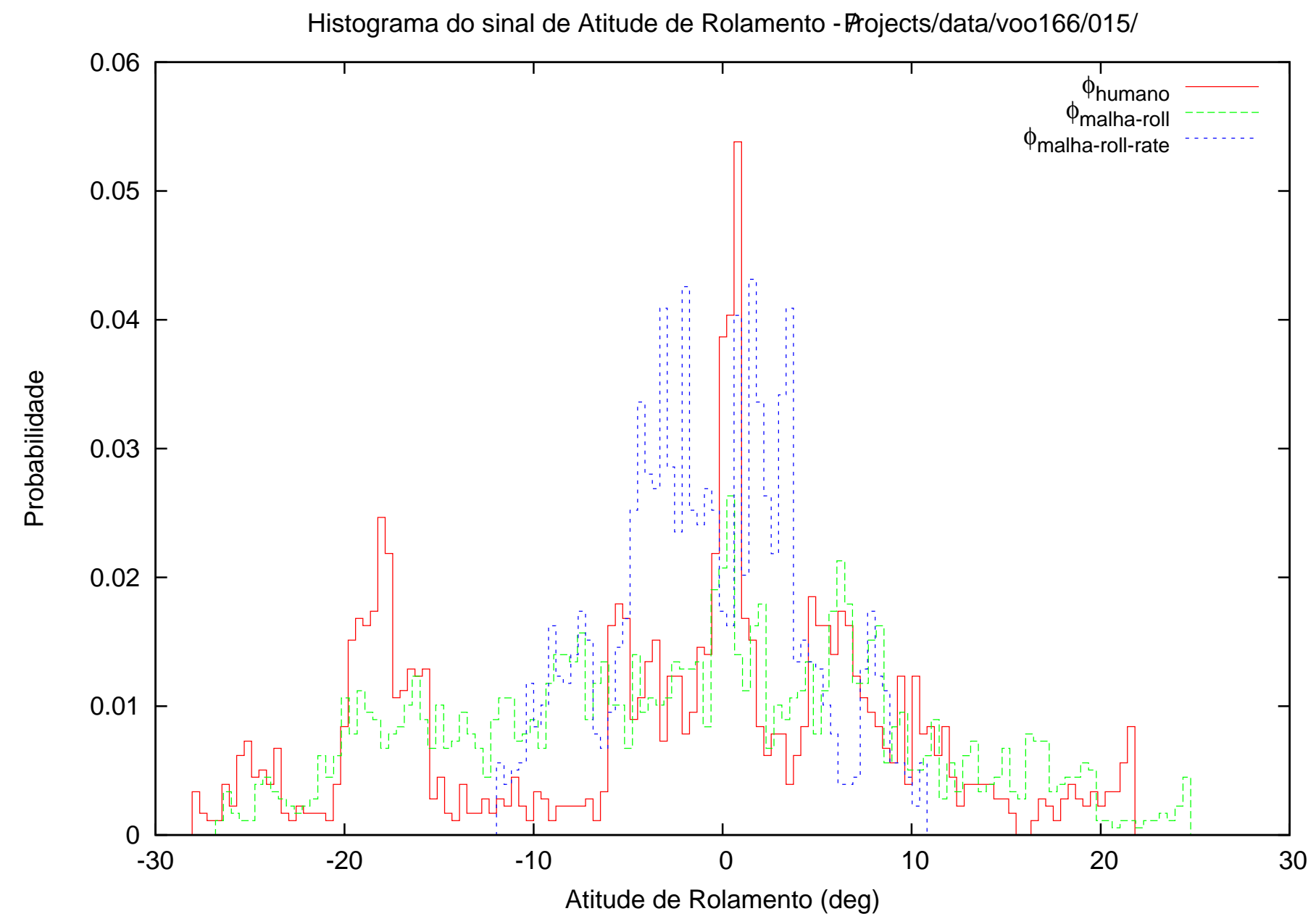

Figura B.4: Vôo 1 - Seqüência \#15 - Configuração P1A - histogramas dos dados 
Sinais de Atitude de Rolamento - Projects/data/voo166/016/

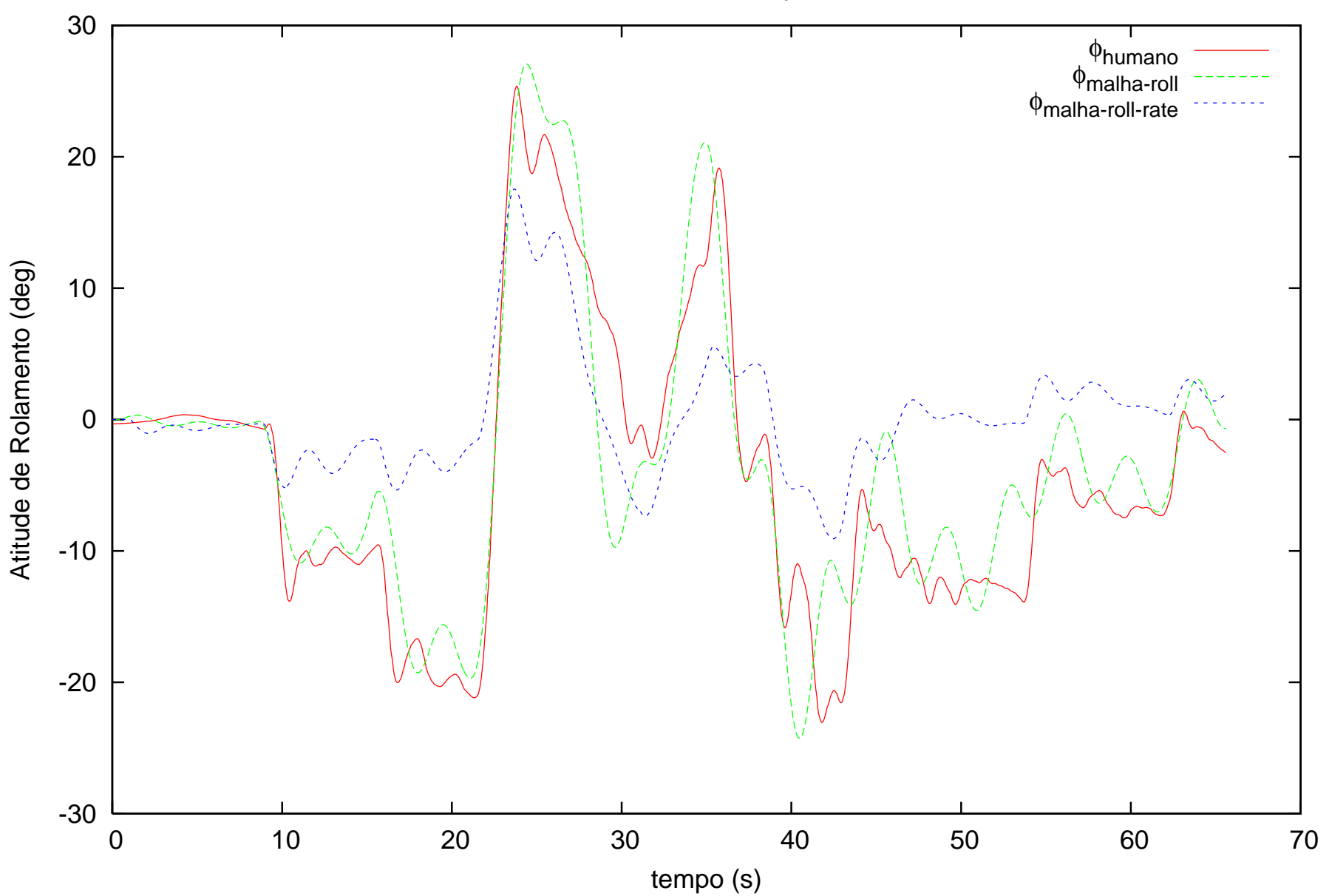

Figura B.5: Vôo 1 - Seqüência \#16 - Configuração P1A - dados do ensaio e das simulações 


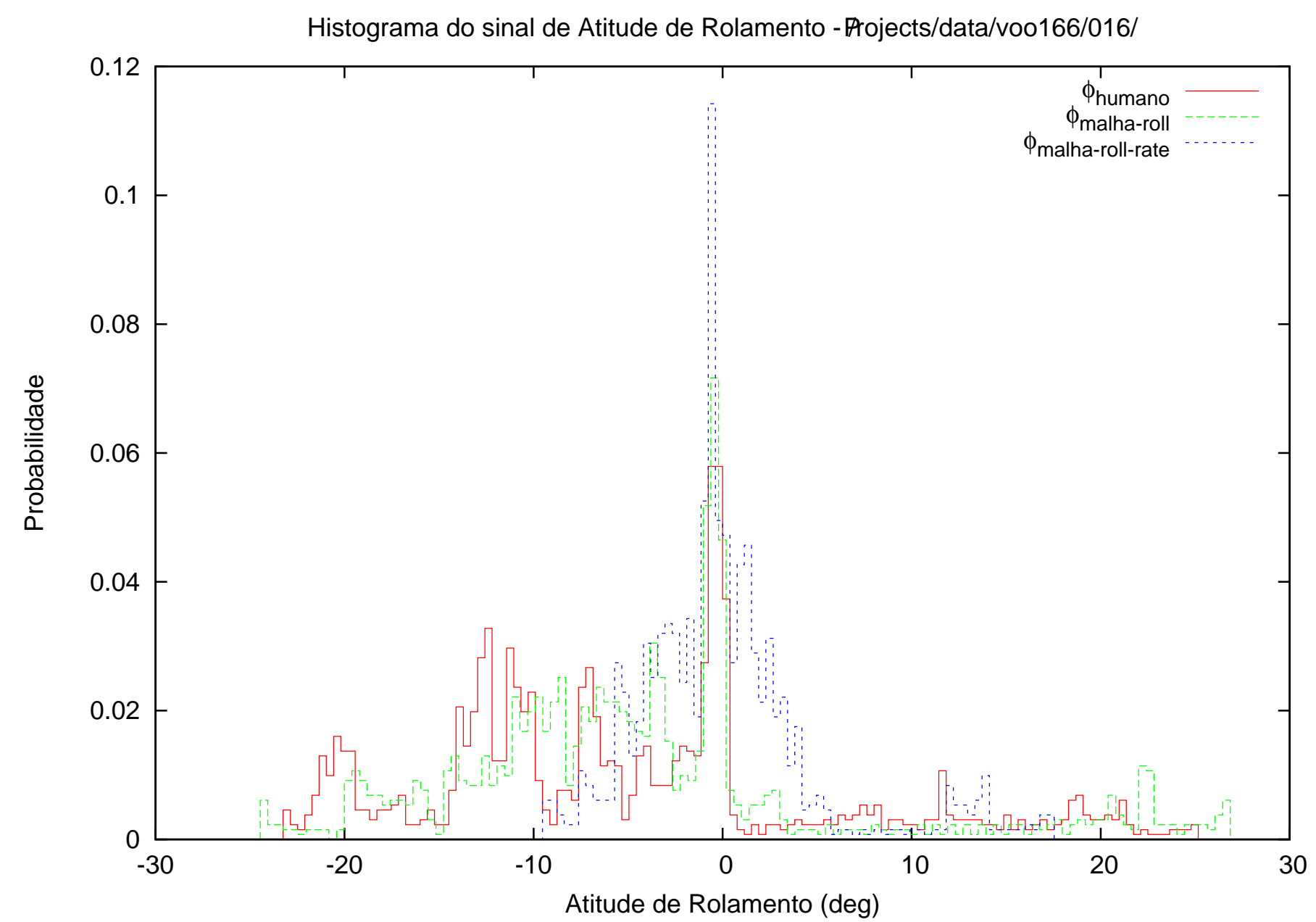

Figura B.6: Vôo 1 - Seqüência \#16 - Configuração P1A - histogramas dos dados 


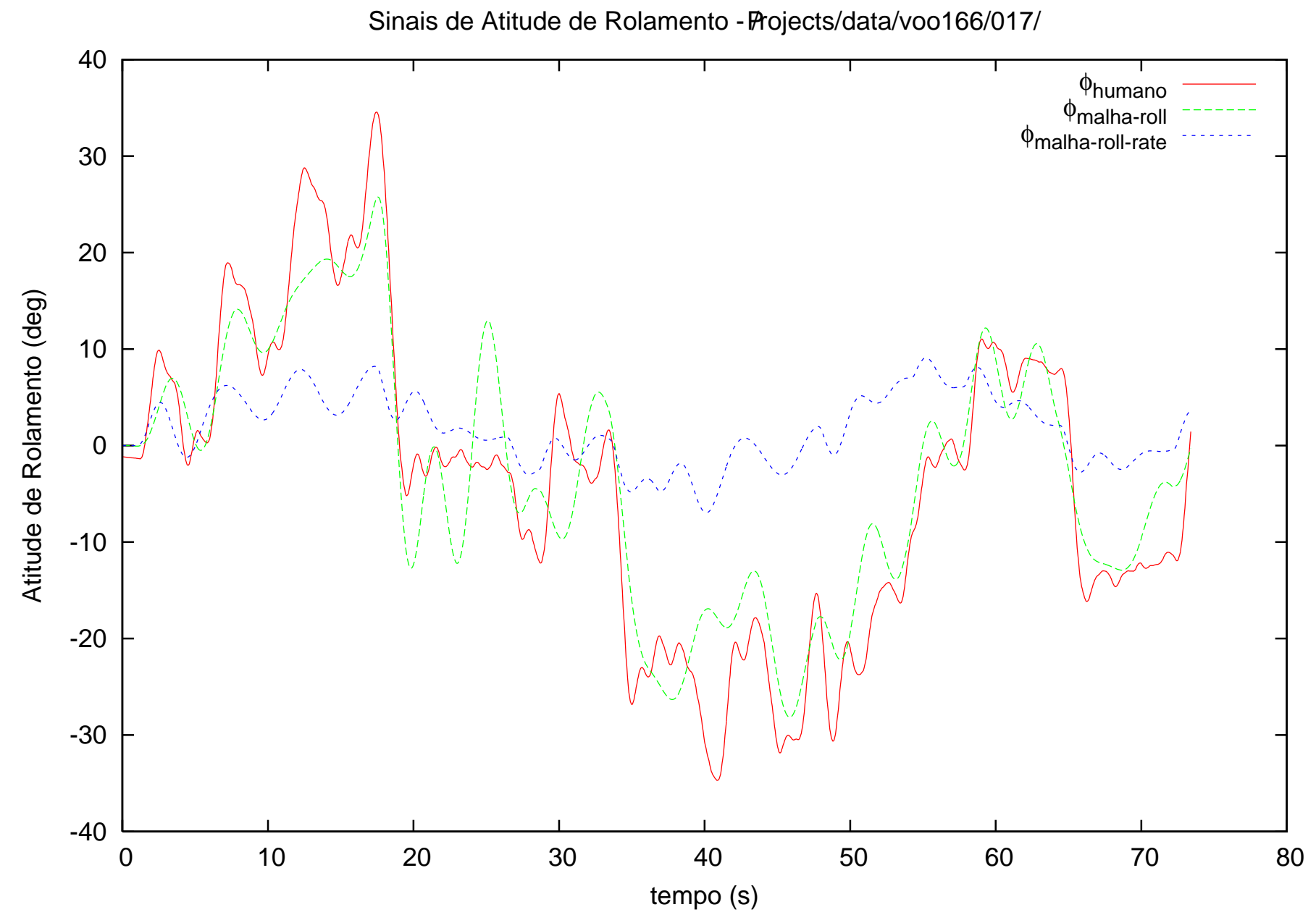

Figura B.7: Vôo 1 - Seqüência \#17 - Configuração P1A - dados do ensaio e das simulações 


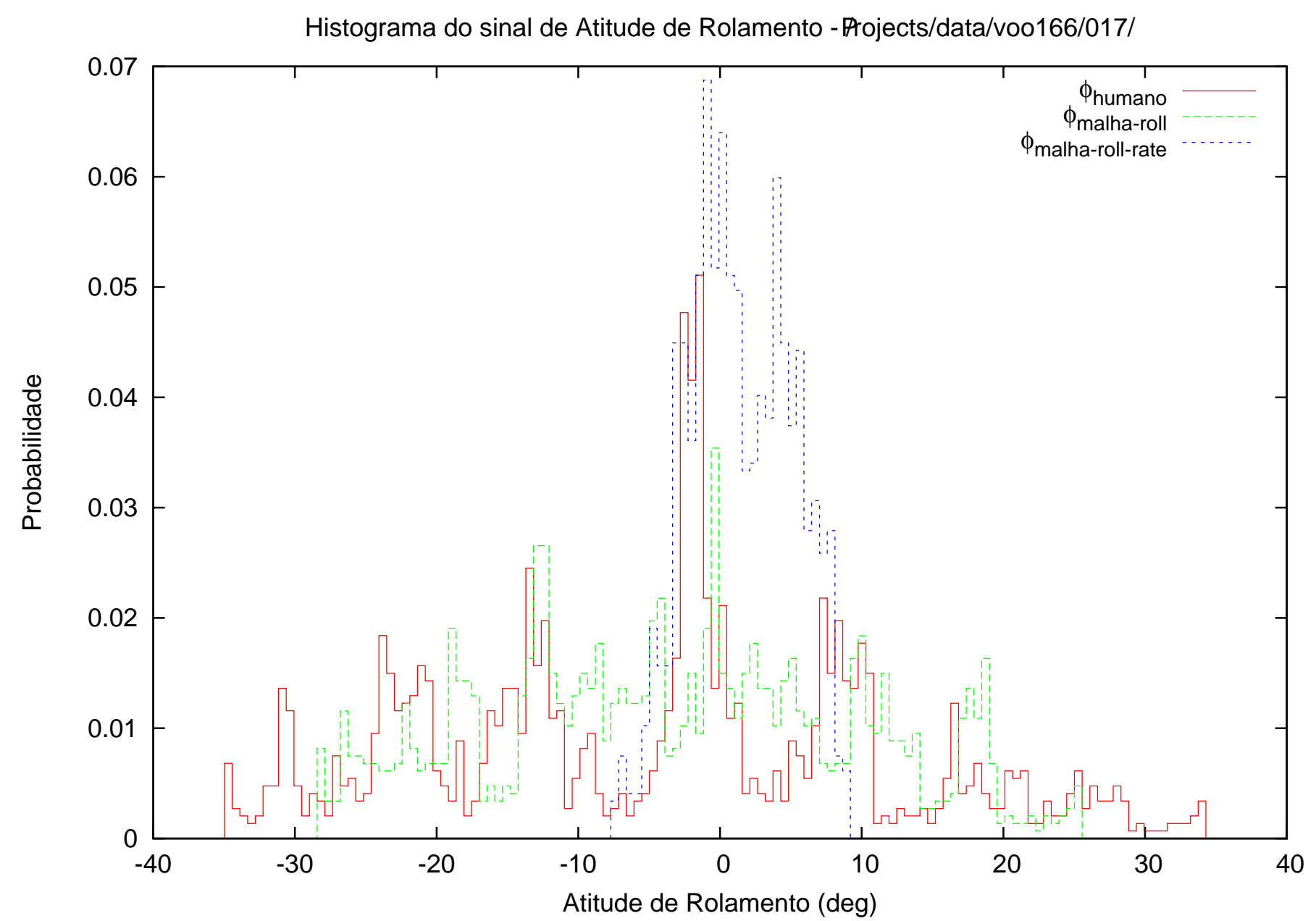

Figura B.8: Vôo 1 - Seqüência \#17 - Configuração P1A - histogramas dos dados 


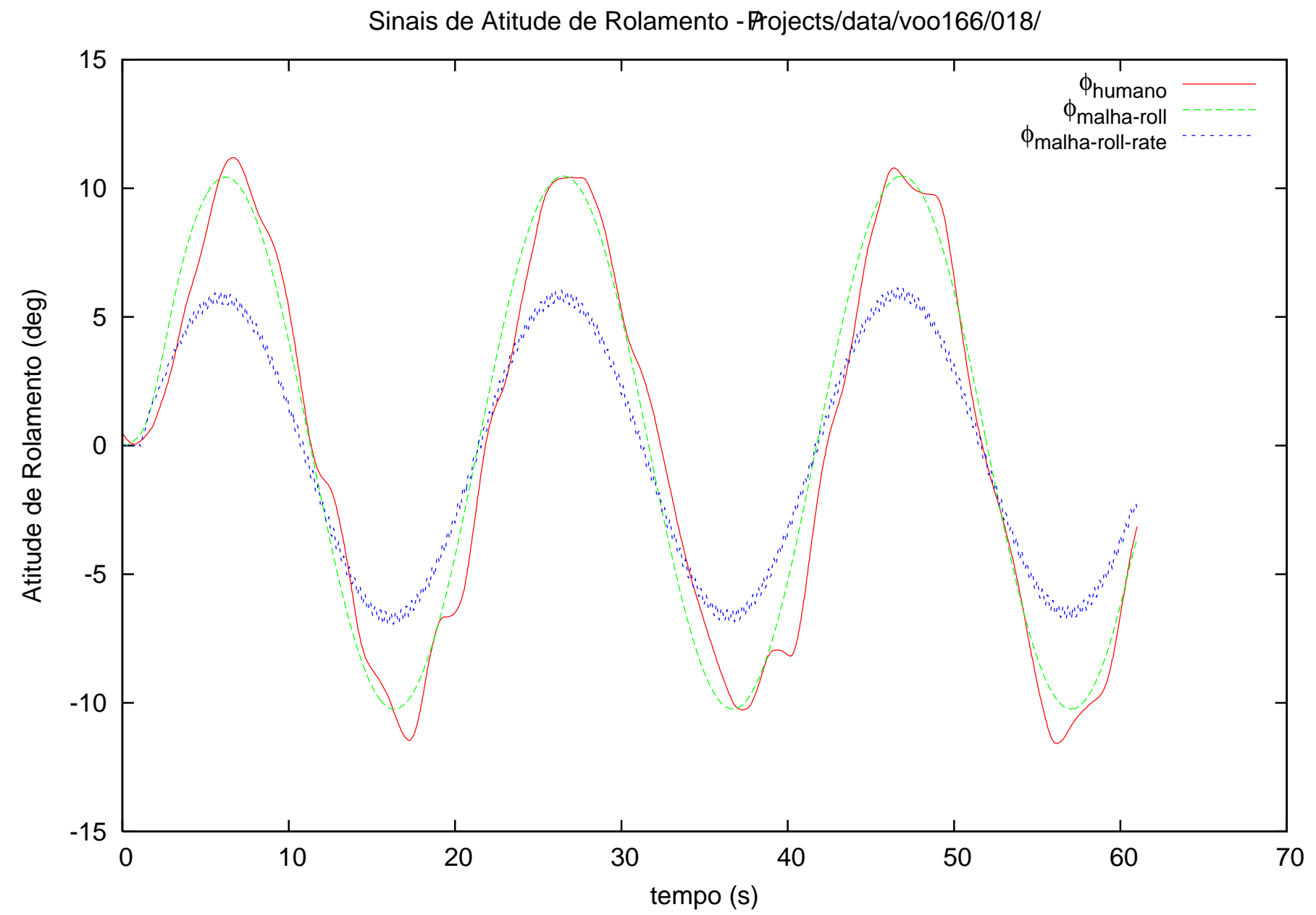

Figura B.9: Vôo 1 - Seqüência \#18 - Configuração D1B - dados do ensaio e das simulações 


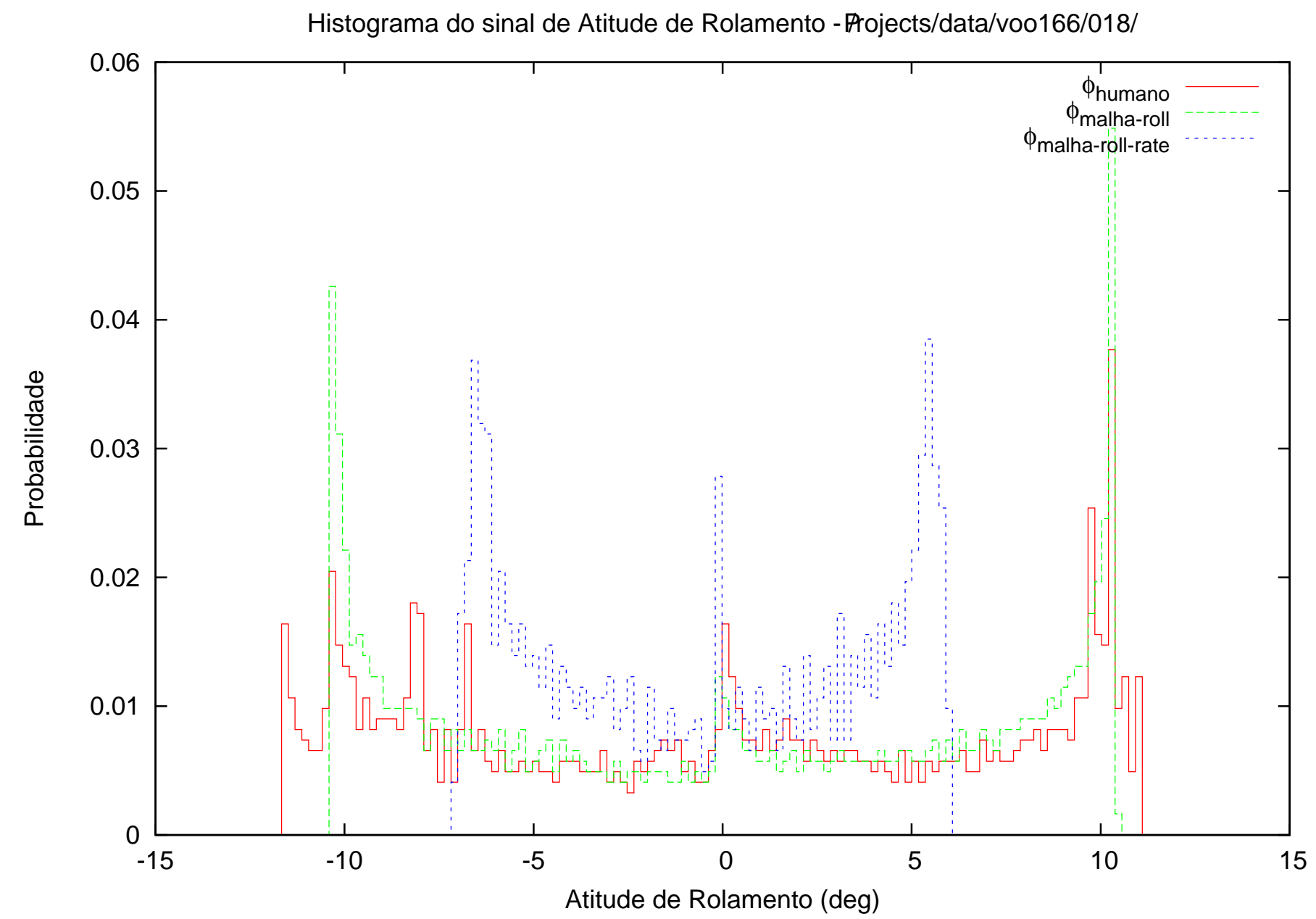

Figura B.10: Vôo 1 - Seqüência \#18 - Configuração D1B - histogramas dos dados 


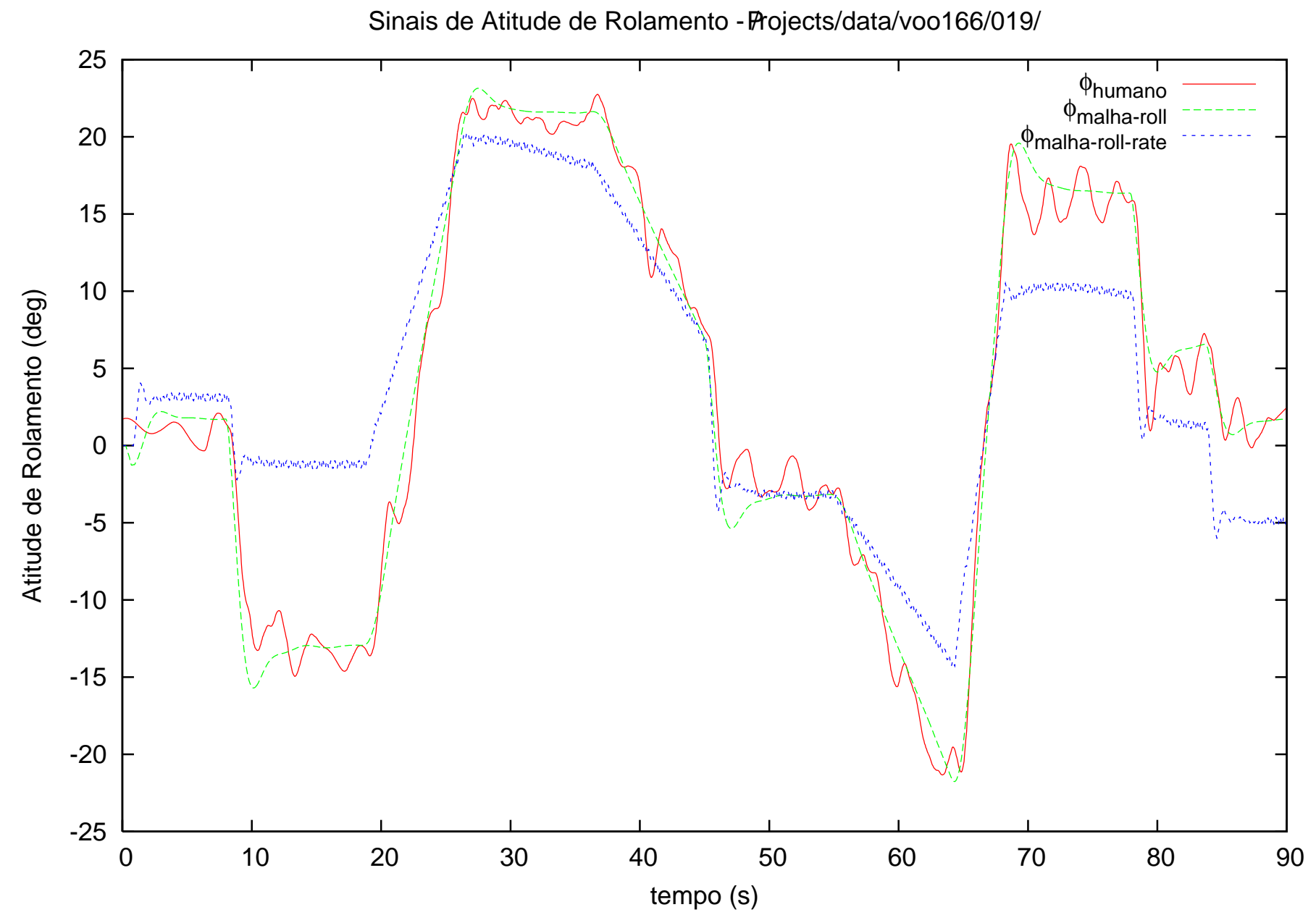

Figura B.11: Vôo 1 - Seqüência \#19 - Configuração D1B - dados do ensaio e das simulações 


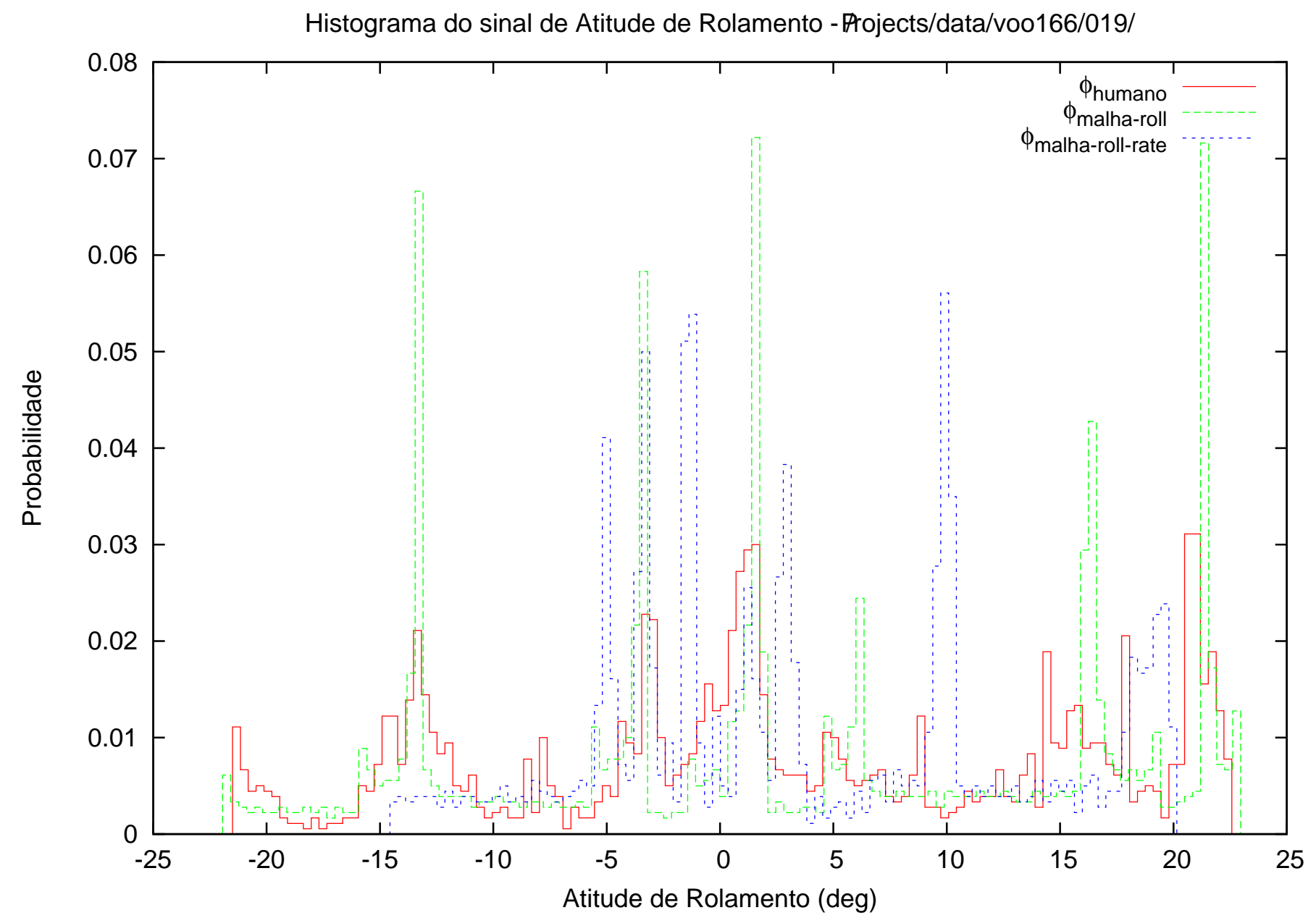

Figura B.12: Vôo 1 - Seqüência \#19 - Configuração D1B - histogramas dos dadoss 


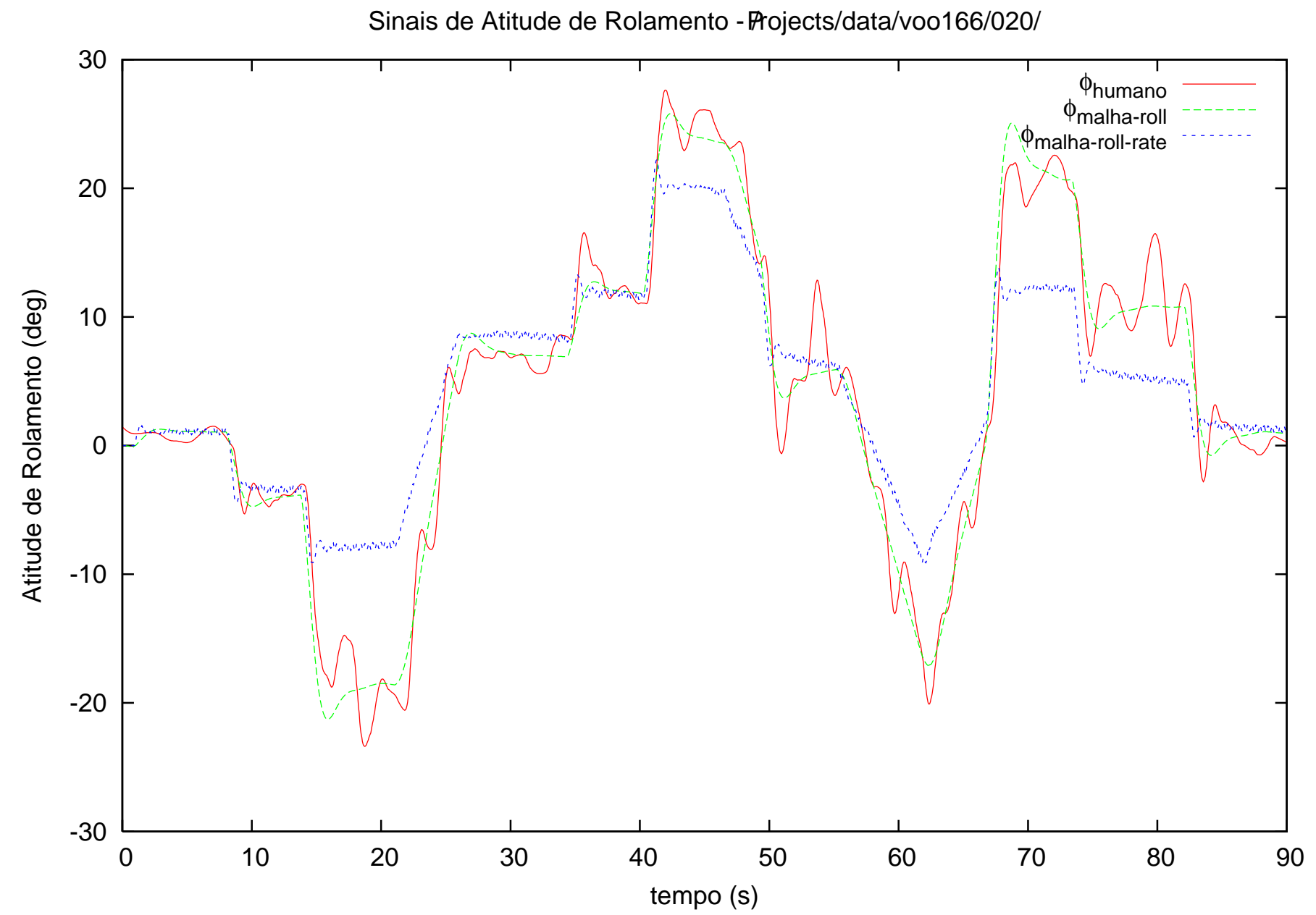

Figura B.13: Vôo 1 - Seqüência \#20 - Configuração D1B - dados do ensaio e das simulações 


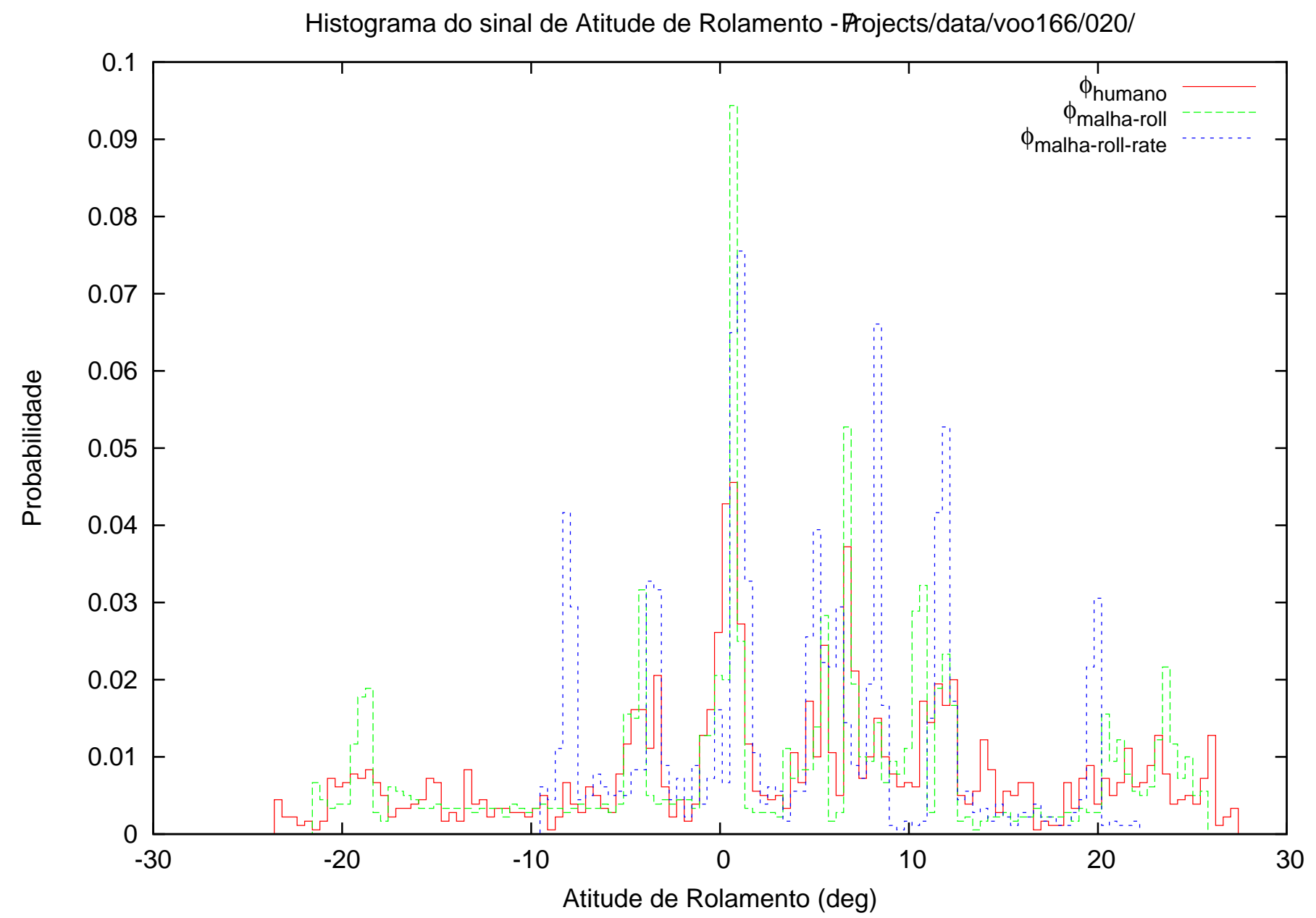

Figura B.14: Vôo 1 - Seqüência \#20 - Configuração D1B - histogramas dos dados 


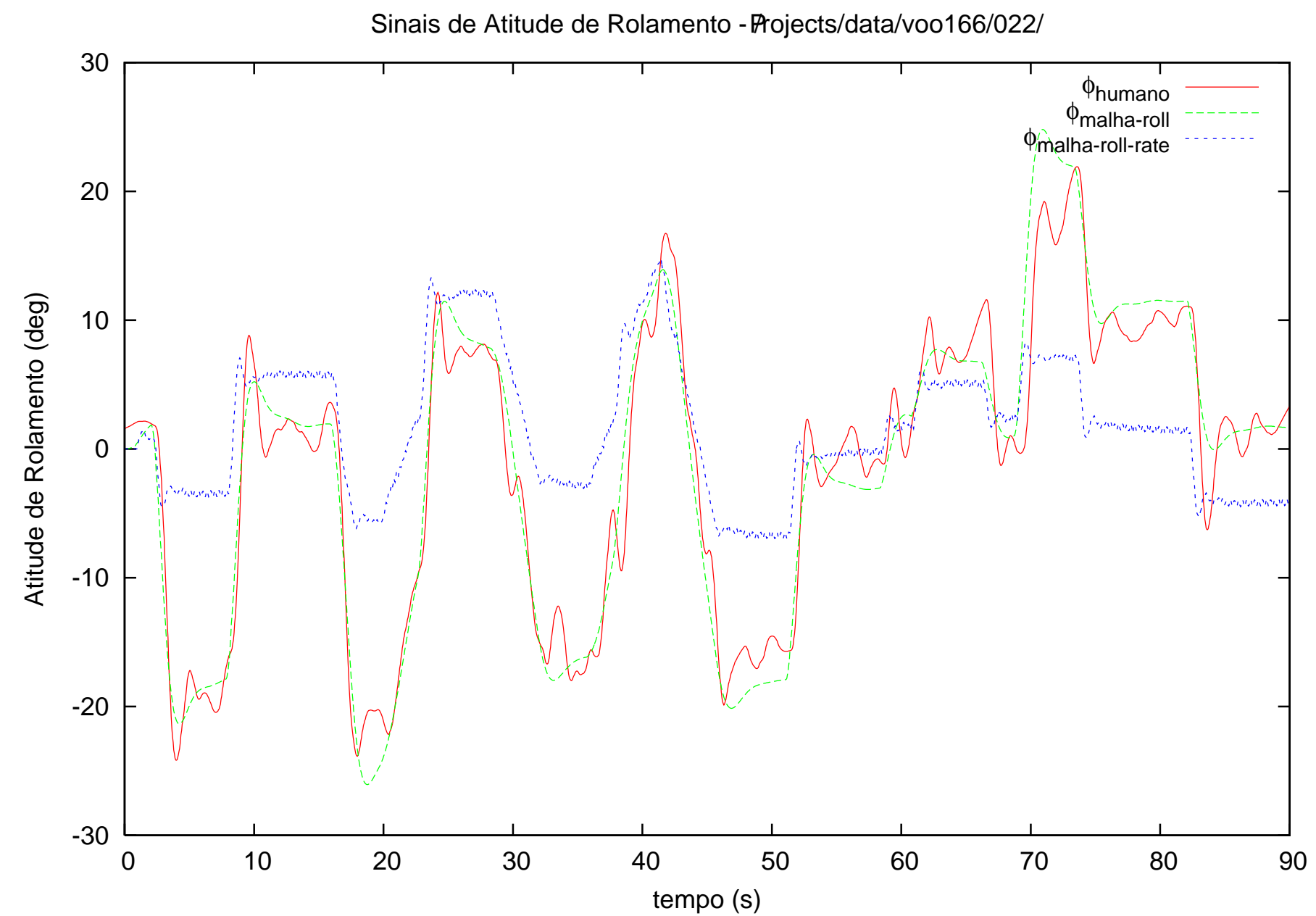

Figura B.15: Vôo 1 - Seqüência \#22 - Configuração D1B - dados do ensaio e das simulações 


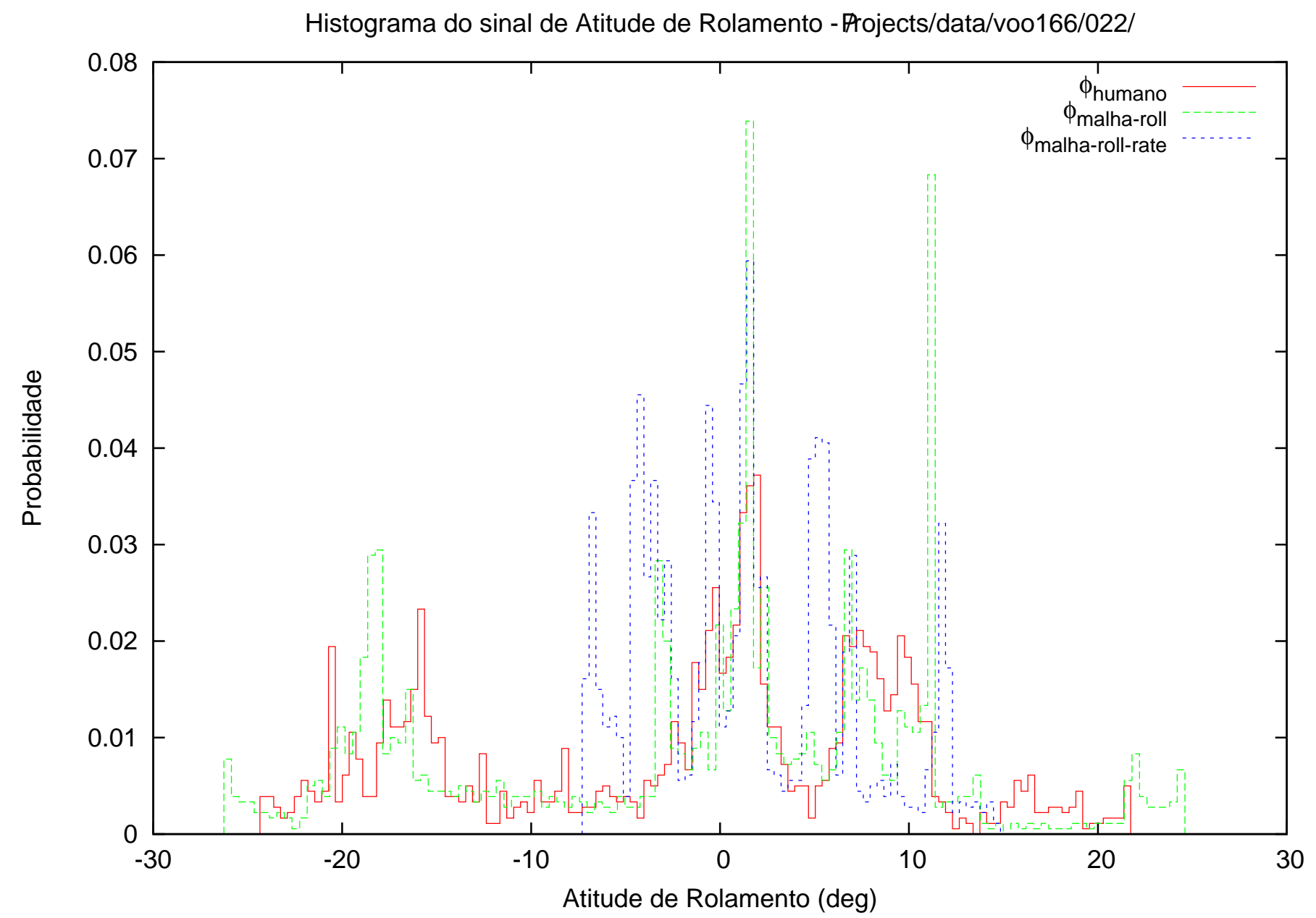

Figura B.16: Vôo 1 - Seqüência \#22 - Configuração D1B - histogramas dos dados 
Sinais de Atitude de Rolamento - Projects/data/voo166/023/

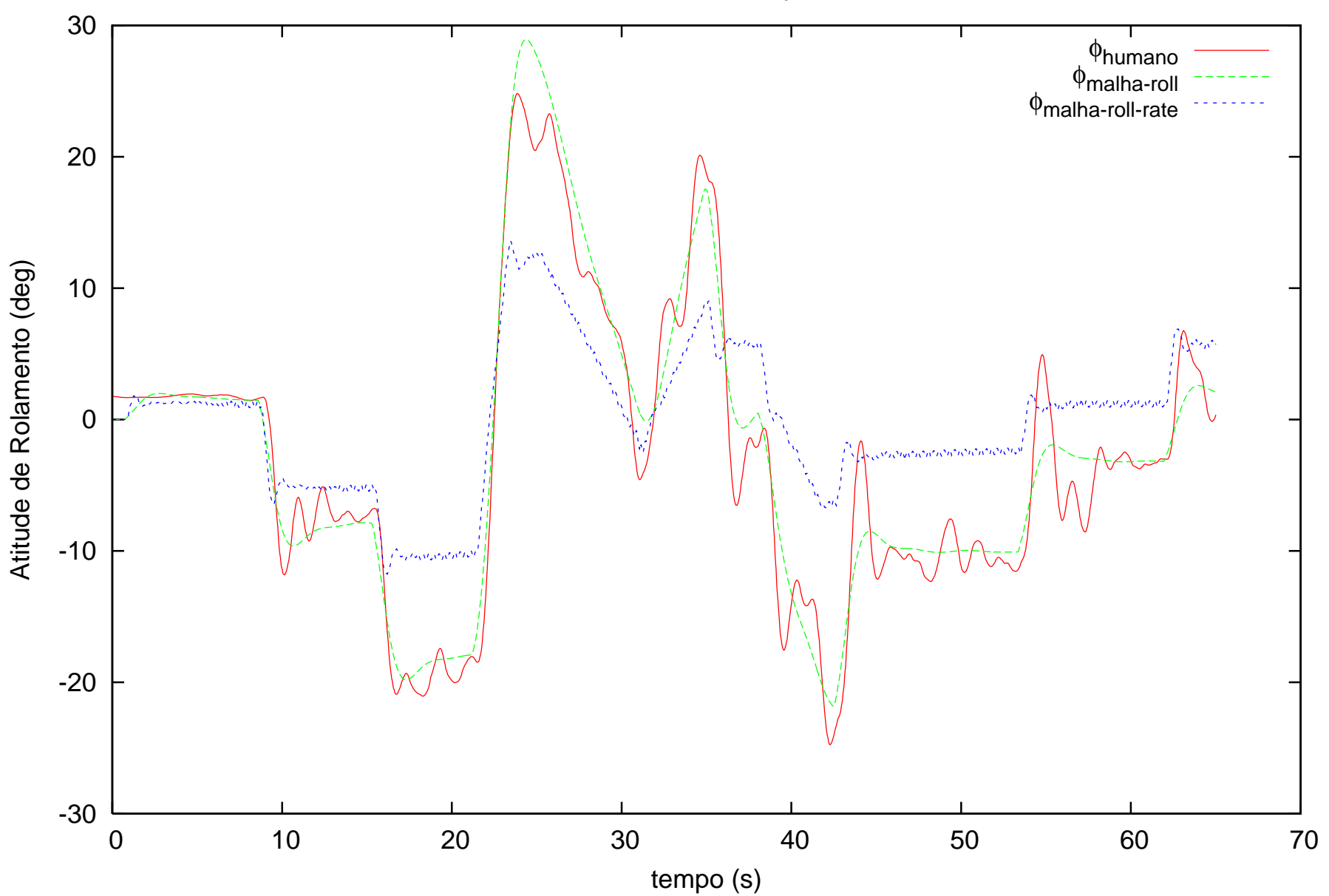

Figura B.17: Vôo 1 - Seqüência \#23 - Configuração D1B - dados do ensaio e das simulações 


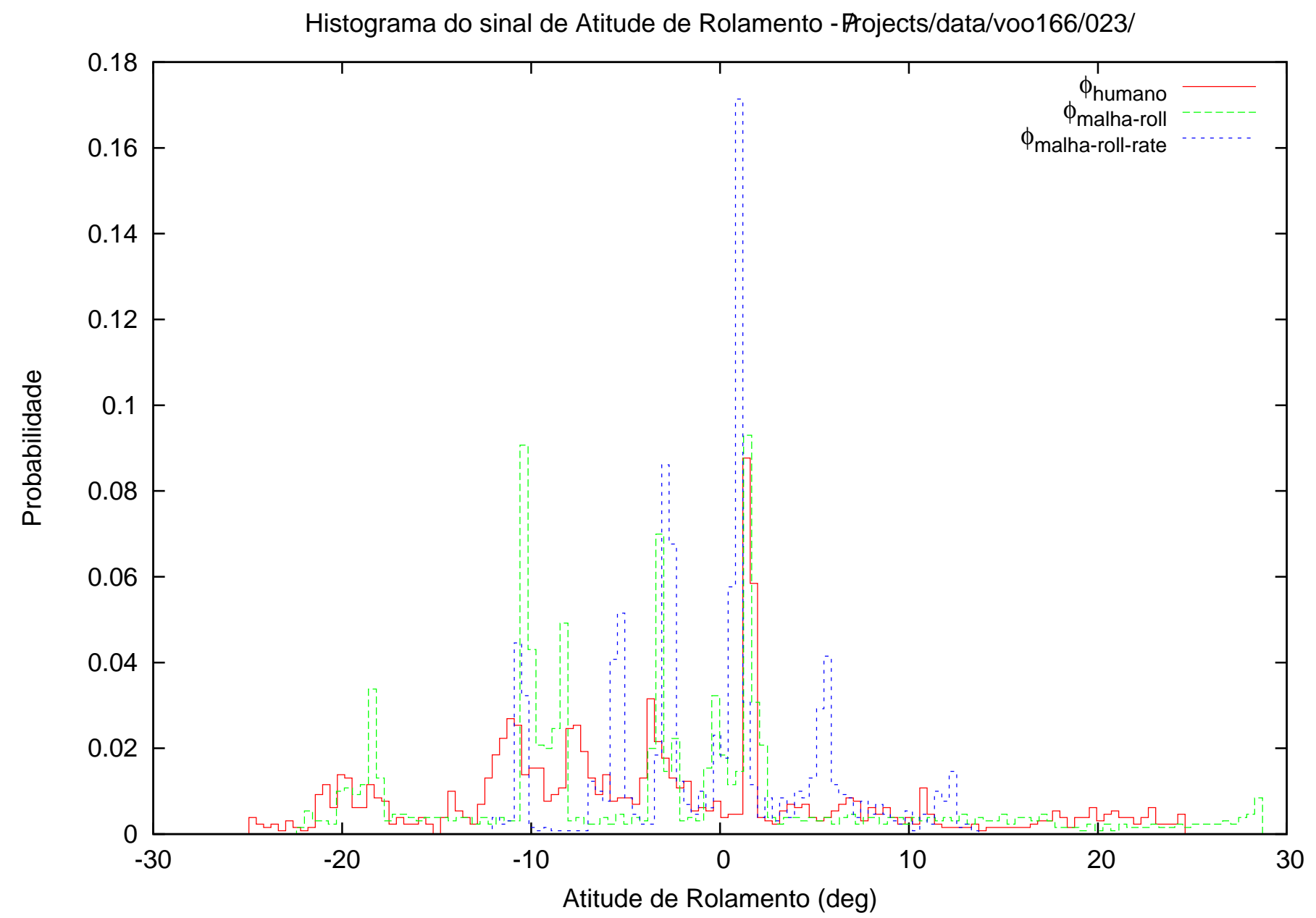

Figura B.18: Vôo 1 - Seqüência \#23 - Configuração D1B - histogramas dos dados 


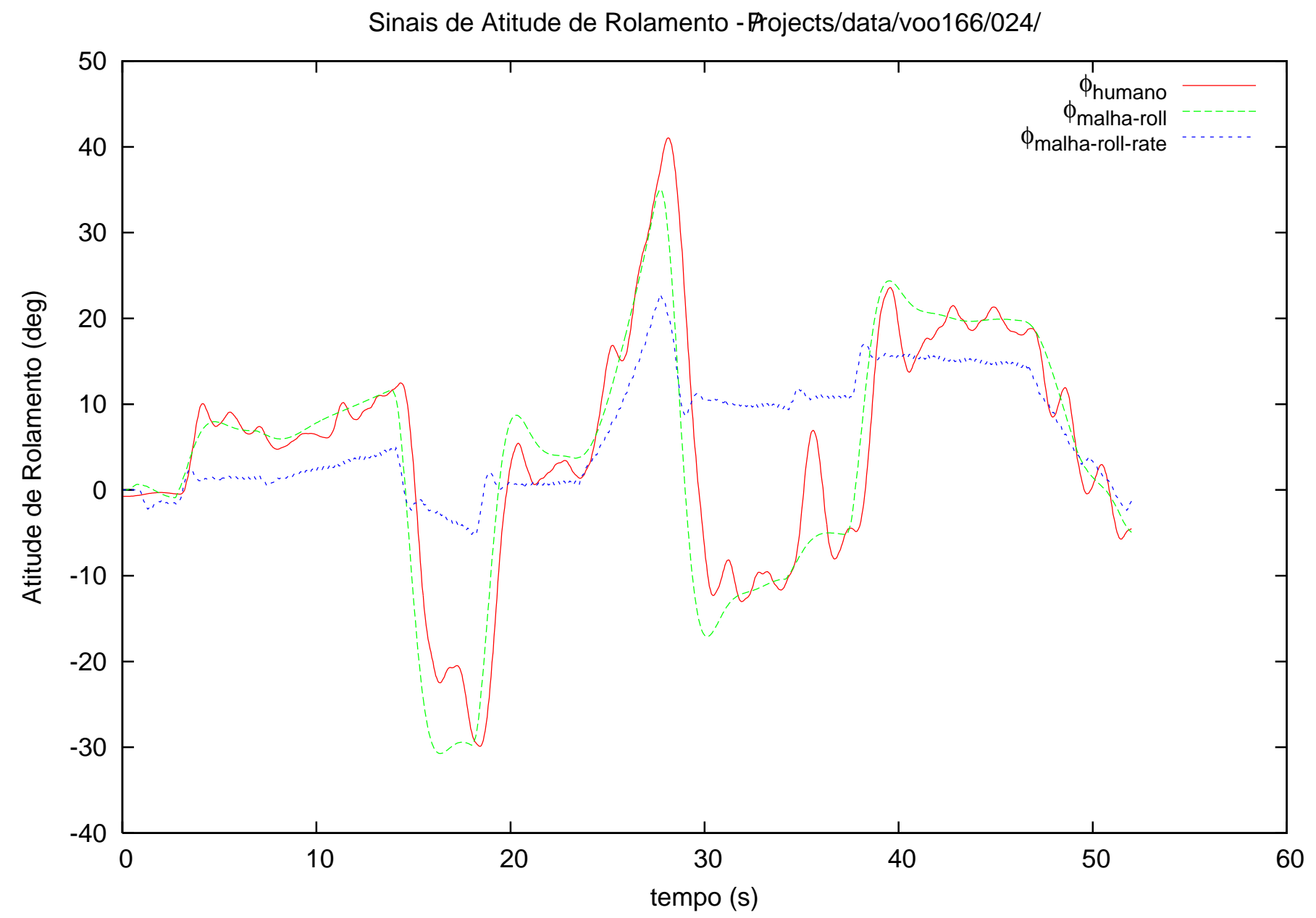

Figura B.19: Vôo 1 - Seqüência \#24 - Configuração D1B - dados do ensaio e das simulações 


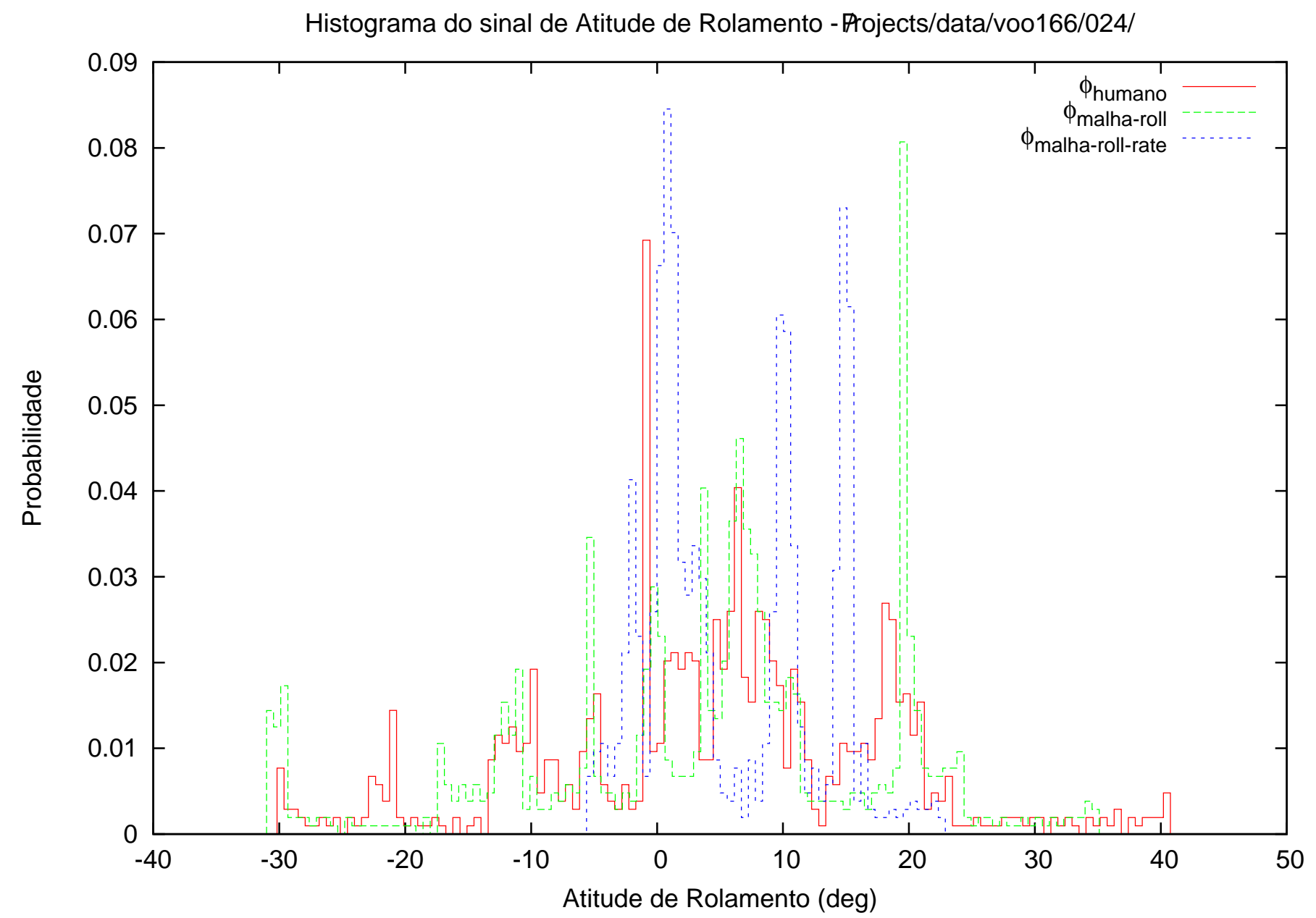

Figura B.20: Vôo 1 - Seqüência \#24 - Configuração D1B - histogramas dos dados 
Sinais de Atitude de Rolamento - Projects/data/voo166/026/

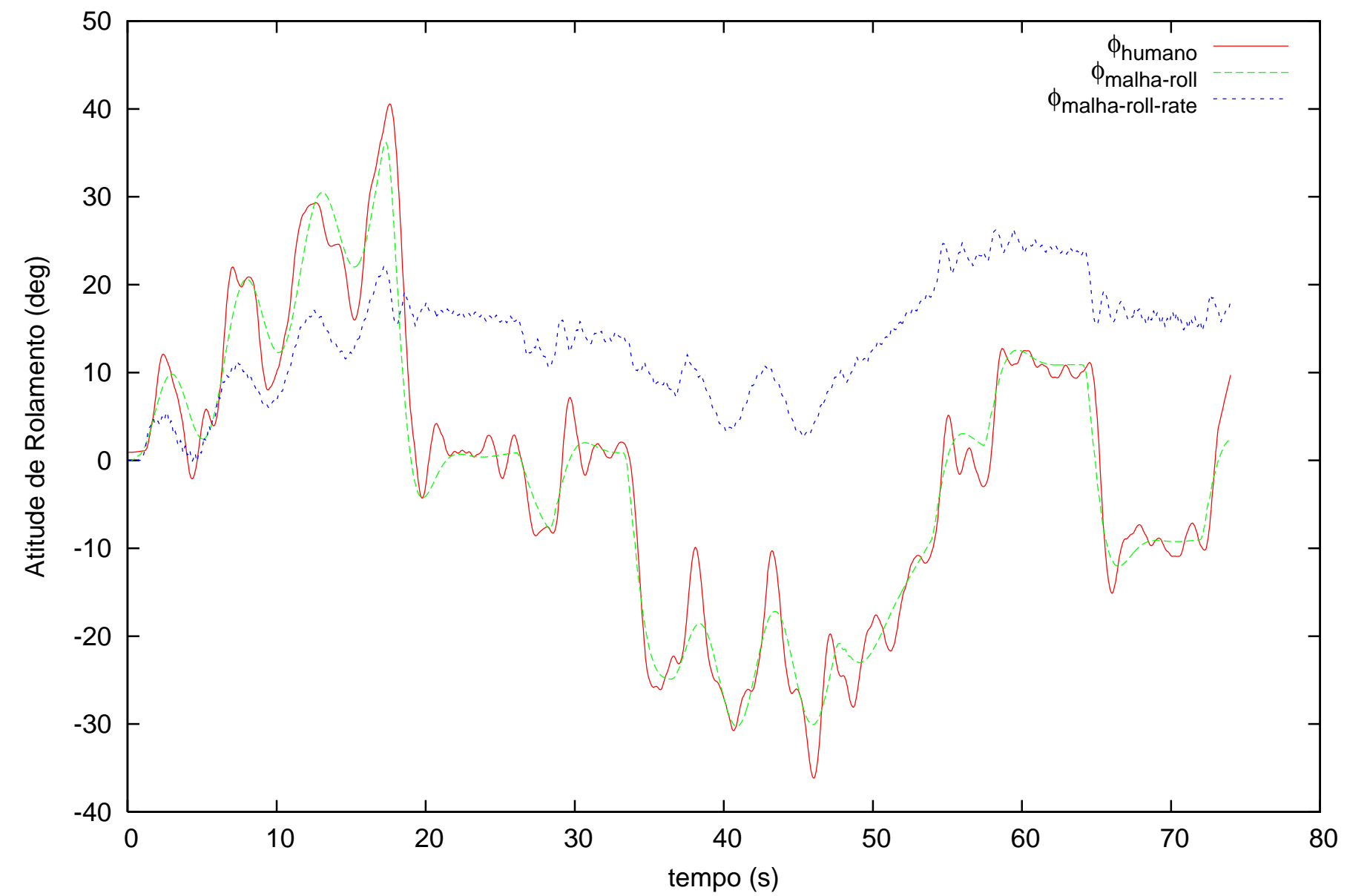

Figura B.21: Vôo 1 - Seqüência \#26 - Configuração D1A - dados do ensaio e das simulações 


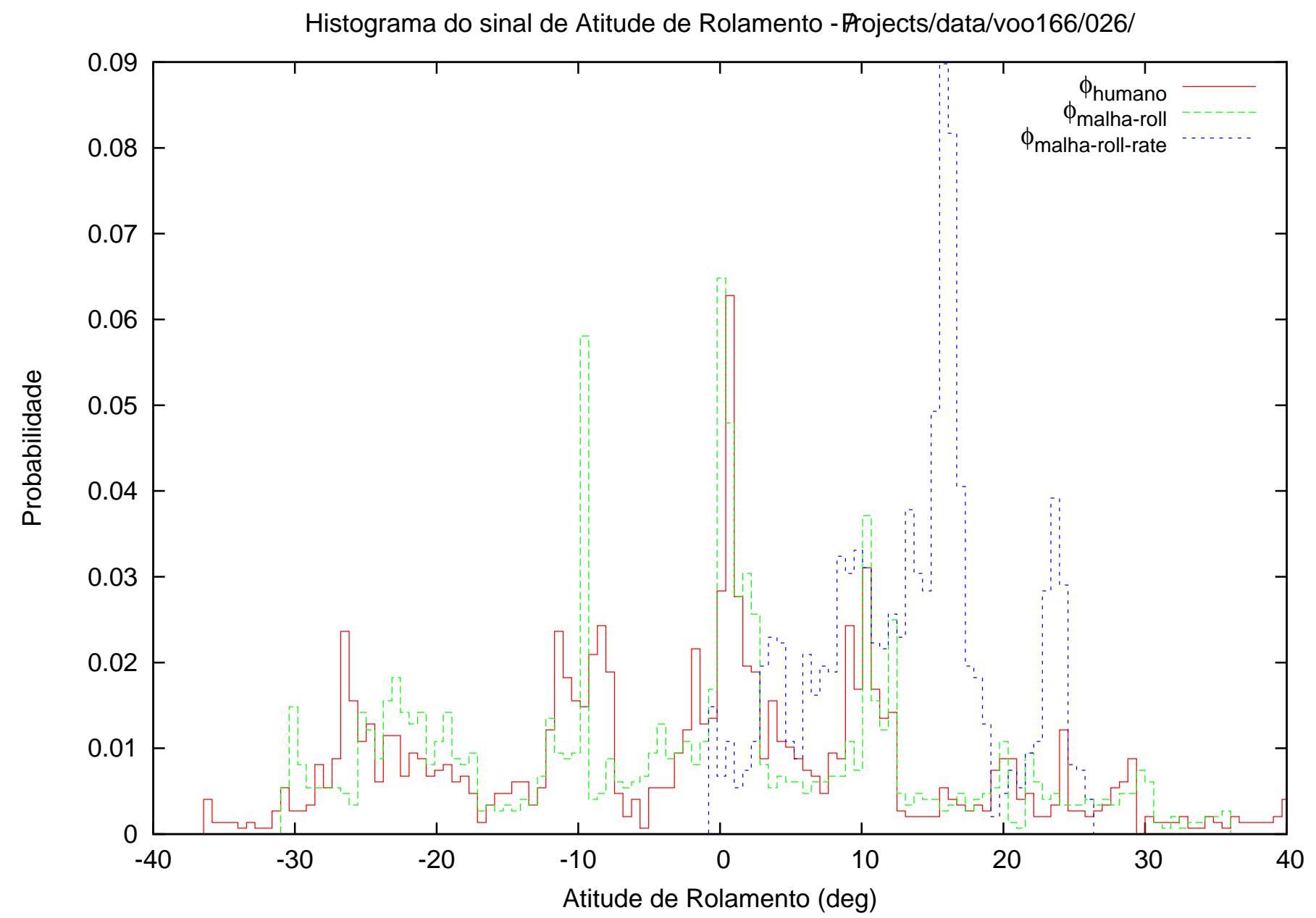

Figura B.22: Vôo 1 - Seqüência \#26 - Configuração D1A - histogramas dos dados 


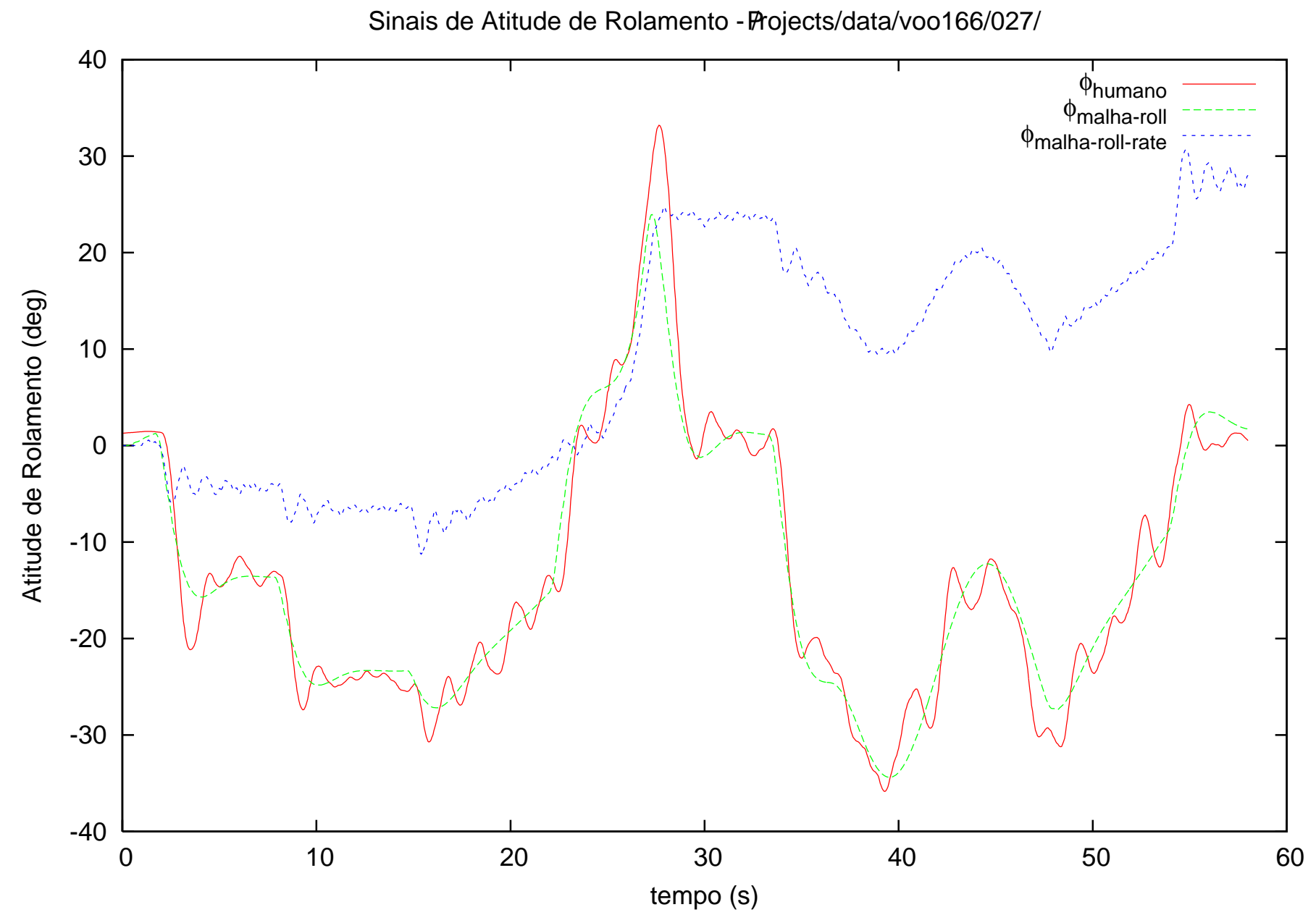

Figura B.23: Vôo 1 - Seqüência \#27 - Configuração D1A - dados do ensaio e das simulações 


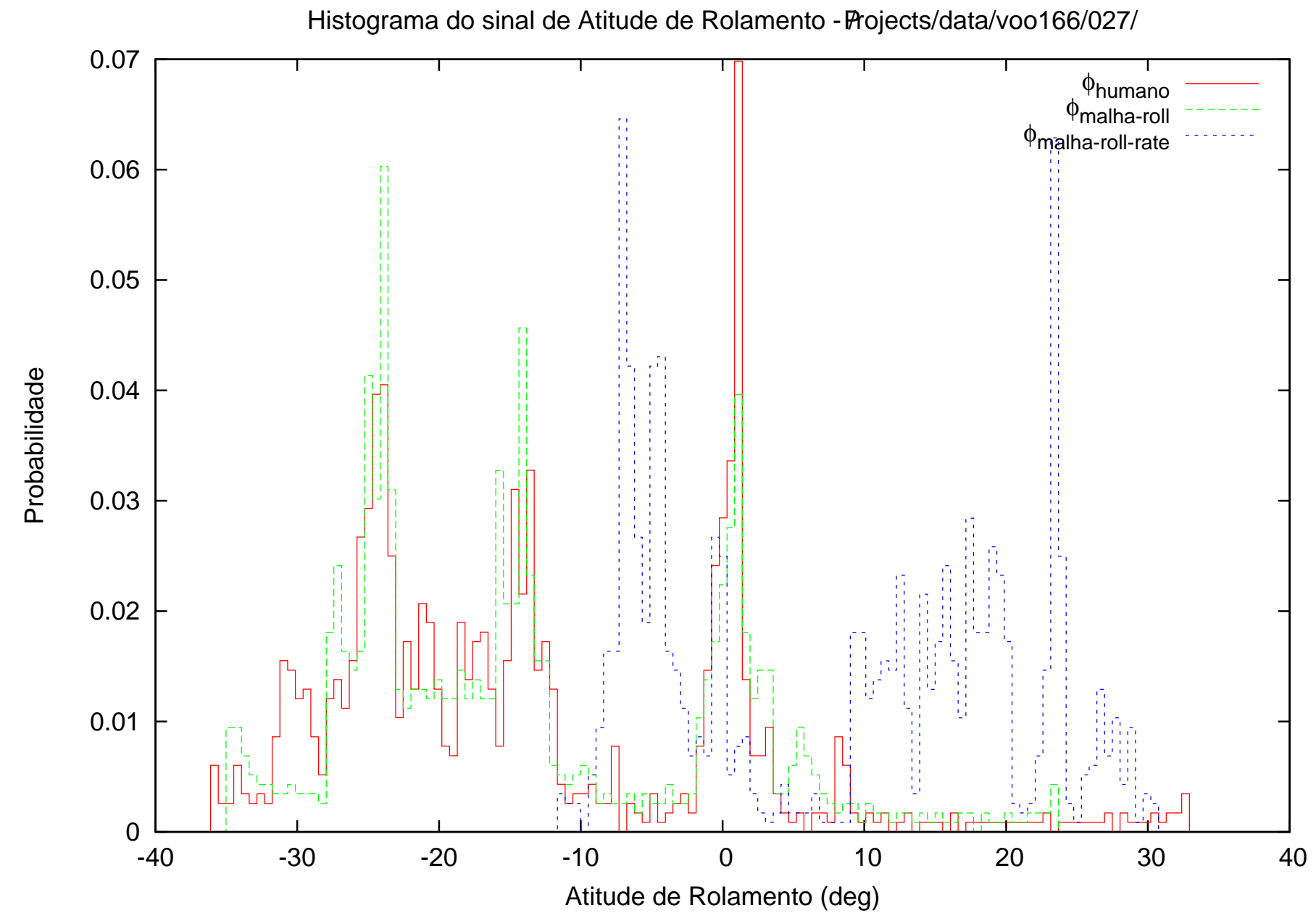

Figura B.24: Vôo 1 - Seqüência \#27 - Configuração D1A - histogramas dos dados 


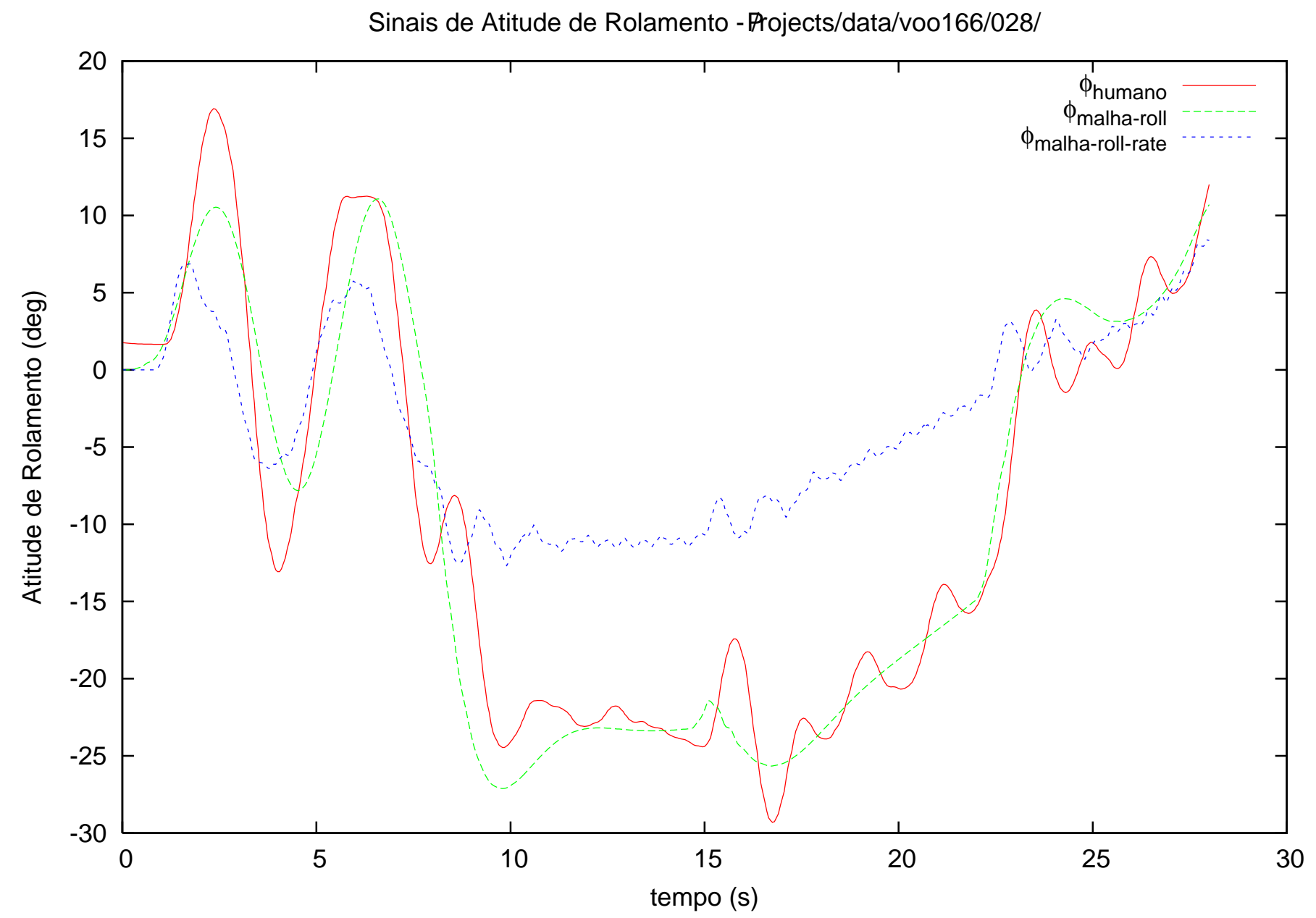

Figura B.25: Vôo 1 - Seqüência \#28 - Configuração D1A - dados do ensaio e das simulações 


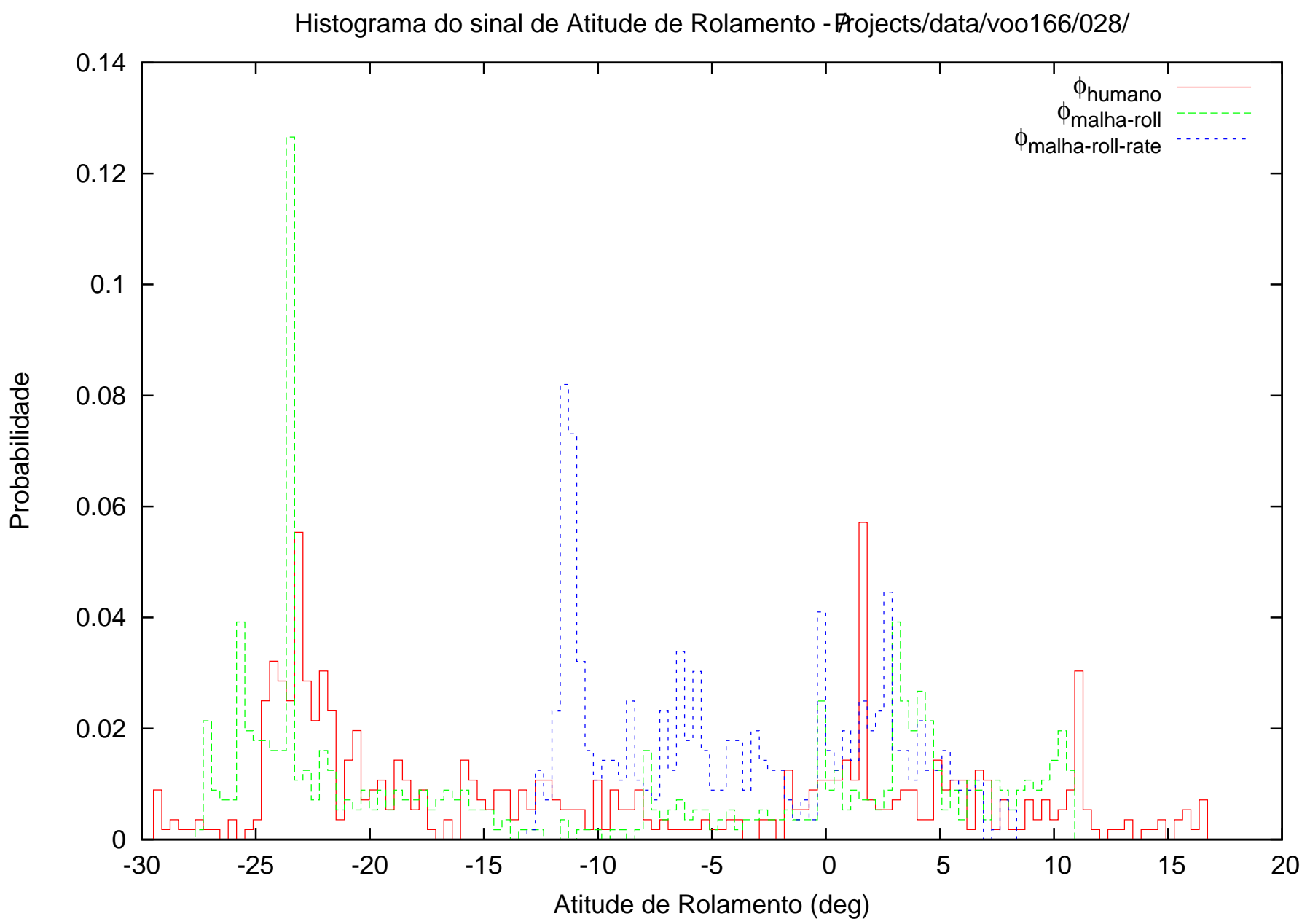

Figura B.26: Vôo 1 - Seqüência \#28 - Configuração D1A - histogramas dos dados 
Sinais de Atitude de Rolamento - Projects/data/voo175/001/

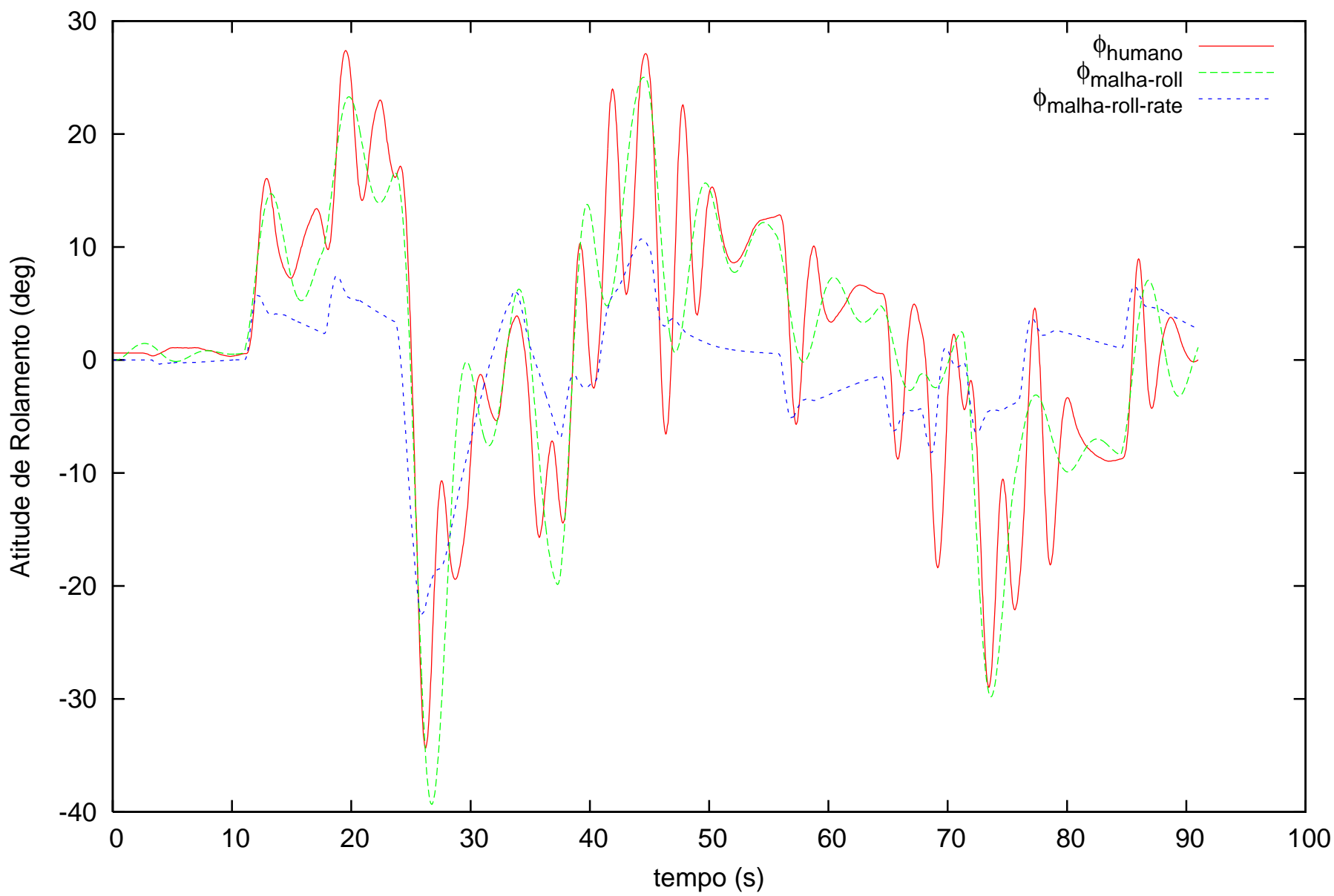

Figura B.27: Vôo 2 - Seqüência \#01 - Configuração P2A - dados do ensaio e das simulações 


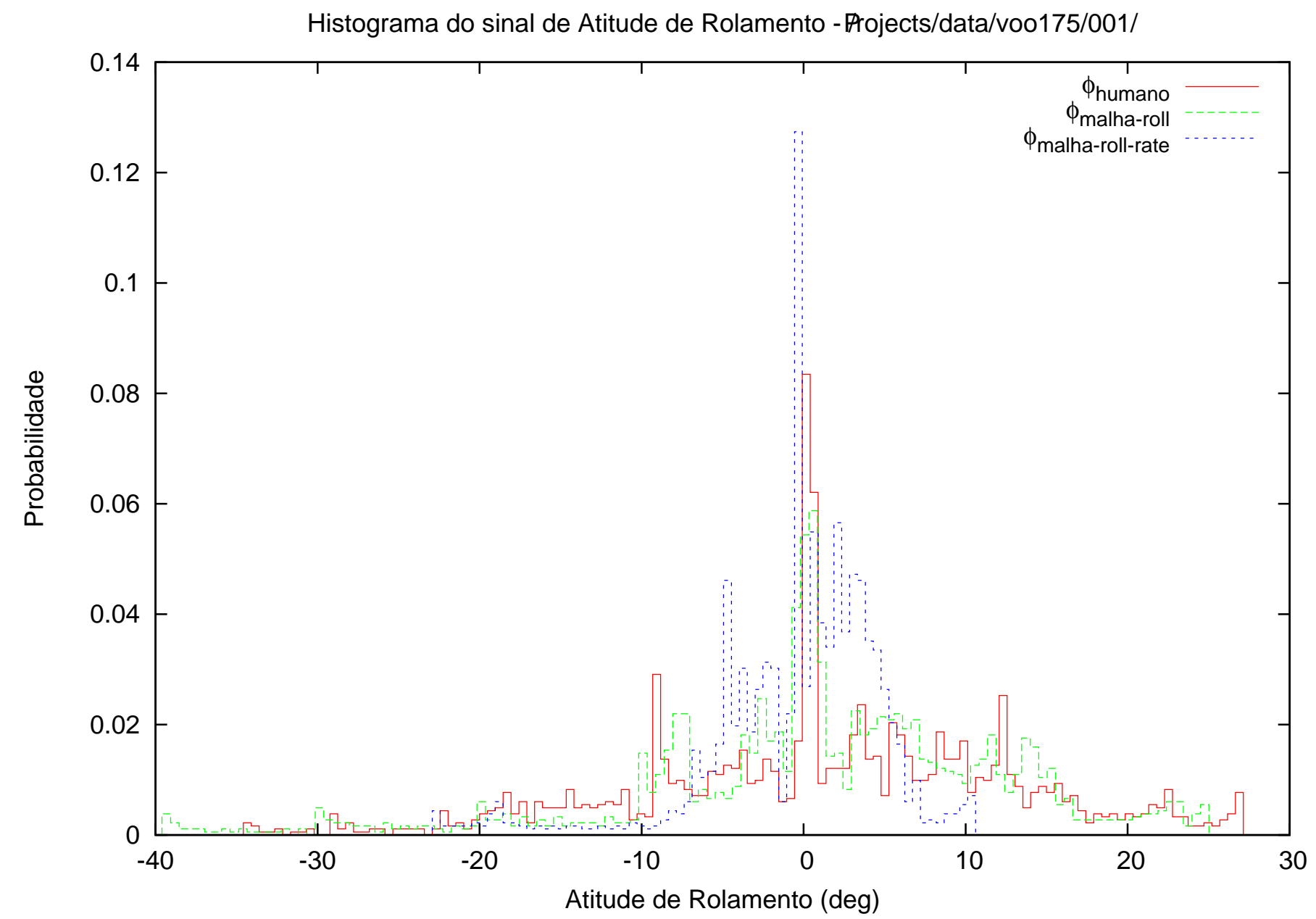

Figura B.28: Vôo 2 - Seqüência \#01 - Configuração P2A - histogramas dos dados 
Sinais de Atitude de Rolamento - Projects/data/voo175/002/

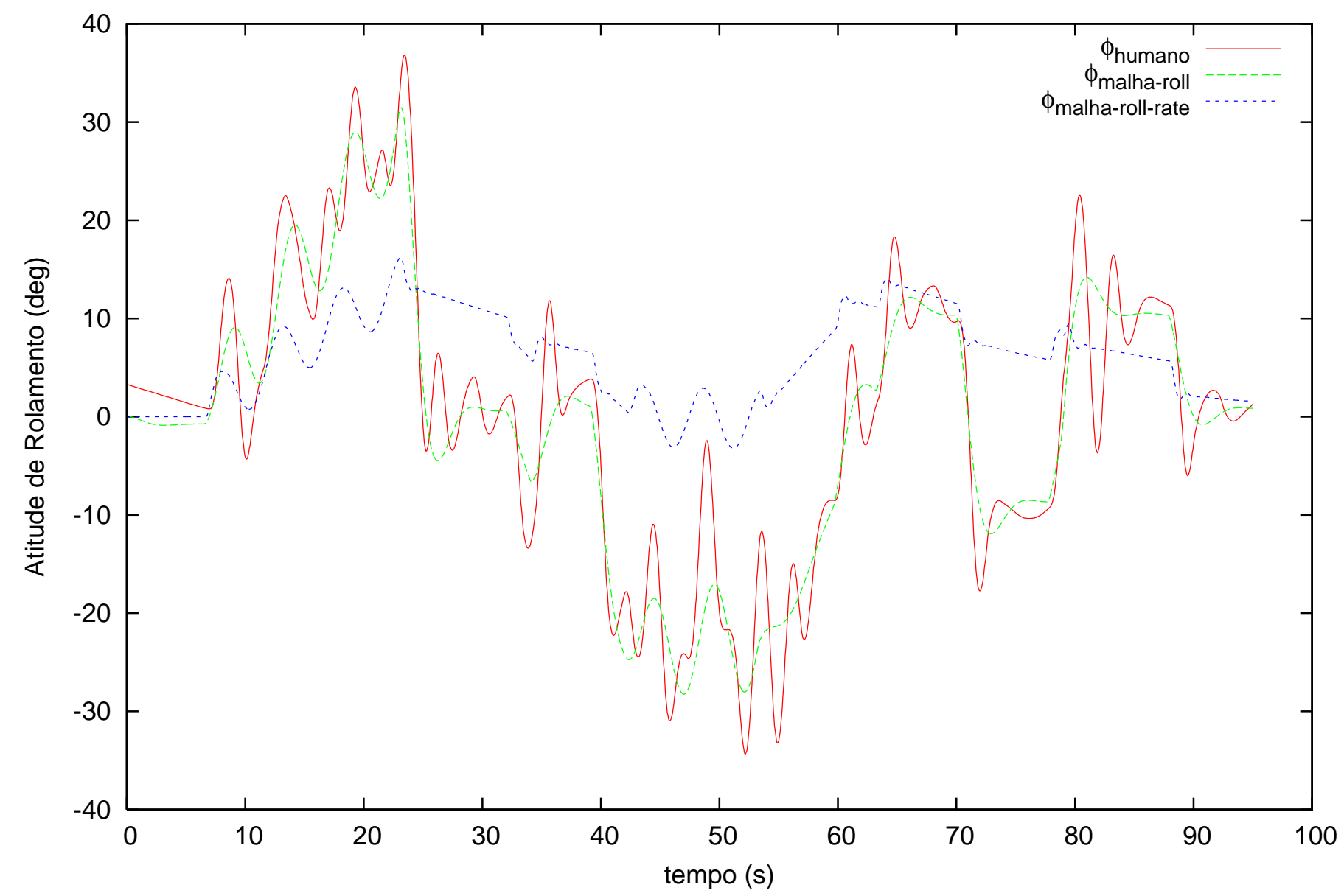

Figura B.29: Vôo 2 - Seqüência \#02 - Configuração D2A - dados do ensaio e das simulações 


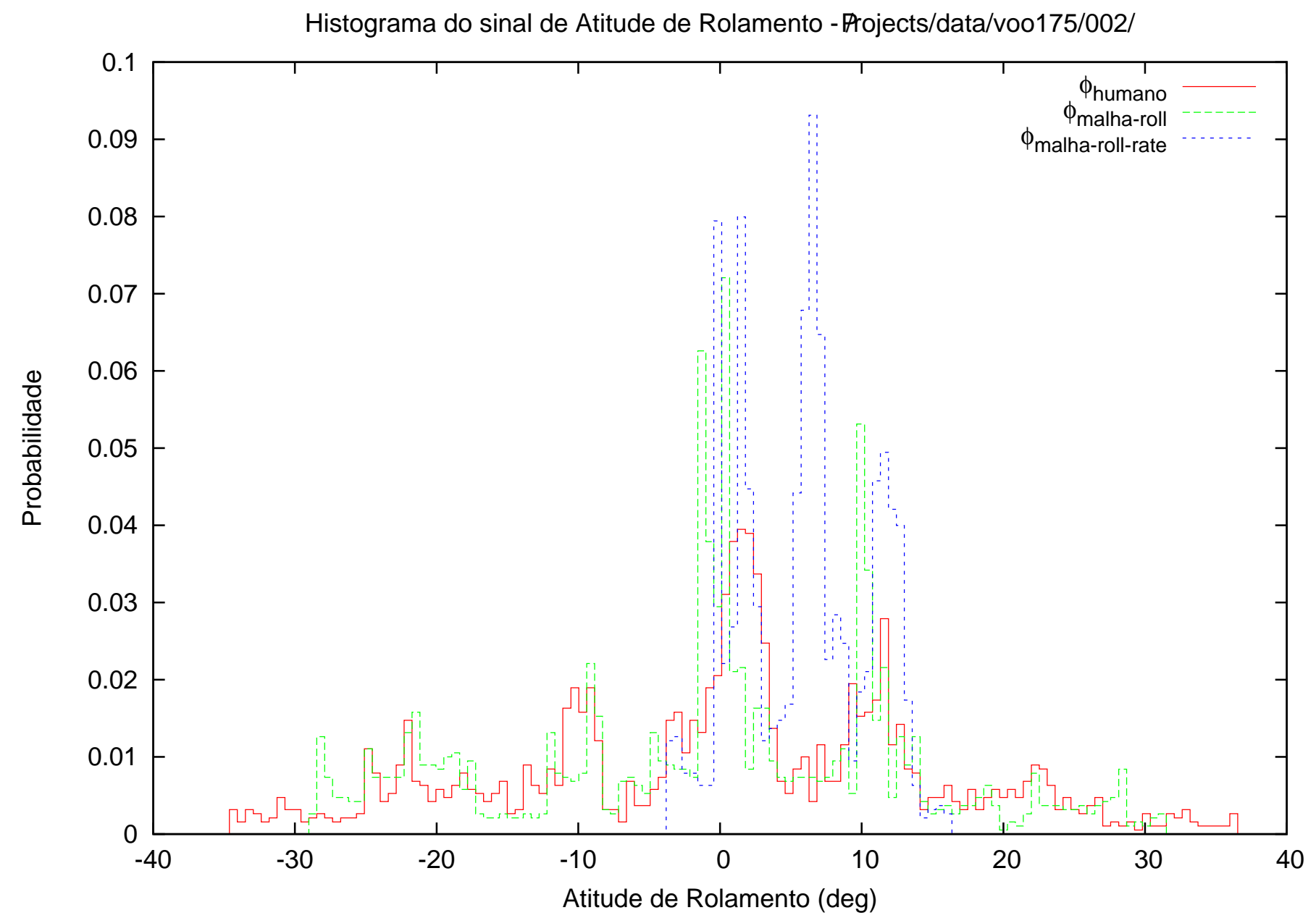

Figura B.30: Vôo 2 - Seqüência \#02 - Configuração D2A - histogramas dos dados 


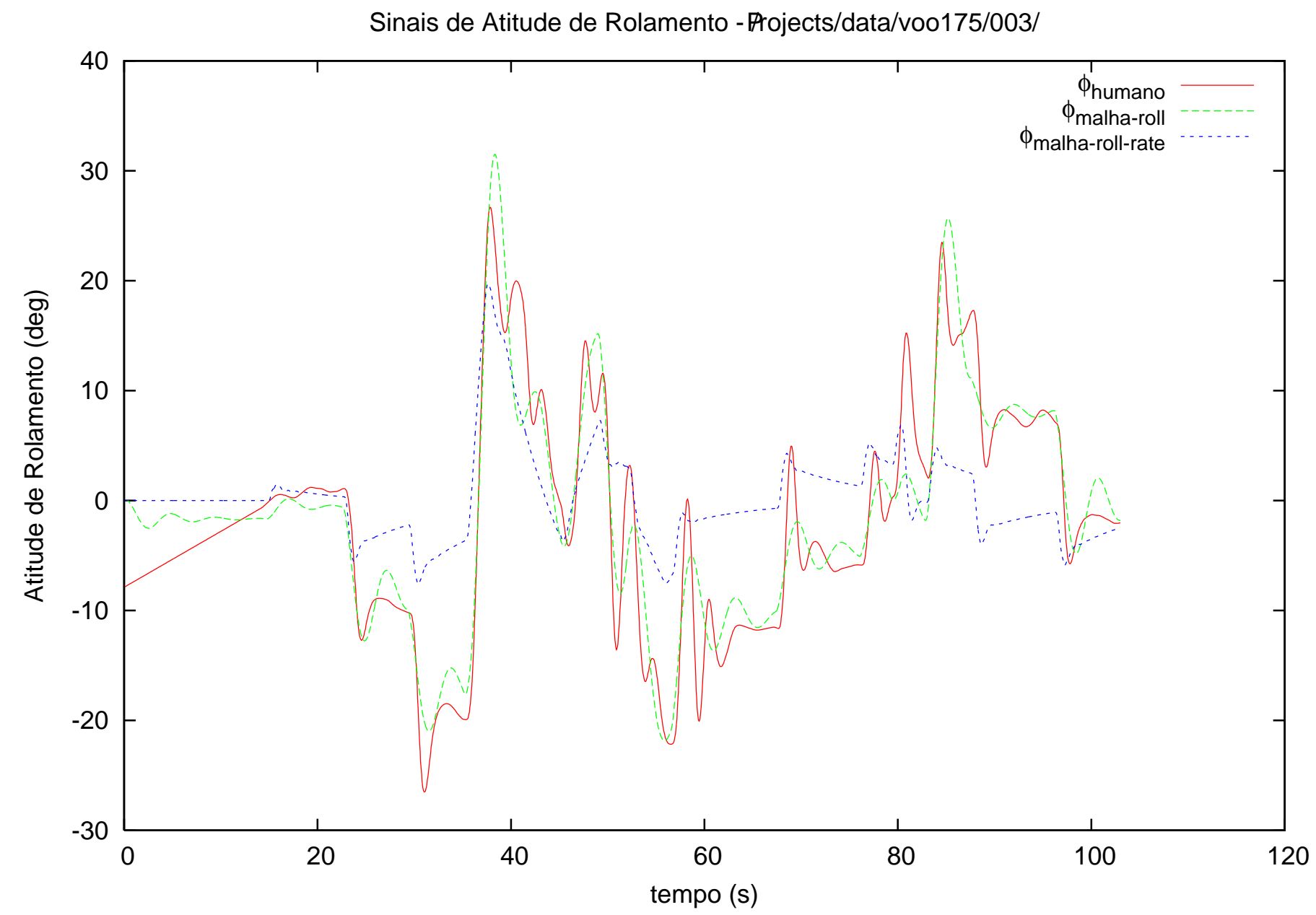

Figura B.31: Vôo 2 - Seqüência \#03 - Configuração D2B - dados do ensaio e das simulações 


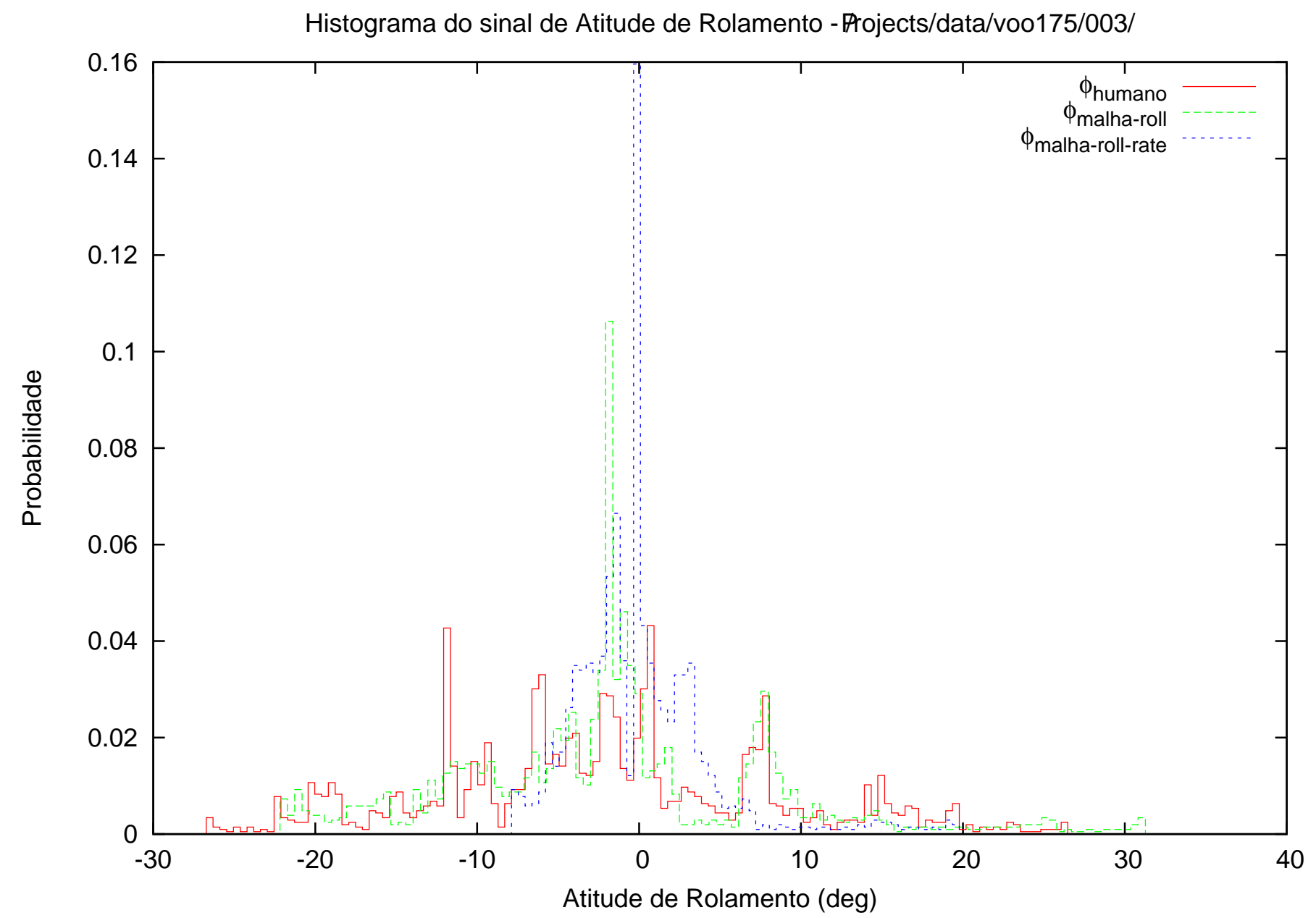

Figura B.32: Vôo 2 - Seqüência \#03 - Configuração D2B - histogramas dos dados 
Sinais de Atitude de Rolamento - Projects/data/voo175/004/

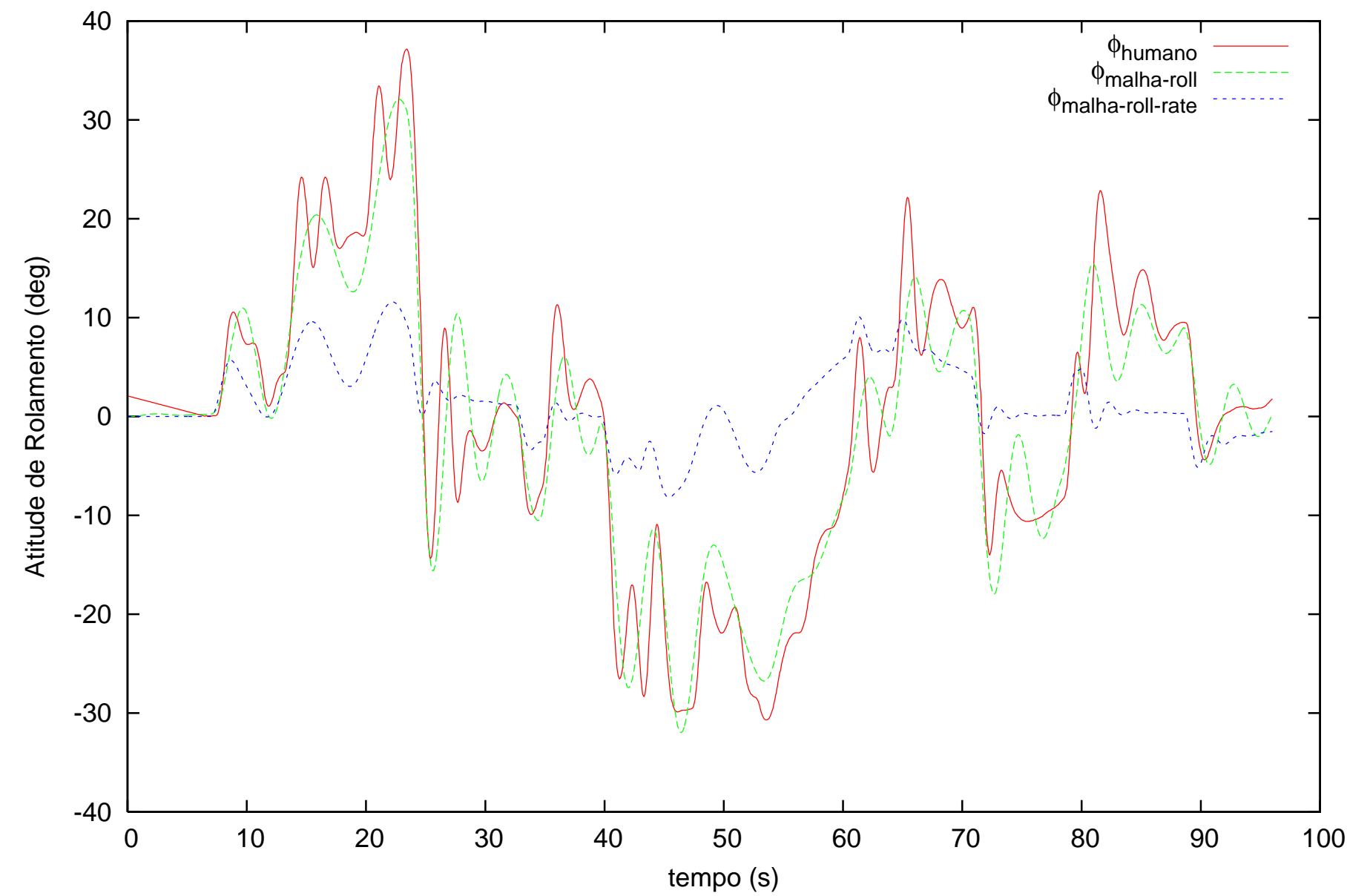

Figura B.33: Vôo 2 - Seqüência \#04 - Configuração P2B - dados do ensaio e das simulações 


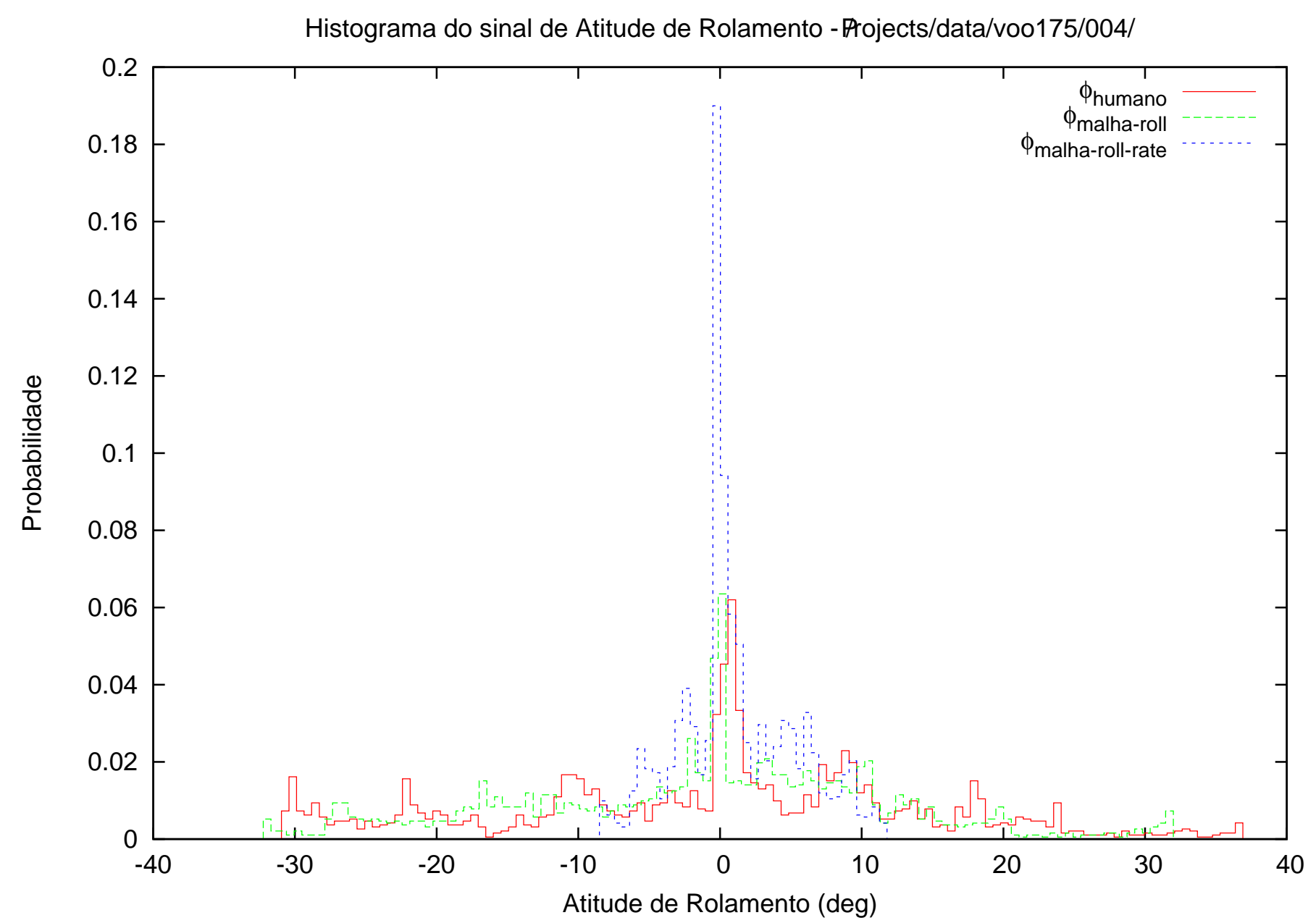

Figura B.34: Vôo 2 - Seqüência \#04 - Configuração P2B - histogramas dos dados 
Sinais de Atitude de Rolamento - Projects/data/voo175/005/

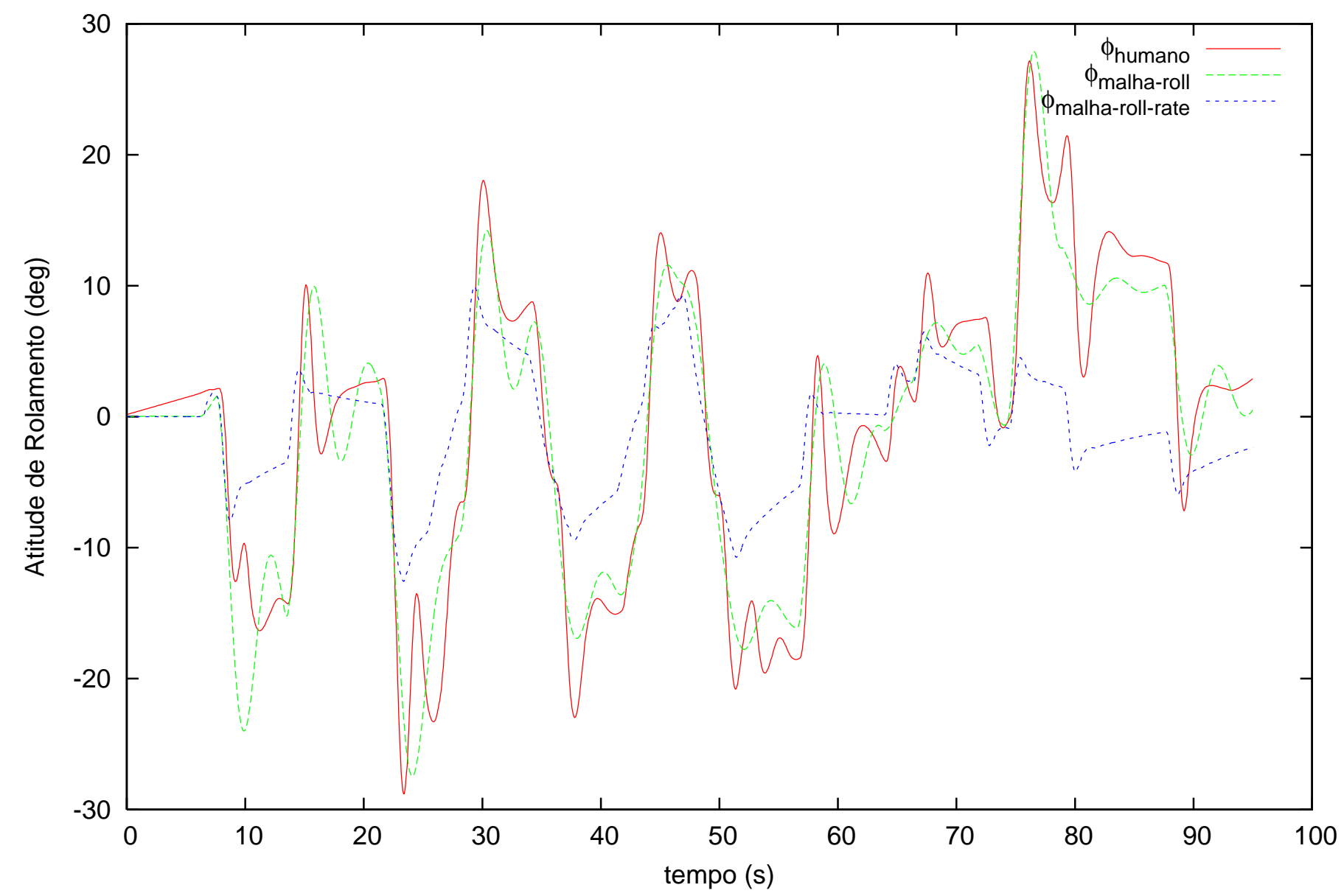

Figura B.35: Vôo 2 - Seqüência \#05 - Configuração D2A - dados do ensaio e das simulações 


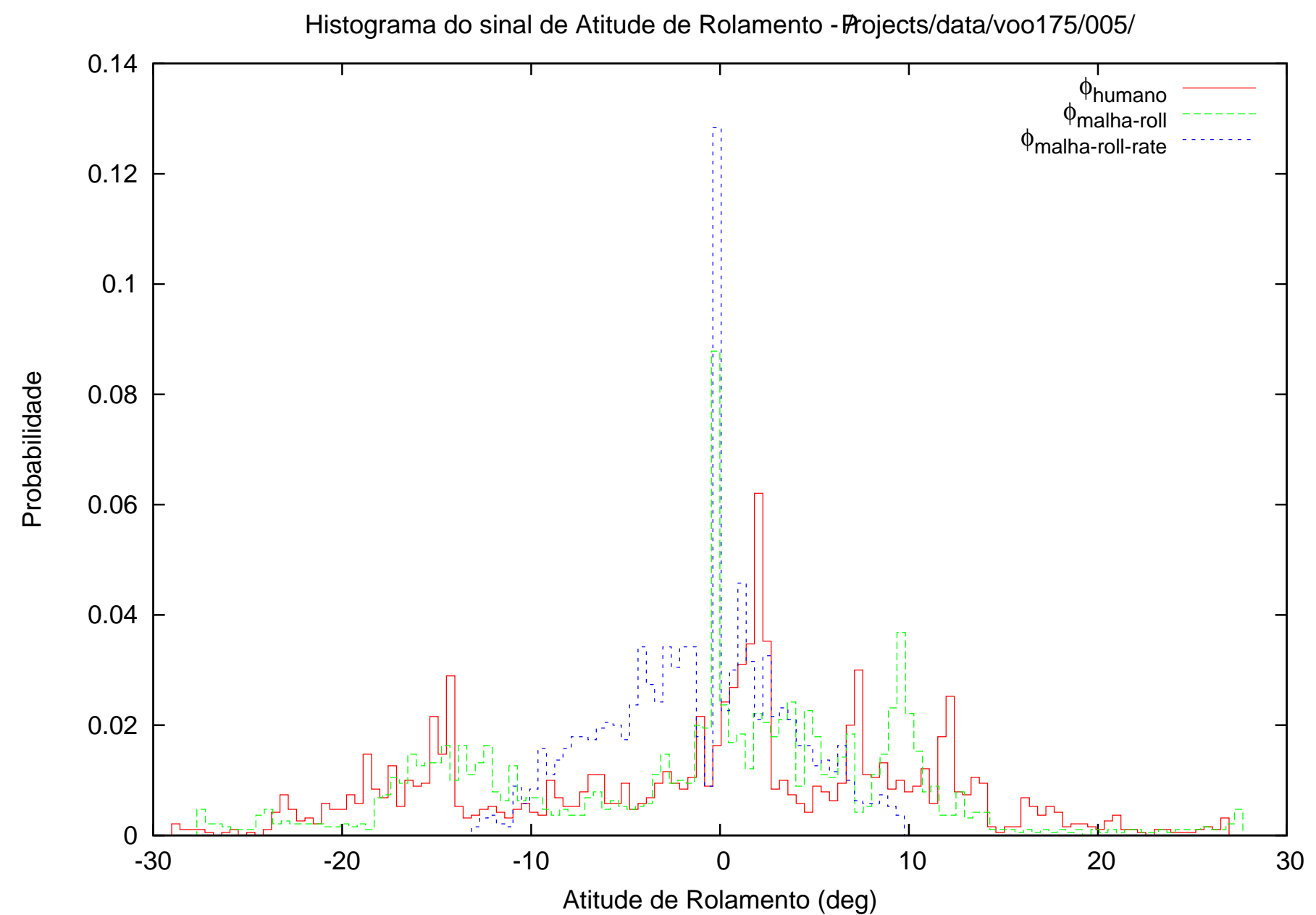

Figura B.36: Vôo 2 - Seqüência \#0 - Configuração D2A - histogramas dos dados 


\section{Apêndice C}

\section{Listagem de Programas}

\section{C.1 Cálculo da Entropia}

O programa que segue foi feito em $\mathrm{C}$ e compilado em sistema operacional Linux - distribuição Fedora 7, kernel 2.6.23.1, GCC 4.1.2 e usando IDE Anjuta 2.2.0. Foi utilizada biblioteca GNU Scientific Library versão 1.8 O programa é disponibilizado como Software Livre sob a licença GPL v3.

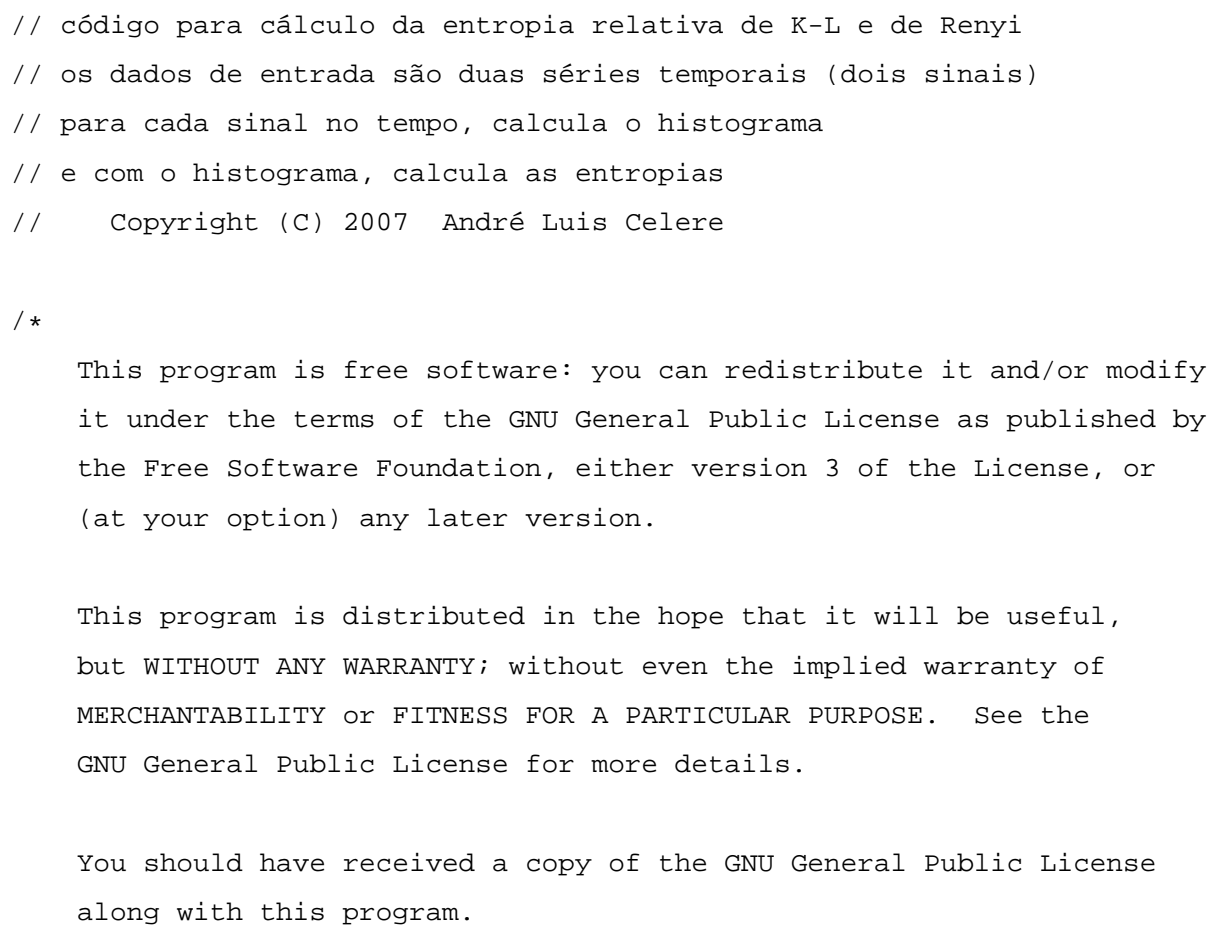


If not, see <http://www.gnu.org/licenses/>.

$\star 1$

\#include <stdio.h>

\#include <string.h>

\#include <stalib.h>

\#include <math.h>

\#include <gsl/gsl_errno.h>

\#include <gsl/gsl_vector.h>

\#include <gsl/gsl_histogram.h>

\#define MAXDATASIZE 8000

\#define MAXBINS 1024 // número MÁXIMO de bins dos histogramas

\#define MAXSPLINESIZE 20000

///////////////////////////////////////////////////////////////

int read_data(double data_out[] [2], char f_name[])

// ATENÇÃo! Não aceita formato engenharia (x.xxez)

// leitura do arquivo

// entrada:

// "f_name[]"=nome do arquivo, contendo path completo

// saída:

// data_out = matriz nx2 contendo os dados

FILE *in;

if $($ in $=$ fopen (f_name, "rt") ) == NULL)

fprintf(stderr, "Cannot open input file.\n");

return 0 ;

int $c$;

int header_lines $=0$;

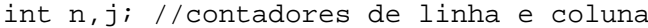

int num_par=1; //isso quer dizer DoIS parametros

for $(\mathrm{n}=0 ; \mathrm{n}<$ header_lines; $\mathrm{n}++) \quad\{$

do \{

$c=$ fgetc $(i n) ;$

\} while $(c !=10) ; / /$ ascii 10 = new line

// char separador=9; //ascii para espaço $=32$; para tab=9

char str_num[200]=""; //string auxiliar, so serve para montar o numero

char ch; //character de leitura

$\mathrm{n}=0 ; / /$ contador de linhas

$j=0 ; / /$ contador de colunas 


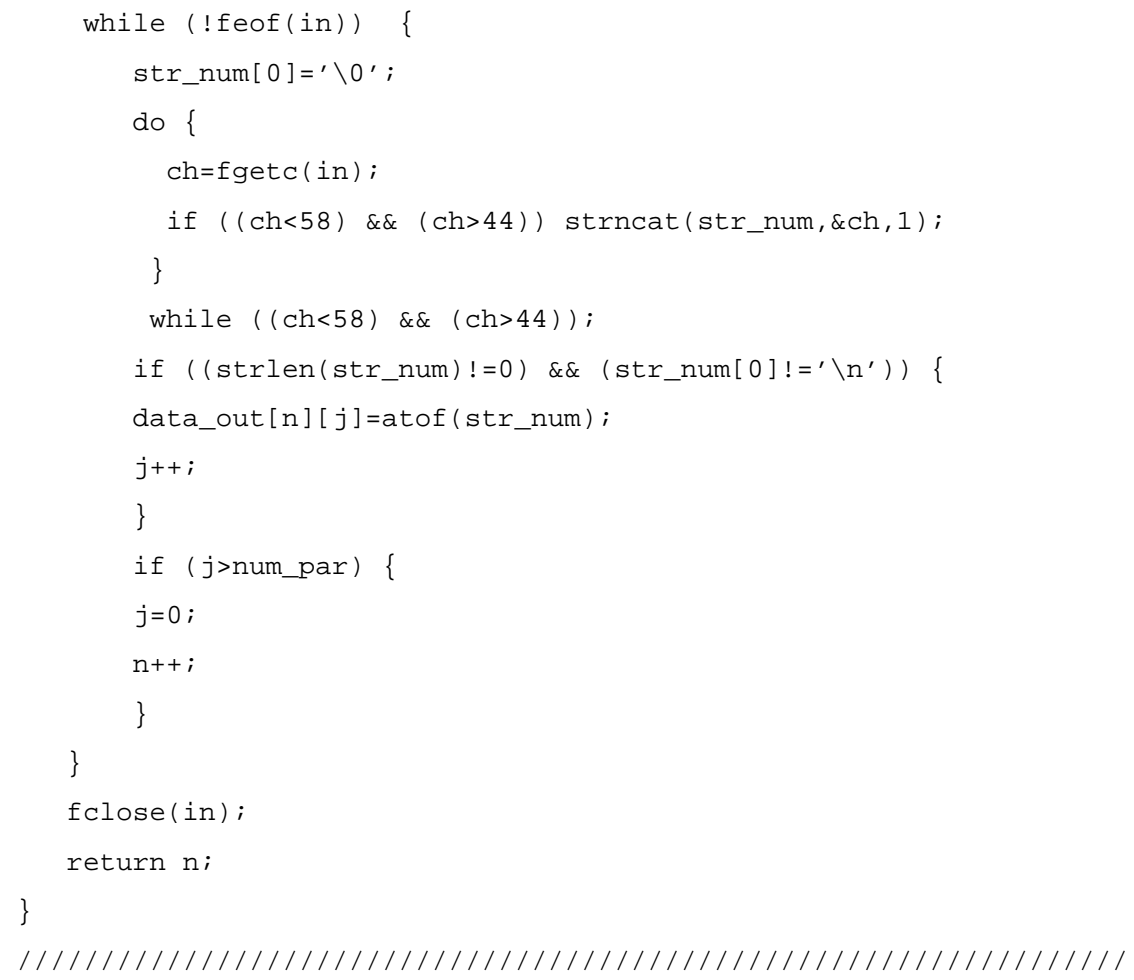




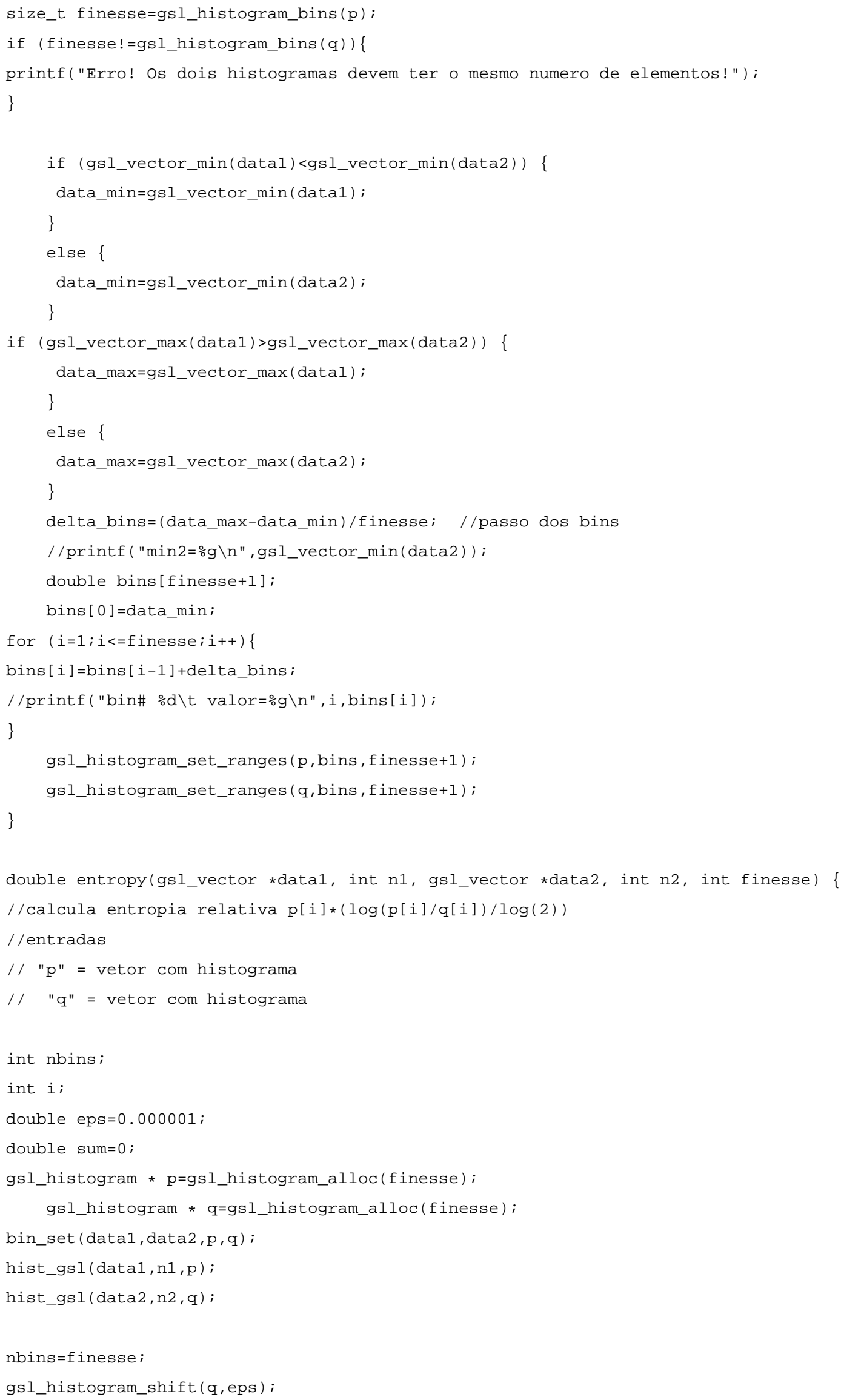




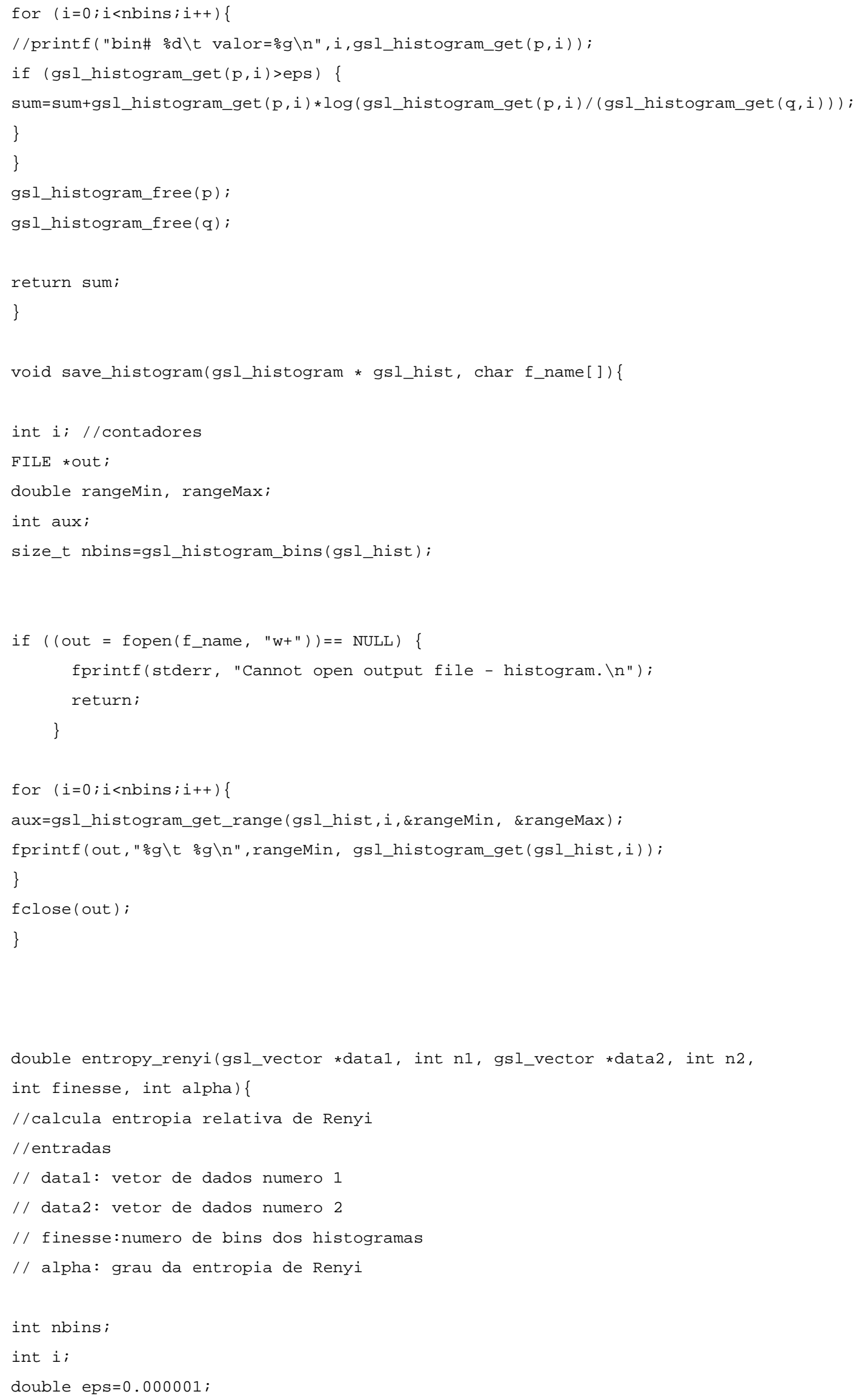




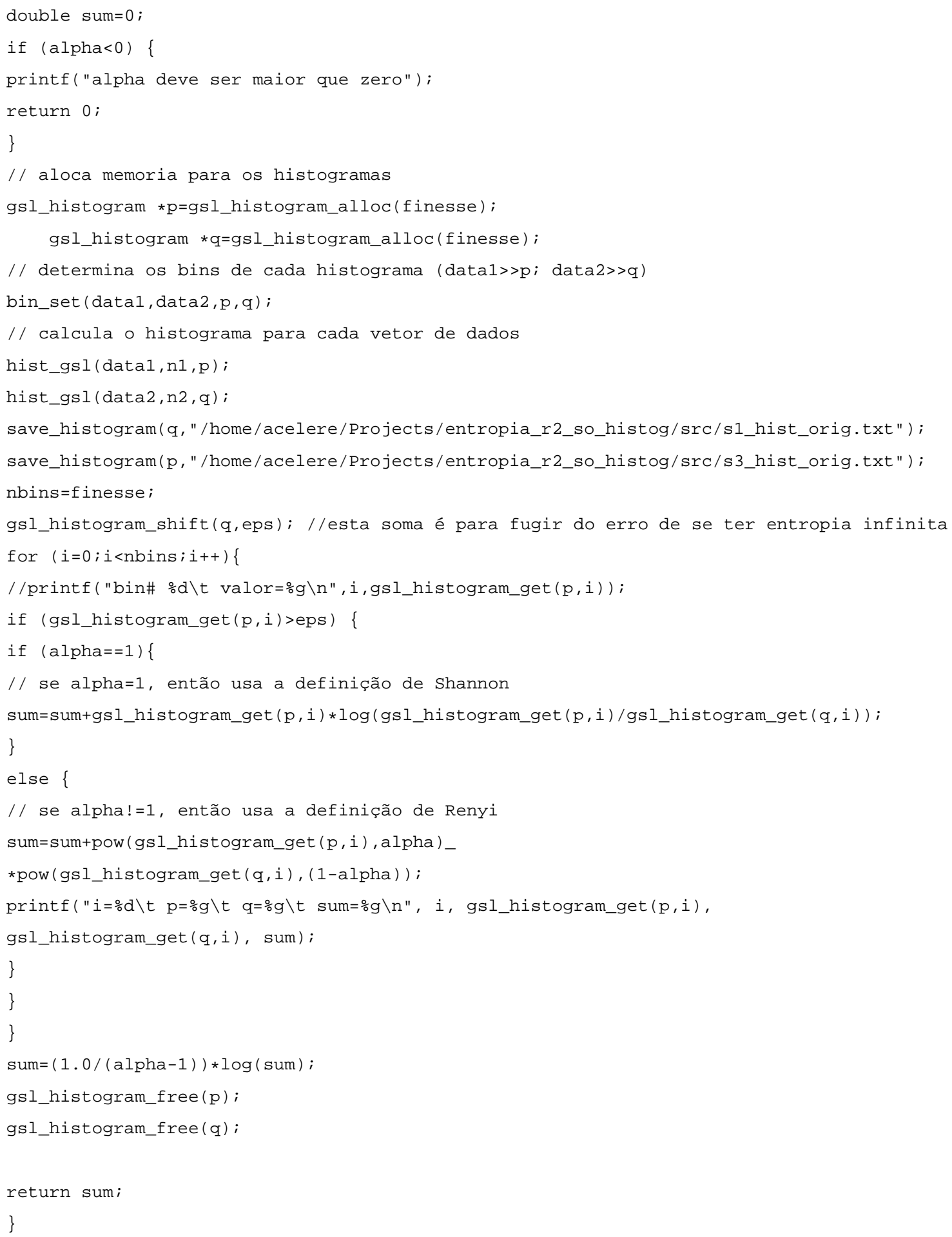




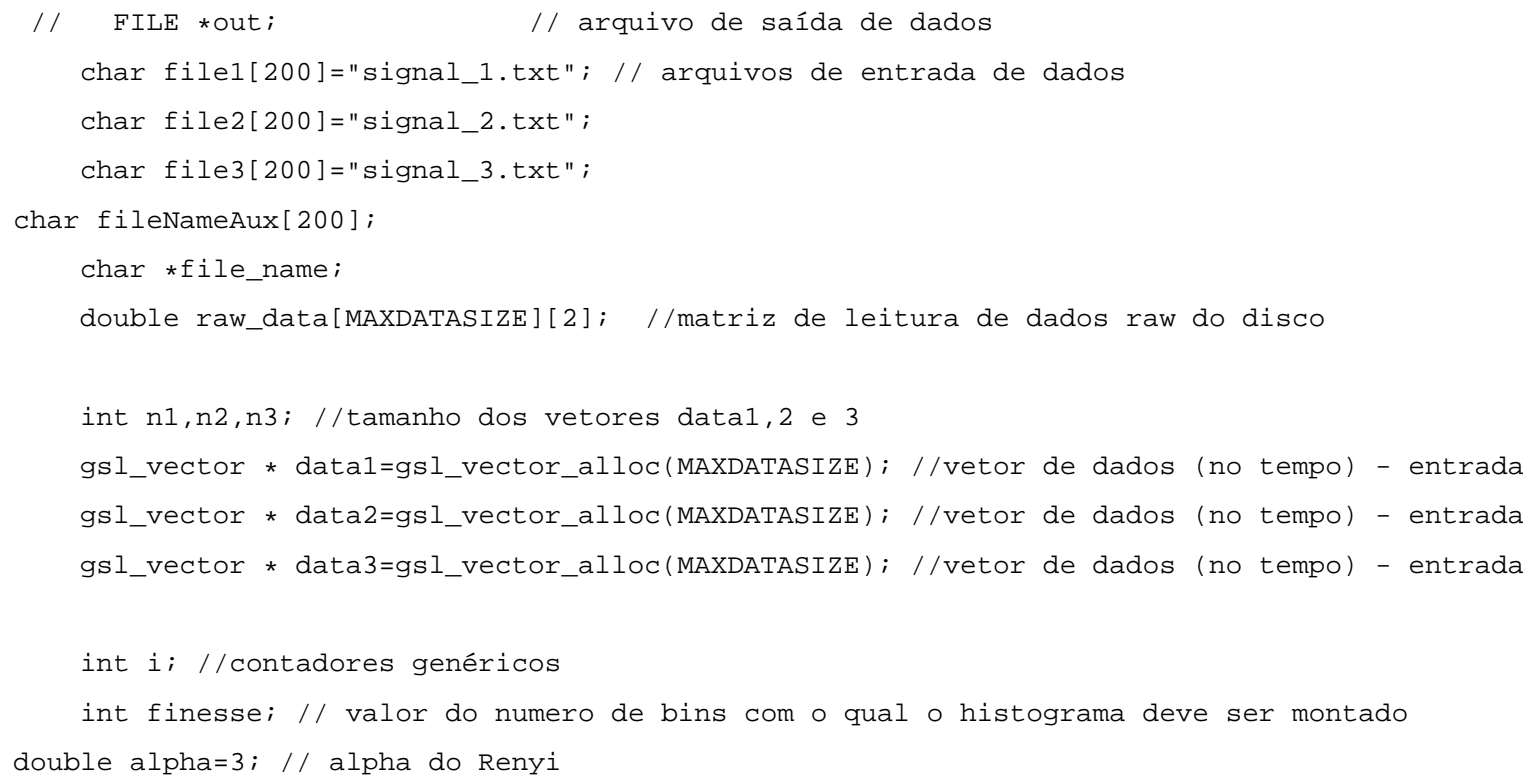




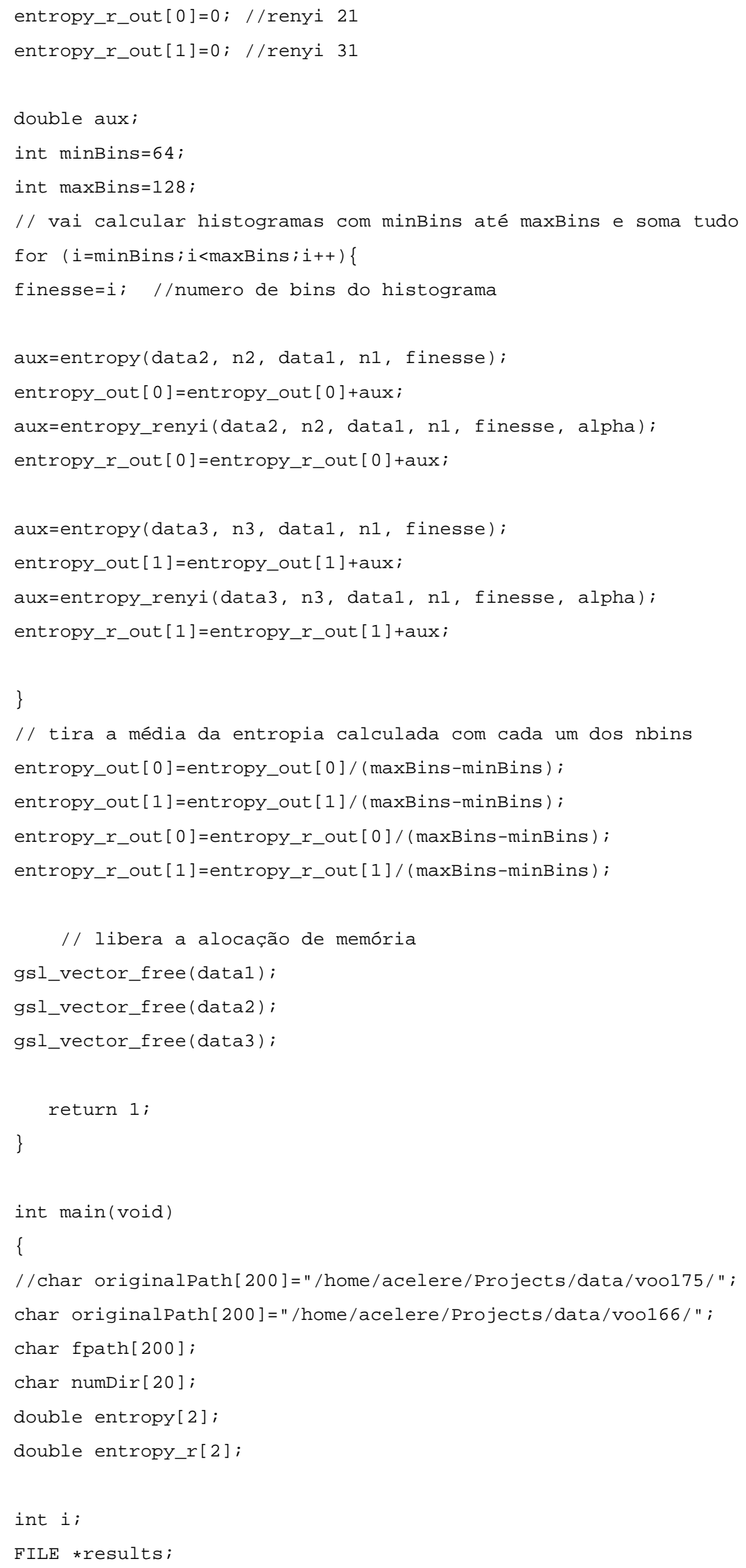




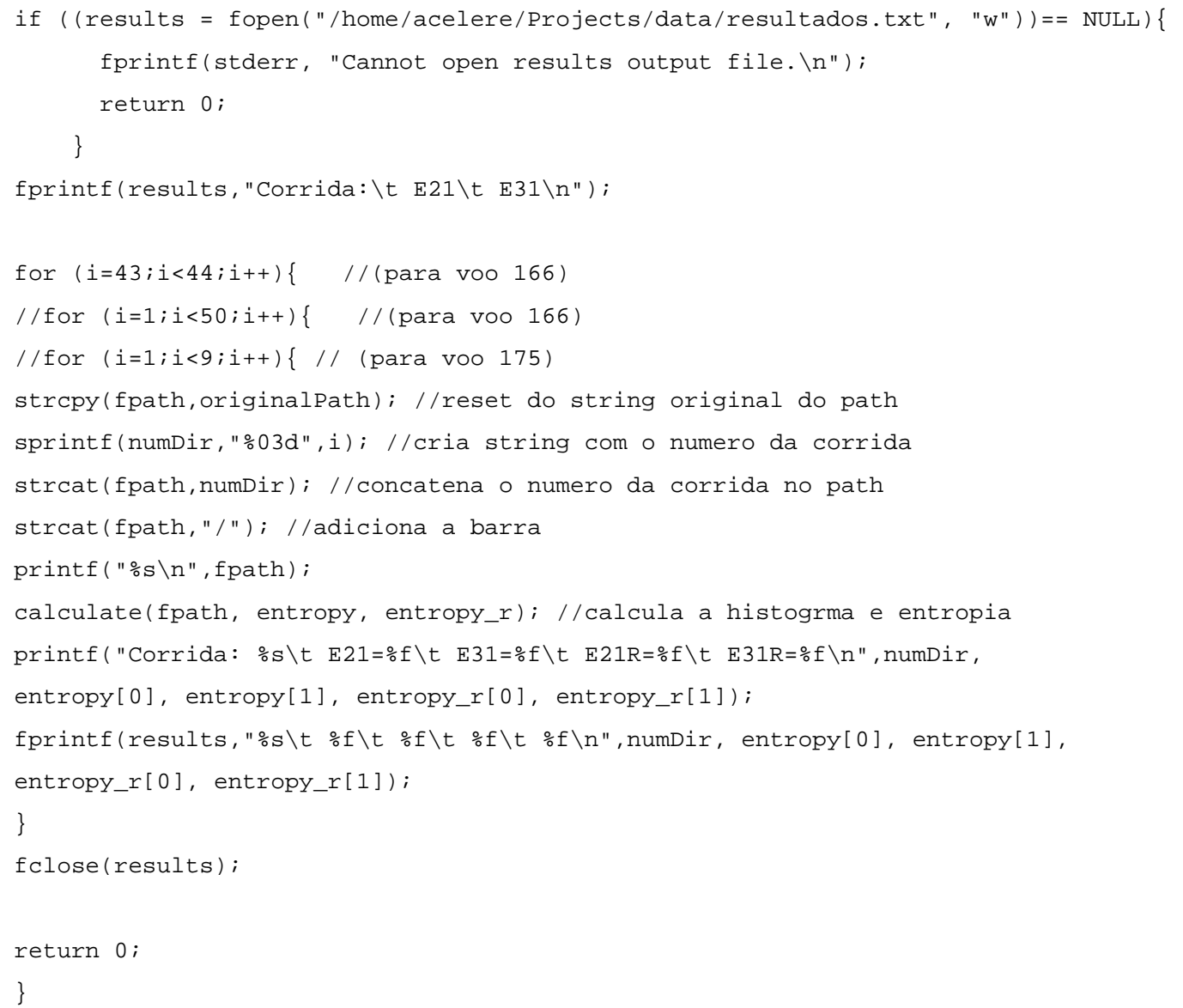

\section{C.2 Scripts de Entrada de Dados}

Os programas que segues foram feitos em Matlab Version 7.1.0.183 (R14) Service Pack 3 / Simulink 6.3 (R14SP3). A função de ambos é inicializar o modelo Simulink.

Entrada de Dados para a Manobra 3211

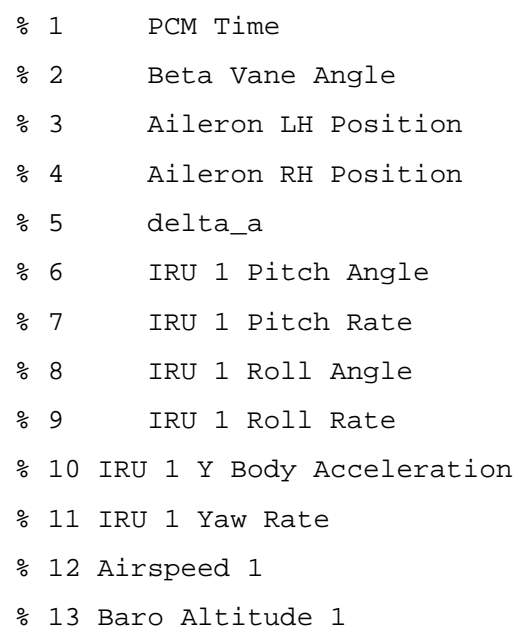




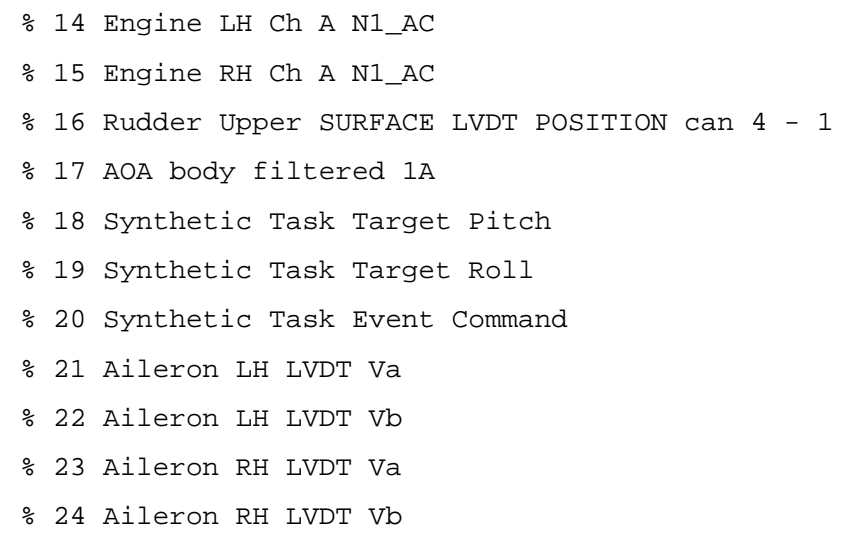


hold on

plot (roll_a,'go')

plot (dadossynt (inicio: fim, 20),' $r^{\prime}$ )

Entrada de Dados para os dados Syntask

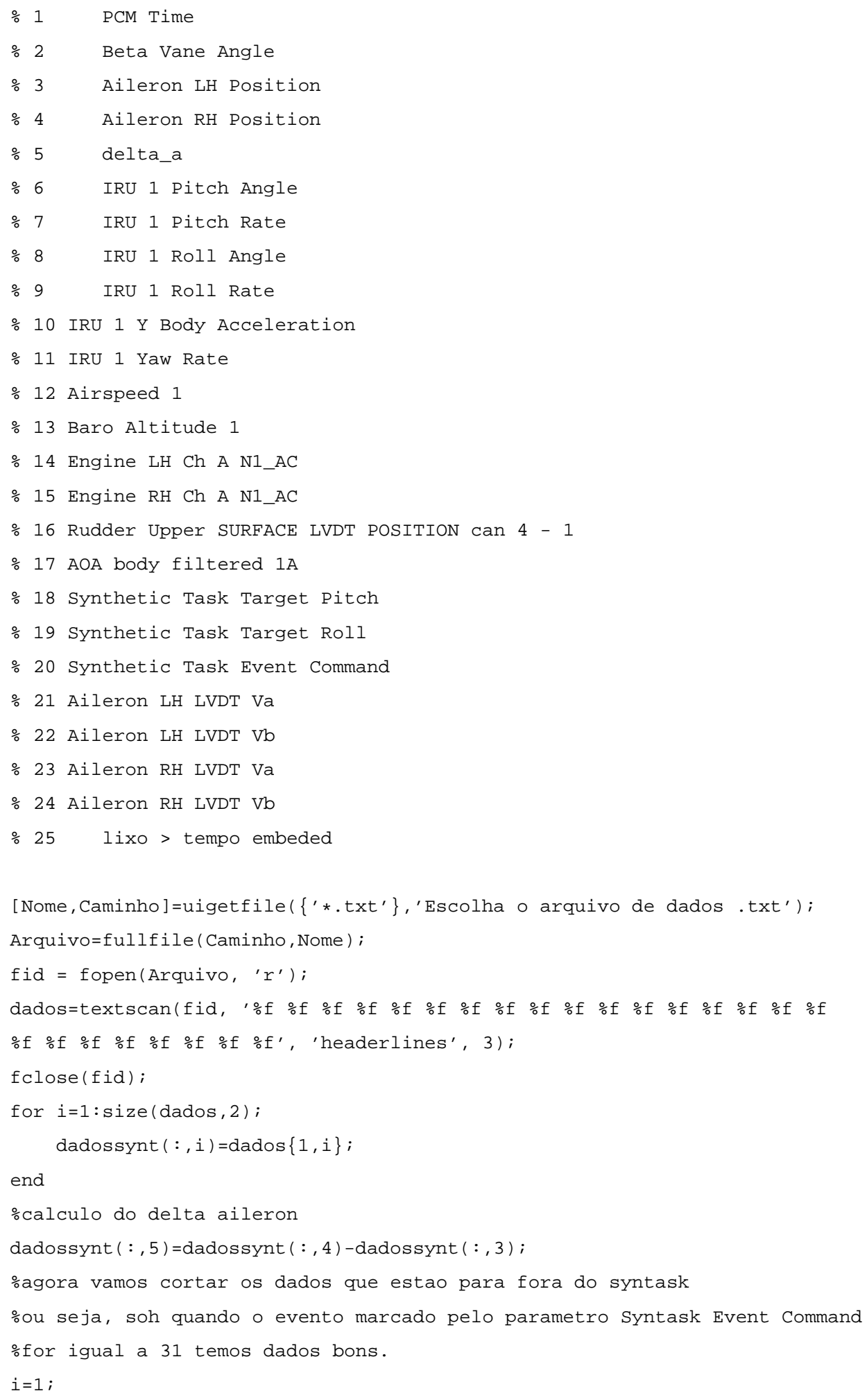




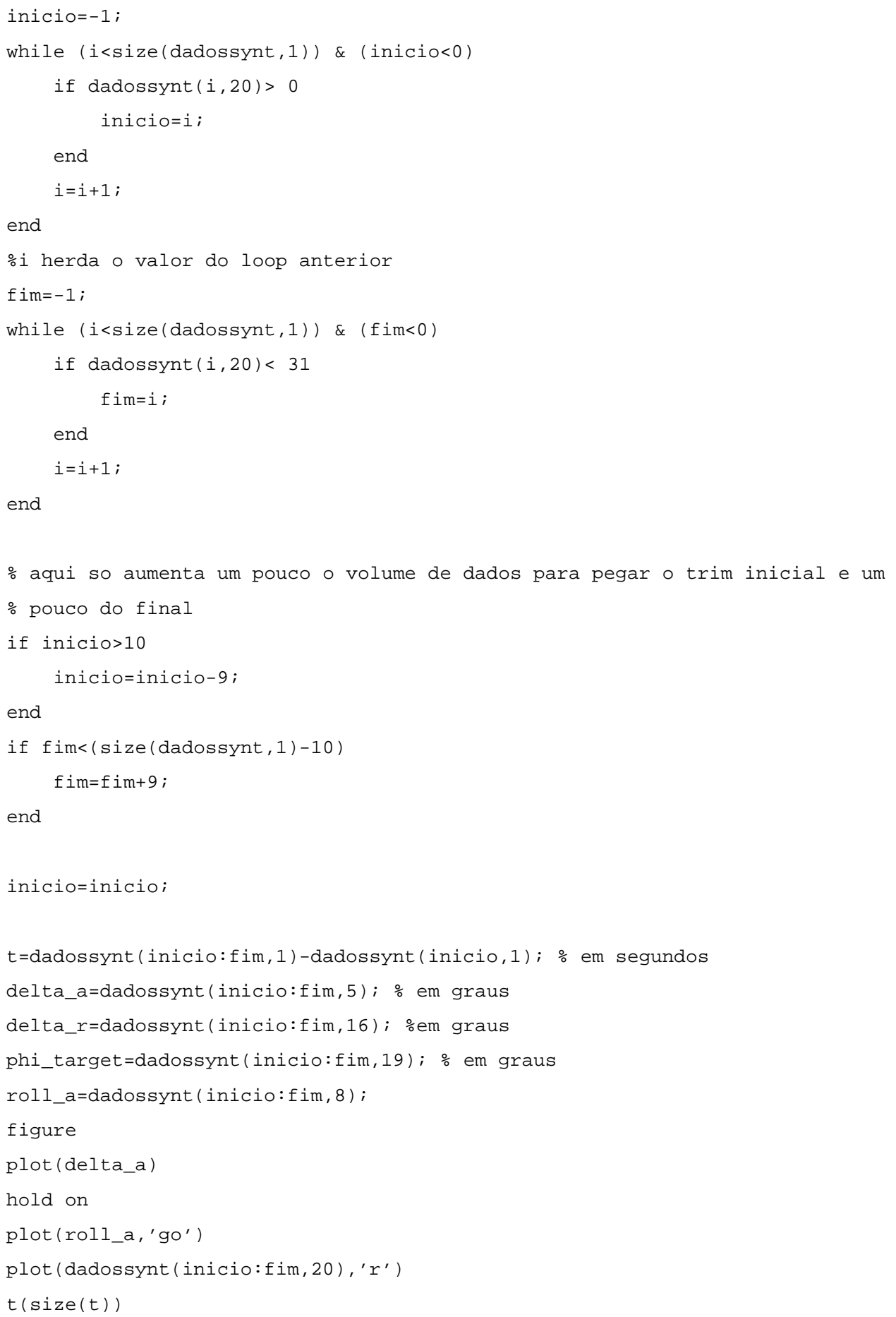

Formatação dos dados do modelo para geração dos Gráficos

[Nome, Caminho]=uigetfile $\left(\left\{{ }^{\prime} . \star^{\prime}\right\},{ }^{\prime}\right.$ Escolha qq arquivo só para pegar o caminho');

Nome='signal_2.mat' ;

aux=Caminho;

Arquivo=fullfile (Caminho, Nome);

signal=load (Arquivo);

t=signal.ans $(1,:)^{\prime} ;$ 


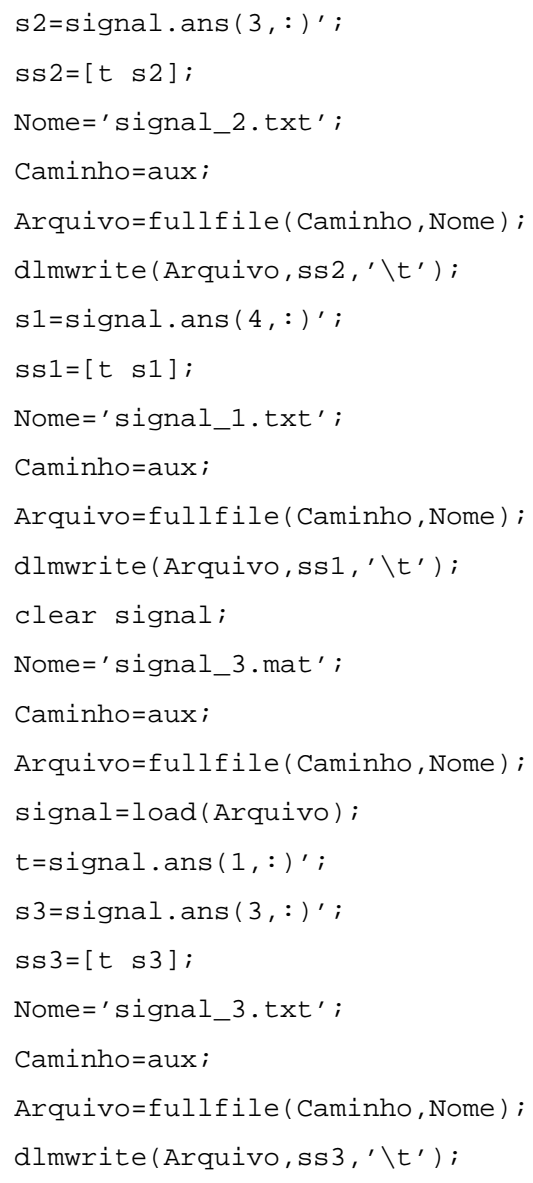



Apêndice $D$

Flight Test Instrumentation List 


\begin{tabular}{|c|c|c|c|c|c|c|}
\hline Number & Description & MinRange & MaxRange & Accuracy & SamplingRate & Unit \\
\hline 1 & Beta Vane Angle & -50.0 & 50.0 & 0.215 & 10.0 & DEG \\
\hline 280 & Aileron LH Position & -30.0 & 20.0 & 0.5 & 20.0 & DEG \\
\hline 297 & Aileron RH Position & -30.0 & 20.0 & 0.5 & 20.0 & DEG \\
\hline 1094 & IRU 1 Pitch Angle & -180.0 & 180.0 & 0.15 & 50.0 & DEG \\
\hline 1095 & IRU 1 Pitch Rate & -128.0 & 128.0 & 2.0 & 40.0 & DEG/S \\
\hline 1096 & IRU 1 Roll Angle & -180.0 & 180.0 & 1.0 & 50.0 & DEG \\
\hline 1097 & IRU 1 Roll Rate & -128.0 & 128.0 & 2.0 & 40.0 & $\mathrm{DEG} / \mathrm{S}$ \\
\hline 1105 & IRU 1 Y Body Acceleration & -4.0 & 4.0 & 0.08 & 40.0 & g \\
\hline 1106 & IRU 1 Yaw Rate & -128.0 & 128.0 & 2.0 & 40.0 & $\mathrm{DEG} / \mathrm{S}$ \\
\hline 1204 & Airspeed 1 & 0.0 & 500.0 & 2.0 & 10.0 & $\mathrm{KT}$ \\
\hline 1207 & Baro Altitude 1 & -2000.0 & 50000.0 & 15.0 & 10.0 & $\mathrm{ft}$ \\
\hline 2733 & Engine LH Ch A N1AC & -256.0 & 256.0 & 0.1 & 32.0 & percent \\
\hline 3271 & Engine RH Ch A N1AC & -256.0 & 256.0 & 0.1 & 32.0 & percent \\
\hline 6279 & Rudder Upper SURFACE LVDT POSITION can 4 - 1 & -36.0 & 36.0 & 0.9 & 80.0 & DEG \\
\hline 10116 & AOA body filtered 1A & 0.0 & 1.0 & 1.0 & 2.0 & $\mathrm{ADM}$ \\
\hline 12306 & Synthetic Task Target Pitch & -90.0 & 90.0 & 0.0 & 40 & DEG \\
\hline 12307 & Synthetic Task Target Roll & -180.0 & 180.0 & 0.0 & 40 & DEG \\
\hline 12308 & Synthetic Task Event Command & 0.0 & 65535.0 & 0.0 & 40 & DEG \\
\hline 20676 & Aileron LH LVDT Va & -0.3 & 0.3 & $1.0 \mathrm{E}-4$ & 40.0 & VDC \\
\hline
\end{tabular}


20677 Aileron LH LVDT Vb

20678 Aileron RH LVDT Va

20679 Aileron RH LVDT Vb
$-0.3$

$-0.3$

$-0.3$

$\begin{array}{lll}0.3 & 1.0 \mathrm{E}-4 & 40 . \\ 0.3 & 1.0 \mathrm{E}-4 & 40.0 \\ 0.3 & 1.0 \mathrm{E}-4 & 40.0\end{array}$

0.0

VDC

VDC

$\mathrm{VDC}$ 



\section{Apêndice $E$}

\section{Modelo Laterodirecional}

Neste apêndice, serão apresentadas as equações de movimento utilizadas para modelar a planta, que, neste caso, é uma aeronave de transporte regional com certificação FAR 25. As equações seguem a proposta de (BABISTER, 1980) e são padrão na indústria aeronáutica. Em primeiro lugar, é necessário definir os eixos principais e o sistema de coordenadas utilizado. Veja a figura E.1. Os eixos $O_{x}, O_{y}$ e $O_{z}$ passam pelo CG da

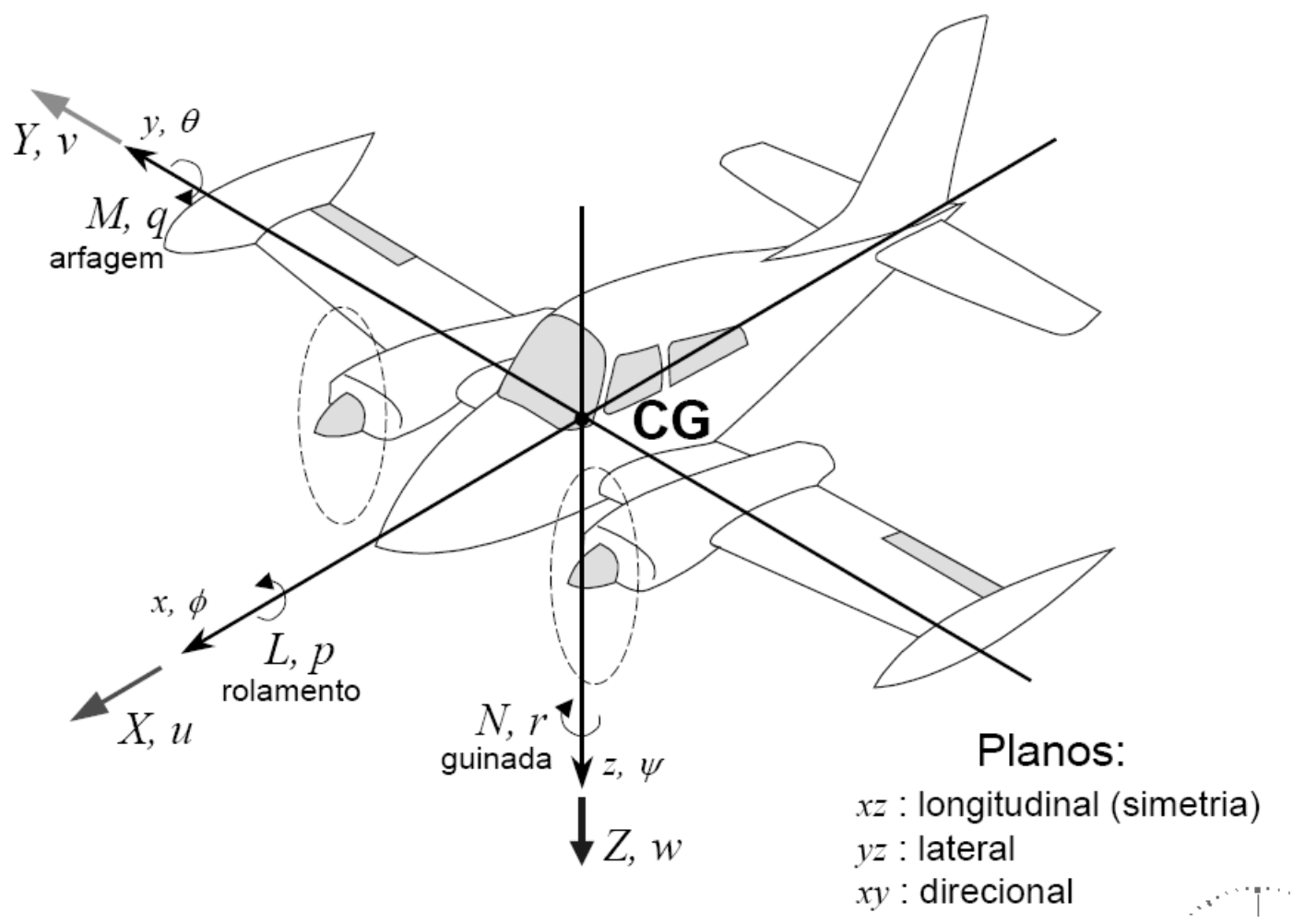

Figura E.1: Eixos do Sistema de Referência da Aeronave 
aeronave; u, v e w são as velocidades decompostas nesses eixos; $\mathbf{p}, \mathbf{q}$ e $\mathbf{r}$ são as velocidades angulares nesses eixos, positivo para o sentido horário; $I_{x}, I_{y}, I_{z}$ são momentos de inércia; $I_{y z}, I_{z x}, I_{x y}$ são produtos de inércia; $\mathbf{X}, \mathbf{Y}, \mathbf{Z}$ são as decomposições de fora nos eixos e aplicada no CG; L, M, N são momentos externos aplicados, decompostos nos eixos.

Para o equacionamento, são assumidas algumas hipóteses, denotadas pela letra $\mathrm{H}$.

Ainda é preciso representar a força da gravidade, atuando na aeronave. É necessária uma hipótese, a saber: H1 - a Terra considerada um sistema inercial, com esta orientação: o eixo $X_{E}$ orientado para o Norte; o eixo $Y_{E}$ orientado para o Leste; o eixo $Z_{E}$ orientado para baixo, apontando para o centro da Terra. Observar que o sistema é dextrógiro (mão direita).

Assim, os ângulos de Euler são definidos como: $\psi$ é o ângulo entre o eixo $O_{z}$ da aeronave e o eixo $Z_{E}$ da Terra; $\theta$ é o ângulo entre o eixo $O_{y}$ da aeronave e o eixo $O_{y}$ da Terra; $\phi$ é o ângulo entre o eixo $O_{x}$ da aeronave e o eixo $X_{E}$ da Terra.

H2: aeronave corpo rígido - não se levam em consideração os efeitos elásticos na estrutura.

Aplicando-se $\mathrm{d} \vec{F}=\vec{a} \mathrm{~d} m$ para a aeronave como um todo, obtém-se:

$$
\begin{aligned}
& \dot{x}=u+q z-r y \\
& \dot{y}=v+r x-p z \\
& \dot{z}=w+p y-q z
\end{aligned}
$$

De onde as acelerações podem ser derivadas diretamente:

$$
\begin{aligned}
\ddot{x} & =\frac{\mathrm{d}}{\mathrm{dt}}(u+q z-r y) \\
\ddot{y} & =\frac{\mathrm{d}}{\mathrm{dt}}(v+r x-p z) \\
\ddot{z} & =\frac{\mathrm{d}}{\mathrm{dt}}(w+p y-q z)
\end{aligned}
$$

resultando em:

$$
\ddot{x}=\dot{u}+\dot{q} z+q(w+p y-q x)-\dot{r} y-r(v+r x-p z)
$$




$$
\begin{aligned}
& \ddot{y}=\dot{v}+\dot{r} x+r(u+q z-r y)-\dot{p} z-p(w+p y-q x) \\
& \ddot{z}=\dot{w}+\dot{p} y+p(v+r x-p z)-\dot{q} x-q(u+q z-r y)
\end{aligned}
$$

e aplicando-se $\vec{F}=m \vec{a}$ :

$$
m \vec{a}=\int_{m}\left(\begin{array}{l}
{[\dot{u}+\dot{q} z+q(w+p y-q x)-\dot{r} y-r(v+r x-p z)] \hat{i}+} \\
{[\dot{v}+\dot{r} x+r(u+q z-r y)-\dot{p} z-p(w+p y-q x)] \hat{j}+} \\
{[\dot{w}+\dot{p} y+p(v+r x-p z)-\dot{q} x-q(u+q z-r)] \hat{k}}
\end{array}\right) d m
$$

porém

$$
\int_{m} x d m=\int_{m} y d m=\int_{m} z d m=0
$$

e, portanto, já decompondo as forças nos eixos, obtém-se:

$$
\begin{aligned}
& m(\dot{u}-r v+q w)=X \\
& m(\dot{v}-p w+r u)=Y \\
& m(\dot{w}-q u+p v)=Z
\end{aligned}
$$

Aplicando-se, agora, uma rotação em $\theta$ e $\phi$, obtém-se a direção do vetor gravidade nos eixos da aeronave. Esta rotação pode ser escrita em forma matricial:

$$
\left(\begin{array}{l}
x \\
y \\
z
\end{array}\right)=\left(\begin{array}{ccc}
\cos \theta & 0 & -\sin \theta \\
\sin \theta \sin \phi & \cos \phi & \cos \theta \sin \phi \\
\sin \theta \cos \phi & -\sin \phi & \cos \theta \cos \phi
\end{array}\right) *\left(\begin{array}{c}
x_{E} \\
y_{E} \\
z_{E}
\end{array}\right)
$$

E, portanto, para decompor a força da gravidade:

$$
\left(\begin{array}{l}
g_{x} \\
g_{y} \\
g_{z}
\end{array}\right)=\left(\begin{array}{ccc}
\cos \theta & 0 & -\sin \theta \\
\sin \theta \sin \phi & \cos \phi & \cos \theta \sin \phi \\
\sin \theta \cos \phi & -\sin \phi & \cos \theta \cos \phi
\end{array}\right) *\left(\begin{array}{l}
0 \\
0 \\
g
\end{array}\right)=\left(\begin{array}{c}
-\sin \theta \\
\cos \theta \sin \phi \\
\cos \theta \cos \phi
\end{array}\right)
$$

Finalmente, o conjunto de forças finais atuantes na aeronave fica:

$$
\begin{array}{r}
X=m(\dot{u}-r v+q w)-m g \sin \theta \\
Y=m(\dot{v}-p w+r u)-m g \cos \theta \sin \phi \\
Z=m(\dot{w}-q u+p v)-m g \cos \theta \cos \phi
\end{array}
$$


Utilizando-se o mesmo tipo de tratamento para os momentos em torno dos eixos, a partir de:

$$
\begin{aligned}
L & =\int_{m}(y \ddot{z}-z \ddot{y}) d m \\
M & =\int_{m}(z \ddot{x}-x \ddot{z}) d m \\
N & =\int_{m}(x \ddot{y}-y \ddot{x}) d m
\end{aligned}
$$

encontra-se:

$$
\begin{gathered}
L=I_{x x} \dot{p}-I_{y z}\left(q^{2}-r^{2}\right)-I_{z x}(\dot{r}+p q)-I_{x y}(\dot{q}-r p)-\left(I_{y y}-I z z\right) q r \\
M=I_{y y} \dot{q}-I_{z x}\left(r^{2}-p^{2}\right)-I_{x y}(\dot{p}+q r)-I_{y z}(\dot{r}-p q)-\left(I_{z z}-I x x\right) r p \\
N=I_{z z} \dot{r}-I_{x y}\left(p^{2}-q^{2}\right)-I_{y z}(\dot{q}+r p)-I_{z x}(\dot{p}-q r)-\left(I_{x x}-I y y\right) p q
\end{gathered}
$$

(E.13)+(E.19) é o conjunto de 6 equações diferenciais não-lineares para os 6 graus de liberdade. Para desacoplar as equações nos modos longitudinais e laterodirecionais, algumas hipóteses adicionais precisam ser formuladas. Introduzindo inicialmente a hipótese de aeronave simétrica:

H3: aeronave simétrica em torno dos seus eixos, levando $I_{x y}=I_{y x}=I_{y z}=I_{z y}=0$

H4: os eixos principais podem ser fixados para $I_{x z}=I_{z x}=0$

O conjunto E.19 pode ser reescrito como

$$
\begin{gathered}
L=I_{x x} \dot{p}-I_{z x}(\dot{r}+p q)-\left(I_{y y}-I z z\right) q r \\
M=I_{y y} \dot{q}-I_{z x}\left(r^{2}-p^{2}\right)-\left(I_{z z}-I x x\right) r p \\
N=I_{z z} \dot{r}-I_{z x}(\dot{p}-q r)-\left(I_{x x}-I y y\right) p q
\end{gathered}
$$

Introduzindo o conceito de pequenas perturbações:

H5: as condições de vôo da aeronave serão modeladas em torno de um valor de referência. Usando-se a notação apresentada por (ETKIN; REID, 1996), na condição compensada tem-se:

$$
\begin{array}{r}
u=u_{0}+u(t) \\
v=0+v(t)
\end{array}
$$




$$
\begin{array}{r}
w=0+w(t) \\
\theta=\theta_{0}+\theta(t) \\
\phi=0+\phi(t) \\
p=0+p(t) \\
q=0+q(t) \\
r=0+r(t) \\
X_{0}=Y_{0}=Z_{0}=0 \\
M_{0}=L_{0}=N_{0}=0
\end{array}
$$

Introduzindo-se essas condições, obtém-se o seguinte:

$$
\begin{array}{r}
X_{0}+\Delta X=m(\dot{u}-r v+q w)-m g \sin \left(\theta_{0}+\theta\right) \\
Y_{0}+\Delta Y=m\left(\dot{v}-p w+r\left(u_{0}+u\right)-m g \cos \left(\theta_{0}+\theta\right) \sin \phi\right. \\
Z_{0}+\Delta Z=m\left(\dot{w}-q\left(u_{0}+u\right)+p v\right)-m g \cos \left(\theta_{0}+\theta\right) \cos \phi \\
\Delta L=I_{x x} \dot{p}-I_{z x}(\dot{r}+p q)-\left(I_{y y}-I_{z z}\right) q r \\
\Delta M=I_{y y} \dot{q}-I_{z x}\left(r^{2}-p^{2}\right)-\left(I_{z z}-I_{x x}\right) r p \\
\Delta N=I_{z z} \dot{r}-I_{z x}(\dot{p}-q r)-\left(I_{x x}-I_{y y}\right) p q
\end{array}
$$

Das relações trigonométricas:

$$
\begin{array}{r}
\sin \left(\theta_{0}+\theta\right)=\sin \theta_{0} \cos \theta+\sin \theta \cos \theta_{0} \\
\cos \left(\theta_{0}+\theta\right)=\cos \left(\theta_{0} \cos \theta-\sin \theta_{0} \cos \theta\right.
\end{array}
$$

$H 6$ - e, se se adotar a hipótese de pequenos ângulos de perturbação:

$$
\begin{aligned}
& \cos \theta \approx 1 \\
& \sin \theta \approx \theta \\
& \cos \phi \approx 1 \\
& \sin \phi \approx \phi
\end{aligned}
$$


conjugados com a eliminação dos termos maiores que segunda ordem, resulta em:

$$
\begin{array}{r}
\Delta X=m(\dot{u})-m g \cos \left(\theta_{0}\right) \theta \\
\Delta Y=m\left(\dot{v}+r u_{0}-m g \cos \left(\theta_{0}\right) \phi\right. \\
\Delta Z=m\left(\dot{w}-q u_{0}\right)-m g \sin \left(\theta_{0}\right) \theta \\
\Delta L=I_{x x} \dot{p}-I_{z x} \dot{r} \\
\Delta M=I_{y y} \dot{q} \\
\Delta N=I_{z z} \dot{r}-I_{z x} \dot{p}
\end{array}
$$

As equações são então expandidas com a série de Taylor ao redor do ponto de equilíbrio e, considerando-se as hipóteses:

H\%: eliminando-se os termos de ordem maior que 1;

H8: aeronave simétrica em torno dos seus eixos, levando a $I_{x y}=I_{y x}=I_{y z}=I_{z y}=$ 0

H9: os eixos principais podem ser fixados para $I_{x z}=I_{z x}=0$

$$
\begin{array}{r}
\dot{\phi}=p+q \sin \phi+r \cos \phi \tan \theta \\
\dot{\theta}=q \cos \phi-r \sin \phi \\
\dot{\psi}=(q \sin \phi+r \cos \phi) \sec \theta \\
\dot{X_{E}}=u \cos \theta \cos \psi+ \\
v(\sin \phi \sin \theta \cos \psi-\cos \phi \sin \psi)+w(\cos \phi \sin \theta \cos \psi+\sin \phi \sin \psi) \\
\dot{Y_{E}}=u \cos \theta \sin \psi \\
+v(\sin \phi \sin \theta \sin \psi+\cos \phi \cos \psi)+w(\cos \phi \sin \theta \sin \psi-\sin \phi \sin \psi) \\
\dot{Z}_{E}=-u \sin \theta+v \sin \phi \cos \theta+w \cos \phi \cos \theta
\end{array}
$$

É possível desacoplar os modos de movimento (longitudinal e laterodirecional) e escrever na forma matricial segundo o modelo de matrizes de espaço de estados:

$$
\dot{x}=A x+B u
$$


obtendo-se para movimento longitudinal:

$$
\left[\begin{array}{c}
\Delta \dot{u} \\
\dot{w} \\
\dot{q} \\
\Delta \dot{\theta}
\end{array}\right]=
$$

$$
\begin{aligned}
& {\left[\begin{array}{cccc}
\frac{X_{u}}{m} & \frac{X_{w}}{m} & 0 & -g \cos \theta_{0} \\
\frac{Z_{u}}{m-Z_{\dot{w}}} & \frac{Z_{w}}{m-Z_{\dot{w}}} & \frac{Z_{q}+m u_{0}}{m-Z_{\dot{w}}} & \frac{-m g \sin \theta_{0}}{m-Z_{\dot{w}}} \\
\frac{1}{I_{y y}}\left[M_{u}+\frac{M_{\dot{w}} Z_{u}}{\left(m-Z_{\dot{w}}\right)}\right] & \frac{1}{I_{y y}}\left[M_{w}+\frac{M_{\dot{w}} Z_{w}}{\left(m-Z_{\dot{w}}\right)}\right] & \frac{1}{I_{y y}}\left[M_{q}+\frac{M_{\dot{w}}\left(Z_{q}+m u_{0}\right)}{\left(m-Z_{\dot{w}}\right)}\right] & -\frac{M_{\dot{w}} m g \sin \theta_{0}}{I_{y y}\left(m-Z_{\dot{w}}\right)} \\
0 & 0 & 1 & 0
\end{array}\right] *} \\
& {\left[\begin{array}{c}
\Delta u \\
w \\
q \\
\Delta \theta
\end{array}\right]+\left[\begin{array}{c}
\frac{\Delta X_{c}}{m} \\
\frac{\Delta Z_{c}}{m-Z_{\dot{w}}} \\
\frac{\Delta M_{c}}{I_{y y}}+\frac{M_{\dot{w}} \Delta Z_{c}}{I_{y y}\left(m-Z_{\dot{w}}\right)} \\
0
\end{array}\right]}
\end{aligned}
$$

E para o movimento laterodirecional:

$$
\begin{aligned}
& {\left[\begin{array}{c}
\Delta \dot{v} \\
\dot{p} \\
\dot{r} \\
\Delta \dot{\phi}
\end{array}\right]=} \\
& {\left[\begin{array}{cccc}
\frac{Y_{v}}{m} & \frac{Y_{p}}{m} & \left(\frac{Y_{r}}{m}-u_{0}\right) & g \cos \theta_{0} \\
\left(I_{z x}^{\prime} L_{v}+\frac{N_{v}}{I_{z z}^{\prime}}\right) & \left(I_{z x}^{\prime} L_{p}+\frac{N_{p}}{I_{z z}^{\prime}}\right) & \left(I_{z x}^{\prime} L_{r}+\frac{N_{r}}{I_{z z}^{\prime}}\right) & 0 \\
\left(\frac{L_{v}}{I_{x x}^{\prime}}+I_{z x}^{\prime} N_{v}\right) & \left(\frac{L_{p}}{I_{x x}^{\prime}}+I_{z x}^{\prime} N_{p}\right) & \left(\frac{L_{r}}{I_{x x}^{\prime}}+I_{z x}^{\prime} N_{r}\right) & 0 \\
0 & 0 & \tan \theta_{0} & 0
\end{array}\right] *} \\
& {\left[\begin{array}{c}
v \\
p \\
r \\
\phi
\end{array}\right]+\left[\begin{array}{c}
\frac{\Delta Y_{c}}{m} \\
\frac{\Delta L_{c}}{I_{x x}^{\prime}}+I_{z x}^{\prime} N_{c} \\
I_{z x}^{\prime} \Delta L_{c}+\frac{\Delta N_{c}}{I_{z x}^{\prime}} \\
0
\end{array}\right]}
\end{aligned}
$$


Com as seguintes definições auxiliares

$$
\begin{aligned}
I_{x x}^{\prime} & =\frac{\left(I_{x x} I_{z z}-I_{z x}^{2}\right)}{I_{z z}} \\
I_{z z}^{\prime} & =\frac{\left(I_{x x} I_{z z}-I_{z x}^{2}\right)}{I_{x x}} \\
I_{z x}^{\prime} & =\frac{I_{z x}}{\left(I_{x x} I_{z z}-I_{z x}^{2}\right)}
\end{aligned}
$$




\section{Apêndice $F$}

\section{Escalas Originais}

As escalas originais estão apresentadas neste anexo para refer?ncia. Elas foram incluídas pois a linguagem utilizada na indústria aeronáutica, e especificamente na área de qualidades de vôo é, essencialmente, a original em Inglês. 
Handling Qualities Rating Scale

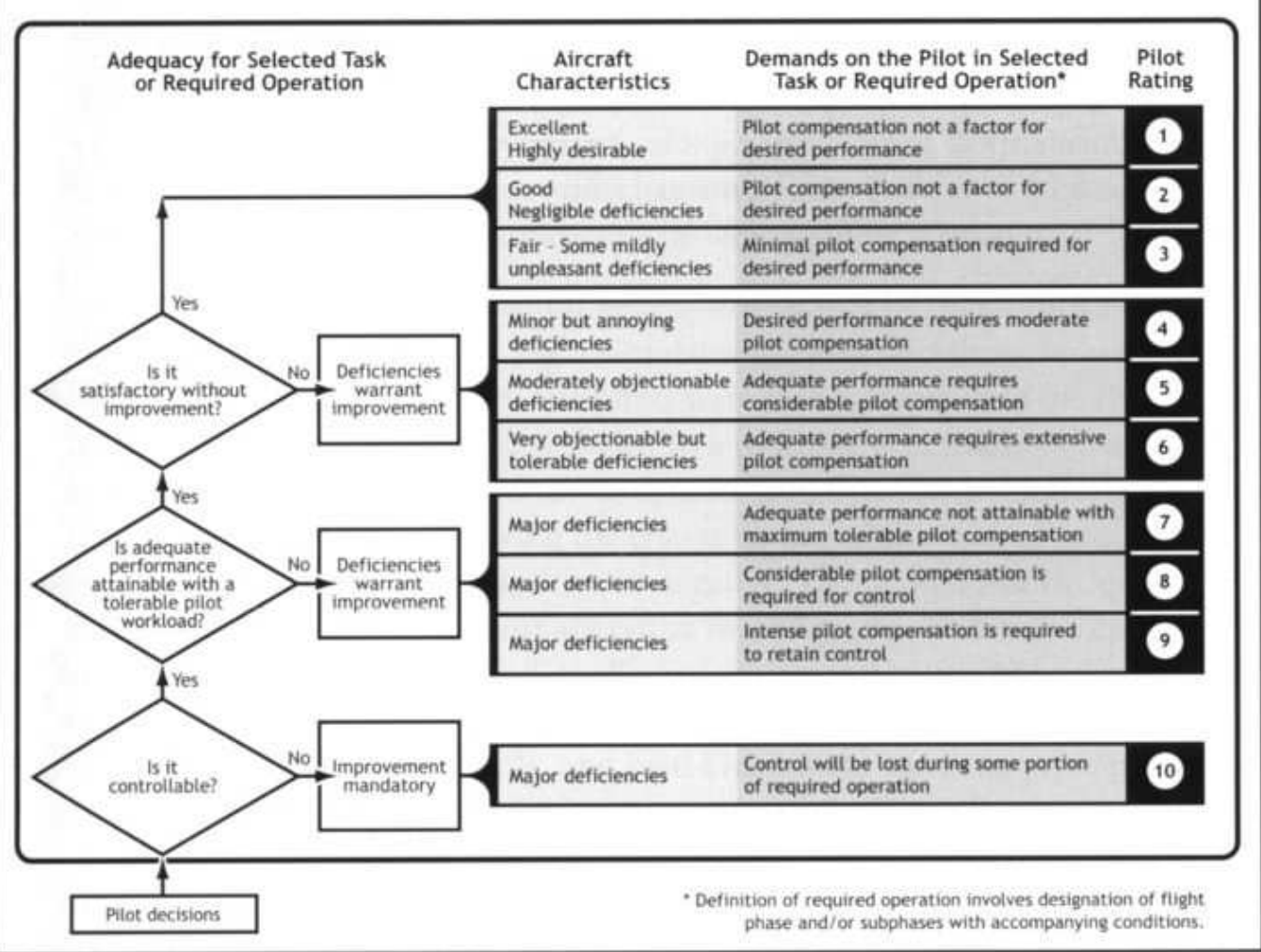

Figura F.1: Escala de Cooper-Harper

fonte: (COOPER; HARPER, 1969) 


\section{PILOT INDUCED OSCILLATION RATING SCALE}

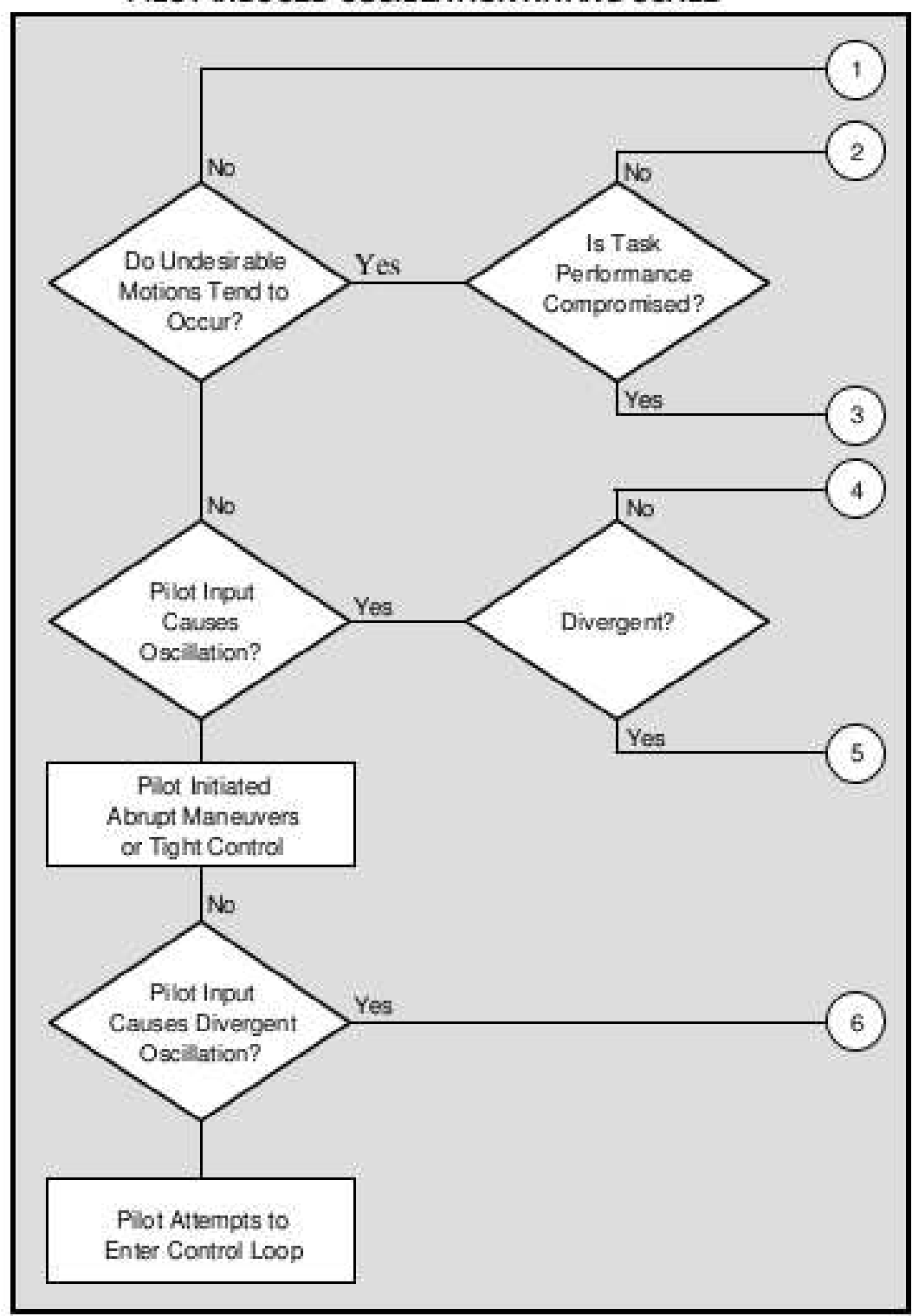

Figura F.2: Escala de PIO - O uso da escala inicia-se pelo fundo, com o início do controle em malha fechada. As perguntas são sucessivamente responsdidas através de uma avaliação entre as respostas obtidas contra as desejadas, até que uma nota seja atingida.

fonte: (US NAVY, 2007) 